\title{
Lithium-0xygen Batteries and Related Systems: Potential, Status, and Future
}

\author{
Won-Jin Kwak, Rosy, Daniel Sharon, Chun Xia, Hun Kim, Lee R. Johnson, Peter G. Bruce, ${ }^{*}$ \\ Linda F. Nazar, ${ }^{*}$ Yang-Kook Sun, ${ }^{*}$ Aryeh A. Frimer, Malachi Noked, Stefan A. Freunberger, \\ Doron Aurbach $^{*}$
}

\begin{abstract}
The goal of limiting global warming to $1.5^{\circ} \mathrm{C}$ requires a drastic reduction in $\mathrm{CO}_{2}$ emissions across many sectors of the world economy. Batteries are vital to this endeavor, whether used in electric vehicles, to store renewable electricity, or in aviation. Present lithium-ion technologies are preparing the public for this inevitable change, but their maximum theoretical specific capacity presents a limitation. Their high cost is another concern for commercial viability. Metal-air batteries have the highest theoretical energy density of all possible secondary battery technologies and could yield step changes in energy storage, if their practical difficulties could be overcome. The scope of this review is to provide an objective, comensive, and authoritative assessment of the intensive work invested in nonaqueous rechargeable metal-air batteries over the past few years, which identified the key problems and guides directions to solve them. We focus primarily on the challenges and outlook for $\mathrm{Li}-\mathrm{O}_{2}$ cells but include $\mathrm{Na}-\mathrm{O}_{2}, \mathrm{~K}-\mathrm{O}_{2}$, and $\mathrm{Mg}-\mathrm{O}_{2}$ cells for comparison. Our review highlights the interdisciplinary nature of this field that involves a combination of materials chemistry, electrochemistry, computation, microscopy, spectroscopy, and surface science. The mechanisms of $\mathrm{O}_{2}$ reduction and evolution are considered in the light of recent findings, along with developments in positive and negative electrodes, electrolytes, electrocatalysis on surfaces and in solution, and the degradative effect of singlet oxygen, which is typically formed in $\mathrm{Li}-\mathrm{O}_{2}$ cells.

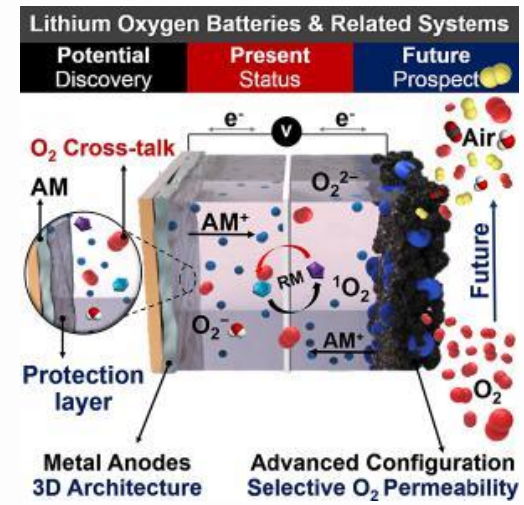

\section{CONTENTS}

1. Introduction

1.1. Contemporary Energy Needs

1.2. Brief Overview of Electrochemical Energy Storage

1.3. Metal-Air Batteries

1.4. Scope of This Review Article

2. Lithium-Oxygen Batteries: Diversity and Evolution

2.1. Configuration of $\mathrm{Li}-\mathrm{O}_{2}$ Cells

2.2. The History and Early-Stage Research on Aprotic $\mathrm{Li}-\mathrm{O}_{2}$ Batteries

3. Current Status

3.1. A Short Introduction on Important Aspects of Nonaqueous Electrochemistry

3.2. Mechanistic Aspects of Nonaqueous Oxygen Electrochemistry

3.2.1. Li2O2 formation on Discharge

3.2.2. Li202 Oxidation Mechanism on Charge

3.3. Parasitic Chemistry

3.3.1. Reactivity of Reduced $\mathrm{O}_{2}$ Species and $\mathrm{O}_{2}$

3.3.2. Singlet Oxygen in Metal- $\mathrm{O}_{2}$ Cells

3.4. Cell Components
3.4.1. Electrolytes

3.4.2. Development of New Solvents for $\mathrm{Li}-\mathrm{O}_{2}$ Batteries

3.4.3. Cathode Materials and Their Stability in $\mathrm{Li}-\mathrm{O}_{2}$ Cells

3.4.4. Negative Electrodes

3.5. Catalysis

3.5.1. Heterogeneous Catalysis for the ORR and OER

3.5.2. Homogenous Catalysis with Redox Mediators

3.5.3. Instability Issues with Mediators

3.6. The Important Analogous Systems

3.6.1. Sodium-Oxygen Batteries

$\mathrm{F}$

3.6.2. The Potassium-Oxygen Battery

3.6.3. The Magnesium-Oxygen Battery
N

\section{$\mathrm{F}$}

$\mathrm{F}$

$\mathrm{H}$

I

I

J 
3.7. Novel Electrolytes and Electrodes

3.7.1. The Possibilities and Development of

3.7.2. Solid-State Li-Air and Na-Air Batteries

3.7.3. On the Use of Ionic Liquids and Molten Salts

3.7.4. On the Possible Use of Solid Li-Oxide Cathodes and the Connection to Lithiated Transition Metals

3.8. Studies with Consideration of Practical Metal-Air Batteries

3.8.1. Li Batteries with Lithium Oxygen Compound Cathodes (and Closed Systems)

3.8.2. Challenges of Capacity and Kinetics

3.8.3. On the Validity of Energy Density Calculation of $\mathrm{Li}(\mathrm{Na})$-Oxygen Batteries

3.8.4. From Oxygen to Air

3.8.5. Configuration of Li-Air Cells and the Balance of Plant

4. Future Perspective

5. Conclusion

Author Information

Corresponding Authors

Authors

Author Contributions

Notes

Biographies

Acknowledgments

Abbreviations Used

References Active Metal ( $\mathrm{Li}, \mathrm{Na}$ ) Protection

AL

\section{INTRODUCTION}

\subsection{Contemporary Energy Needs}

Over the last decades, the intensive use of fossil fuels and electricity has dramatically increased the standard of living. Energy, particularly electrical energy, is core to a modern society. Presently, over $70 \%$ of the world's energy requirement is met by fossil fuels including coal, oil, and natural gas, but this is damaging our environment. Serious issues like global warming and air pollution make it extremely clear that it is imperative to reduce our dependence on fossil fuels to meet our energy requirements. To implement the necessary changes, scientific advances and technological solutions are urgently required.

Electrochemical power sources and energy storage systems will play a vital role in shifting the paradigm of the future energy network toward clean, renewable sources. This is because such systems form a vital bridge between dispatchable energy generation and intermittent supply from renewable sources such as wind and solar power., ${ }^{1,2}$ The most impressive scientific and applicative successes of modern electrochemistry are lithium-ion batteries (LIBs), which today power most of our mobile electronic devices. Building on this progress, the scientific community has set ambitious targets in the hope of substantially reducing fossil fuel use in the near future and promote the propulsion of ground transportation by electric power. It is well-known that in powering the 3Cs, computers, communication devices, and consumer electronics, LIBs have deeply penetrated every corner of our daily lives. ${ }^{1,3}$ Despite LIBs' successful history so far, there has been a continuous call to improve their capabilities and performance, primarily driven by their inability to meet society's emerging needs. ${ }^{2}$ For example, the present LIBs, with a maximum specific energy of ca. 250 $\mathrm{Wh} \mathrm{kg}^{-1}$ (at the cell level), do not possess sufficient energy, rate, durability, or affordability to match the performance of traditional automotive gasoline/internal combustion engines (Figure 1). ${ }^{2}$ In addition, detrimental climatic change has

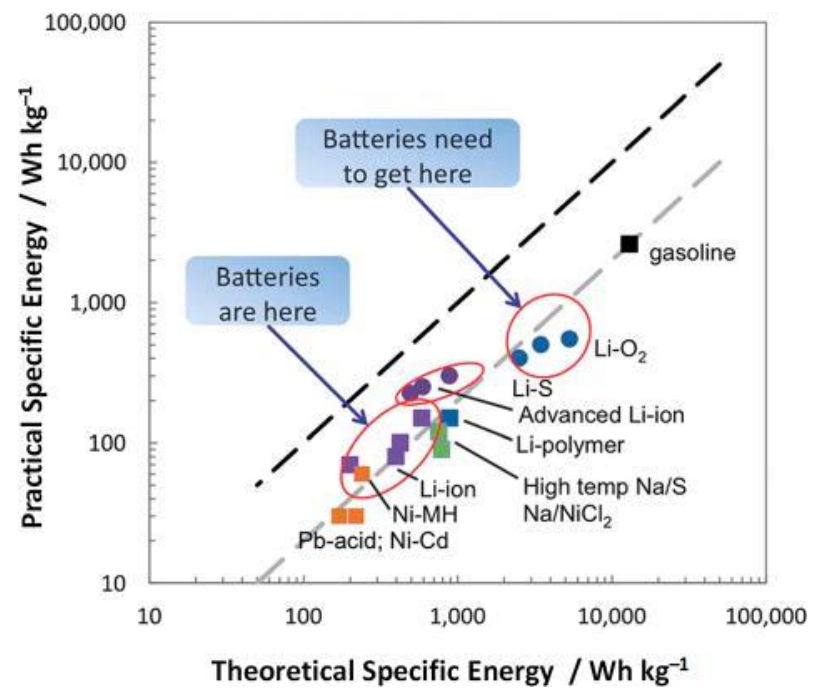

Figure 1. Graph shows the present position of various batteries on a plot of practical specific energy versus theoretical energy density. This illustrates the enormous challenge of increasing the practical energy density of advanced batteries beyond that of present state-of-the-art LIBs if they have to compete with the energy stored and delivered by fossil fuels like gasoline. Reproduced with permission from ref 2 . Copyright 2012 Royal Society of Chemistry.

hastened the need to electrify transport and develop reliable energy storage systems. These urgent requirements drive the scientific community to further increase the energy and power density of electrochemical power sources and decrease the ecological footprint beyond the limits of LIBs.

Relying on recent research efforts from both academia and industry, it is believed that further advancements in LIB technology and composition will eventually push their specific

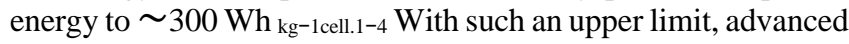
LIBs can meet the requirement of midsized passenger or light goods electric vehicles. Nevertheless, for the realization of fullelectric vehicles (EVs) with long driving range (500 miles), and especially for long-range small vehicles and heavy goods vehicles (HGVs), new electrochemical couples and chemistries, with a targeted specific energy of $500 \mathrm{Wh} \mathrm{kg}^{-1}$ cell and beyond, need to be developed; In addition, the low reserves (0.0017 wt $\%$ ) of Li in the earth's crust has spurred extensive research in innovative battery platforms, exploiting other active metals such as $\mathrm{Na}, \mathrm{Mg}$, or $\mathrm{K}$.

\subsection{Brief Overview of Electrochemical Energy Storage}

The electrification of many technologies has motivated researchers to develop advanced batteries replete with innovation. Currently, the development of $\mathrm{Li}$-ion batteries is a topic of prime importance. Significant progress has been achieved with the discovery and development of some high energy layered cathode materials of the general formula $\mathrm{Li}_{1}+\mathrm{x} \mathrm{Ni}_{2} \mathrm{CowMny} \mathrm{O}_{2}$, denoted as Li- and Mn-rich NMC compounds $(x>0, y>0.5, x+y+z+w=$ 1). These cathodes can deliver a specific capacity $>260 \mathrm{mAh} \mathrm{g}^{-1}$, almost twice that of conventional layered, spinel, or olivine type cathode materi- 
als. $^{3-8}$ Unfortunately, these high specific capacity cathode materials require high charging potentials $>4.6 \mathrm{~V}$, which challenge the stability of most relevant electrolyte solutions. Also, they suffer from stability problems, plagued by both capacity and average voltage fading during their cycling due to their complex structure and operation mechanism. ${ }^{6,9,10}$ Another approach to boost the energy densities of the LIBs is to use layered transition metal oxide cathodes with a high nickel content, denoted as Ni-rich NMC cathode materials (Li$\left.\mathrm{Ni}_{x} \mathrm{Co}_{y} \mathrm{Mn}_{z} \mathrm{O} 2, x>0.8\right)^{8,11_{-} 13}$ As the $\mathrm{Ni}$ content approaches $100 \%$, their specific capacity can reach $240 \mathrm{mAh} \mathrm{g}^{-1}$, with a maximal charging potential $<4.3 \mathrm{~V}$. These materials also suffer from capacity fading problems upon cycling; however, those issues can be mitigated by using judicious doping and coating. ${ }^{7,10,14-18}$ Using high voltage cathode materials (>4.7 V) like $\mathrm{LiCoPO}_{4}$ (olivine) and $\mathrm{LiNi}_{0.5 \mathrm{Mn} 1.5 \mathrm{O} 4}$ may also be attractive for some applications; however, the relatively low specific capacity of these cathodes (practically $<140 \mathrm{mAh} \mathrm{g}^{-1}$ ) weakens their importance. ${ }^{19-21}$ Because LIBs use graphite anodes (with a theoretical capacity of $372 \mathrm{mAh} \mathrm{g}^{-1}$ ), it is possible to increase their energy density by moving to high capacity Si-based anodes (theoretically > $3000 \mathrm{mAh}$ g-1).22-25 However, Si-based anodes suffer from intrinsic instability issues related to SEI formation. ${ }^{23,24}$ Lithium metal anodes were also suggested as an alternative to conventional graphite anodes. For instance, Hwang et al. proposed Li/NCM batteries with outstanding longterm cycling stability even under high loading conditions. ${ }^{26}$ Despite the high capacity, faster kinetics, and higher operational voltage window offered by metallic anodes, their practical applicability is hindered by safety concerns associated with dendritic growth and high reactivity of $\mathrm{Li}$ deposits upon charging. However, intensive work on solid-state electrolytes in recent years may enable the use of active metal anodes in practical rechargeable batteries. ${ }^{27,28}$ Nonetheless, because the limiting factor is the cathode side, changing the anodes in LIBs cannot drastically increase their energy density. The durability and cycle life of LIBs depends on complex interfacial interactions between the electrodes and the electrolyte solution and development of passivation phenomena on the electrode surfaces. ${ }^{29,30}$ Thereby, much attention has been devoted to developing suitable electrolyte solutions for LIBs. ${ }^{31,32}$ The success in developing commercial LIBs which currently conquer the markets and the fear about a possible shortage in lithium if the electromobility revolution succeeds, promotes development of more battery technologies based on other active metals. Excellent examples are the intensive efforts to develop Na-ion batteries in recent years. ${ }^{33,34}$ Hence, despite the constant progress in LIBs' performance, and encouraged by their success, worldwide efforts are underway to find new types of even more promising redox couples. ${ }^{22,35}$ Relying on the benefits of metallic anodes, the choice of sulfur and oxygen as the cathode is based on their high specific capacity (1168 $\mathrm{mAh} \mathrm{g-1}$ for $\mathrm{Li}_{2} \mathrm{O}_{2}$ ). Yet the practical performance of batteries based on these redox couples lags significantly behind their theoretical promise. Nevertheless, metal-sulfur and metal-oxygen batteries may outperform all other possible choices from a cost perspective and have attracted global attention from both academia and industries. This is because of their 3-5-fold higher specific energy, as seen in Figure ${ }^{2.22,36-38}$ The key determinant in the advancement of these batteries relies on combating parasitic reactions that take a toll in terms of efficiency, cyclability, and safety. ${ }^{2}$ There is much research activity ongoing in the field of $\mathrm{Li}-\mathrm{S}$ batteries, ${ }^{39,40}$ but this topic is beyond the

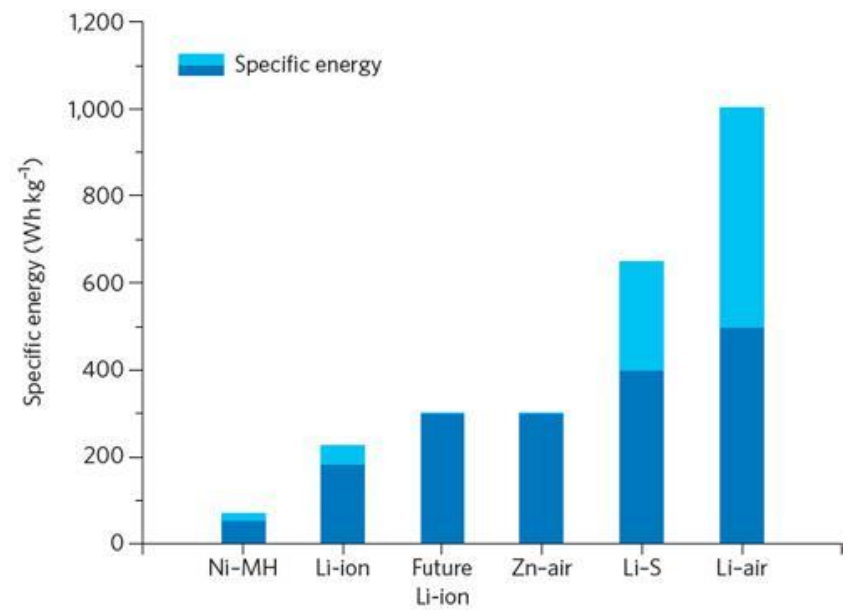

Figure 2. Bar graph demonstrating the practical specific energies in the battery world. These are reduced from the theoretical values by current collectors, cell packaging, and system overheads. Light-blue boxes indicate the range of specific energies. Reproduced with permission from ref 37. Copyright 2016 Springer Nature.

scope of this review, which focuses on the alluring lithiumoxygen $\left(\mathrm{Li}-\mathrm{O}_{2}\right)$ batteries based on their formal specific energy of $3500 \mathrm{Wh} \mathrm{kg}^{-1}$. First, however, we introduce the reader to metal-air batteries in the next section.

\subsection{Metal-Air Batteries}

Metal-air batteries ${ }^{36,41}$ promise a higher specific energy in comparison to the state of art LIBs and thus have arguably gained the most attention under the topic of "post Li-ion batteries". On the basis of the pairing of a metal anode and an oxygen-air electrode (called as anode and cathode respectively in this paper), metal-air batteries present a hybrid architecture combining the features of both batteries and fuel cells. To date, several metal-air batteries using alkali metals ( $\mathrm{Li}, \mathrm{Na}$, and $\mathrm{K}$ ), alkaline earth metal $(\mathrm{Mg})$, and first-row transition metals (Fe, $\mathrm{Zn}$ ) or $\mathrm{Al}$ as the anode have been reported and their formal specific energies are presented in Figure 3. At this point, it is important to note that, despite being the motivation for the research, there is lots of ambiguity with what energy metal- $\mathrm{O}_{2}$ batteries could potentially store. The problem arises from

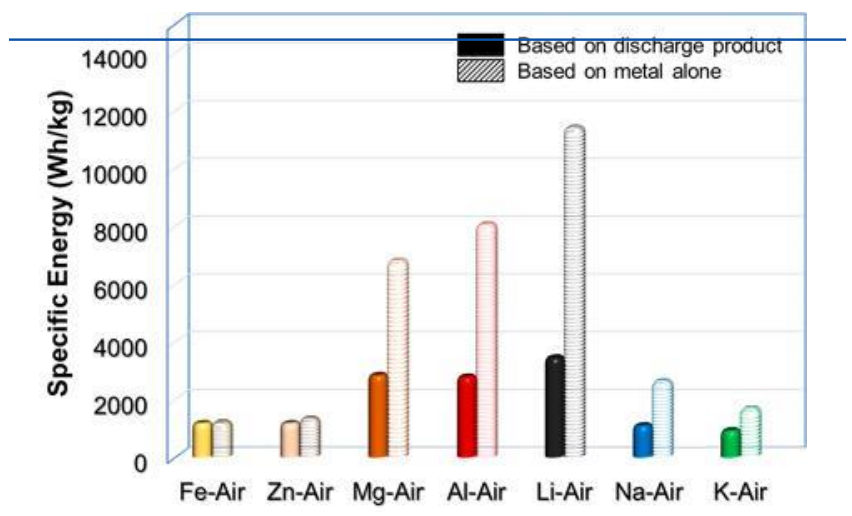

Figure 3. Specific energies of metal-air batteries. Solid-colored bars represent specific energy densities based on the discharge product and one equivalent of the metal anode, whereas patterned bars are based on the formal specific energies taking only metal into account. Reproduced with permission from ref 42. Copyright 2017 American Chemical Society. 
confusing formal capacity $\left(1168 \mathrm{mAh} \cdot \mathrm{g}^{-1}, 2500 \mathrm{mAh} \cdot \mathrm{cm}^{-3} \mathrm{Li}_{2} \mathrm{O}_{2}\right)$ with theoretical capacity $\left(\mathrm{Li}_{2} \mathrm{O}_{2}\right.$ including the minimum electron and ion conductor to allow the storage process $\mathrm{O}_{2}+2 \mathrm{e}-+2 \mathrm{Li}^{+}$ $\leftrightarrow \mathrm{Li}_{2} \mathrm{O}_{2}$ to take place). ${ }^{37,38}$ As broadly discussed in section 3, $\mathrm{Li} 2 \mathrm{O} 2$ can by far not be cycled in pure substance, which cuts the theoretical well below formal capacity. Yet there is no theoretical barrier for the $\mathrm{Li}-\mathrm{O}_{2}$ cathode to achieve higher true capacity than LIB cathodes (see section 3.4).

The nonaqueous systems have gained recent attention specifically due to the high formal specific energy of $\mathrm{Li}-\mathrm{O}_{2}$ batteries. However, aqueous electrolyte solution-based configurations have been researched since the early 1900s. ${ }^{43}$ The commercialization of metal-air batteries commenced with the primary $\mathrm{Zn}$-air battery in $1932 .{ }^{44}$ Later, other aqueous systems like $\mathrm{Al}-$ air $^{45,46}$ and $\mathrm{Mg}-$ air $^{47}$ came into existence in 1960s. Among the aqueous counterparts, the aluminum-air battery was considered to be an attractive candidate as a power source for electric vehicles (EVs) because of its high formal energy density $\left(2800 \mathrm{Wh} \mathrm{kg}^{-1}\right)$. Notably, in 2016, an Al-air battery weighing $100 \mathrm{~kg}$ was fabricated by Alcoa and Phinergy Co. Ltd. and shown to be capable of running a car on air for more than 1000 miles. ${ }^{45}$ Unfortunately, most of the aqueous metal-air cells, including the Al-air battery, function as primary cells and can only be mechanically charged by replacing the used metal anodes and the electrolyte solution. Additionally, corrosion of metallic anodes in the presence of water, high self-discharge rate, sluggish discharge kinetics, and short shelf life render these systems inappropriate for demanding applications like full EV vehicles.

On the other hand, nonaqueous metal-air systems ${ }^{48}$ are comparatively new but offer rechargeability with extremely high theoretical capacity. In 1996, Abraham et al. ${ }^{49}$ reported the first rechargeable nonaqueous lithium- $\mathrm{O}_{2}$ battery, which opened up a completely new field for researchers that led to development of other analogous systems such as $\mathrm{Na}-\mathrm{O}_{2}$ and $\mathrm{K}-\mathrm{O}_{2}$ batteries. Among these, the $\mathrm{Li}-\mathrm{O}_{2}$ battery is the most attractive because it offers the highest operational voltage $(-2.96 \mathrm{~V})$ with a formal specific energy of $-3500 \mathrm{Wh} \mathrm{kg}^{-1}$ (based on formation of $\mathrm{Li}_{2} \mathrm{O}_{2}$ on discharge). The societal need for energy storage that exceeds $\mathrm{Li}$-ion and the possibility that $\mathrm{Li}-$ air could deliver the required step-change, has convinced the research community of its importance. Significant effort was devoted a decade ago to commercialize $\mathrm{Li}$-air, which failed, but prompted research aimed at a deeper understanding of the poorly understood underpinning chemistry and electrochemistry, including the processes of degradation.

\subsection{Scope of This Review Article}

In the past, diverse aspects of metal-air batteries, in general, and the most promising $\mathrm{Li}-\mathrm{O}_{2}$ batteries, in particular, have been reviewed by various leading research groups. ${ }^{37,48,50-56}$ Detailed reviews with emphasis on the strategies toward a stable metal anode, ${ }^{57-59}$ methodologies for mechanistic studies, ${ }^{60-62}$ effect of contaminants, ${ }^{63-65}$ stability of the electrolyte solutions, ${ }^{66}$ and the role of redox mediators on the performance of $\mathrm{Li}-\mathrm{O}_{2}$ batteries $^{54,67}$ have appeared. Even overviews questioning the practical reality of metal-air batteries have been published recently. ${ }^{42,68,69}$ The intensive work in this area over the past decade has identified the key problems and guided directions to solve them. Thus, the preparation of a comprehensive report covering the challenges, possible solutions, and recent developments associated with the progress of these batteries is called for. It is hoped that such a review will give the interested and educated reader a clear picture of the potential prospects of $\mathrm{Li}-$ $\mathrm{O}_{2}$ and related batteries.

This review has four major goals:

(1) To clearly describe the current status of $\mathrm{Li}-\mathrm{O}_{2}$ batteries with respect to new mechanistic insights, the stability and degradation of the electrolyte solutions and the electrodes in the presence of reactive oxygen species (ROS), singlet oxygen, and other contaminants, and the catalytic ability of anchored and mobile catalysts (redox mediators) to address the problematic oxygen reduction and evolution reactions.

(2) To extend the knowledge gained by in-depth research in the field of $\mathrm{Li}-\mathrm{O}_{2}$ batteries to analogous systems like $\mathrm{Na}-\mathrm{O}_{2}, \mathrm{~K}-\mathrm{O}_{2}$, and $\mathrm{Mg}-\mathrm{O}_{2}$ batteries which are still in their infancy.

(3) To introduce novel electrolyte solutions and electrode architectures which stabilize extremely reactive systems without compromising their promising energy density.

(4) To present a critical, yet realistic overview of the accumulated knowledge in this rapidly expanding field in order to overcome the gap between breakthroughs and commercialization. We have, therefore, tried avoiding redundant areas while carefully maintaining the comprehensive nature of the review to keep it relevant for readers of broad interest.

\section{LITHIUM-OXYGEN BATTERIES: DIVERSITY AND EVOLUTION}

\subsection{Configuration of $\mathrm{Li}^{-} \mathrm{O}_{2}$ Cells}

The $\mathrm{Li}-\mathrm{O}_{2}$ battery, composed of a metallic lithium as the negative electrode, namely the anode, air- $\mathrm{O}_{2}$ as the cathode active mass, and a $\mathrm{Li}^{+}$containing electrolyte solution, is one of the most studied class of metal-air batteries. The cathode in these systems is a composite electronically conducting porous matrix that enables the electrochemical contact between oxygen gas and $\mathrm{Li}$ ions in the electrolyte solution phase. It primarily functions with the dissolution/deposition of lithium metal at the anode and an oxygen reduction reaction (ORR)/oxygen evolution reaction (OER) at the cathode, ${ }^{55}$ as schematically outlined in Figure 4.

\section{Lithium-Oxygen Battery}

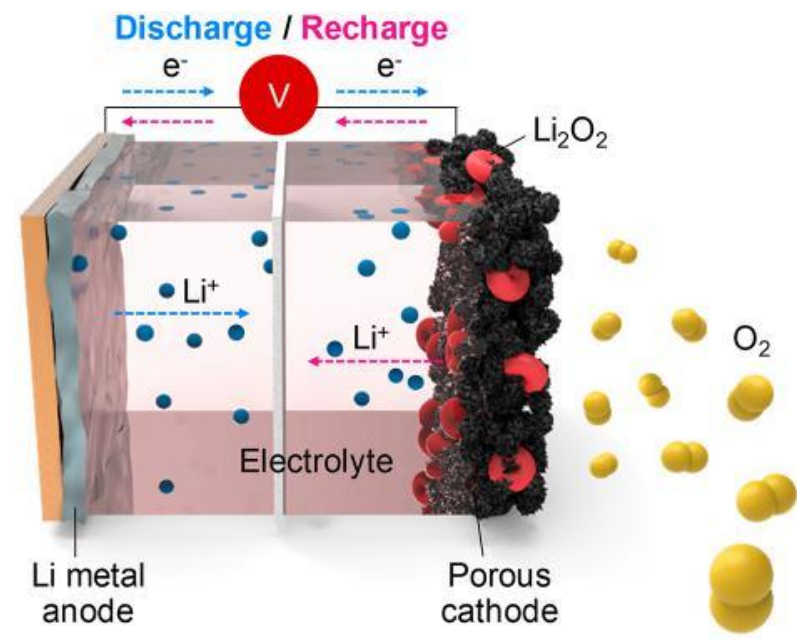

Figure 4. Schematic presentation of $\mathrm{Li}-\mathrm{O}_{2}$ battery. 

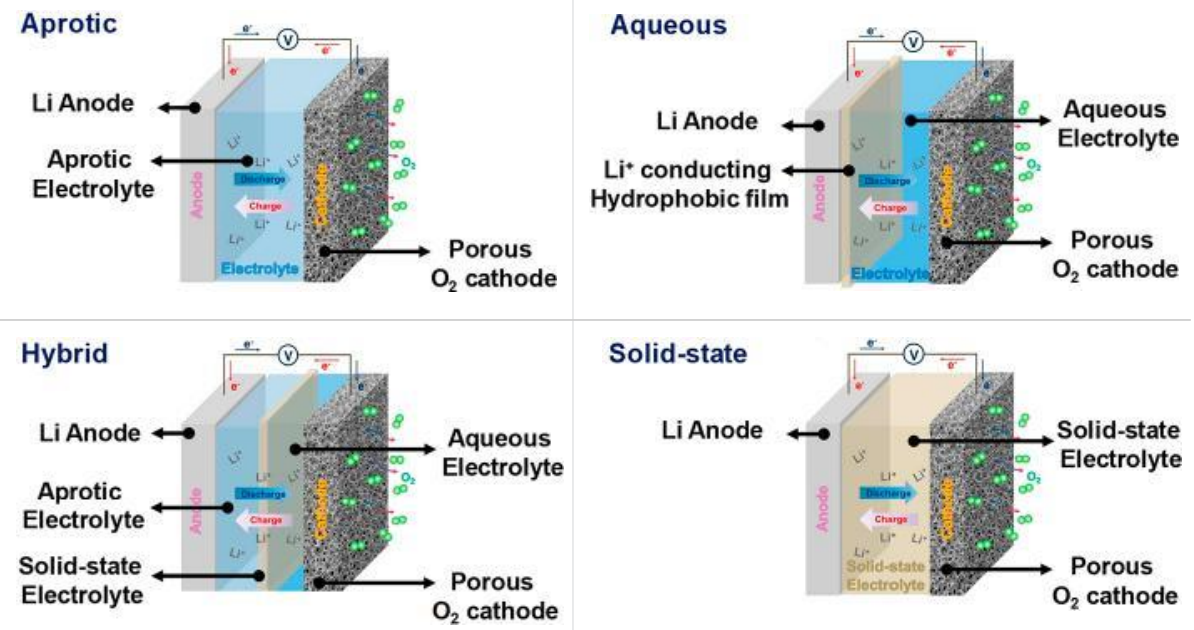

Figure 5. Schematic configuration of all types of $\mathrm{Li}-\mathrm{O}_{2}$ cells. Reproduced with permission from ref 56. Copyright 2017 Elsevier.

There are currently four categories of $\mathrm{Li}-\mathrm{O}_{2}$ systems under investigation, referred to as aprotic, aqueous, hybrid, and solidstate batteries. The four types differ from each other regarding the electrolyte species involved. The latter, in turn, determines the specific electrochemical reactions during energy storage and release. A schematic illustration of these four types of batteries is provided in Figure 5.56

The "aprotic LOB" 49,70 consists of a lithium anode, a porous air cathode, and an electrolyte composed of a lithium salt dissolved in nonaqueous, organic solvent. Electrochemical reaction pathways for this type of LOB were proposed by Abraham et al.70-72 and, not surprisingly, involve the reduction of molecular oxygen to lithium superoxide $\left(\mathrm{LiO}_{2}\right)$ via one electron transfer, as depicted in eq 1:

$+$

This reduction is followed by either disproportionation (eq 2) or receipt of a second electron (eq 3), both pathways forming lithium peroxide $\left(\mathrm{Li}_{2} \mathrm{O}_{2}\right)$ as the main discharge product.

$$
\begin{aligned}
& 2 \mathrm{LiO}_{2} \square \mathrm{Li} 2 \mathrm{O}_{2}+\mathrm{O}_{2} \\
& \mathrm{LiO}_{2}+\mathrm{Li}+\mathrm{e} \square \mathrm{Li}_{2} \mathrm{O}_{2}
\end{aligned}
$$

The resulting lithium peroxide is insoluble in the aprotic solvents, ${ }^{73}$ and thus deposits on the cathode either as an insulating thin film, or crystallizes in the shape of large toroidal precipitates. Consequently, the capacity of this battery is limited by the thickness of the $\mathrm{Li}_{2} \mathrm{O} 2$ film ( $\sim 7 \mathrm{~nm}$ for this insulating solid) in case of an electrolyte solution that forms a $\mathrm{Li}_{2 \mathrm{O} 2} \mathrm{film}$, and by the volume of the porosity of the cathode if the product is toroidal particles. During charge, the deposited $\mathrm{Li}_{2} \mathrm{O} 2$ undergoes oxidation at the positive electrode surface, regenerating molecular oxygen.

Researchers at the PolyPlus Battery Company eliminated the solid, insoluble discharge product of Aprotic LOB by replacing the nonaqueous solvent with an aqueous solution and employing an Ohara glass Li-ion conducting membrane to protect the $\mathrm{Li}$ anode from corrosion. ${ }^{74}$ In 2004, such a cell was reported by Visco et al. (see Figure 5).50,75 The use of an aqueous electrolyte resulted in the formation of soluble lithium hydroxide $(\mathrm{LiOH})$ as the discharge product, in contrast to solid $\mathrm{Li}_{2} \mathrm{O}_{2}$. This system has not yet become a commercial reality.
Another attempt to implement an aqueous system brought the "Hybrid LOB" into existence..$^{73,76-78}$ In the proposed design, the anode side of the battery was filled with an aprotic solvent, whereas the air electrode was in contact with an aqueous electrolyte. The two electrolyte solutions were decoupled by a solid electrolyte membrane. The hybrid LOB avoided direct contact between the lithium and the solid electrolyte membrane and indeed resulted in improved lithium ion conductivity. However, the design leads to added complications and different diffusion kinetics in the two solutions.

"Solid-state LOBs" were also developed which do not use any liquid electrolytes, as shown in Figure 5. The development and application of solid-state lithium ion conducting materials for use in LOBs gained pace around 2010 ${ }^{79}$ However, a truly allsolid-state LOB is challenged by how much $\mathrm{Li}_{2} \mathrm{O} 2$ can be stored in the cathode.

Because only the aprotic configuration of a LOB has shown a considerable rechargeability, it has attracted the largest effort worldwide. Consequently, in the following section, we will focus our discussion on this configuration.

\subsection{The History and Early-Stage Research on Aprotic Li- $\mathbf{O}_{2}$ Batteries}

$\mathrm{A} \mathrm{Li}$ and $\mathrm{O}_{2}$ electrochemical couple for batteries was proposed in early 1970s; however, the first experimental observation was made in 1996 by Abraham et al., ${ }^{49}$ and that in a serendipitous manner. ${ }^{70}$ During the in situ investigation of the electrochemical intercalation of graphite in a $\mathrm{Li} /$ graphite cell with a polymer electrolyte, $\mathrm{O}_{2}$ was accidentally injected while collecting the evolved gases for infrared spectroscopy. On resuming the experiment, a higher OCV and increased capacity was observed which was attributed to the formation of $\mathrm{Li}_{2} \mathrm{O} 2$ and other products as a result of reaction between $\mathrm{Li}$ and $\mathrm{O}_{2}$. These unexpected conclusions led them to build the first $\mathrm{Li}-$ air cell and study this hybrid fuel cell. The field took off a decade later to unravel many electrochemical and mechanistic details. In 2002, Read et al.80-82 illustrated that the discharge capacity, rate performance, and cyclability of $\mathrm{Li}-\mathrm{O}_{2}$ cells depends largely on the electrolyte solution and the air cathode formulation. In 2006, Ogasawara et al., ${ }^{83}$ demonstrated for the first time that $\mathrm{Li}_{2} \mathrm{O}_{2}$ could be oxidized electrochemically, using mass spectrometry to prove $\mathrm{O}_{2}$ evolution. Many of these early pioneering studies used carbonate electrolytes and manganese dioxide as the electro- 
catalyst, which have since been shown to be unstable. ${ }^{84,85}$ Overall, it can be said unequivocally that by 2008, the pioneering work of the research groups of Abraham, Read, and Bruce laid the foundation which attracted immense attention to $\mathrm{Li}-\mathrm{O}_{2}$ systems.

\section{CURRENT STATUS}

\subsection{A Short Introduction on Important Aspects of Nonaqueous Electrochemistry}

As already noted, the use of $\mathrm{Li}$ metal anodes in $\mathrm{Li}-\mathrm{O}_{2}$ batteries is mandatory to achieve high energy density. This dictates the use of cell components that can enable safe and controllable operation of anodes comprising this reactive alkali metal. It is very likely that a $\mathrm{Li}$ anode protected by a solid electrolyte membrane will be required as the criteria for a liquid electrolyte in direct contact with Li metal is a major challenge. We can summarize a few of the criteria that are relevant to any chosen system:

(1) The polarity of the solvent should be sufficient to enable facile dissolution of salts.

(2) The overall physical properties (polarity, viscosity) should enable high ionic conductivity.

(3) The electrochemical window available must be wide enough to allow the full operation of the battery.

(4) The systems must be stable against side reactions (e.g., via development of effective passivation phenomena).

(5) The components must be of high purity, due to possible undesirable side reactions with contaminants such as atmospheric species, acidic moieties, etc.

(6) The electrolyte should exhibit appropriate safety features (e.g., low volatility, flammability, and opportunity for thermal runaway routes).

While many possible combinations of aprotic solvents and lithium salts answer the first and second criteria, only a few candidates at best can fit criteria 3-6. In fact, all electrolyte solutions are only metastable toward the electroactive species and working potentials of standard lithium-oxygen batteries. The empirical physical and chemical properties of various aprotic solvents and lithium salts that affect (or even determine) the mechanisms of oxygen electrochemistry in them became more and more understood thanks to systematic studies during the past decade. We note, however, that nonaqueous electrolyte solutions that are truly suitable alone for controllable $\mathrm{Li}-\mathrm{O}_{2}$ electrochemistry have yet to be found. Nevertheless, the insights and fundamental knowledge gleaned over the past decade attests to the great progress made in understanding the limitations of many types of electrolytes examined to date in $\mathrm{Li}-\mathrm{O}_{2}$ cells and, hence, inform the properties required from suitable systems.

\subsection{Mechanistic Aspects of Nonaqueous Oxygen Electrochemistry}

3.2.1. Li202 formation on Discharge. Studies of oxygen electrochemistry in nonaqueous electrolyte solutions took place much before the appearance of the $\mathrm{Li}-\mathrm{O}_{2}$ battery concept. ${ }^{86,87}$ These studies were conducted with the aim of understanding the behavior of reactive oxygen species (ROS) in the absence of proton donors such as water. It was found (even by simple voltammetric measurements) that oxygen electrochemistry is very dependent on the nature of polar aprotic solvent and the electrolyte salt (especially the identity of the cation). In some cases, oxygen exhibited reversible redox behavior, while in others the response was more complex (irreversible in many cases). Therefore, to properly describe the oxygen reduction reaction (ORR) and oxygen evolution reaction (OER), one must consider the media in which the reaction is taking place. ${ }^{88}$

The important parameters that govern the mechanism of $\mathrm{O}_{2}$ reduction to $\mathrm{Li}_{2} \mathrm{O} 2$ are: (1) The donor number (DN) of the solvent and salt. These are critically important as they determine the solubility and dissociation of $\mathrm{LiO}_{2}$ and hence whether $\mathrm{Li}_{2} \mathrm{O}_{2}$ grows on the electrode (low DN) or in solution (high DN). (2) The Lewis acidity of the solvated lithium cation. (3) Contaminants and additives in the electrolyte solution. (4) The stability of the solvent toward the reduced oxygen species generated and toward possible formation of a very reactive molecular oxygen state (as discussed further below). These parameters can have a synergetic effect; therefore, must be described together. The stability of various aprotic solvents is described in the next section of this review.

The first step in $\mathrm{O}_{2}$ reduction is the one electron reduction to form the superoxide radical $\left(\mathrm{O}_{2}^{-{ }^{-}}\right)$as confirmed by early experiments in nonaqueous solutions with solvents such as DMSO. ${ }^{86,87}$ The subsequent fate of the superoxide is dependent on the nature of the countercation. With large cations such as $\mathrm{K}^{\prime}$ and tetrabutylammonium (TBA'), the metal peroxides are less stable compared to $\mathrm{Na}_{2} \mathrm{O}_{2}$ and ${ }_{\mathrm{Li} 2 \mathrm{O} 2}$ (the latter being the most stabilized peroxide). The level of stability of the metal peroxide affects the lifetime of superoxide intermediates in these systems. Hence, with cations like $\mathrm{TBA}^{+}$or $\mathrm{Na}$, it is possible to observe reversible reduction of oxygen to superoxide moieties, while with the lithium cation such a reversible behavior is not seen. Using methods such as Raman and UV spectroscopy coupled with electrochemical measurements, it was demonstrated that the superoxide does form in lithium containing solutions (eq 1 above). ${ }^{89,90}$ However, this unstable radical quickly dispropor-tionates to form lithium peroxide, Li2O2 (eq 2 above). While the superoxide is somewhat soluble and can diffuse in the electrolyte solution, the peroxide moieties are insoluble in aprotic solvents (if their DN are not high enough). ${ }^{71,72}$

The mechanisms of $\mathrm{O}_{2}$ reduction in different aprotic solvents that vary in their donor numbers were extensively studied in recent years. The mechanism of $\mathrm{O}_{2}$ reduction to form $\mathrm{Li}_{2} \mathrm{O} 2$ is summarized in Figure 6. In all solvents of high donor number (DN), following reduction of $\mathrm{O}_{2}$ to $\mathrm{O}_{2}$ - at the electrode surface, the $\mathrm{O}_{2}$ - is present in solution due to the strong solvation of the Li' ion by coordination with the solvent molecules. In other words, in a high DN solvent, $\mathrm{LiO}_{2}$ does not exist and is instead present as solvated ions. However, as $\mathrm{Li}_{2} \mathrm{O} 2$ is more stable than $\mathrm{LiO}_{2}$, disproportionation occurs for $\mathrm{LiO}_{2}$ to grow relatively large toroidal $\mathrm{Li2} 2$ particles directly from solution. In contrast, when the DN is sufficiently low, $\mathrm{Li}$ is not strongly solvated and $\mathrm{LiO}_{2}$ (ion coupled electron transfer) forms on the electrode surface. Either rapid disproportionation or a second electron transfer forms $\mathrm{Li}_{2} \mathrm{O} 2$ that grows as a film on the electrode. This understanding of the role of the $\mathrm{DN}$ in determining whether $\mathrm{LiO}_{2}$ will dissolve in solution or will deposit on the electrode surface following the first electron transfer was a milestone in understanding the $\mathrm{Li}-\mathrm{O}_{2}$ cell. It showed that high DN electrolyte solutions will promote growth of $\mathrm{Li}_{2} \mathrm{O} 2$ from solution, thus forming large toroidal particles in the pores of the electrode that do not passivate the electrode. This results in relatively high rates and capacities of ORR in high DN solvents, whereas low DN electrolyte solutions, like ethers, lead to $\mathrm{Li}_{2} \mathrm{O}_{2}$ film growth and consequently low rates and capacities. Recently, the growth mechanism and morphology of the discharge products were also reported as being dominated by the 


$$
\begin{aligned}
& \text { Solution mechanism } \\
& \mathrm{Li}_{(\text {sol })}^{+}+\mathrm{e}^{-}+\mathrm{O}_{2(\mathrm{sol})}=\mathrm{Li}_{(\text {sol })}^{+}+\mathrm{O}_{2(\text { (sol) }}^{-} \\
& 2\left(\mathrm{Li}^{+}{ }_{(\mathrm{sol})}+\mathrm{O}_{2}{ }^{-}{ }_{\text {(sol) }}\right)=\mathrm{Li}_{2} \mathrm{O}_{2}+\mathrm{O}_{2} \\
& 2 \mathrm{Li}^{+}{ }_{\text {(sol) }}+\mathrm{O}_{2}^{-} \text {(sol) }^{-}+\mathrm{e}^{-}=\mathrm{Li}_{2} \mathrm{O}_{2}
\end{aligned}
$$

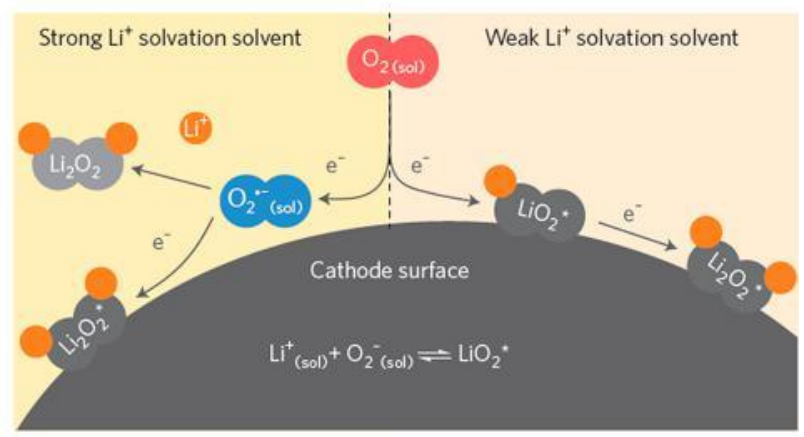

B

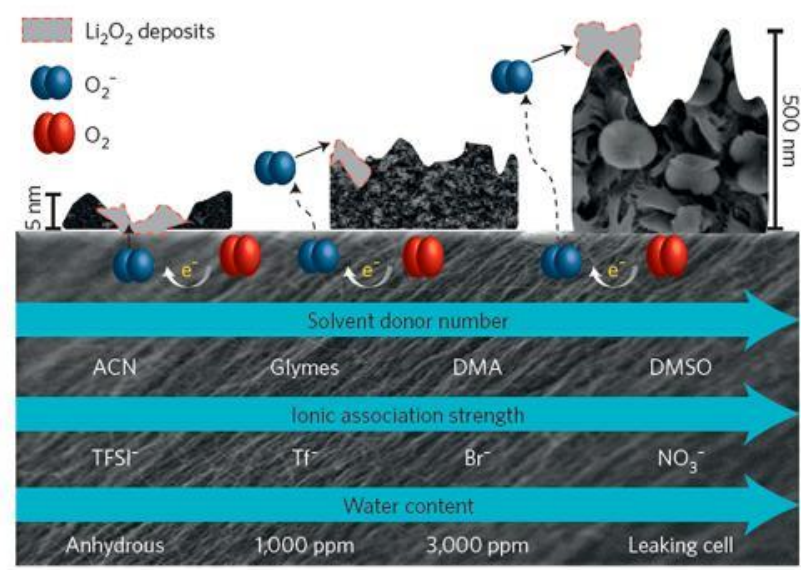

Figure 6. (A) Oxygen reduction mechanistic pathways in nonaqueous $\mathrm{Li}-\mathrm{O}_{2}$ batteries. Reproduced with permission from ref 90 . Copyright 2014 Springer Nature. (B) The influence of solvents, counteranions, and water content on the Li2O2 growth mechanism during ORR. Reproduced with permission from ref 37. Copyright 2016 Springer Nature.

reactions' temperature. ${ }^{91}$ Depending on the lifetime of the superoxide/peroxide species and the kinetics of the ORR, the temperature was found to affect the shape and size of the $\mathrm{Li}_{2} \mathrm{O}_{2}$ deposits. Elevated temperatures of $40^{\circ} \mathrm{C}$ were found to result in toroidal particles, attributed to a faster kinetics and formation of discharge products through solvent mediated, disproportiona-tion reactions. In turn, spherical or flakes like particles were observed at low temperatures resulting from surface mediated growth. Given the important role of $\mathrm{LiO}_{2}$ solvation/stabilization and the importance of the interactions of the solvent molecules with the $\mathrm{Li}$ ions, the effective DN and acceptor number (AN) of the solutions determines whether $\mathrm{Li}_{2 \mathrm{O} 2}$ forms via a solution or surface mediated pathways. High DN and AN additives were shown to favor solution pathways. Considering first the DN, the counteranion can strongly tune the $\mathrm{DN}$ of the electrolyte solution. ${ }^{92,93}$ The degree in which the anion can interact with the solvated Li cation can be quantified by the association strength of the salt. Strongly dissociated salts such as LiTFSI form solvated complexes where the Li cation hardly interacts with the TFSI anion. In weakly dissociated or associated salts such as LiTf and $\mathrm{LiNO}_{3}$, the negatively charged functional groups of the anions interact with the $\mathrm{Li}$ cations in complexes such as $\mathrm{NO}_{3}{ }^{-}-\mathrm{Li}^{+}$-solvent are strongly solvated. The stabilization of the $\mathrm{Li}$ cations by the anion will promote $\mathrm{LiO}_{2}$ in solution. We note that the effect of the anion was shown to be relevant only for lower DN solvents, such as polyethers (ref 37 and discussions therein).

In the solution mediated mechanism, after the initial nucleation of $\mathrm{Li2O}_{\mathrm{O} 2}$ seeds, the growth of $\mathrm{Li}_{\mathrm{L} 22}$ particles can proceed from solution and therefore leave behind an active cathode interface. It is the avoidance of a passivating surface film of $\mathrm{Li2O}_{\mathrm{L}}$ that leads to high rates and high capacities in high DN electrolyte solutions.

High AN additives, particularly protic ones, were further found to favor large discharge capacities with big toroidal $\mathrm{Li}_{2} \mathrm{O}_{2}$ particles. The most common protic additive/contaminant is water. The reaction of water (if in large concentration) with a superoxide species can lead to the formation of insoluble $\mathrm{LiOH}$ deposits on the cathode interface. However, it was demonstrated that with small to medium amounts of water, the main discharge product can still be $\mathrm{Li}_{2} \mathrm{O}_{2}$. By the addition of $0.01-1 \%$ water into a polyether-based electrolyte solution. the discharge capacity increased by more than 25 -fold. In addition, the yield and size of
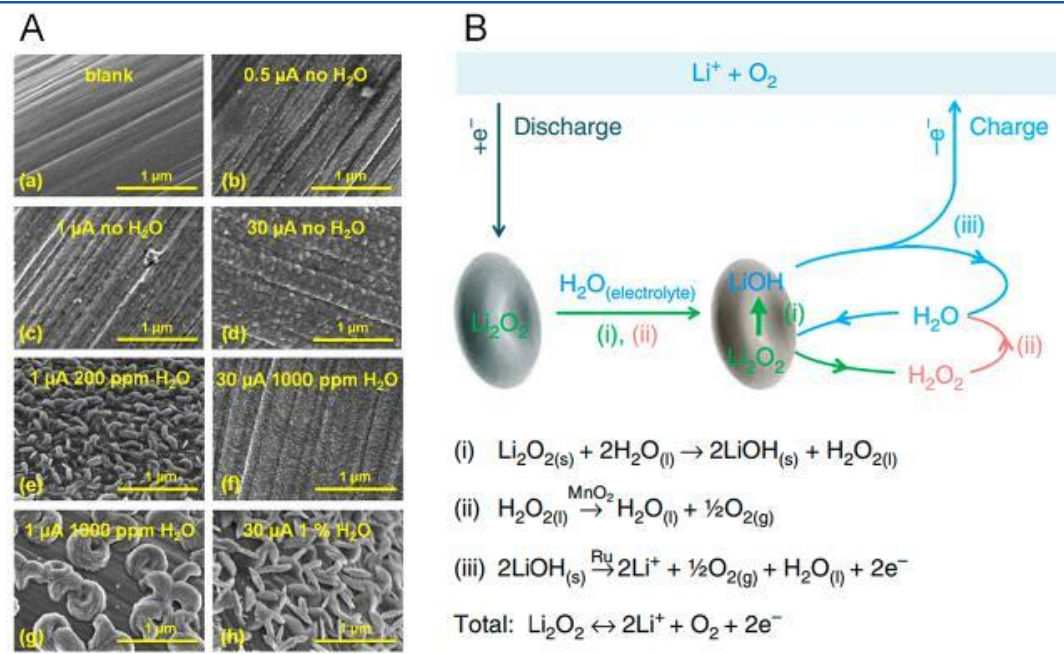

Figure 7. (A) SEM images of the carbon cathodes of $\mathrm{Li}-\mathrm{O}_{2}$ cell after discharged in the presence of water at different concentrations. Reproduced with permission from ref 96. Copyright 2015 The Electrochemical Society. (B) The ORR and OER mechanistic scheme in a nonaqueous Li- $\mathrm{O}_{2}$ cell in the presence of added water. Reproduced with permission from ref 98. Copyright 2015 Springer Nature. 
A
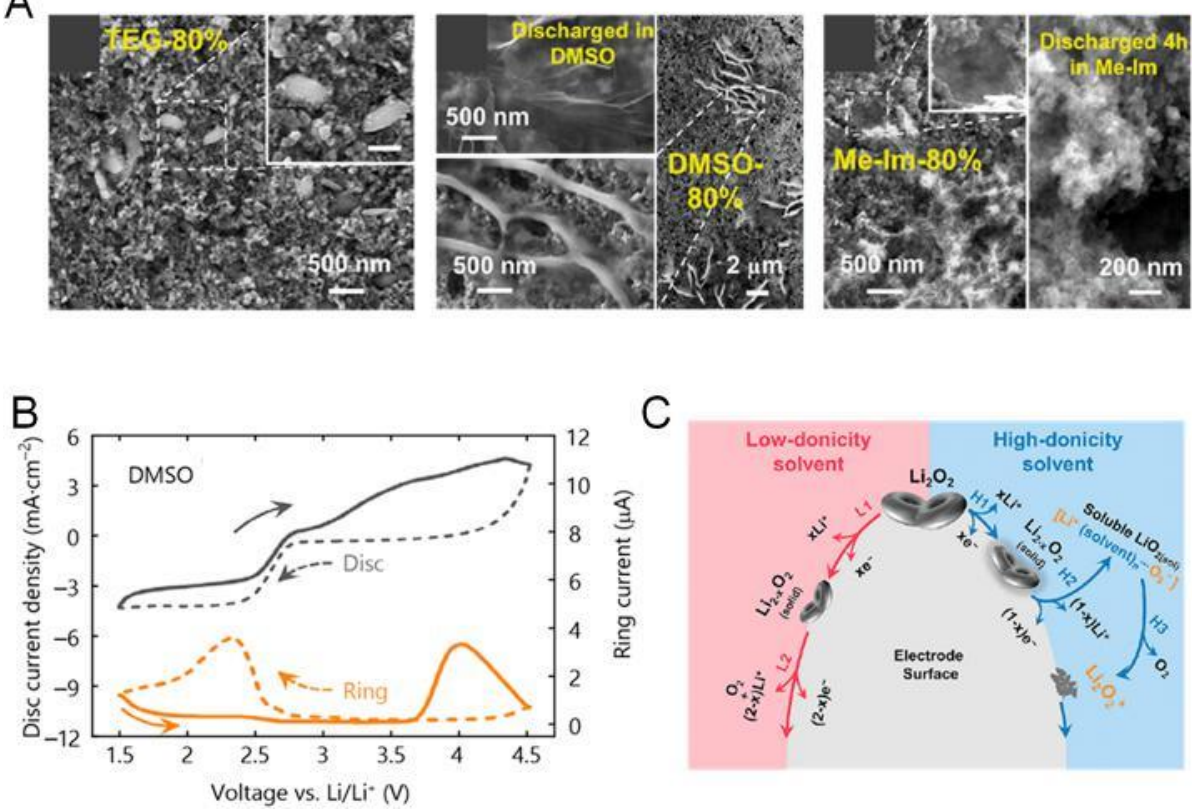

Figure 8. Solvent controlled charge mechanism of $\mathrm{Li}_{2} \mathrm{O}_{2}$. (A) SEM images of $\mathrm{Li}_{2} \mathrm{O}_{2}$-packed electrodes after $80 \%$ recharge in different solvents containing 1 M LiTFSI. The inserts show recrystallization of $\mathrm{Li}_{2 \mathrm{O} 2}$ into lamellar structures due to disproportionation in DMSO and Me-Im. (B) RRDE measurement of oxygen reduction/evolution in $\mathrm{O}_{2}$ saturated DMSO with $0.2 \mathrm{M}$ LiTFSI. The ring current indicates the superoxide reduction during both discharge and charge and hence $\mathrm{LiO}_{\text {(sol) }}$ to be present. (C) Scheme of the charge mechanism via surface or solution mechanism in low or high DN solvents, respectively. Reproduced with permission from ref 113. Copyright 2018 Elsevier.

$\mathrm{Li}_{2} \mathrm{O}_{2}$ particles increased with added water. ${ }^{94}$ However, Aetukuri et al. reported that discharge capacity increased 4-fold with 4000 ppm of water with increasing size of $\mathrm{Li}_{2} \mathrm{O}_{2}$ particles, but the number (yield) of ${ }_{\mathrm{Li} 2 \mathrm{O} 2}$ particles decreased. ${ }^{94}$

The mechanism by which water induces the formation of large toroidal shaped particles is still unclear. One proposed explanation is that protic molecules increase the effective AN of the electrolyte and improve solvation of superoxide much more efficiently than aprotic solvents. This can lead to $\mathrm{Li}_{2} \mathrm{O}_{2}$ growth by a solution-based mechanism. Alternatively, proto-nation of $\mathrm{O}_{2}$ - to form $\mathrm{HO}_{2}$ can occur, which diffuses from the electrode surface and forms ${ }_{\mathrm{Li} 2 \mathrm{O} 2}$ in solution. ${ }^{95-97}$ The presence of water can also influence the oxidation of $\mathrm{Li}_{2} \mathrm{O}_{2}$ during the OER. Li et al. suggested that the addition of water to a $\mathrm{Li}-\mathrm{O}_{2}$ cell can significantly reduce the OER overpotential. ${ }^{98}$ They found that some $\mathrm{Li}_{2} \mathrm{O} 2$ was converted to $\mathrm{LiOH}$ during the cathode discharge (Figure 7A). However, it is not clear that $\mathrm{LiOH}$ can be oxidized to molecular oxygen, even catalytically, as suggested in the mechanism of Figure 7B. To avoid the consumption of water by $\mathrm{Li}_{2} \mathrm{O}_{2}, \mathrm{MnO}_{2}$ was introduced to regenerate water by catalyzing the reduction of $\mathrm{H}_{2} \mathrm{O} 2$. However, as described below, these catalysts are known to induce decomposition reactions in the battery. A similar regenerative process was described in $\mathrm{Li}-\mathrm{O}_{2}$ systems that include water impurities and LiI salt. ${ }^{99-101}$ Therefore, the influence of water in $\mathrm{Li}-\mathrm{O}_{2}$ cells should be examined very carefully to avoid any misperceptions that may rise from the chemical complexity of this kind of system.

3.2.2. Li202 Oxidation Mechanism on Charge. In contrast to the steady discharge voltage plateau during the formation of $\mathrm{Li}_{2} \mathrm{O}_{2}$, the oxidation curve of ${ }_{\mathrm{Li} 2 \mathrm{O} 2}$ is seemingly comprised of multiple voltage steps. A fundamental hysteresis exists because while disproportionation of $\mathrm{LiO}_{2}$ to form $\mathrm{Li}_{2} \mathrm{O}_{2}$ dominates on discharge, the reverse process (comproportiona-tion) cannot occur on charge. Charge usually initiates around
$3.2 \mathrm{~V}$ and can continue up to $4.5 \mathrm{~V}$ in many $\mathrm{Li}-\mathrm{O}_{2}$ systems. In an early study, it was suggested that the different slopes in the OER voltage curve might be associated first with the oxidation of surface Li2O2 and subsequently with bulk $\mathrm{Li}_{2} \mathrm{O}_{2}$. Using operando X-ray diffraction, Ganapathy et al. found that ORR forms both crystalline and amorphous $\mathrm{Li}_{2} \mathrm{O} 2$ products. ${ }^{102}$ They proposed that initially the amorphous phase starts to oxidize at low overpotentials, while the toroidal Li2O2 crystalline aggregates, depending on their size, begin to decompose at much higher overpotentials. The enhanced charge transport of the amorphous phase was later confirmed by charging very pure chemically synthesized amorphous $\mathrm{Li}_{2} \mathrm{O}_{2.103}$ It was suggested that the higher mobility of $\mathrm{Li}$ ions, and increased superoxide concentration within the amorphous $\mathrm{Li}_{2} \mathrm{O}_{2}$, lead to relatively lower overpotentials. Enhancement in the local Li ion mobility was also observed in mechanically induced defects of nano-crystalline $\mathrm{Li}_{2} \mathrm{O}_{2.104}$ In practice, the OER overpotential required for complete removal of the $\mathrm{Li2O}_{2}$ layer is more than $1 \mathrm{~V}$. During investigation of OER mechanisms, it became clear that during oxidation of $\mathrm{Li}_{2} \mathrm{O}_{2}$, different parasitic reactions take place with the electrolyte and carbon to form organic decomposition products and $\mathrm{Li}_{2} \mathrm{CO}_{3}$. Potentials greater than $4 \mathrm{~V}$ vs $\mathrm{Li}_{2} / \mathrm{Li}^{+}$are needed to remove those species. ${ }^{105}$ Online electrochemical mass spectroscopy (OEMS) studies showed that the oxidation reaction required more than $2 \mathrm{e}^{-}$per $\mathrm{O}_{2}$, which implies that some ROS react with cell components in an irreversible manner. A very important recent result from several groups is the recognition that the instability of the electrolyte and carbon is associated with the formation of singlet oxygen $\left({ }^{1} \mathrm{O}_{2}\right)$ during the OER. ${ }^{106-109} \mathrm{By}$ operando electron paramagnetic resonance (EPR) spectroscopy, Wandt et al. suggested that at potentials of around $3.5 \mathrm{~V}$, approximately $0.5 \%$ of highly reactive ${ }^{1} \mathrm{O}_{2}$ is evolved. ${ }^{107}$ Subsequently, ${ }^{1} \mathrm{O}_{2}$ has also been shown to evolve both on discharge and from the onset of charge. ${ }^{108}$ Its generation is intimately tied to the ORR and OER through 
superoxide disproportionation steps which generates ${ }^{1} \mathrm{O}_{2} \cdot{ }^{109}{ }^{1} \mathrm{O}_{2}$ is

the key to the degradation mechanism of $\mathrm{Li}-\mathrm{O}_{2}$ batteries, and thus it is discussed in detail in the following section.

Recent studies visualized the decomposition of $\mathrm{Li2}_{22}$ deposits by in situ atomic force microscopy (AFM) and vibrational spectroscopy of sum frequency generation (SFG) measurement during the OER. ${ }^{110-112}$ They concluded that at relatively low potentials $(<3.7 \mathrm{~V})$, a thin film of $\mathrm{Li}_{2} \mathrm{O} 2$ which is in direct contact with the cathode surface is oxidized to produce superoxide radicals. As the surface layer oxidizes, the upper $\mathrm{Li}_{2} \mathrm{O} 2$ layer is detached from the cathode surface. ${ }^{12}$ This disconnected product layer was found to be oxidized only at potentials above $4.5 \mathrm{~V}$, which is above the oxidation potentials of most aprotic solvents, thus leading to instability. In general, the mechanisms described above clearly implies that properties such as size, morphology, and crystallinity of the $\mathrm{Li}_{2} \mathrm{O} 2$ deposited during the ORR should govern the efficiency of the OER and are controlled by the choice of electrolyte solutions.

Recently, a comprehensive unified model for $\mathrm{Li}_{2} \mathrm{O} 2$ oxidation was introduced by Lu et al. that shows, analogously to discharge, the solvent $\mathrm{DN}$ to govern the oxidation mechanism (Figure 8). ${ }^{113}$

They used a thin film rotating ring-disc electrode (RRDE) to show that in high DN solvents the superoxide intermediate forms

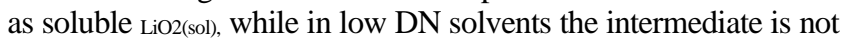
soluble, Figure 8B. Using X-ray absorption near edge spectroscopy (XANES), they showed surface $\mathrm{LiO}_{2}$ formation upon charging in high DN solvents but its absence in low DN solvents. As for charge, the solvent influences the $\mathrm{Li}_{2} \mathrm{O} 2$ decomposition pathway, via either soluble superoxide species or $\mathrm{Li}$-deficient $\mathrm{Li}_{2} \mathrm{O}_{2}$. ${ }^{90,114,115}$ The unified reaction mechanism is illustrated in Figure $8 \mathrm{C}$ and commences with delithiation:

$$
\mathrm{Li}_{2} \mathrm{O}_{2} \square \mathrm{Li}_{2}{ }_{x} \mathrm{O}_{2}+\mathrm{x} \mathrm{Li}+\mathrm{xe}
$$

$$
+
$$

The $\mathrm{Li}_{2}-\mathrm{xO2}$ formed in low $\mathrm{DN}^{+}$solvents was suggested to undergo a second oxidation:

$$
\mathrm{Li} 2 \mathrm{xO}_{2} \square \mathrm{O}_{2}+(2 \quad \mathrm{x}) \mathrm{Li}+(2 \quad \mathrm{x}) \mathrm{e}
$$

At the same time, disproportionation of these solid superoxide intermediates cannot be strictly excluded however, a plausible mechanism for such a solid-state reaction is hard to suggest 1 io ln mechanism for such a solid-state reaction is hard to suggest. releases then $\mathrm{O}_{2}$ by disproportionation:

$$
2 \mathrm{LiO}_{2} \text { (sol) } \square \mathrm{Li}_{2} \mathrm{O}_{2}+\mathrm{O}_{2}
$$

$\mathrm{Lu}$ et al. used SEM imaging to elegantly prove that disproportionation of soluble $\mathrm{LiO}_{\text {(sol) }}$ does happen in high DN solvents because upon partial charge, large particles of chemically synthesized $\mathrm{Li}_{2} \mathrm{O} 2$ recrystallized to layered structures as typically observed on discharge in high DN such as DMSO and methyl-imidazole (Me-Im) (Figure 8A). Because superoxide disproportionation is now recognized as the principal route to ${ }^{1} \mathrm{O}_{2}$, its prevalence as the $\mathrm{O}_{2}$ releasing step has a major impact on parasitic chemistry as further discussed in the following section.

\subsection{Parasitic Chemistry}

Parasitic chemistry at the cathode is the prime obstacle for reversible operation of $\mathrm{Li}-\mathrm{O}_{2}$ cells, and hence understanding the mechanisms underpinning parasitic reactions is the most pressing research need in the field. Current understanding has resulted in a unified mechanism of parasitic chemistry across the alkali metal $-\mathrm{O}_{2}$ cells $(\mathrm{M}=\mathrm{Li}, \mathrm{Na}, \mathrm{K})$ and will hence be treated together. ${ }^{109}$ Metal $-\mathrm{O}_{2}$ chemistries typically consume close to 
the ideal number of electrons per $\mathrm{O}_{2}$ upon discharge according to

$\mathrm{O}_{2}+\mathrm{xe}+\mathrm{xM}^{+} \square \mathrm{M}_{\mathrm{x}} \mathrm{O}_{2}$

The products that typically form are $\mathrm{Li}_{2} \mathrm{O}_{2}, \mathrm{Na}_{2} \mathrm{O}_{2}, \mathrm{NaO}_{2}$, or $\mathrm{KO} 2.37,117-120$ However, for $\mathrm{Li}-\mathrm{O}_{2}$ cells, significant amounts of side products such as $\mathrm{Li}_{2} \mathrm{CO}_{3}, \mathrm{Li}$ formate, and $\mathrm{Li}$ acetate were found, and the $\mathrm{Li}_{2 \mathrm{O} 2}$ yield was significantly lower than expected from the charge passed. ${ }^{84,121-123}$ Similarly, on charge, the amount of $\mathrm{O}_{2}$ evolved falls below the expected amount and more side products form. $\mathrm{Na}-\mathrm{O}_{2}$ cells have been recognized to be more reversible if superoxide $\left(\mathrm{NaO}_{2}\right)$ is the product, but things are much worse with $\mathrm{Na}_{2} \mathrm{O} 2$ as the product. ${ }^{124} \mathrm{~K}-\mathrm{O}_{2}$ cells perform best in all cases. ${ }^{120}(\mathrm{Su})$ peroxide yields on discharge and $\mathrm{O}_{2}$ yields on recharge (based on charge passed) from a wide range of studies that give quantitative values are summarized in Table 1 . The general trend is that irreversibility becomes worse when moving from $\mathrm{K}$ to $\mathrm{Na}$ and $\mathrm{Li}$, which goes along with the peroxide rather than the superoxide being the product.

Table 1. Typical MxO2 Yields on Discharge and $\mathrm{O}_{2}$ Yields on Recharge of $\mathrm{M}-\mathrm{O}_{2}$ Cells $(\mathrm{M}=\mathrm{Li}, \mathrm{Na}, \mathrm{K})^{\mathrm{a}}$

$\begin{array}{lccl}\text { product } & \mathrm{Li}-\mathrm{O}_{2}(\%) & \mathrm{Na}^{-} \mathrm{O}_{2}(\%) & \mathrm{K}-\mathrm{O}_{2}(\%) \\ \begin{array}{l}\text { superoxide } \\ \text { peroxide }\end{array} & 50-93 & 90-95 & 99-100 \\ & 50-50 & \end{array}$

aData are compiled from refs 96,109,118,120,123,125-133. Defi-nitions of reversibility and means to quantify them have been summarized in detail in refs 134,135 .

The parasitic reactions have traditionally been ascribed to the direct reactivity of electrolyte or carbon with superoxides and peroxides.37,118,123,127,128,130,132,133

However, the extent of side reactions would suggest the reactivity to seemingly severely grow in the order $\mathrm{KO}_{2}<\mathrm{NaO}_{2}<\mathrm{LiO}_{2}$ and peroxides to be much more reactive than superoxide. In the following section, we summarize the current knowledge about these reactivities and the recognition that the highly reactive singlet oxygen $\left({ }^{1} \mathrm{O}_{2}\right)$ forms in metal- $\mathrm{O}_{2}$ cells, which conclusively explains the pattern of irreversibility and guides pathways to counteract the problem.

3.3.1. Reactivity of Reduced $\mathrm{O}_{2}$ Species and $\mathrm{O}_{2}$. Reduced reactive oxygen species (RROS) have for long been known for their reactivity with many organic substrates owing to their nucleophilicity, basicity, and radical nature and are recognized as a reactant or source of parasitic chemis-tries. ${ }^{37,136,137}$ The primary species are $\mathrm{O}_{2}{ }^{-}, \mathrm{O}_{2}{ }^{2-}, \mathrm{HOO}^{\circ}, \mathrm{HOO}^{-}$, and $\mathrm{HO}^{-}$that may react via nucleophilic substitutions, $\mathrm{H}+$ and $\mathrm{H}$ atom abstraction. Superoxide is furthermore an electron transfer agent and molecular oxygen may equally react via $\mathrm{H}$ atom abstraction in autoreactions.

Salt solubility in nonaqueous media for use as electrolyte is introduced via polarity by means of heteroatoms, which however makes the solvents susceptible to the mentioned reactions, particularly at $\mathrm{C}$ and $\mathrm{H}$ atoms adjacent to the heteroatom. Along this line, nucleophilic attack has for long been considered the primary source of side reactions in metal- $\mathrm{O}_{2}$ cells, which is certainly true for carbonates. ${ }^{84,137,138}$ Since also all so far investigated classes of organic solvents have shown a certain degree of decomposition, superoxide's reactivity has equally been made responsible for the reactions. Bryantsev et al.138-142 pioneered density functional theory (DFT) calculations to understand the reactivity of electrolyte solvents with reduced $\mathrm{O}_{2}$ species and $\mathrm{O}_{2}$ with the aim to possibly predict more stable ones. 
Table 2. Reactions of Organic Electrolytes with Reduced Oxygen Species and Molecular Oxygen and Their Calculated Activation Energy Barriers ${ }^{\mathbf{a}}$

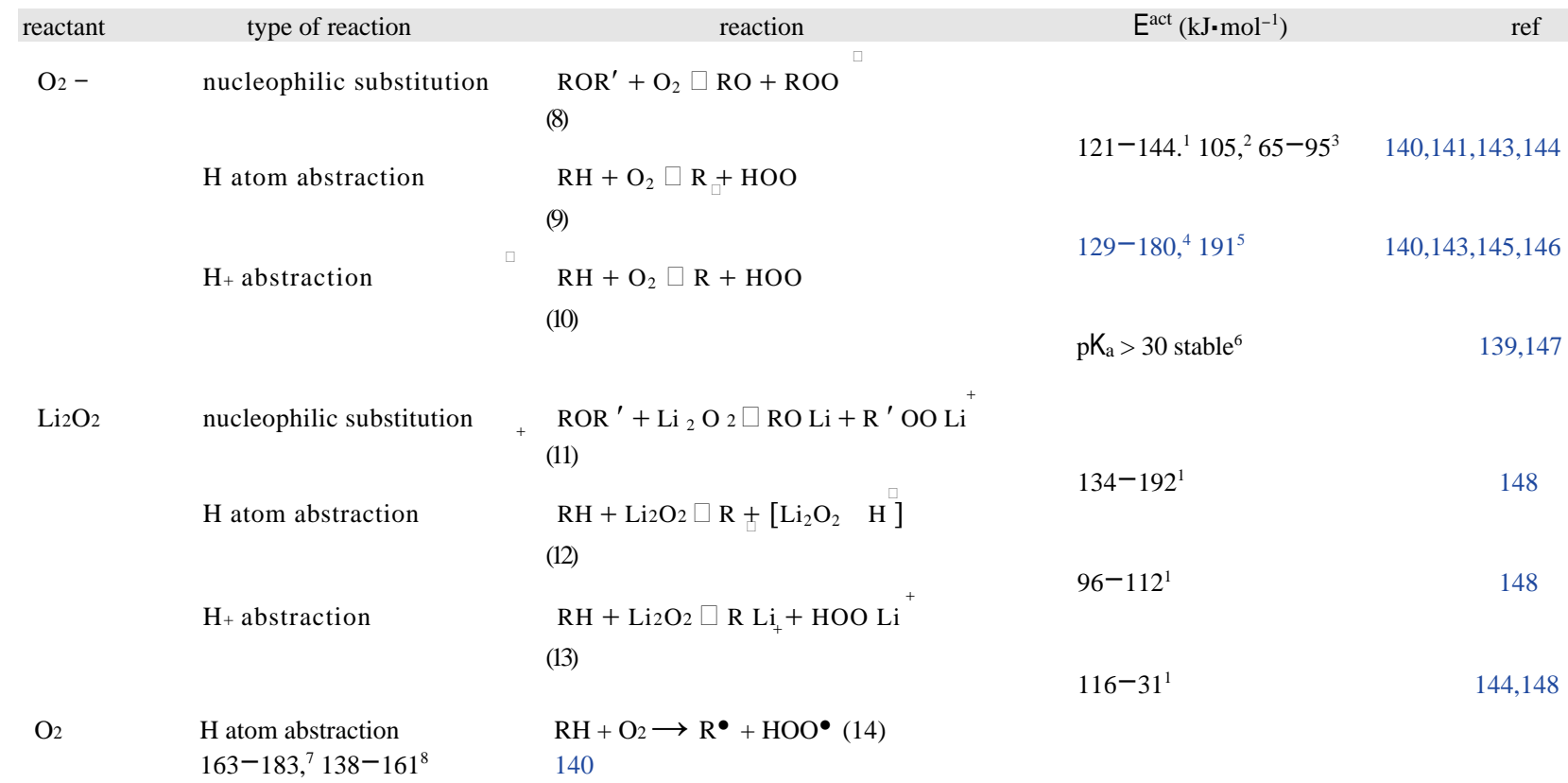

${ }^{a} \mathrm{ROR}^{\prime}$ is generically used for organic moieties with polarizing heteroatoms and reactions may accordingly be translated to, e.g., $\mathrm{N}$ or $\mathrm{S}$ containing solvents. Adapted with permission from ref 135. Copyright 2016 The Royal Society of Chemistry.

Table 2 summarizes their data and those of several other groups for activation energies for reactions of superoxide, peroxide, and molecular oxygen with various classes of organic solvents via nucleophilic substitution, $\mathrm{H}$ atom, and $\mathrm{H}^{+}$abstraction.

A striking feature is that for all considered reactions the activation energies are too high to explain major reactivity. Solvent stability screening experiments with $\mathrm{KO}_{2}$ as the superoxide source have shown that reactions with activation energies $>100 \mathrm{~kJ} \cdot \mathrm{mol}^{-1}$ can be considered not to contribute noticeably. ${ }^{141}$ All pathways with ethers, for example, require high activation energy and are strongly endothermic. Only one study found $\mathrm{H}$-abstraction by $\mathrm{Li}_{2} \mathrm{O} 2$ clusters to be slightly exothermic with $E^{\text {act }}<100 \mathrm{~kJ} \cdot \mathrm{mol}^{-1} \cdot{ }^{148}$ Generally, $\mathrm{Li}^{+}$ coordinated solvents were reported to be more stable against $\mathrm{H}$ abstraction by $\mathrm{O}_{2}-$ and $\mathrm{O}_{2}$ than the free molecules.140,146

As reviewed in section 3.2, protic additives have recently been proposed to have a certain positive effect on discharge capacity despite reports of increased parasitic chemistry. ${ }^{94,96}$ However, in the presence of proton sources, $\mathrm{HOO}^{\circ}, \mathrm{HOO}^{-}$, and $\mathrm{HO}^{\circ}$ may form, which are potentially more reactive than the nonprotonated species. ${ }^{139}$ The $\mathrm{HOO}^{-}$species may more easily abstract $\mathrm{H}^{+}$, as it is a stronger base than superoxide. $\mathrm{HO}^{-}$readily abstracts $\mathrm{H}$ atoms and forms $\mathrm{C}$-centered radicals, which initiate favorable chain reactions in the presence of $\mathrm{O}_{2}$ akin to combustion reactions. ${ }^{84,140}$ Nevertheless, the described reactivity of reduced reactive oxygen species including the protonated species cannot consistently explain the observed pattern of parasitic chemistry shown in Table 2. For example, much stronger side reactions on charge compared to discharge directly oppose superoxide's reactivity as an explanation. Very reversible cyclability of $\mathrm{KO}_{2}$ in DMSO for thousands of cycles further forcefully demonstrates that the direct reactivity of reduced $\mathrm{O}_{2}$ species with cell components is not the prime source of side reactions. ${ }^{120}$

3.3.2. Singlet Oxygen in Metal- $\mathbf{O}_{2}$ Cells. 3.3.2.1. Evidence for Singlet Oxygen As the Main Culprit for Parasitic
Chemistry. Chemical oxidation of peroxides is recognized as a source of the highly reactive singlet oxygen $\left({ }^{1} \mathrm{O}_{2}\right) .{ }^{149}$ Similarly, electrochemical oxidation of $\mathrm{Li}_{2} \mathrm{O} 2$ was hypothesized in 2011 to possibly evolve singlet oxygen in $\mathrm{Li}-\mathrm{O}_{2}$ cells. ${ }^{150}$ Singlet oxygen is the first excited state of ground-state triplet oxygen and has an energy difference of $-1 \mathrm{eV}$. Considering energy, charging of $\mathrm{Li}_{2} \mathrm{O}_{2}$ beyond $3.5-3.9 \mathrm{~V}$ vs $\mathrm{Li} / \mathrm{Li}^{+}$was hypothesized to potentially form ${ }^{102.106,131,150}$ Furthermore, disproportionation of $\mathrm{HOO}^{*}$ has been considered as a source of ${ }^{1} \mathrm{O}_{2}$ although it is now recognized to negligibly form it.109,151-153 Because ${ }^{1} \mathrm{O}_{2}$ is difficult to detect, this idea was only discussed in a few reports but not proven except for a seminal study by Wandt et al., ${ }^{106}$ who used operando EPR to prove a small degree of ${ }^{1} \mathrm{O}_{2}$ evolution upon charging between 3.55 and $3.75 \mathrm{~V}$. The process was explained via direct $2 \mathrm{e}^{-}$oxidation according to $\mathrm{Li}_{2} \mathrm{O}_{2} \rightarrow$ $\mathrm{O}_{2}+2 \mathrm{Li}^{+}+{ }^{2 \mathrm{e}-92,106,153}$ However, measurements during discharge and higher charge voltages were not possible with the used spin trap. ${ }^{1} \mathrm{O}_{2}$ forming above $-3.5 \mathrm{~V}$ helped explain parasitic chemistry at high charge potentials. However, it left parasitic chemistry on discharge unexplained and particularly also why significant amounts of side products form at the onset of charge, where always less than $1 \mathrm{~mol}$ $\mathrm{O}_{2}$ evolved per $1 \mathrm{~mol}$ of $\mathrm{Li}_{2} \mathrm{O}_{2}$

oxidized.105,123,154

To investigate involvement of ${ }^{1} \mathrm{O}_{2}$ more comprehensively, Freunberger et al. developed a set of methods to sensitively and quantitatively detect ${ }^{1} \mathrm{O}_{2}$ over the entire relevant voltage range during discharge and charge of metal $-\mathrm{O}_{2}$ cells. ${ }^{108}$ As direct unambiguous proof they detected the characteristic $1270 \mathrm{~nm}$ emission when ${ }^{1} \mathrm{O}_{2}$ transits from the singlet to the triplet state. The process has a low quantum yield because this phosphorescent radiative decay is forbidden and is strongly influenced by the environment and is hence insensitive. Nevertheless, in situ measurements have shown unequivocal proof for ${ }^{1} \mathrm{O}_{2}$ from the onset of charge, Figure 9A. ${ }^{108}$ As a more sensitive and quantifiable method, 9,10-dimethylanthracene (DMA) was identified as a suitable ${ }^{1} \mathrm{O}_{2}$ trap, which fulfils all requirements 

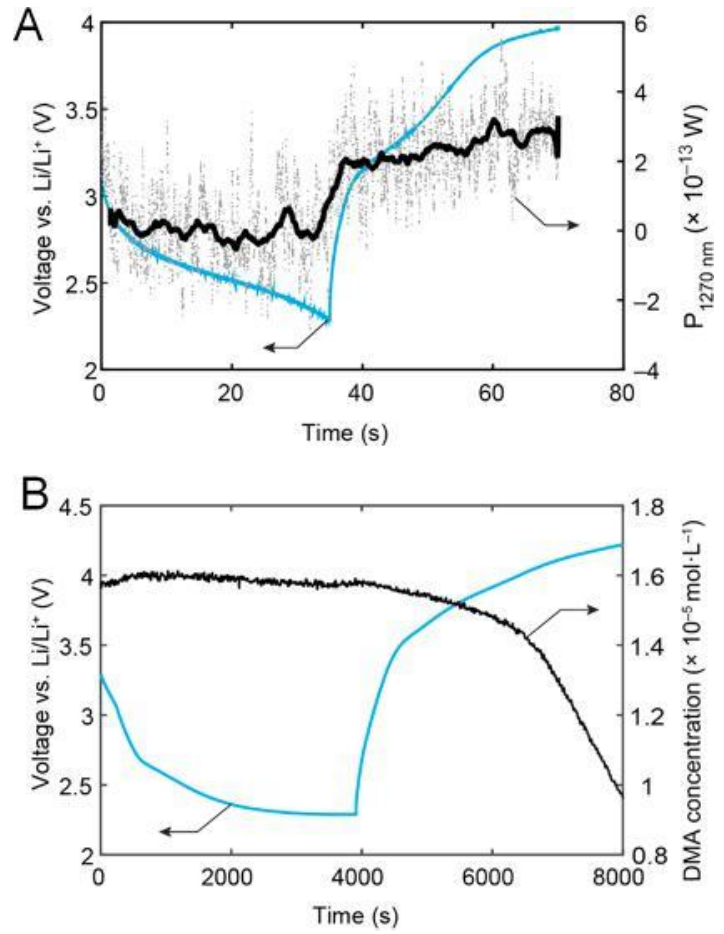

Figure 9. Singlet oxygen formation in $\mathrm{Li}-\mathrm{O}_{2}$ cells. (A) Operando detection of ${ }^{1} \mathrm{O}_{2}$ by detecting the near-infrared (NIR) emission at $1270 \mathrm{~nm}$ during galvanostatic cycling of an $\mathrm{Au}$ grid electrode in $\mathrm{O}_{2}$ saturated deuterated acetonitrile containing $0.1 \mathrm{M} \mathrm{LiClO}_{4}$ and $1000 \mathrm{ppm} \mathrm{D}_{2} \mathrm{O}$. The black trace is the moving average of the raw data in gray. (B) Voltage profile and DMA concentration during galvanostatic cycling of a carbon black electrode at $25 \mu \mathrm{A} \cdot \mathrm{cm}^{-2}$ in $\mathrm{O}_{2}$ saturated tetraethylene glycol dimethyl ether (TEGDME) containing $0.1 \mathrm{M} \mathrm{LiClO}_{4}$ and $1000 \mathrm{ppm}$ water. DMA consumption indicates ${ }^{1} \mathrm{O}_{2}$ formation. Adapted with permission from ref 108. Copyright 2017 Springer Nature.

for the cell environment. DMA forms seleetively and rapidly its endoperoxide form $\left(D M A-\mathrm{O}_{2}\right)$ in the presence of ${ }^{1} \mathrm{O}_{2}$; both DMA and DMA- $\mathrm{O}_{2}$ are electrochemically stable in the relevant voltage range between 2 and $-4 \mathrm{~V}$ vs $\mathrm{Li} / \mathrm{Li}^{+}$, and importantly, DMA does not form DMA-O $\mathrm{O}_{2}$ in contact with superoxide and peroxide alone, which otherwise could falsely indicate ${ }^{1} \mathrm{O}_{2}$ formation. Further, DMA- $\mathrm{O}_{2}$ forms only with ${ }^{1} \mathrm{O}_{2}$ but not with other possibly reactive $\mathrm{O}$-containing species like $\mathrm{Li}_{2} \mathrm{CO}_{3}, \mathrm{O}_{2}$, or $\mathrm{CO}_{2}$. DMA-to-DMA- $\mathrm{O}_{2}$ can be probed in various ways such as ex-situ HPLC of electrolyte extracted from cells or in situ fluorescence of DMA (Figure 9B).

These studies proved that ${ }^{1} \mathrm{O}_{2}$ forms both during discharge and from the onset of charge and with growing rate as the charge voltage rises, Figure 9B. The rates of ${ }^{1} \mathrm{O}_{2}$ formation resemble the rates at which parasitic reactions occur in $\mathrm{Li}-\mathrm{O}_{2}$ cells. ${ }^{155}$ Further, it was proven that ${ }^{1} \mathrm{O}_{2}$ accounts for the majority of parasitic reaction products on discharge and charge. Thus, ${ }^{1} \mathrm{O}_{2}$ arises as the biggest obstacle for cycling of the $\mathrm{Li}-\mathrm{O}_{2}$ cell by reversible formation/decomposition of $\mathrm{Li}_{2} \mathrm{O}_{2}$. The first report suggested up two possible means to counter ${ }^{1} \mathrm{O}_{2}$-related side reactions. First, the ${ }^{1} \mathrm{O}_{2}$ probe DMA, which acts by trapping ${ }^{1} \mathrm{O}_{2}$, was shown to reduce parasitic products during both discharge and charge if large concentrations were used. However, at the rate of ${ }^{1} \mathrm{O}_{2}$ formation, DMA is consumed within a few cycles. Second, they introduced the ${ }^{1} \mathrm{O}_{2}$ quencher 1,4-diazabicyclo[2.2.2] octane (DABCO) into $\mathrm{Li}-\mathrm{O}_{2}$ cells and have shown that it even more strongly reduced parasitic chemistry by physically deactivating ${ }^{1} \mathrm{O}_{2}$ to ${ }^{3} \mathrm{O}_{2}$ without consumption of the quencher itself. DABCO is, however, not electrochemically stable above $3.6 \mathrm{~V}$ and hence does not allow for full recharge, which requires more oxidation-stable quenchers as described below. Singlet oxygen was also shown to form on discharge and charge in $\mathrm{Na}-\mathrm{O}_{2}$ cells, where $\mathrm{NaO}_{2}$ forms as the discharge product. ${ }^{107}$

${ }^{1} \mathrm{O}_{2}$ is not only responsible for electrolyte and carbon decomposition but has also been shown to be the prime source of redox mediator decomposition (see section 3.5 for a further discussion on the use of redox mediators). Kwak et al. studied the deactivation of two representative redox mediators by $\mathrm{O}_{2}$, superoxide, peroxide, and ${ }^{1} \mathrm{O}_{2}$ and found ${ }^{1} \mathrm{O}_{2}$ to dominate decomposition by far. ${ }^{156}$ Its reactivity could conclusively be explained by electrophilic addition of ${ }^{1} \mathrm{O}_{2}$ to electron-rich moieties. In turn, DABCO, as mentioned above, has shown to preserve the mediator. ${ }^{157}$

3.3.2.2. Pathways toward Singlet Oxygen. A direct twoelectron oxidation step along $\mathrm{Li}_{2} \mathrm{O}_{2} \rightarrow \mathrm{O}_{2}+2 \mathrm{Li}^{+}+2 \mathrm{e}^{-}$was initially suggested by Hassoun et al. ${ }^{150}$ and Wandt et al. ${ }^{106}$ to possibly form ${ }^{1} \mathrm{O}_{2}$ above $3.9 \mathrm{~V}$ or $-3.55 \mathrm{~V}$. However, more recent insights into the $\mathrm{Li}_{2} \mathrm{O} 2$ oxidation mechanism suggest no direct twoelectron process to exist as discussed above in Figure 8. Instead, superoxide disproportionation is now accepted to be involved on discharge and charge of the perox-ides. ${ }^{37,90,102,113,114,116,117,158-160} \mathrm{On}$ the basis of this recognition, recently, a unified mechanism for ${ }^{1} \mathrm{O}_{2}$ generation in metal- $\mathrm{O}_{2}$ cells was established, ${ }^{109}$ which links the Lewis acidity of cations in the electrolyte with the production of ${ }^{1} \mathrm{O}_{2}$. Whether the initial one-electron reduction product superoxide reacts further to peroxide is governed by the relative thermodynamic stability of peroxide and superoxide with the respective cation as illustrated in Figure 10A, which also gives rise to the favored products in Table 1. Strong Lewis acids such as $\mathrm{Li}^{+}$ or $\mathrm{Na}^{+}$favor the peroxide, albeit only slightly for sodium.119,124,128,160-162 $\mathrm{K}^{+}$and even weaker Lewis acids (e.g., quaternary amines like tetrabutylammonium $\left(\mathrm{TBA}^{+}\right)$and imidazolium) favor the superoxide. ${ }^{125,159,163,164}$ The latter constitute often-used ionic liquid electrolytes.

$\underbrace{}_{2} \Theta_{2}$ erallø the dispreportionation

$$
2+3
$$

$$
2+
$$$$
2
$$

in the presence of the alkali metal cations, $\mathrm{H}^{+}$, or weakly Lewis acidic cations was found to cause varying fractions of ${ }^{1} \mathrm{O}_{2}$ as shown in Figure 10B. According to Figure 10A, the overall reaction is driven by the stability of peroxide and thus favored by stronger Lewis acidic cations $\mathrm{H}^{+}, \mathrm{Li}^{+}$, and $\mathrm{Na}^{+}$. However, the ${ }^{1} \mathrm{O}_{2}$ fraction grows with decreasing Lewis acidity of the cation, giving rise to insignificant ${ }^{1} \mathrm{O}_{2}$ with $\mathrm{H}^{+}$and strongly growing ${ }^{1} \mathrm{O}_{2}$ fractions with $\mathrm{Li}^{+}$and $\mathrm{Na}^{+}$. Importantly and surprisingly, weakly Lewis acidic cations such as $\mathrm{TBA}^{+}$alone do not drive disproportionation but, when combined with strong Lewis acids, cause substantially larger fractions of ${ }^{1} \mathrm{O}_{2}$. This is generally true for prototypical motifs of cations used in ionic liquid electrolytes such as quaternary ammonium and imidazolium. How weak Lewis acids act to favor ${ }^{1} \mathrm{O}_{2}$ can be explained by DFT calculations as shown in Figure. 10C. ${ }^{1} \mathrm{O}_{2}$ release from $\mathrm{LiO}_{2}$ disproportionation faces a barrier of $-1 \mathrm{eV}$ (red path with dashed lines). However, when a weak Lewis acid is present next to $\mathrm{Li}^{+}$in the electrolyte, asymmetric pairs of $\mathrm{LiO}_{2}$ and, e.g., $\mathrm{TBAO}_{2}$ will disproportionate. $\mathrm{TBAO}_{2}$ may be seen as a free solvated $\mathrm{O}_{2}-$ anion. Triplet and singlet paths pass via $3 \mathrm{Li}\left(\mathrm{O}_{2}\right)_{2}-$ and $1 \mathrm{Li}\left(\mathrm{O}_{2}\right)_{2}-$ dimers that are stabilized versus $\mathrm{LiO}_{2}+\mathrm{O}_{2}-$ by $-0.5 \mathrm{eV}$. Ongoing pathways are much more facile than for 


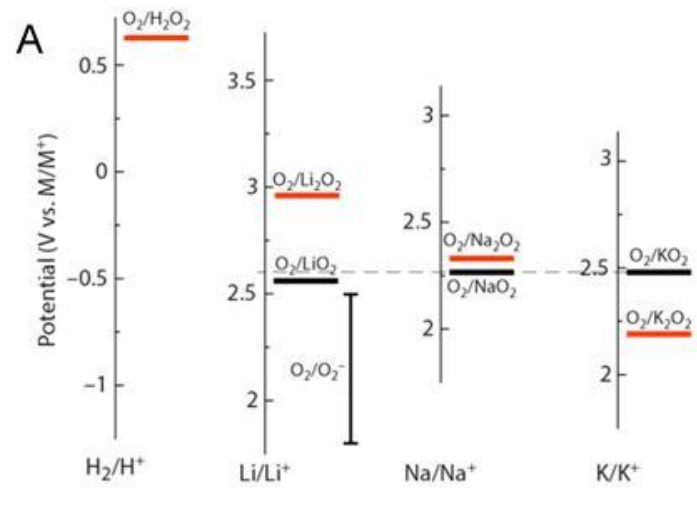

Increasing Lewis acidity of the cation
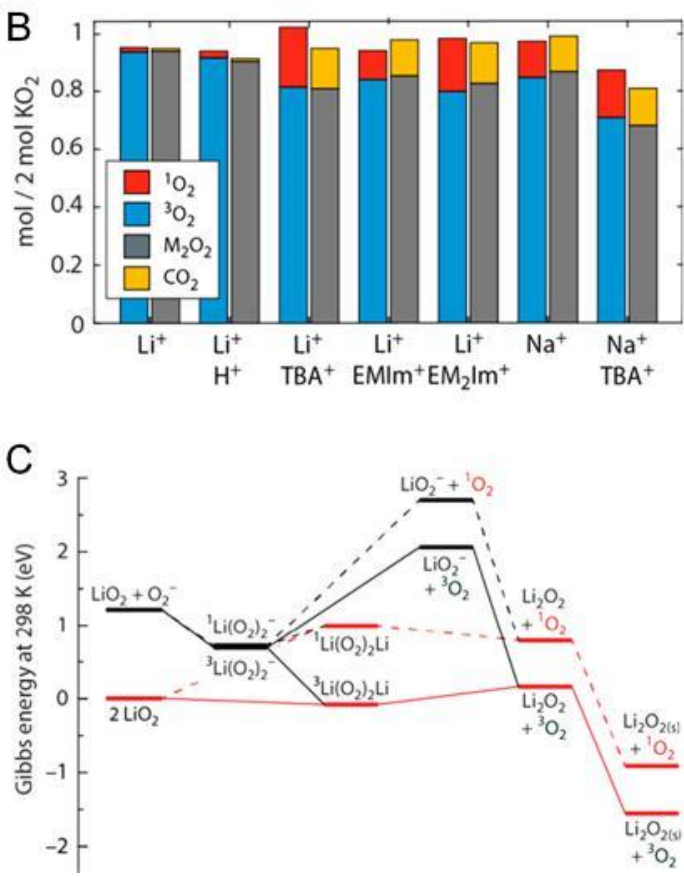

Figure 10. Singlet oxygen formation mechanism. (A) Thermodynamics of alkali peroxides and superoxides and the Lewis acidity of the involved cations. Standard potentials of the $\mathrm{O}_{2} / \mathrm{MO}_{2}$ and $\mathrm{O}_{2} / \mathrm{M}_{2} \mathrm{O} 2$ redox couples on the $\mathrm{M} / \mathrm{M}^{+}$scales with $\mathrm{M}=\mathrm{Li}, \mathrm{Na}, \mathrm{K}$ as well as for the $\mathrm{O}_{2} / \mathrm{H}_{2} \mathrm{O}_{2}$ couple. The scales are brought to a common scale based on their $\mathrm{M} / \mathrm{M}^{+}$standard potentials. The dashed horizontal line indicates the $\mathrm{O}_{2} / \mathrm{KO}_{2}$ couple. The $\mathrm{O}_{2} / \mathrm{LiO}_{2}$ potential is adopted from ref 165 but also values between 2.29 and $2.46 \mathrm{~V}$ vs $\mathrm{Li} / \mathrm{Li}^{+}$have been reported.114,128 $\mathrm{O}_{2} / \mathrm{O}_{2}-$ denotes the potential range reported for $\mathrm{O}_{2}$ reduction in $\mathrm{TBA}^{+}$ electrolytes. ${ }^{90,158,159,165,166}$ (B) ${ }^{1} \mathrm{O}_{2}$ from superoxide disproportiona-tion in the presence of various cations. Obtained $\mathrm{O}_{2},{ }^{1} \mathrm{O}_{2}$, and $\mathrm{Li}_{2} \mathrm{O} 2$ (or $\mathrm{Na}_{2} \mathrm{O}_{2}$ ) upon reacting $\mathrm{KO}_{2}$ in TEGDME that contained equimolar 18-crown-6, 30 mM DMA, 0.5 $\mathrm{M} \mathrm{Li}^{+}\left(\right.$or $\mathrm{Na}^{+}$), and either no additive, $0.1 \mathrm{M} \mathrm{TBA}^{+}$, $\mathrm{EMIm}^{+}$, or $\mathrm{EM}_{2} \mathrm{Im}^{+}$, or $\mathrm{F}_{3} \mathrm{CCOOH}$. Ideally $1 \mathrm{~mol} \mathrm{O}_{2}$ and $1 \mathrm{~mol}_{\mathrm{M} 202}$ would form according to $2 \mathrm{KO}_{2}+2 \mathrm{M}^{+} \rightarrow \mathrm{M}_{2} \mathrm{O}_{2}+\mathrm{O}_{2}+2 \mathrm{~K}^{+}$. (C) Reaction free energy profiles for $\mathrm{LiO}_{2}$ disproportionation with itself or $\mathrm{O}_{2}$ - to $\mathrm{Li}_{2} \mathrm{O} 2$ and molecular oxygen. Pathways to release ${ }^{3} \mathrm{O}_{2}$ and ${ }^{1} \mathrm{O}_{2}$ are indicated by full and dashed lines, respectively. Adapted with permission from ref 109. Copyright 2019 The Royal Society of Chemistry.

symmetric $\mathrm{LiO}_{2}$ pairs: the $\mathrm{Li}\left(\mathrm{O}_{2}\right) 2$ - dimers exchange $\mathrm{TBA}^{+}$for $\mathrm{Li}^{+}$and go on to the symmetric $\mathrm{Li}\left(\mathrm{O}_{2}\right) 2 \mathrm{Li}$ pathways. Crucially, the weak Lewis acid curbs the largest barrier toward ${ }^{1} \mathrm{O}_{2}$, the endergonicity to the ${ }^{1} \mathrm{Li}\left(\mathrm{O}_{2}\right)_{2} \mathrm{Li}$ dimer, from $\sim 1 \mathrm{eV}$ to only 0.27
eV. Overall, weak Lewis acids allow for pathways that bypass the most unfavorable reaction steps and hence strongly facilitate ${ }^{1} \mathrm{O}_{2}$ evolution. Moreover, $\mathrm{TBA}^{+}$arises as a probe for disproportionation steps. If the presence of $\mathrm{TBA}^{+}$increases the ${ }^{1} \mathrm{O}_{2}$ yield, then disproportionation must be involved.

This insight was used to probe ${ }^{1} \mathrm{O}_{2}$ formation during discharge and charge. Larger ${ }^{1} \mathrm{O}_{2}$ yields in mixed $\mathrm{Li}^{+} / \mathrm{TBA}^{+}$electrolytes as compared to pure $\mathrm{Li}^{+}$electrolytes verified that the described pathways are active both on discharge and charge. Strong sensitivity of the ${ }^{1} \mathrm{O}_{2}$ yield toward the presence of $\mathrm{TBA}^{+}$confirms discharge to significantly occur via disproportionation, although possible second one-electron reduction of the $\mathrm{LiO}_{2}$ intermediate is not ruled out. On charge, the initial charging step forms a $\mathrm{LiO}_{2}$ like surface species as discussed above113-115,167 and its disproportionation forms ${ }^{1} \mathrm{O}_{2}$ analogously. This pathway is active from the onset of charge. Another possible pathway is a second one-electron oxidation of the superoxide intermediate that could give ${ }^{1} \mathrm{O}_{2}$ above $\sim 3.5 \mathrm{~V}$.

Electrochemical oxidation of $\mathrm{Li}_{2} \mathrm{CO}_{3}$ has recently been revealed as another pathway toward ${ }^{1} \mathrm{O}_{2} . \mathrm{Li}_{2} \mathrm{CO}_{3}$ is a common side product on discharge and charge $\mathrm{e}^{105,154}$ and its formation known to contribute to the ever increasing voltage on charge because of its high oxidation potential. ${ }^{84,85,105,123,131,168,169}$ The burden of $\mathrm{Li}_{2} \mathrm{CO}_{3}$ formation was seemingly harnessed in in rechargeable metal $-\mathrm{O}_{2} / \mathrm{CO}_{2}$ batteries based on the observation that $\mathrm{Li}_{2} \mathrm{CO}_{3}$ can be electrochemically decomposed.84,166,170,171 For long, the fate of the third $\mathrm{O}$ atom in $\mathrm{CO}_{3}{ }^{2-}$ has led to various theories because no $\mathrm{O}_{2}$ evolves as expected from the formal oxidation reaction:84,171-173

$$
\begin{aligned}
& 2 \mathrm{Li} C \mathrm{O} 4 \mathrm{Li} 4 \text { e } 2 \mathrm{CO} \mathrm{O} \\
& \mathrm{E} 0=3.82 \mathrm{~V} \text { vs } \mathrm{Li} / \mathrm{Li}^{+}
\end{aligned}
$$

To explain the absence of $\mathrm{O}_{2}$, the formation of superoxide or "nascent oxygen" was proposed, which could react with cell components $^{173}$ (without, however, definite proof for these mechanisms). Mahne et al. provided evidence that the electrochemical oxidation of $\mathrm{Li}_{2} \mathrm{CO}_{3}$ forms ${ }^{1} \mathrm{O}_{2}$, which, through the parasitic reaction of ${ }^{1} \mathrm{O}_{2}$ with battery components, explains the absence of $\mathrm{O}_{2}$ evolution. ${ }^{174}$ Because $\mathrm{Li}_{2} \mathrm{CO}_{3}$ is also a common residual component on transition metal oxide (TMO) cathode materials, ${ }^{172}{ }^{1} \mathrm{O}_{2}$ from $\mathrm{Li}_{2} \mathrm{CO}_{3}$ oxidation has far-reaching implications for the surface reactivity of TMO cathodes that operate beyond $3.8 \mathrm{~V}$ and couples parasitic reactions upon recharging metal $-\mathrm{O}_{2}$ and metal $-\mathrm{O}_{2} / \mathrm{CO}_{2}$ batteries.

${ }^{1} \mathrm{O}_{2}$ generation upon oxidation of $\mathrm{Li}_{2} \mathrm{CO}_{3}$ was probed by charging cells with $\mathrm{Li}_{2} \mathrm{CO}_{3}$-packed working electrodes in the presence of DMA. High-performance liquid chromatography (HPLC) analysis of the extracted electrolyte (Figure 11A) shows that $\mathrm{DMA}-\mathrm{O}_{2}$ is formed from $3.8 \mathrm{~V}$ onward and hence from the onset of $\mathrm{Li}_{2} \mathrm{CO}_{3}$ oxidation. In quantitative terms, the amount of ${ }^{1} \mathrm{O}_{2}$ shows that the majority of the "missing $\mathrm{O}_{2}$ " from the electrochemical $\mathrm{Li}_{2} \mathrm{CO}_{3}$ oxidation forms ${ }^{1} \mathrm{O}_{2}$, explaining its absence in the gas phase. Absent $\mathrm{O}_{2}$ evolution implies that the formed ${ }^{1} \mathrm{O}_{2}$ reacts with cell components rather than being, even in part, deactivated to ${ }^{3} \mathrm{O}_{2}$. In presence of the ${ }^{1} \mathrm{O}_{2}$ quencher DABCO, $\mathrm{O}_{2}$ evolution started together with $\mathrm{CO}_{2}$ evolution at $\sim 3.8 \mathrm{~V}$ with a similarly growing rate as the voltage rose (Figure 11B). Hence, with a suitable quencher $\mathrm{Li}_{2} \mathrm{CO}_{3}$ could potentially be oxidized without the detrimental effects of ${ }^{1} \mathrm{O}_{2}$ formation. The ${ }^{1} \mathrm{O}_{2}$ formation mechanism was suggested to occur via a peroxodicarbonate intermediate that forms from two $\mathrm{Li}_{2} \mathrm{CO}_{3}$ moieties via two $\mathrm{LiO}_{2} \mathrm{CO}^{\circ}$ moieties, which combine to 
A

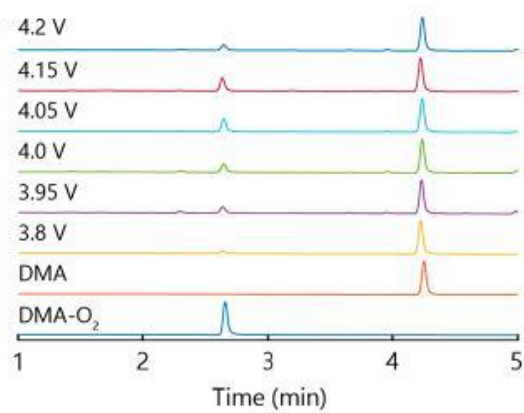

B

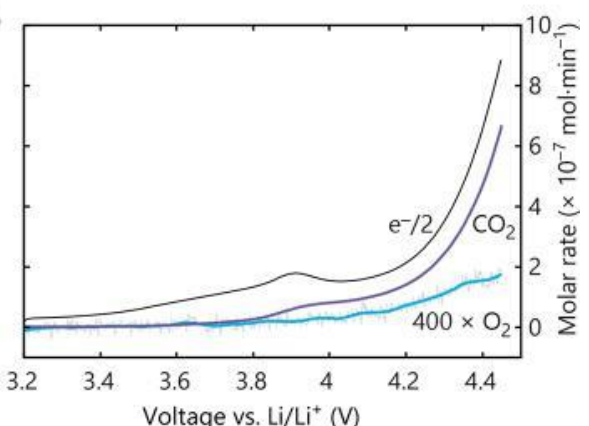

Figure 11. Singlet oxygen from $\mathrm{Li}_{2} \mathrm{CO}_{3}$ oxidation. (A) HPLC determination of DMA-O $\mathrm{O}_{2}$ upon polarizing $\mathrm{Li}_{2} \mathrm{CO}_{3}$-packed electrodes at different potentials in 1,2-dimethoxyethane (DME) containing $0.1 \mathrm{M}$ LiTFSI and $30 \mathrm{mM}$ DMA. (B) $\mathrm{CO}_{2}$ and $\mathrm{O}_{2}$ evolution during electrochemical oxidation of $\mathrm{Li}_{2} \mathrm{CO}_{3}$ in the presence of the quencher DABCO. Adapted with permission from ref 174. Copyright 2018 Wiley-VCH.

$\mathrm{LiO}_{2} \mathrm{COOCO}_{2} \mathrm{Li}$. Its further oxidation and decarboxylation to yield $\mathrm{LiCO}_{4}$ could in turn yield ${ }^{1} \mathrm{O}_{2}$.

3.3.2.3. Quenching Singlet Oxygen. While superoxide disproportionation is now known to be the source of ${ }^{1} \mathrm{O}_{2}$ via eq 16 , it is also known to readily deactivate it via quenching. ${ }^{175}$

$\mathrm{O}_{2} \mathrm{O}$

$$
\begin{array}{lll}
+1 & 2 \mathrm{O}^{3} & \mathrm{O} \\
& &
\end{array}
$$

The net formation of singlet oxygen will hence not simply scale with the superoxide concentration. It will rather depend on the relative kinetics of all superoxide sources and sinks with ${ }^{1} \mathrm{O}_{2}$ being involved in both. Many factors may influence the kinetics, which may be governed by electrolyte, electrodes, current, or potential, for example.

Because cell-inherent quenching by superoxide is too inefficient to deactivate ${ }^{1} \mathrm{O}_{2}$, quenchers may be added. Early work has shown that $\mathrm{DABCO}$ significantly reduces ${ }^{1} \mathrm{O}_{2}$-related side reactions on discharge and charge. However, its oxidation stability of $3.6 \mathrm{~V}$ is too low for recharge. ${ }^{108}$ Physical quenchers deactivate ${ }^{1} \mathrm{O}_{2}$ to ${ }^{3} \mathrm{O}_{2}$ without quencher consumption, and no new products accumulate. Radiationless physical quenching converts the excess energy of ${ }^{1} \mathrm{O}_{2}$ into heat via three mechanisms: ${ }^{175}$ electronic-tovibrational $\left(e^{-}-v\right)$ energy transfer $\left({ }^{1} \mathrm{O}_{2}\right.$ quenching by solvents, slow), charge transfer (CT) induced quenching $\left(-10^{7}\right.$ times faster than $\mathrm{e}^{-\mathrm{v}}$ ), and electronic energy transfer (faster yet unsuitable for electrochemical systems because of too low oxidation stability). Suitable quenchers for electrochemical systems use the CT mechanism which passes via a singlet encounter complex $1\left(\mathrm{Q}_{1} \Delta\right) \mathrm{EC}_{\mathrm{E}}$ and a singlet charge transfer complex $1\left(\mathrm{Q}_{1} \Delta\right)_{\mathrm{CT}}$, where electronic charge is partially transferred to the oxygen. Intersystem crossing (isc) to the triplet ground-state complex $3\left(\mathrm{Q}_{3} \Sigma\right)_{\mathrm{CT}}$ releases engrgy. The latter (issociates to $\left(2\right.$ ) ${ }^{3}{ }^{3} \mathrm{O}_{2}$

$$
\begin{aligned}
& 211 \Delta \\
& { }_{\Delta}^{11} \mathrm{CT} \text { isc }(\stackrel{3}{3})_{\Sigma} \mathrm{CT} \\
& \mathrm{Q}+{ }^{3} \mathrm{O}_{2}
\end{aligned}
$$

This mechanism was first suggested for DABCO and has generally been shown to be applicable for electron-rich quenchers such as amines. The partial charge transfer causes the quenching efficiency to correlate logarithmically with the ionization potential and hence oxidation potential. ${ }^{175} \mathrm{~A}$ suitable, sufficiently oxidation-stable quencher should therefore allow for high concentrations to balance for the inevitably lower molar activity.

Monoalkylating DABCO to form the DABCOnium salt has recently been shown to shift its oxidation stability to $-4.2 \mathrm{~V}$ vs $\mathrm{Li} / \mathrm{Li}^{+}$while still quenching effectively. ${ }^{176}$ Previously known quenchers are strongly Lewis basic amines with too low an oxidative stability. DABCOnium is a cation of a nonvolatile ionic liquid, highly soluble in electrolytes, stable against superoxide and peroxide, and compatible with lithium metal. The electrochemical stability covers the required range for metal- $\mathrm{O}_{2}$ batteries and greatly reduces ${ }^{1} \mathrm{O}_{2}$ related parasitic chemistry as demonstrated for the $\mathrm{Li}-\mathrm{O}_{2}$ cell. $\mathrm{DABCOnium}$ was shown to drastically reduce the amount of side products during discharge and charge. Its effect was especially clear during charge, where $\mathrm{O}_{2}$ evolved at the ideal rate of $2 \mathrm{e}^{-} / \mathrm{O}_{2}$ up to the oxidative stability limit of $-4.2 \mathrm{~V}$, which proves that all electrons are extracted from $\mathrm{Li}_{22}$ rather than partly from side products.

Given the stellar importance of ${ }^{1} \mathrm{O}_{2}$ for the reversibility of metal $-\mathrm{O}_{2}$ cells, further research into ways to prevent its formation appear highly appropriate. Recognizing that ${ }^{1} \mathrm{O}_{2}$ formation is deeply rooted in the way current metal- $\mathrm{O}_{2}$ cells operate has serious consequences for aspects to avoid and on directions that should be taken. First, caution must be exercised with weak Lewis acids as electrolytes or additives. Given that ionic liquid cations suitable for electrolytes are most typically weak Lewis acids, the effect can likely be generalized. Favored ${ }^{1} \mathrm{O}_{2}$ formation explains why quantitative studies of metal $-\mathrm{O}_{2}$ chemistry with a broad variety of ionic liquids have shown worse parasitic chemistry on discharge and charge than molecular electrolytes. ${ }^{131,177,178}$ Second, protic additives drive ${ }^{1} \mathrm{O}_{2}$ formation insignificantly but may drive parasitic chemistry in other ways. Third, reversible chemistry based on alkali metal carbonate formation/decomposition (metal- $\mathrm{O}_{2} / \mathrm{CO}_{2}$ cells) is questionable based on the involvement of ${ }^{1} \mathrm{O}_{2}$ and other reactive species. ${ }^{174-176,179}$ The most prominent consequence is that reactions involving superoxide disproportionation must be avoided. Cells based on metastable $\mathrm{LiO}_{2}$ or $\mathrm{NaO}_{2}$ as target products lack the practically required tolerance to slow discharge and rest periods as the superoxides gradually convert to peroxide and side products. ${ }^{107,116,118,132,161,162,180}$ Peroxide products are preferred as they are much higher in energy density and are the thermodynamically stable products. ${ }^{124,128,181}$ Cycling them highly reversibly requires finding routes to form and decompose them without superoxide disproportionation steps. It is not yet clear whether ${ }^{1} \mathrm{O}_{2}$-related parasitic chemistry can be completely avoided, but practical realization of aprotic $\mathrm{Li}-\mathrm{O}_{2}$ and $\mathrm{Na}-\mathrm{O}_{2}$ batteries will, in our opinion, stand or fall with mastering ${ }^{1} \mathrm{O}_{2}$ formation. 


\subsection{Cell Components}

3.4.1. Electrolytes. In this section, we will divide our discussion into two categories: (1) aprotic solvents and (2) Li-salts. As an initial note, it must be stated that the vast majority of work described in this section was published before recognizing the importance of ${ }^{1} \mathrm{O}_{2}$ in parasitic chemistry (see the previous section). Therefore, proposed side reactions and mitigation strategies were based on the assumption that the nucleophilicity, basicity, or radical nature of reduced $\mathrm{O}_{2}$ species governed reactivity.

3.4.1.1. Aprotic Solvents. As noted previously, early research on $\mathrm{Li}-\mathrm{O}_{2}$ batteries utilized organic carbonates as the solvents, following their dominance in Li-ion batteries. ${ }^{81}$ In 2006, Ogasawara et al. ${ }^{83}$ demonstrated a rechargeable $\mathrm{Li}-\mathrm{O}_{2}$ battery with -50 cycles using alkyl carbonates. Importantly, they also demonstrated for the first time that $\mathrm{Li}_{2} \mathrm{O} 2$ can be electrochemically oxidized to $\mathrm{O}_{2}$. A few years later, Mizuno et al. ${ }^{182}$ demonstrated a $\mathrm{Li}-\mathrm{O}_{2}$ battery that was discharged and recharged for 100 cycles, with almost $60 \%$ capacity retention. To explain the large voltage hysteresis of over $1.4 \mathrm{~V}$, they suggested the formation of significant quantities of $\mathrm{Li}_{2} \mathrm{CO}_{3}$, as well as $\mathrm{Li}_{2} \mathrm{O}_{2}$, as the discharge products, the former originating from the decomposition of carbonates. ${ }^{182}$ Later, Freunberger et al. illustrated the cathodic decomposition pathways of carbonates in an oxygen environment, specifically in the presence of the superoxide radical. ${ }^{84}$ Proposing the degradation mechanism during the discharge and charge shown in Figure 12,

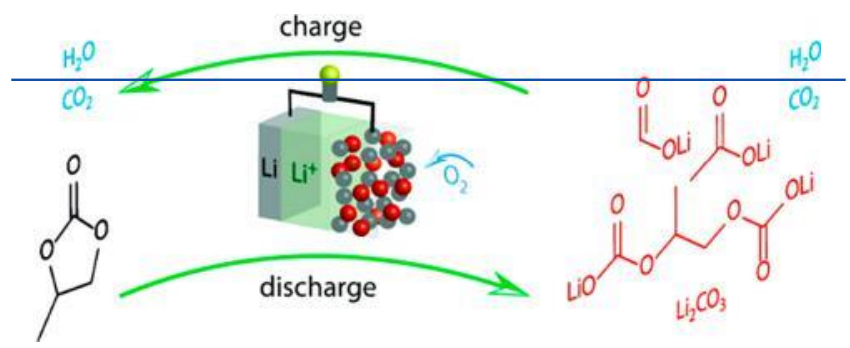

Figure 12. Graphical representation of charge-discharge of $\mathrm{Li}^{-} \mathrm{O}_{2}$ cell with 1 M LiPF6 in PC. Reproduced with permission from ref 84. Copyright 2011 American Chemical Society.

they showed that the prolonged cyclability of $\mathrm{Li}-\mathrm{O}_{2}$ cells containing alkyl carbonate-based electrolyte solutions was attributed to the irreversible decomposition and oxidation of $\mathrm{Li}_{2} \mathrm{CO}_{3}$ along with other species, namely $\mathrm{C}_{3} \mathrm{H}_{6}(\mathrm{OCOOLi})_{2}$, $\mathrm{CH}_{3} \mathrm{COOLi}, \mathrm{HCOOLi}, \mathrm{CO}_{2}$, and $\mathrm{H}_{2} \mathrm{O}$ with no evidence of reversible oxygen reduction to $\mathrm{Li}_{2} \mathrm{O}_{2}$. Furthermore, they reported the accumulation of side products on the cathode in a polymer like film, resulting in increased overpotential, capacity fading, and ultimately cell failure. The dramatic instability of organic carbonates in the highly reactive environment of $\mathrm{Li}-\mathrm{O}_{2}$ led to studies of other solvents and catalyzed the search for better and more stable solvents.

Building on their initial experience ${ }^{82}$ with the carbonate instability, Read et al. ${ }^{80}$ investigated the use of ethers as electrolyte solvents. Using DME (dimethoxyethane) and DOL (1,3dioxolane), they described a $\mathrm{Li}-\mathrm{O}_{2}$ cell showing both good stability and excellent rate capability. They attributed these properties to the high oxygen solubility and low viscosity, which results in facilitated oxygen transport in the $\mathrm{Li}-\mathrm{O}_{2}$ cell. Later McCloskey et al. ${ }^{183}$ studied the fundamental chemistry, in particular, the discharge product during the recharging of $\mathrm{Li}^{-} \mathrm{O}_{2}$ cells. They confirmed that in DME-based solvents, Li2O2 is the major discharge product; however, DME undergoes oxidative degradation during recharge in the presence of $\mathrm{Li}_{2} \mathrm{O}_{2}$. Sharon et al. and Freunberger et ${ }^{\text {al.121,184 }}$ further confirmed the degradation of $\mathrm{DME}$ and other ether-based solvents and proposed the formation of $\mathrm{CO}_{2}, \mathrm{HCOOLi}, \mathrm{CH}_{3} \mathrm{COOLi}$, $\mathrm{LiOCOOLi}$, and $\mathrm{LiOCH}_{2} \mathrm{CH}_{2} \mathrm{OLi}$ following the mechanisms shown in Scheme 1. Compared to the carbonates, ether-based

\section{Scheme 1. Proposed Mechanism for the Decomposition of Ether-Based Solvents during the Oxygen Reduction Reactions in $\mathrm{Li}^{-}-\mathrm{O}_{2}$ Batteries $^{\mathrm{a}}$}

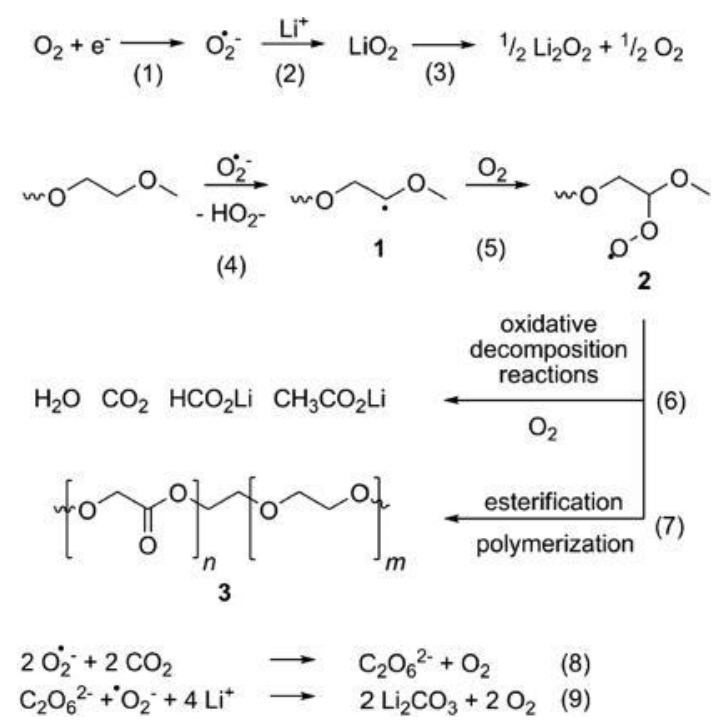

aReproduced with permission from ref 121. Copyright 2011 Wiley$\mathrm{VCH}$.

electrolytes are relatively more stable, attributable to the ether solvents' greater resistance to nucleophilic attack and higher cathodic stability. ${ }^{183}$ Hence, they are considered to be the best compromise for such active systems. Indeed, progress ${ }^{185,186}$ in $\mathrm{Li}-\mathrm{O}_{2}$ batteries would not have been possible without glymebased electrolyte solutions. It is important to note that various glymes differ in their reactivity toward the oxygen species formed in $\mathrm{Li}-\mathrm{O}_{2}$ cells. In a study summarized in Figure 13, it was clearly found that diglyme is the most stable glyme solvent in $\mathrm{Li}-\mathrm{O}_{2}$ cells. The reason for that may relate to the nature of the active sites in the poly ether molecules. This depends on the chain length, number of oxygens, the steric conformations, and the interactions of the oxygen atoms with the $\mathrm{Li}$ ions.

While the glyme polyether solvents were found indeed to be more stable than the carbonates, there was a lack of unanimity on the extent of this stability. Their relatively nonpolar nature also keeps the concentration of Li salts rather low. Crucially, they resulted in cells that exhibited low rates and capacities, which we now understand is because they promote the formation of $\mathrm{Li}_{2} \mathrm{O}_{2}$ films on the electrode surface on discharge, which are insulating and limited to approximately $7 \mathrm{~nm},{ }^{187}$ as discussed in the section describing the mechanism of $02 / \mathrm{Li} 2 \mathrm{O} 2$ above. This low rate and capacity promoted examination of other solvents including higher DN solvents such as dimethyl sulfoxide (DMSO). Peng et al. reported on $\mathrm{Li}-\mathrm{O}_{2}$ cells with DMSO as the solvent, with a porous gold electrode, exhibiting $-95 \%$ capacity retention for 100 cycles (Figure 14A). ${ }^{188}$ Subsequently, several other groups reported excellent reversibility of $\mathrm{Li}-\mathrm{O}_{2}$ cells, with $\mathrm{Li2} 2$ as the 

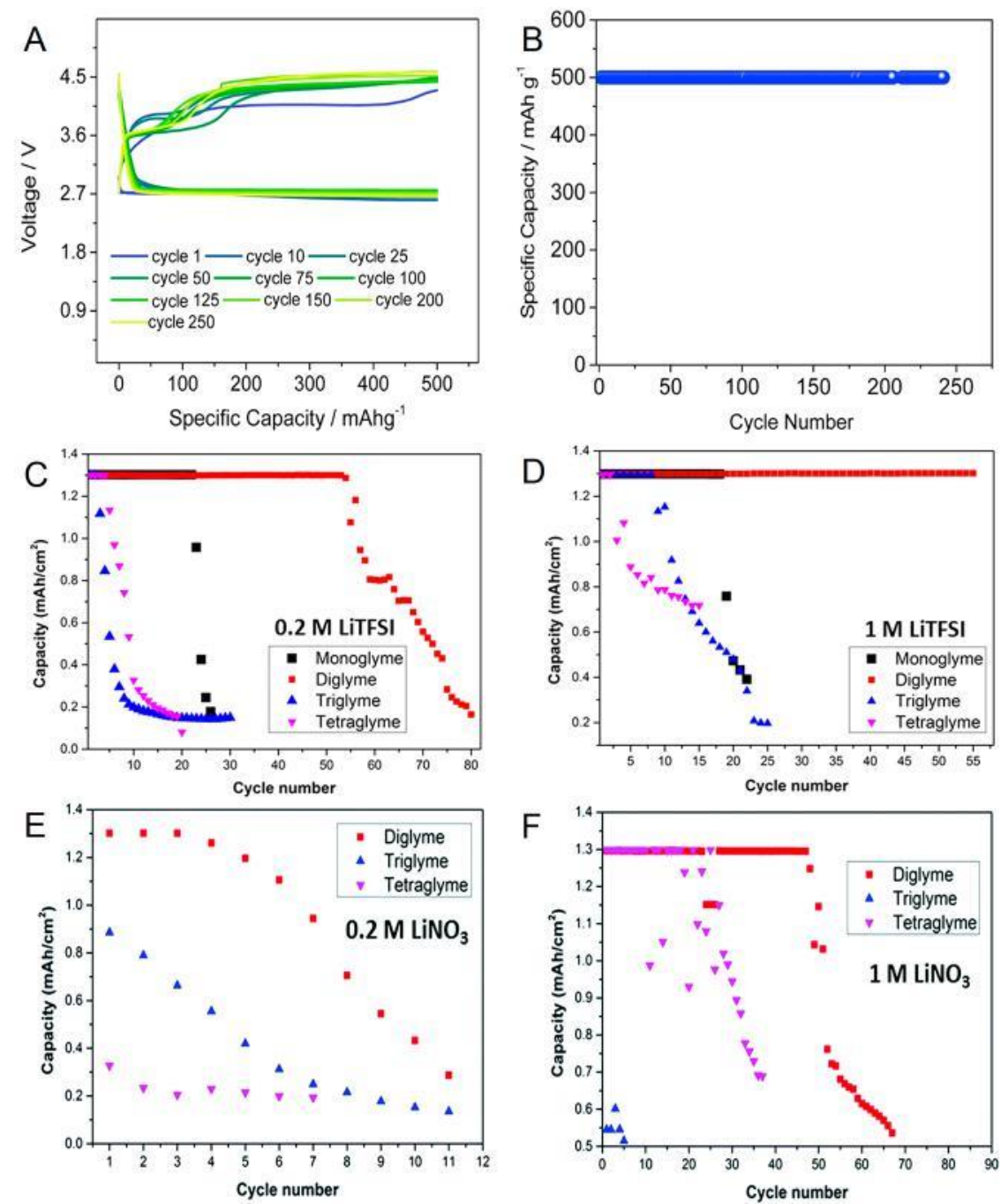

Figure 13. Performance of $\mathrm{Li}-\mathrm{O}_{2}$ cells with glyme-based electrolyte solutions and the relative stability of glymes solvents: (A) Galvanostatic voltage profiles and (B) corresponding cycling trend of the lithium oxygen batteries using the TEGDME-LiTFSI $\left(1 \mathrm{~mol} \mathrm{~kg}^{-1}\right)$ electrolyte and the $\mathrm{N}_{2} @$ MWCNT (multiwalled carbon nanotubes) electrode. Reproduced with permission from ref 186. Copyright 2018 American Chemical Society. Cycling behavior of $\mathrm{Li}-\mathrm{O}_{2}$ cells in different glymes containing (C) $0.2 \mathrm{M}$ LiTFSI, (D) $1 \mathrm{M} \mathrm{LiTFSI}$, (E) $0.2 \mathrm{M} \mathrm{LiNO}_{3}$, and (F) $1 \mathrm{M} \mathrm{LiNO}_{3}$ electrolyte solutions. Reproduced with permission from ref 185 . Copyright 2017 Royal Society of Chemistry.

discharge product. ${ }^{189,190}$ However, the capacity of the Au electrode was intrinsically low due the limited pore volume. Investigation with larger pore volume carbon electrodes revealed significant degradation of DMSO, attributed to the susceptibility of DMSO to nucleophilic attack by reduced oxygen species, forming sulfone, and dimethyl sulfone, following the mechanism outlined in Figure 14B. ${ }^{191}$ It should, however, be noted that excellent cyclability of $\mathrm{KO}_{2}$ in DMSO has been reported recently, ${ }^{120}$ which casts doubt at the major influence of direct reactivity of superoxide.

Nevertheless, Liu et al. have recently reported a superconcentrated salt/DMSO based $\mathrm{Li}-\mathrm{O}_{2}$ cell, which showed excellent stability and reversibility even with an unprotected $\mathrm{Li}$ anode. Because DMSO molecules are corrosive to the Li metal anode and unstable to $\mathrm{O}_{2} \cdot-$ attack, the better performance of the superconcentrated solutions can be attributed to the absence of free DMSO solvent molecules and existence of only TFSI $^{-}-$ $\mathrm{Li}^{+}-(\text {DMSO })_{3}$ complexes. ${ }^{192}$

The unsatisfactory stability of DMSO spurred further search of new solvent candidates showing stability toward ROS. Amidebased solvents like N,N-dimethylacetamide, dimethylforma- mide (DMF), and $\mathrm{N}$-methyl-2-pyrrolidone (NMP) were next investigated because of their presumed stability toward the superoxide radical. However, the amines do have facile reactivity toward lithium metal. To minimize the latter issue, Uddin et al. ${ }^{193}$ proposed the use of $\mathrm{LiNO}_{3}$ as a passivation agent for metallic lithium. Similarly, by exploiting these passivating properties of the $\mathrm{LiNO}_{3}$, Walker et al. ${ }^{194}$ showed reversible cycling of a $\mathrm{Li}-\mathrm{O}_{2}$ battery for more than $2000 \mathrm{~h}$ in N,N-dimethylacetamide, with $\mathrm{Li}_{2} \mathrm{O} 2$ as the main discharge product. Unfortunately, this amide-based solvent cycling stability was found to be unsuitable for oxygen reduction applications. As outlined in Scheme 2, studies by Chen et al. ${ }^{195}$ and Sharon et al. ${ }^{196}$ demonstrated the oxidative cleavage of amides and their further degradation to various species including dimethylamine, acetate, carbonate, and various $\mathrm{N}-\mathrm{O}$ species. Although the stability results of amide-based solvents are debatable, it may be concluded that amide stability toward reduced oxygen species is not sufficient for rechargeable aprotic $\mathrm{Li}-\mathrm{O}_{2}$ cells. Another popular polar solvent, acetonitrile, ${ }^{131}$ also showed some success owing to its stability toward superoxide; however, because of its 

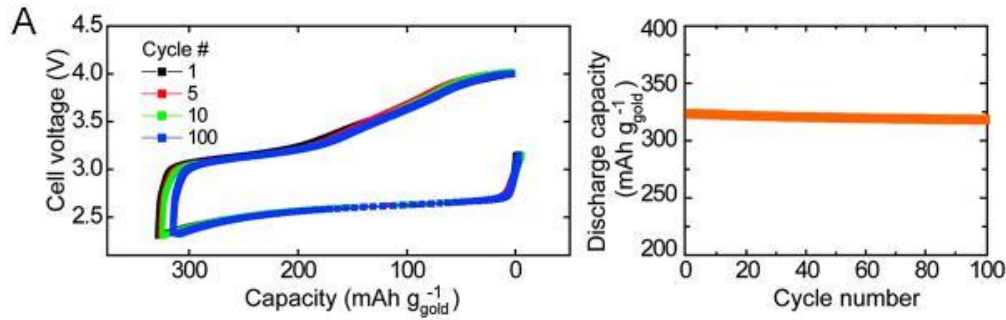

B
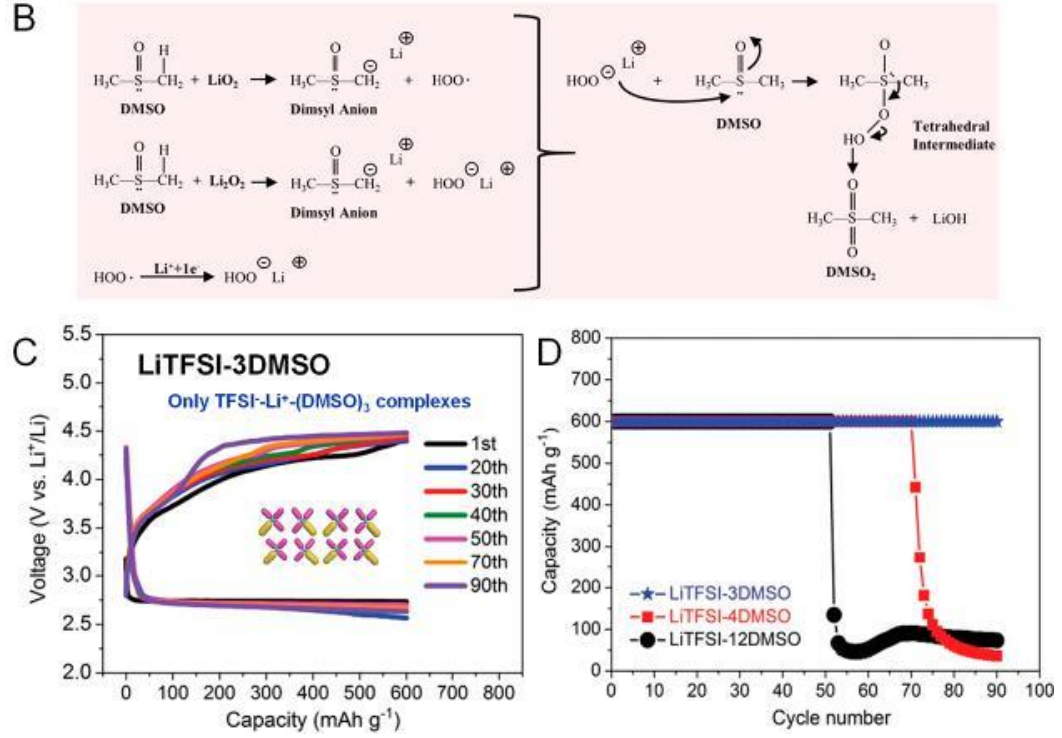

Figure 14. On the stability of DMSO: (A) Performance of $\mathrm{Li}^{-} \mathrm{O}_{2}$ battery with DMSO as solvent and a porous gold cathode. Reproduced with permission from ref 188. Copyright 2012 The American Association for the Advancement of Science. (B) Proposed mechanism of degradation of DMSO. Reproduced with permission from ref 191. Copyright 2013 American Chemical Society. Voltage profiles for (C) LiTFSI-3DMSO electrolyte and (D) cycling stability of the three electrolytes with different concentration. Reproduced with permission from ref 192. Copyright $2017 \mathrm{Wiley-VCH.}$

Scheme 2. Proposed Mechanism for Degradation of Dimethylacetamide during Oxygen Reduction Reactions ${ }^{\mathrm{a}}$

$$
\begin{aligned}
& \mathrm{O}_{2} \underset{(1)}{\stackrel{\mathrm{e}^{-}}{\rightarrow}} \mathrm{O}_{2}^{--} \underset{(2)}{\stackrel{\mathrm{Li}^{+}}{\longrightarrow}} \mathrm{LiO}_{2} \underset{(3)}{\longrightarrow} 1 / 2 \mathrm{Li}_{2} \mathrm{O}_{2}+1 / 2 \mathrm{O}_{2}
\end{aligned}
$$

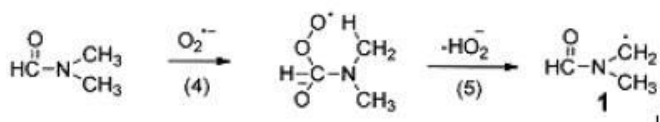

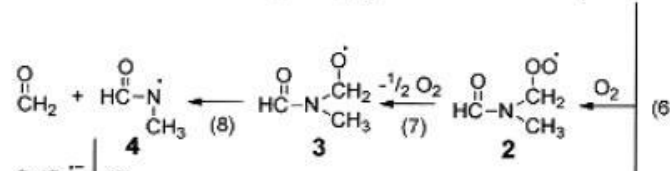

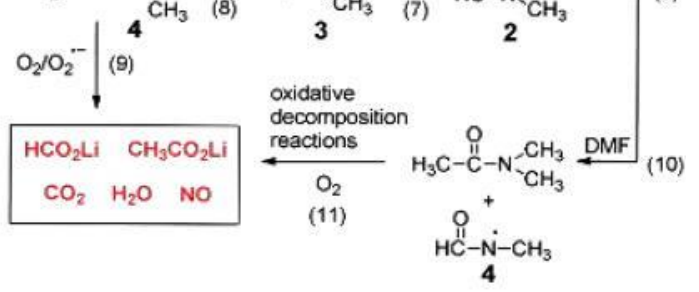

$$
\begin{aligned}
& 2 \mathrm{O}_{2}^{-}+2 \mathrm{CO}_{2} \quad \longrightarrow \quad \mathrm{C}_{2} \mathrm{O}_{\mathrm{e}}^{2-}+\mathrm{O}_{2} \\
& \mathrm{C}_{2} \mathrm{O}_{6}^{2-}+2 \mathrm{O}_{2}^{--}+4 \mathrm{Li}^{+} \longrightarrow \quad 2 \mathrm{Li}_{2} \mathrm{CO}_{3}+2 \mathrm{O}_{2}
\end{aligned}
$$

${ }^{a}$ Reproduced with permission from ref 195. Copyright 2012 American Chemical Society.

high volatility and high reactivity toward lithium metal, it was not extensively explored for $\mathrm{Li}-\mathrm{O}_{2}$ batteries.

In summary, almost all of the available aprotic solvents degrade to a greater or lesser extent under the highly reactive environment of $\mathrm{Li}-\mathrm{O}_{2}$ batteries. Four modes of degradation mechanisms can be listed: nucleophilic attack, $\mathrm{H}$ atom abstraction, acid/base reactions, and reductive degradation at the metallic lithium anodes. The strongly nucleophilic superoxide anion $\left(\mathrm{O}_{2}{ }^{-}\right)$readily attacks the electron deficient sites of polar solvents such as carbonyl or sulfoxides groups. These include carbonates, amides, as well as sulfoxides (like DMSO), which undergo degradation via nucleophilic attacks. In other modes of action, superoxide can mediate $\alpha$-hydrogen atom and/ or flproton abstraction via acid/base reactions, leading to solvent deprotonation and decomposition. Ethers, which are generally stable to nucleophilic attack, can undergo some autoxidative decomposition in the presence of these reactive oxygen species. Hence, the ethers solvents are proven to be the most appropriate class of solvents (among the available options) for $\mathrm{Li}-\mathrm{O}_{2}$ batteries.

It is important to emphasize here that the extent of degradation also depends on the possible stabilization of reduced oxygen species by the electrolyte solutions (nature of the solvent, salt anions, additives). Such a stabilization leads to prolonged exposure of electrolyte solution to the reactive species, thereby enhancing the probability of nucleophilic attack, H-abstraction etc. This leads to the conundrum in which solutions that promote a top-down growth of the Li2O2 during discharge, leading to enhanced discharge capacity, may be also exposed to accelerated decomposition (stabilization of reduced oxygen species increase their retention time, thus their ability to attach solution species). The various degradation pathways utilized by the various families of solvents are listed in Figure 

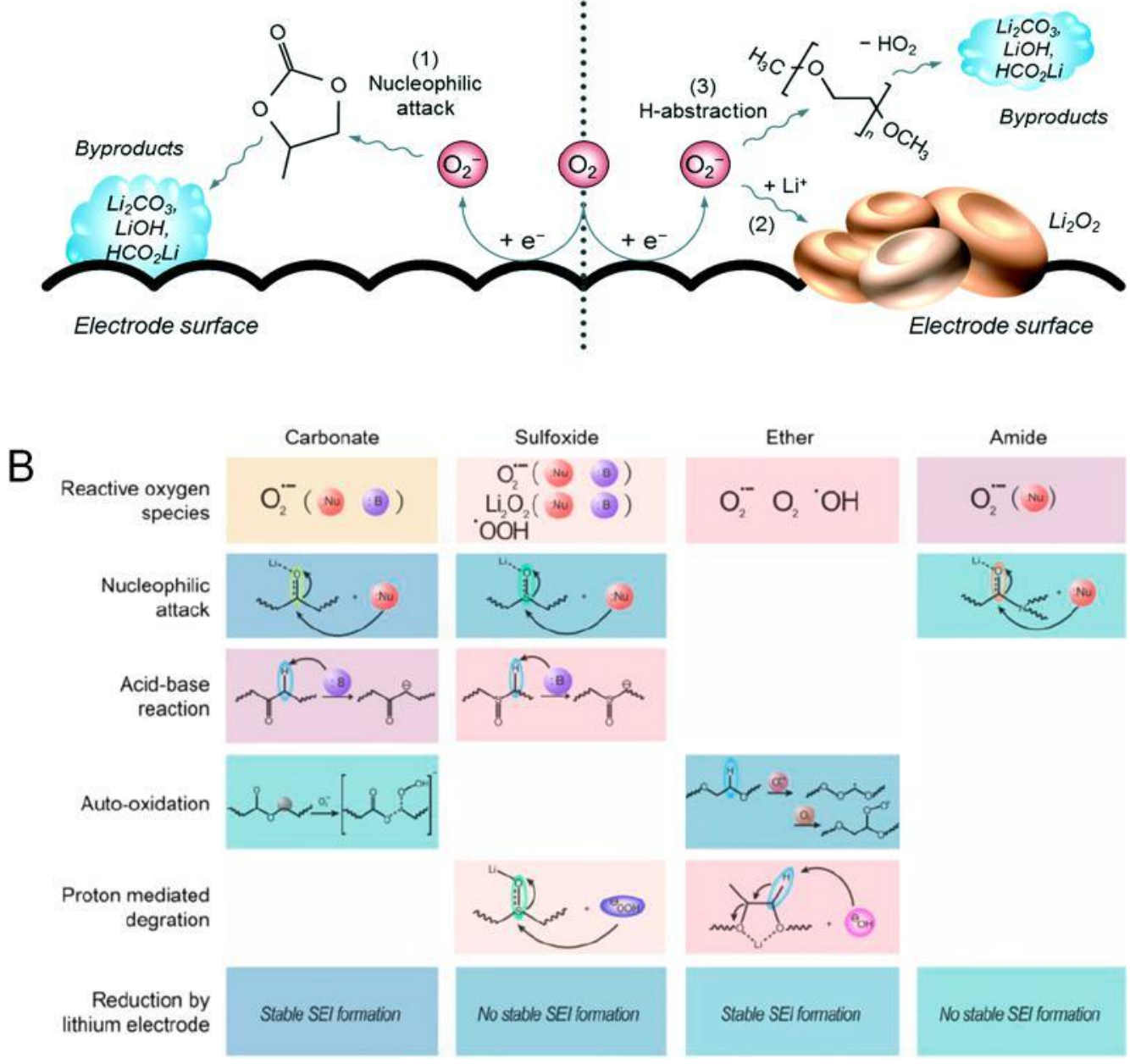

Figure 15. (A) Schematic illustration of possible discharge reactions involving oxygen radicals in different electrolyte systems. (1) Nucleophilic attack of an oxygen radical in a carbonate-based electrolyte and the subsequently produced byproducts. (2) Reaction between oxygen radicals and Li ions to produce $\mathrm{Li}_{2 \mathrm{O} 2}$ in a noncarbonate-based electrolyte. (3) H-Abstraction reaction induced by oxygen radicals and the subsequently produced byproducts in a noncarbonate-based electrolyte. Reproduced with permission from ref 197. Copyright 2017 Royal Society of Chemistry. (B) Possible degradation pathways of the solvents. Reproduced with permission from ref 66. Copyright 2019 Wiley-VCH.
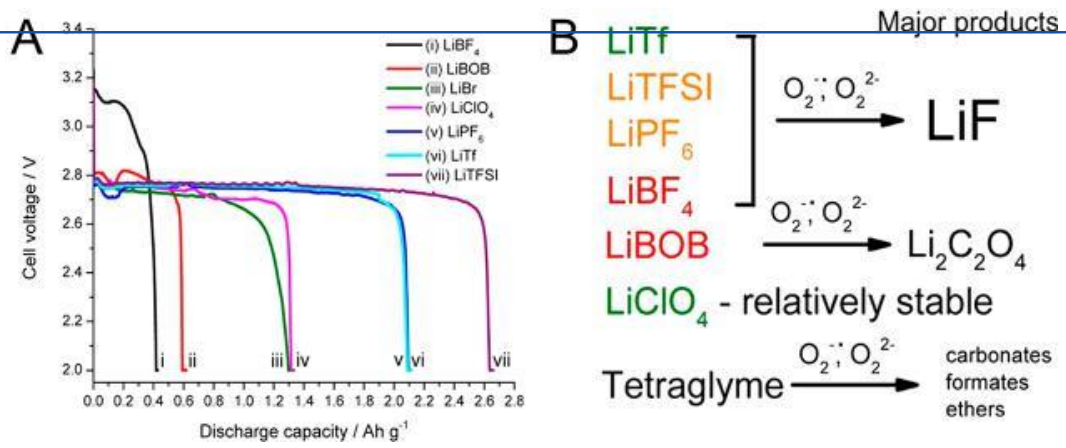

Figure 16. (A) Discharge profiles of $\mathrm{Li}^{-} \mathrm{O}_{2}$ battery with various anions of $\mathrm{Li}$-salt dissolved in TEGDME. (B) Decomposition products of Li-salts in the presence of reactive oxygen species. Reproduced with permission from ref 201. Copyright 2013 American Chemical Society.

$15^{66}$ New solvents continue to he synthesized and tested for use in $\mathrm{Li}-\mathrm{O}_{2}$ batteries, as discussed in the next section.

3.4.1.2. Salts. Li salts are an indispensable component of the electrolyte solutions which strongly influence the course of ORR/OER. As already pointed out, the donor number of the solvents as well as the counteranion (as expressed in the ionic association/dissociation level of the salt) play important roles in guiding the discharge product, especially in terms of its morphology.

$\mathrm{LiNO}_{3}$ is one of the most explored salts in $\mathrm{Li}-\mathrm{O}_{2}$ batteries. In addition to promoting solution mediated growth, $\mathrm{LiNO}_{3}$ also exhibits a bifunctional role. It catalyzes the OER198,199 and passivates the carbon electrode against oxidative damage. ${ }^{200} \mathrm{~A}$ myriad of other salts have also been employed in $\mathrm{Li}-\mathrm{O}_{2}$ battery 

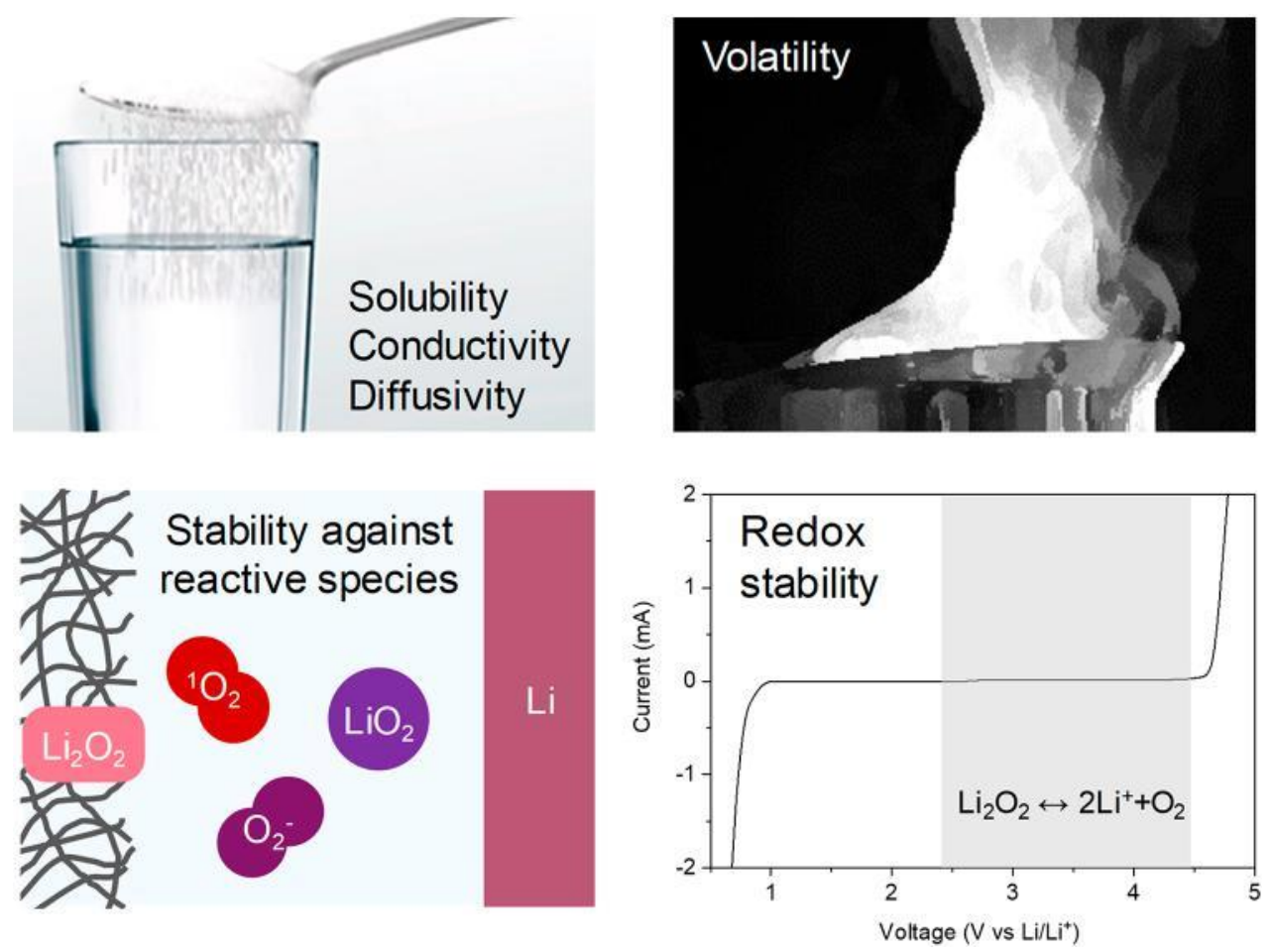

Figure 17. Important parameters for promising solvents for $\mathrm{Li}-\mathrm{O}_{2}$ batteries.

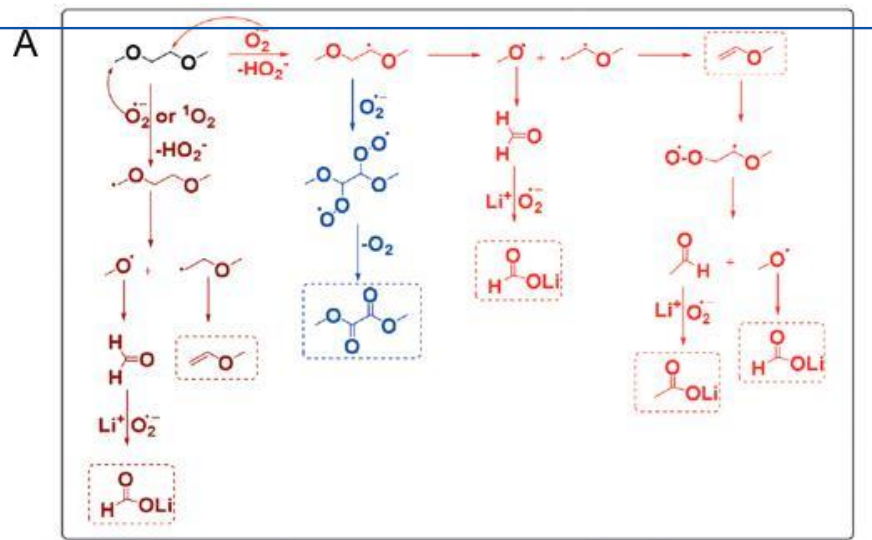

Stable (without hydrogen abstract reaction)

B
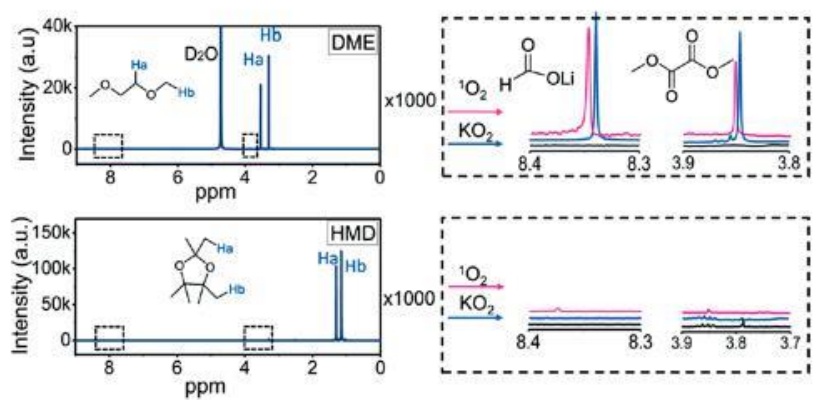

C<smiles>COC(C)(C)C(C)(C)OC</smiles>

2,3-dimethyl-2,3-dimethoxybutane (DMDMB)<smiles>COC(C)(C)C(=O)C(C)(C)OC</smiles>

2,4-Dimethoxy-2,4-dimethylpentan-3-one (DMDMP)

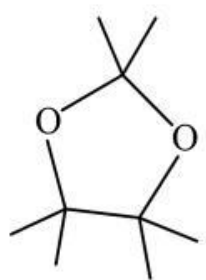

2,2,4,4,5,5-hexamethyl-1,3-dioxolane (HMD)

Figure 18. (A) Possible decomposition mechanism of DME (top) and HMD (down). (B) ${ }^{1} \mathrm{H}$ NMR spectra (left) with magnified views (right) for checking stability of DME (top) and HMD (down) against ${ }^{1} \mathrm{O}_{2}$ and $\mathrm{KO}_{2}$. (C) Proposed candidates as stable solvents in $\mathrm{Li}-\mathrm{O}_{2}$ batteries in previous articles. ${ }^{133,204,205}$ Reproduced with permission from ref 205. Copyright 2019 John Wiley \& Sons.

electrolyte solutions, and their discharge voltage profiles are presented in Figure 16A. Distinct discharge capacity and voltage plateaus are observed for each of the different anions. LiTFSI exhibited the maximum discharge capacity followed by LiTf and 
LiPF6. LiTFSI is also among the most frequently used salts reported for $\mathrm{Li}-\mathrm{O}_{2}$ batteries because of its good chemical and electrochemical stability and considerable ionic conductivity. However, it also undergoes partial decomposition to form $\mathrm{LiF}$ on the cathode surface, similar to LiTf and LiPF6. ${ }^{201}$

Using X-ray diffraction (XRD) and X-ray photoelectron spectroscopy (XPS), Nasybulin et al. ${ }^{201}$ studied various salts in $\mathrm{Li}-\mathrm{O}_{2}$ batteries and showed that almost every salt undergoes at least partial decomposition, reacting with the in situ generated reactive oxygen species. $\mathrm{LiBF}_{4}$ and LiBOB suffered from complete decomposition to $\mathrm{LiF}$, boron-oxygen com-pounds, ${ }^{66,201}$ and $\mathrm{Li}_{2} \mathrm{CO}_{3}$ on the cathode surface. The degradation of $\mathrm{LiBF}_{4}$ and $\mathrm{LiBOB}$ is reflected in the abnormally high discharge plateaus seen in Figure 16A. By contrast, LiTFSI, $\mathrm{LiNO}_{3}, \mathrm{LiClO}_{4}$, and $\mathrm{LiBr}$ showed relatively stable performance. The beneficial role of $\mathrm{LiBr}$ and LiI as redox mediators has also been reported recently and is discussed further below.202,203 This emphasizes that in describing the performance of $\mathrm{Li}-\mathrm{O}_{2}$ battery chemistry, the involvement of the salts holds an equal importance to the stability of the solvents. Consequently, this aspect should be comprehensively investigated in order to come up with stable electrolyte solutions.

3.4.2. Development of New Solvents for $\mathrm{Li}-\mathrm{O}_{2}$ Batteries. From the discussion above, the importance of finding appropriate solvents is crucial for the development of durable $\mathrm{Li}-\mathrm{O}_{2}$ batteries. As shown in Figure 17, the various characteristics of solvents that can be suitable for $\mathrm{Li}-\mathrm{O}_{2}$ batteries have to be considered.

The solubility of the Li salt must be considered because the solution must be capable of ion transfer. In addition, the solubility of $\mathrm{O}_{2}$ gas should also be considered because the $\mathrm{O}_{2}$ gas is the cathode's active mass, which should be dissolved in the electrolyte solution in order to react electrochemically. The conductivity and diffusivity, which are critical properties of any electrolyte solution, can also be controlled by the nature of the solvent and thereby should be considered. The volatility of the solvents is also a factor that should be considered for long-term operation. Nonvolatile solvents like tetraglyme are indeed widely used in these systems.

It is also important to have enough redox stability to prevent decomposition during discharge and charge, but it should be noted that practical lithium-air batteries would aim to operate below $3.5 \mathrm{~V}$ and significant anodic stability is not requisite. However, when the stability window of the electrolyte is exceeded, decomposition of the solvent occurs and such side reactions not only interfere with the desired decomposition of $\mathrm{Li}_{2} \mathrm{O}_{2}$ but also decreases the cyclability of the batteries due to the accumulation of byproducts on the cathode.

Hence, in general, the reversibility of $\mathrm{Li}-\mathrm{O}_{2}$ cells is very poor if the solvent is decomposed by possible reactions with $\mathrm{O}_{2}{ }^{-}, \mathrm{LiO}_{2}$, or the recently reported ${ }^{1} \mathrm{O}_{2}$, produced by the formation and decomposition of $\mathrm{Li}_{2} \mathrm{O}_{2}$. Because $\mathrm{Li}_{2} \mathrm{O} 2$ is an indispensable product of the battery reaction, stability of solvents against $\mathrm{Li}_{2} \mathrm{O}_{2}$ must be ensured. Therefore, the stability of any solvent examined for $\mathrm{Li}-\mathrm{O}_{2}$ batteries to $\mathrm{ROS}$ should be first verified. Several candidate solvents that have been reported as more stable than glyme solvents in $\mathrm{Li}-\mathrm{O}_{2}$ cells are summarized in Figure 18 below.

Adams et al. ${ }^{133}$ synthesized 2,3-dimethyl-2,3-dimethyoxybutane (DMDMB). In this compound, the internal $\beta$-hydrogens of 1,2-dimethoxyethane (DME) are replaced with methyl groups. As shown in Figure 18A, this prevents facile elimination by preventing abstraction of these hydrogens. In their paper,
DMDMB reduced the amount of generated $\mathrm{CO}_{2}$ by 10 -fold and did not form byproducts such as lithium formate compared to DME.

Sharon et al. ${ }^{204}$ synthesized 2,4-dimethoxy-2,4-dimethylpentan-3-one (DMDMP) by replacing the acidic hydrogens alpha to the carbonyl of 1,3-dimethoxyacetone with methyl groups. The DMDMP is stable to nucleophilic attacks and $\mathrm{H}$-abstraction by reduced oxygen species.

Huang et al. ${ }^{205}$ proposed 2,2,4,4,5,5-hexamethyl-1,3-dioxolane (HMD), which does not have any hydrogen atoms on the $\boldsymbol{\alpha}$-carbon, also preventing $\mathrm{H}$-abstraction by superoxide. Compared to DMDMB and DMDMP, nuclear magnetic resonance (NMR) data demonstrated that HMD is stable to both reduced oxygen species and singlet oxygen.

The common strategy in all the above studies is to substitute labile hydrogens, which are the starting point for solvent decomposition, with methyl or methoxy groups, generating structures more stable to ROS. However, because only a few examples of such compounds appear in the literature, more examples are required. Furthermore, in addition to improving the stability by using steric hindrance, various other properties such as solubility, conductivity, and volatility of these solvents must be examined.

It is expected that stable and reliable solvents, which can improve the actual performance, can be found as substitutes for polyethers (glymes), which were predominantly used until now as the best compromised family of solvents. However, the development of a suitable solvent that meets all conditions may be difficult in practice.

Strategies that can compensate for instability of solvents should be considered, such as a high concentration of electrolytes (the concept of solvent in salt). Liu et al.146,192 proposed highly concentrated solutions as more stable electrolytes. These include $3 \mathrm{M}$ solutions of LiTFSI in DME and highly concentrated LiTFSI-DMSO $(1 / 3 \mathrm{n} / \mathrm{n})$, which in either case contain no free solvent molecules and which could in comparison to less concentrated solutions demonstrate improved stability toward Li-metal anodes and air cathodes.

Dong et al. ${ }^{206}$ have also seemingly solved the problem of parasitic reactions in $\mathrm{Li}-\mathrm{O}_{2}$ cells by replacing the organic solvent with superconcentrated LiTFSI $(21 \mathrm{M})$ in $\mathrm{H}_{2} \mathrm{O}$. $\mathrm{Li}_{2} \mathrm{O}_{2}$ was confirmed as the only discharge product, with no $\mathrm{LiOH}$ formation, although $\mathrm{H}_{2} \mathrm{O}$ is used as the solvent in this system.

Zhao et al. ${ }^{207}$ mixed tetraglyme with 1,1,2,2-tetrafluoroethyl 2,2,3,3-tetrafluoropropyl ether (TTE) in a 1:1 volume ratio. This was done in order to improve the electrochemical stability as well as to increase the ionic conductivity and wettability and reduce viscosity and flammability. In addition, the stability of the $\mathrm{Li}$ metal anodes in the cells were improved due to formation of passivating surface films thanks to the presence of the fluorinated cosolvent.

In summary, this section definitely shows some light at the end of the tunnel, demonstrating interesting attempts to develop new solvents in light of understanding the mechanisms of side reactions. Also, the use of superconcentrated solutions can also help to stabilize $\mathrm{Li}-\mathrm{O}_{2}$ batteries.

3.4.3. Cathode Materials and Their Stability in $\mathrm{Li}-\mathrm{O}_{2}$ Cells. In contrast to lithium-ion batteries, in lithium-air batteries, the full mass of the storage material $\mathrm{Li}_{2} \mathrm{O} 2$ is fully formed and decomposed in every cycle. The role of the cathode is to provide a framework within which this can occur. The cathode must possess high electronic conductivity and high open porosity to allow for $\mathrm{Li}_{2} \mathrm{O} 2$ storage and $\mathrm{O}_{2}$ and $\mathrm{Li}^{+}$ 
transport. The accessible surface area governs the true surface area discharge current and impacts the ORR; larger current densities form thinner deposits, which calls for properly balancing inner surface area and pore space. This must be accomplished while introducing minimal additional mass and volume to the battery. ${ }^{181,208}$ Perhaps most importantly, and yet rarely acknowledged, is the need to fill large fractions of the cathode volume with $\mathrm{Li}_{2 \mathrm{O} 2}$ during discharge (ORR) ${ }^{53,208}$ In our opinion, the cathodes should be able to host $\mathrm{Li} 2 \mathrm{O} 2$ deposits after discharge that fill at least half of their volume while not impeding battery performance to achieve the ambitious performance targets envisaged for the lithium-air battery. Unfortunately, most work in the field fails to consider this requirement and it is common practice to measure the capacity per unit mass of the cathode material.

In too many publications, the mass and volume of all other nonactive components (electrolyte solution, displaced volume, binder, accumulated lithium peroxide, etc.) are commonly disregarded in the calculations of specific capacity or energy. As shown in Figure 19 and the excellent perspective article from

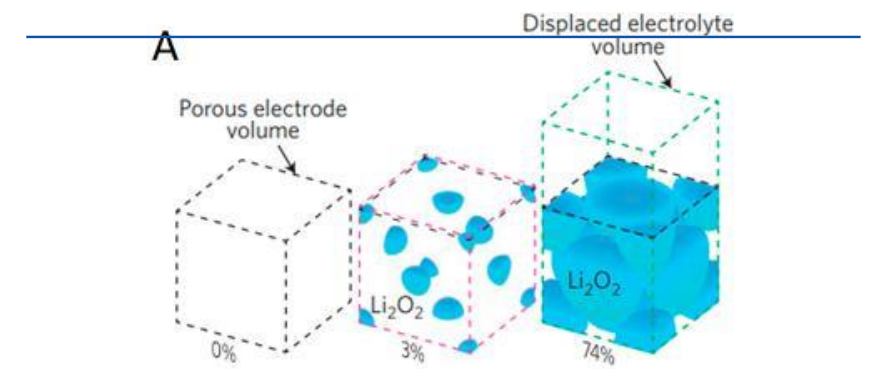

B

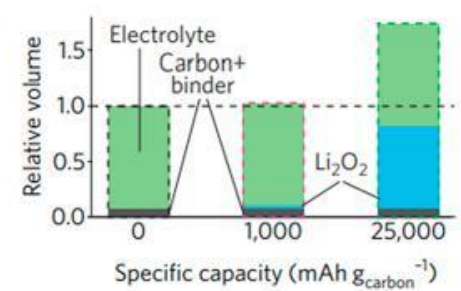

Figure 19. (A) Space filling of spherical Li2O2 particles inside a porous electrode and the displaced electrolyte volume at discharge capacities of 0,1000 , and $25000 \mathrm{mAh}$ g-1carbon. (B) Volumes of the electrode components at these capacities normalized to the full electrode volume in the delithiated state. Reproduced with permission from ref 181. Copyright 2017 Springer Nature.

Freunberger, ${ }^{181}$ such calculations mislead the true evaluation of the metrics of $\mathrm{Li}-\mathrm{O}_{2}$ cells. Below, we attempt to review advances in cathodes in the context of their true electrochemical performance in lithium-air batteries.

3.4.3.1. Carbon Cathodes and Their Stability. Carbon cathodes are ubiquitous in $\mathrm{Li}-\mathrm{O}_{2}$ batteries due to their high conductivity, low weight, low cost, and flexible structure. Typically, carbons have been selected to provide a large surface area and pore volume in which the Li2O2 ORR product can be hosted. Early work in the lithium-air field employed carbon blacks such as Super P, Vulcan XC 72R, and Ketjen Black. ${ }^{83,153,209}$ These materials, while having relatively moderate surface area, possess reasonably high specific pore volume. Consequently, calculating specific discharge capacity of such carbons in cathodes of $\mathrm{Li}-\mathrm{O}_{2}$ cells may provide capacities $>2000 \mathrm{mAh}_{\mathrm{g}-1 \text { carbon.210 }}$ Ding et al. used silica templates to form a series of hierarchical carbons with varying pore sizes and volume and the discharge capacity. ${ }^{211}$ However, they also showed that a general correlation exists between the pore showed that pores of ultrahigh surface area mesoporous carbons are not accessible for $\mathrm{Li} 2 \mathrm{O} 2$ storage. ${ }^{211} \mathrm{Nie}$ et al. demonstrated the importance of large macropores that remain open and able to deliver oxygen through the cathode. ${ }^{212}$ Graphene-based carbons have been reported to offer capacities in excess of $10000 \mathrm{mAh}$ carbon,213 but there is also an unanswered question regarding $\mathrm{g}-1$

the long-term stability of graphene-based cathodes. However, graphene-based materials should not be dismissed, as rigid, freestanding graphene foams and papers meet many of the requirement for housing $\mathrm{Li}_{2 \mathrm{O} 2}$ deposits (Figure 20). ${ }^{214}$ In addition, the lack of a binder may increase stability.

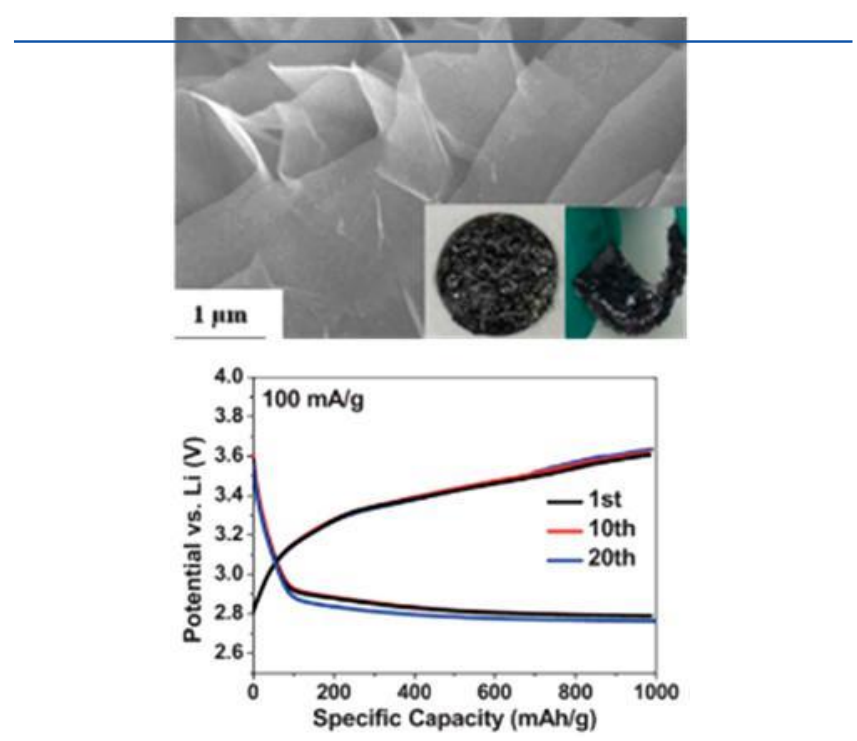

Figure 20. SEM image of a graphene foam cathode (inset optical images) and the resulting cycling profile of $\mathrm{Li}-\mathrm{O}_{2}$ cells when it is used as the cathode. Reproduced with permission from ref 214. Copyright 2013 Royal Society of Chemistry.

Unfortunately, most studies have failed to account for the mass of $\mathrm{Li}_{2} \mathrm{O}_{2}$. When additional considerations of the electrolyte solution are included in the volume of highly porous cathodes, few, if any, reported cathodes offer suitable performance for viable lithium-air batteries (in terms of attractive specific capacity). This is exemplified by a laudable contribution from Mitchell et al. (Figure $21),{ }^{215}$ where the capacity per mass of carbon only and per mass of carbon $+{ }_{\mathrm{Li} 2 \mathrm{O} 2}$ is provided for a lithium $-\mathrm{O}_{2}$ cell containing a CNT cathode. The CNT cathode capacities are $4720 \mathrm{mAh} g-1$ carbon versus $944 \mathrm{mAh} \mathrm{g}-1$ carbon+Li2O2, demonstrating the fallacy of measuring capacity as a function of carbon mass only. Zhao et al. ${ }^{216}$ calculated the capacity of a graphene cathode to be ca. $1000 \mathrm{mAh}$ $\mathrm{g}-1$ carbon+Li202. These variations in performance metrics have resulted in a move toward presenting real capacities and the use of fibrous carbon gas diffusion electrodes previously used in fuel cells. ${ }^{217}$ These materials are not practical due to their large mass, but they do offer physical properties similar to those presumably required in a practical lithium-air cathode, i.e., large porous volume, large pores for $\mathrm{O}_{2}$ delivery, reasonable surface area, and a rigid and robust 3D structure. Thus, they offer a suitable testbed. With the advent of redox mediators able to direct significant discharge via a solution route, Gao et al. ${ }^{208}$ have presented discharge capacity 

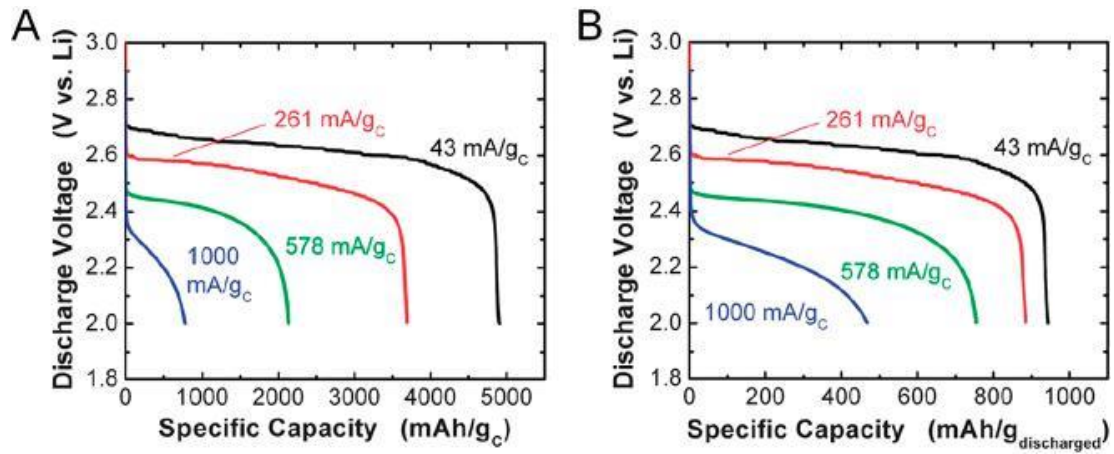

Figure 21. First-discharge profiles of $\mathrm{Li}-\mathrm{O}_{2}$ cells containing CNF electrodes with the capacity normalized to (A) the weight of the carbon and (B) to the carbon $+\mathrm{Li}_{2} \mathrm{O}_{2}$. Reproduced with permission from ref 215. Copyright 2011 Royal Society of Chemistry.
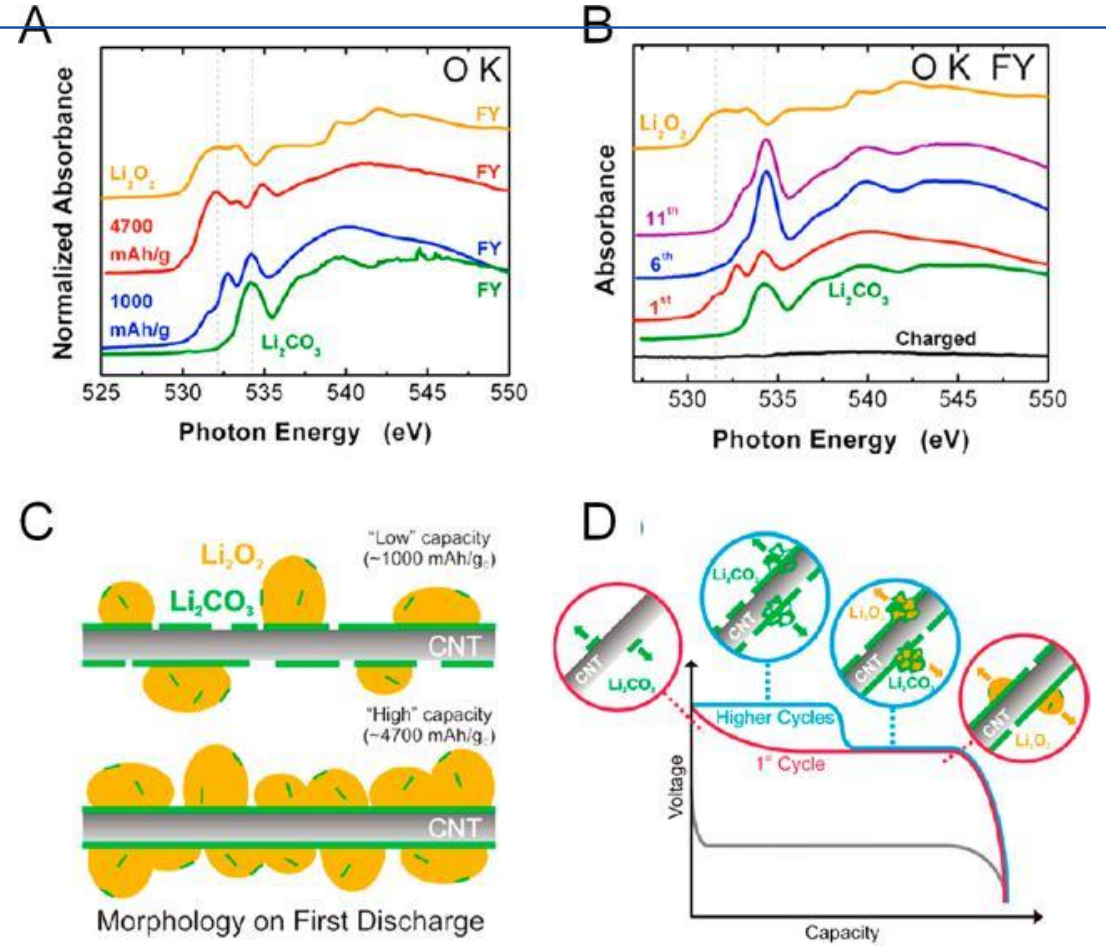

Figure 22. O K-edge FY spectra of $\mathrm{Li}^{-} \mathrm{O}_{2}$ electrodes (A) discharged to 1000 (at 250) and $4700 \mathrm{mAh} \mathrm{g-1}$ (at $100 \mathrm{~mA} \mathrm{~g}{ }^{-1} \mathrm{c}$ ) on the first discharge and (B) cycled electrodes ending on the first, sixth, or eleventh discharge. (C) Schematic of discharge products formed at low and high capacity on carbon on the first discharge and (D) during first and higher cycle numbers and the corresponding influence on the charging voltage. Reproduced with permission from ref 218. Copyright 2012 American Chemical Society.

as a volume fraction, which provides a more robust measure of improvement and paves the way for meaningful comparisons of cathode performance.

Stability is the Achilles' heel of carbon cathodes. Gallant et al. reported the formation of lithium carbonate at the interface between ${ }_{\mathrm{Li} 2 \mathrm{O} 2}$ and carbon. ${ }^{218}$ XANES spectra of discharged cathodes showed significant amounts of lithium carbonate after discharge to low capacities, which gives way to predominantly lithium peroxide as the discharge capacity increases (Figure 22). Moreover, the surface of carbon was found to be oxidized. They interpreted this as a reaction between the lithium peroxide in close proximity with the carbon followed by growth of higher purity lithium peroxide on the outer layer (Figure 22C). During subsequent cycling, they identified an accumulation of lithium carbonate, accompanied by a shift to higher charging voltages due to oxidation of lithium carbonate.
Thotiyl et al. demonstrated the evolution of ${ }^{13} \mathrm{CO}_{2}$ when charging a lithium $-\mathrm{O}_{2}$ battery containing a cathode containing ${ }^{13} \mathrm{C}$, conclusively demonstrating carbon decomposition in this battery (Figure 23). ${ }^{154}$ Analysis of the cathode at various states of discharge and charge showed that carbon decomposition predominantly occurred during charging and at high voltages. Oxidation of $\mathrm{Li}_{2} \mathrm{CO}_{3}$ and $\mathrm{CO}_{2}$ evolution was shown to occur below $4 \mathrm{~V}$ in accord with other studies. ${ }^{84,174}$ Analysis over successive cycles indicated that $\mathrm{Li}_{2} \mathrm{CO}_{3}$ from carbon decomposition accumulates in the cell. Comparison of hydrophobic and hydrophilic carbons showed that the latter offers higher stability due to the lack of reactive surface groups. ${ }^{154}$ The preferential reactivity of functional groups on carbons has been observed also by others and is also relevant during the discharge processes. 219,220

Summarizing the above results, it seemed that carbonaceous materials, despite all their promising attributes, suffered 


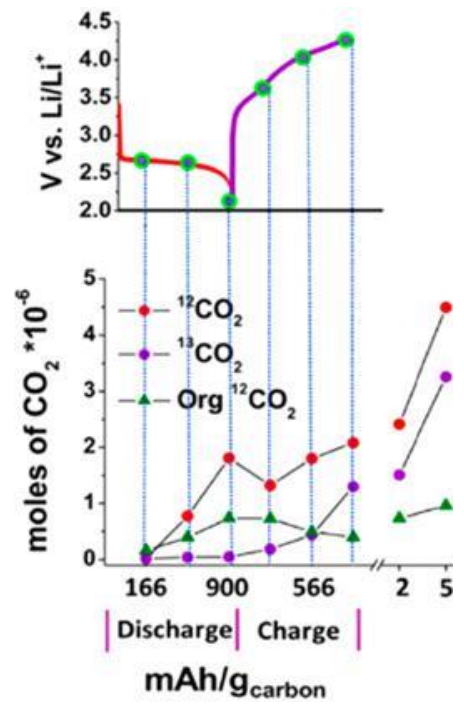

Figure 23. (upper) Discharge-charge curves on the first cycle for $\mathrm{Li}^{-}$ $\mathrm{O}_{2}$ cells containing a tetraglyme-based electrolyte and a ${ }^{13} \mathrm{C}$ cathode. (lower) Moles of $\mathrm{CO}_{2}$ evolved during chemical treatment of the removed cathodes due to decomposition of (red) the electrolyte, (purple) the cathode, and (green) electrolyte (organic fragments) during cycling to the point indicated by the markers on the plot. Reproduced with permission from ref 154. Copyright 2012 American Chemical Society.

instability in lithium-air batteries. This led to a search for alternative stable materials (reviewed below). However, when using redox mediators for the charging processes of $\mathrm{Li}-\mathrm{O}_{2}$ batteries, a significant decrease in degradation of the battery components is observed. ${ }^{221}$ Gao et al. demonstrated a dual mediator cell with both discharge and charge mediators, including cathodes containing ${ }^{13} \mathrm{C}$, and showed that the use of redox mediators increase the stability of the carbon cathodes. ${ }^{208}$ This is shown in Figure 24, where the $\mathrm{Li}_{2} \mathrm{CO}_{3}$ content of discharged cathodes was analyzed ex situ. $\mathrm{Li}_{2} \mathrm{CO}_{3}$ rapidly accumulates in standard cells, but cells using dual mediators showed markedly less decomposition and accumulation.

The authors assigned this improved stability to three factors: (1) when using soluble discharge redox mediators, the products

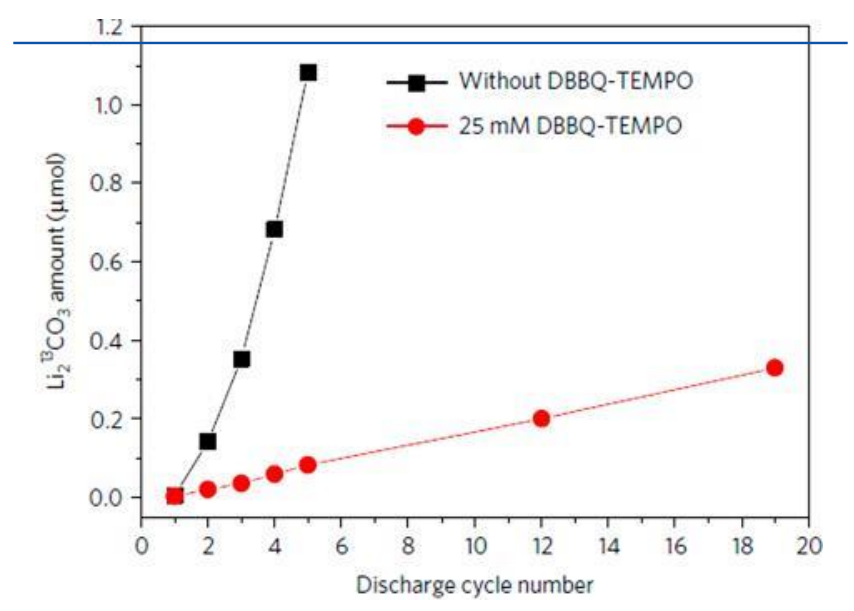

Figure 24. Amounts of $\mathrm{Li}_{213} \mathrm{CO}_{3}$ at the end of discharge of successive cycles of cells contain ${ }^{13} \mathrm{C}$ cathodes, with and without dual mediators. Reproduced with permission from ref 208. Copyright 2017 Springer Nature. forms in solution and lacks intermediate contact with the carbon thus lowering the propensity for decomposition; (2) the redox mediators force the cells to undergo charging at $3.6 \mathrm{~V}$, thus avoiding the highly positive potentials that drive carbon oxidation; (3) the redox mediators are less affected by surface area loss from passivation by $\mathrm{Li}_{2} \mathrm{CO}_{3}$ that would otherwise increase the OER overpotentials. These recent results using redox mediators rekindle the possibility of using carbon in the lithium-air cell.

3.4.3.2. Noncarbon Cathodes. Alternative stable cathode materials have been sought to replace carbon. As proof of concept, Peng et al. ${ }^{188}$ showed that a cell containing an Au cathode could deliver improved cycling efficiency. In the absence of carbon, the evolution of $\mathrm{CO}_{2}$ upon charge was much reduced, indicating less decomposition. A search for more practical alternatives identified metal carbides as promising cathode materials, in particular TiC. ${ }^{222}$ These studies showed that the surface of $\mathrm{TiC}$ forms an oxide layer, which is stable during cycling. This was supported by theoretical work showing that a $\mathrm{TiC}$ surface in contact with $\mathrm{Li2} 2$ would lead to termination with a stable oxide layer. ${ }^{223}$ Adams et al. showed that the thickness of these surface oxide layers is critically important. A complete oxide coverage can passivate the cathode and stop the charge reaction. ${ }^{224}$ However, $\mathrm{TiC}$ is one of the few metal carbides identified that is stable during cycling. ${ }^{225}$

The surface of metal carbides during cycling is predominantly oxide based, suggesting that conducting metal oxides may be considered as viable cathode materials. Kundu et al. reported the use of Magneli phase $\mathrm{Ti}_{4} \mathrm{O} 7$ as a cathode in the lithium- $-\mathrm{O}_{2}$ battery (Figure 25). ${ }^{226}$ The ${ }^{\mathrm{Ti}} 4 \mathrm{O} 7$ was synthesized with a particle size of 80-100 nm consisting of smaller 10-20 nm crystallites with 2-10 $\mathrm{nm}$ pores. The cycling performance and accompanying online electrochemical mass spectrometry on charge are shown in parts $\mathrm{E}$ and $\mathrm{F}$ of Figure 25. The overpotential during charge was below $3.5 \mathrm{~V}$ for the bulk of the charge process, and $\mathrm{CO}_{2}$ release is greatly reduced. The $\mathrm{e}^{-} / \mathrm{O}_{2}$ ratio was shown to be 2.6, which is an improvement compared to what is measured with Vulcan carbon cathodes (indicating much less side reactions). A number of other metal oxides have been used in the $\mathrm{Li}-\mathrm{O}_{2}$ cells, such as $\mathrm{MnO}_{2},{ }^{227} \mathrm{Co}_{3} \mathrm{O}_{4}, 228 \mathrm{Mn} 3 \mathrm{O}_{4}, 229$ and $\mathrm{Al}_{2} \mathrm{O}_{3} .230$ However, without careful analysis, similar to those described above, it is difficult to judge the efficacy of these materials. Other materials considered include precious metal catalysts and metal sulfide materials, but in this review, we consider these in the context of heterogeneous catalysis.

3.4.3.3. On the Stability of Polymeric Binders in the Cathodes. The stability of polymers as binders in the cathodes was evaluated by Amanchukwu et al. ${ }^{231}$ by checking their reactivity with $\mathrm{Li}_{2} \mathrm{O}_{2}$. The polymeric binders PAN, PVC, PVdF, PVdF-HFP, and PVP were found to be unstable to $\mathrm{Li}_{2} \mathrm{O}_{2}$, in agreement with previous studies revealing the instability of $\mathrm{PVdF}{ }^{232}$ In contrast, PMMA, PTFE, and Nafion polymers were found to be chemically stable under these conditions. PEO is generally stable; however, some cross-linking can occur. The instability of polymeric binders like PVdF may complicate the analysis of composite cathodes. For instance, the side products formed by the decomposition of PVDF show Raman spectroscopic absorptions which resemble those of $\mathrm{LiO}_{2}$ moieties; this in turn, can lead to a severe misunderstanding of the results. ${ }^{233}$ Hence, it is important to note that the use of unstable materials may cause errors in the interpretation of the cathodes' reaction mechanisms. This is on top of the poor 

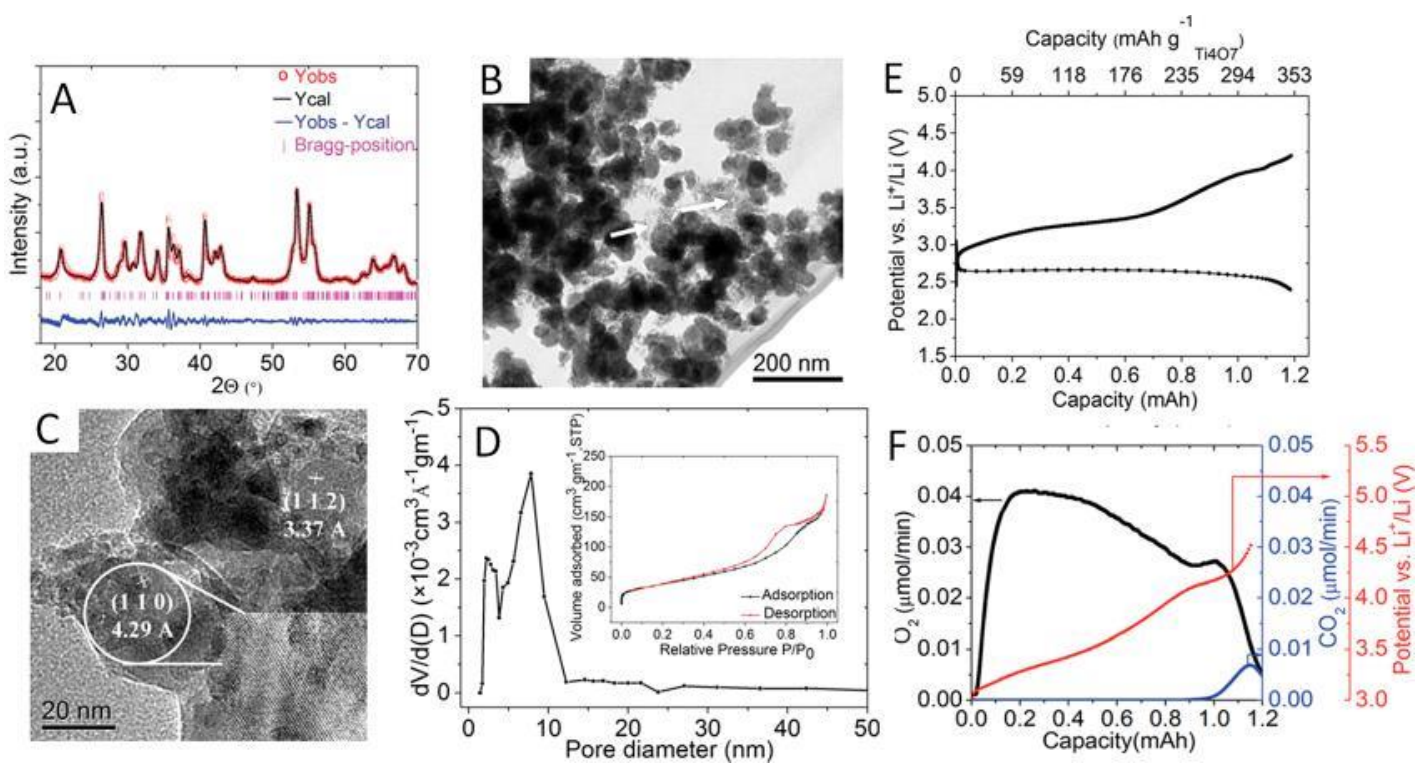

Figure 25. Characterization of a Magneli phase $\mathrm{Ti}_{407}$ cathode material including (A) XRD pattern, (B,C) TEM images, and (D) pore size analysis and the (E) cycling profiles for $\mathrm{Li}-\mathrm{O}_{2}$ cells containing magneli phase ${ }_{\mathrm{Ti}} \mathrm{O}_{7}$ cathode and $(\mathrm{F})$ gas analysis during cycling of the cell during charge. Reproduced with permission from ref 226. Copyright 2015 Royal Society of Chemistry.

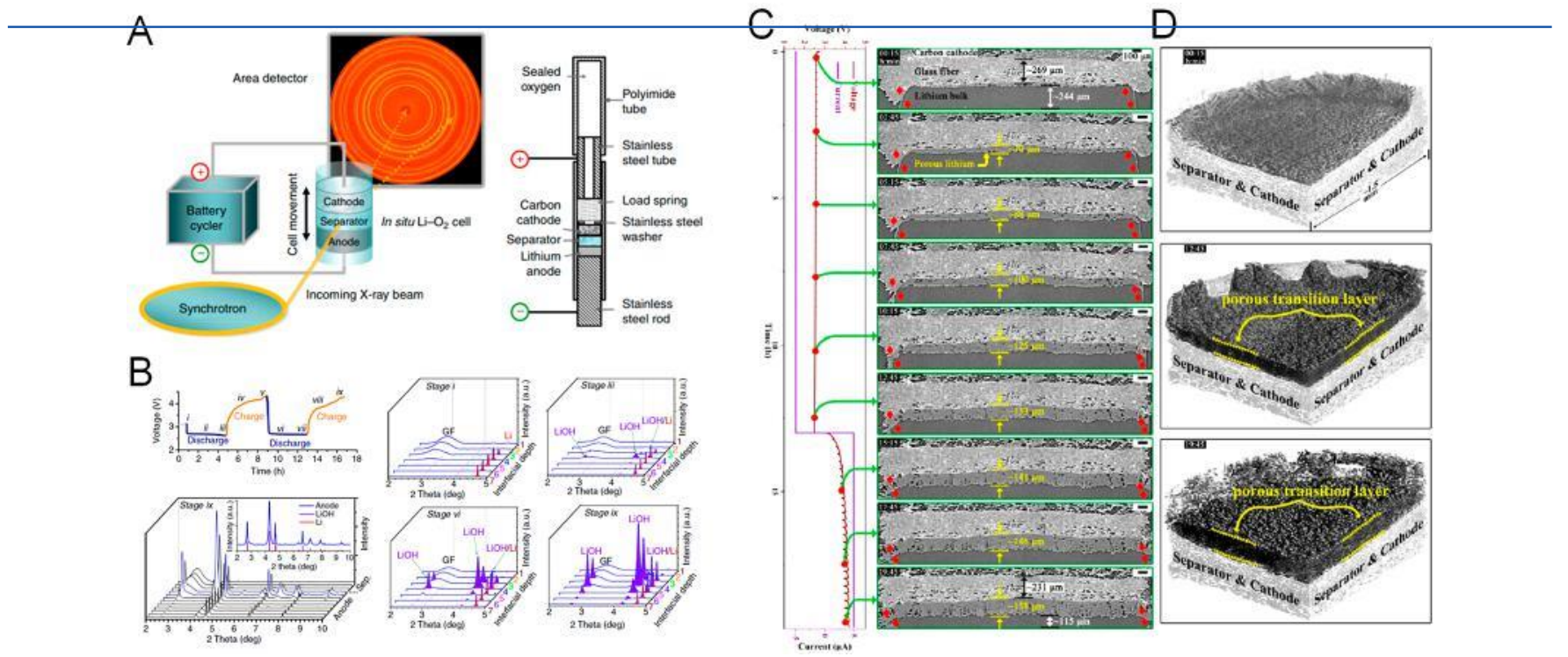

Figure 26. Observation of $\mathrm{Li}$ metal degradation in $\mathrm{Li}-\mathrm{O}_{2}$ batteries. (A) The experimental setup for operando XRD and schematic design of the cell. (B) The change of lithium anode during discharge-charge cycling in $\mathrm{Li}-\mathrm{O}_{2}$ batteries. XRD patterns exhibit LiOH formation during cycling tests. (C) Electrochemical and morphological results of cell during discharge and recharge process in situ measured at energy dispersive diffraction (EDDI) beamline. (D) Selected 3D demonstrations of the reconstructed data sets shown in C with time stamps (top) 00:15, (middle) 12:45, and (bottom) 19:45. (A,B) Reproduced with permission from ref 234. Copyright 2013 Springer. (C) Reproduced with permission from ref 235. Copyright 2019 American Chemical Society.

stability that could obviously lead to poor electrochemical performance.

3.4.4. Negative Electrodes. As mentioned above, the $\mathrm{Li}-$ $\mathrm{O}_{2}$ battery has generated much interest because of its 4-5-fold higher theoretical specific energy compared to conventional LIBs. This high energy density depends primarily on the use of metallic lithium as the anode, which has a very high theoretical specific capacity $\left(\sim 3860 \mathrm{mAh} \mathrm{g}^{-1}\right)$ and the most negative reduction potential $(-3.040 \mathrm{~V}$ versus the standard hydrogen electrode). To date, numerous efforts have been invested in introducing lithium as a practical anode in order to meet the progressing demand of advanced, lightweight, high-energy batteries, but unfortunately, all the impressive traits of this metallic anode come at the cost of three important factors, namely reactivity, efficiency, and safety, which impede its successful application in rechargeable energy storage devices.

The high Fermi energy level and negative reduction potential of lithium, on the one hand, offers the benefits of high operational voltage. However, these factors also make the lithium electrode extremely chemically reactive toward almost all liquid electrolyte solutions. Undesirable parasitic reactions occur as soon as the electrolyte solution is exposed to a lithium surface. These spontaneous reactions result in the formation of a fragile solid electrolyte interphase (SEI) that temporarily 

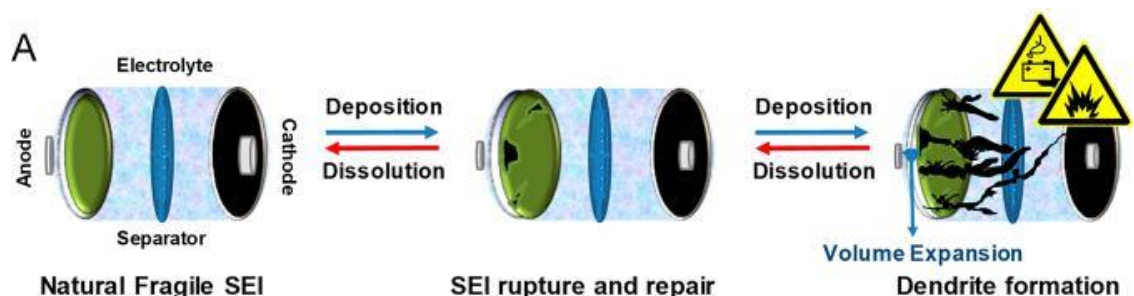

Natural Fragile SEI

SEI rupture and repair

Dendrite formation
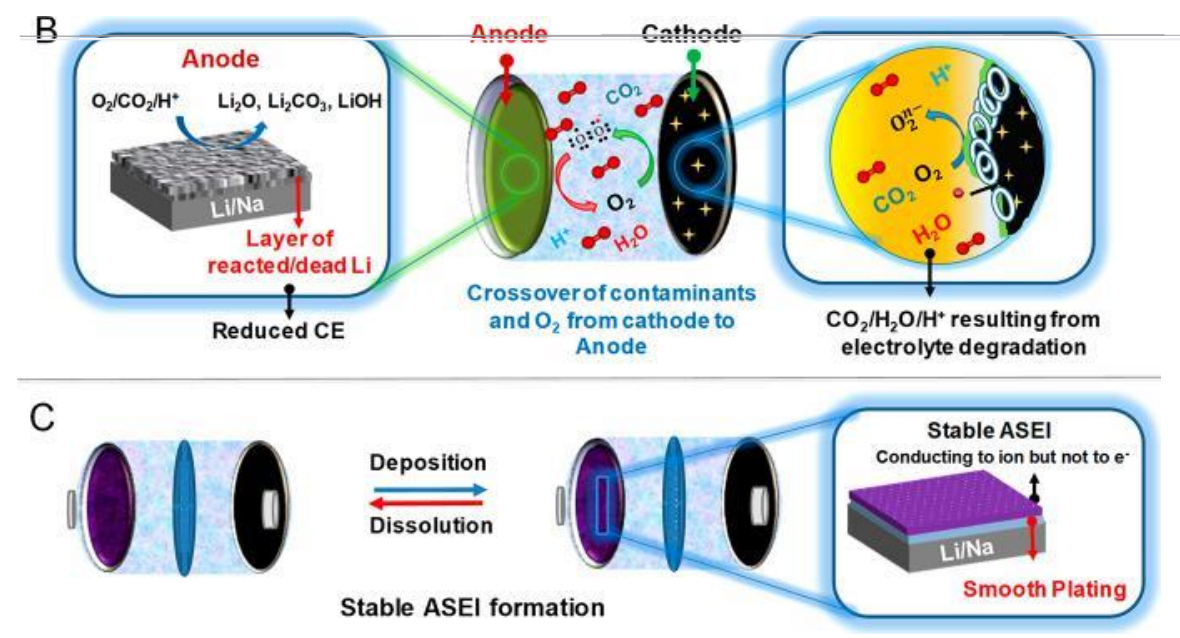

Figure 27. Graphic representation of the mechanistic issues associated with the use of metallic anodes. The figure illustrates: (A) dendrite formation and concomitant safety issues originating from the rupture and repair of the fragile solid electrolyte interface (SEI), (B) effect of $\mathrm{O}_{2}$ crossover on the columbic efficiency (CE), and (C) the benefits of an artificial SEI (ASEI) in stabilizing the metal anode.

passivates the lithium from further reaction. The oxygen environment of the $\mathrm{Li}-\mathrm{O}_{2}$ system complicates matters further, as the presence of reactive oxygen species (ROS) promote parallel degradation pathways proceeding toward the accumulation of insulating byproducts (Li2O/Li2O2, $\mathrm{Li}_{2} \mathrm{CO}_{3}$, and various types of insoluble ionic Li compounds) on the anode surface. Additionally, during cycling, the crossover of $\mathrm{CO}_{2}$, trace levels of $\mathrm{H}_{2} \mathrm{O}$ (arising from electrolyte decomposition), and redox mediators (used for catalyzing OER/ORR), from the cathode to the negative electrode, have a detrimental effect on the performance of Li metal electrode by direct reactions. These species also affect the composition and morphology of the SEI at the lithium/electrolyte solution interface. Recently, the effect of $\mathrm{O}_{2}$ crossover on SEI formation has been investigated in ether-based solvents. ${ }^{64}$ With the help of in situ XRD and computational studies, Assary et al. ${ }^{64}$ have revealed the formation of $\mathrm{LiOH}$, aldehydes, and carbonates at the anode. These impede the migration of lithium ions, leading to increased charge transfer resistance and failure of the electrode (Figure 26).

In general, the formation of the SEI and other side reactions between lithium metal and crossover contaminants, irreversibly consumes lithium and the electrolyte solution, which results in limited Coulombic efficiency (CE). If the formed SEI is selflimiting and stable throughout the cycle life, the CE of the Lianode will be greatly improved after the first cycle, but, unfortunately, with repeated stripping/plating, the morphology of the lithium surface changes and the natural SEI undergoes repeated rupture and repair cycles. This leads to both undesirable electrolyte solution consumption and inhomoge-neous and uncontrolled deposition of $\mathrm{Li}$ as sharp needles or in branchlike patterns commonly known as dendrites. These severely reduce the $\mathrm{CE}$ as illustrated in Figure 27. These dendrites act as hotspots and in further cycles become the preferred site for Li-ion deposition because of fast reaction kinetics and shorter diffusion lengths. This results in their continuous growth, which not only leads to large volumetric and morphological changes but also creates a safety issue by short circuiting the cell. This poses a threat of thermal runaway and explosion. To deal with the low $\mathrm{CE}$ of the lithium anode and dendritic growth at high current densities, researchers typically carry out experiments using a large mass of lithium. Consequently, technical breakthroughs focusing on the use of a massive excess of lithium or its complete replacement by a stable substitute ignore the consequences of the proposed protocols in a full practical $\mathrm{Li}-\mathrm{O}_{2}$ cells and are of less practical merit. It is important to emphasize that to attain practical goals, a protected $\mathrm{Li}$ anode is needed for $\mathrm{Li}-\mathrm{O}_{2}$ and many other $\mathrm{Li}$ metal batteries.

Nevertheless, despite the formidable challenges associated with metallic lithium, the recent development of the $\mathrm{Li}-\mathrm{O}_{2} /$ air battery has undoubtedly hastened the possible discovery of practical solutions to surmount these challenges. Specifically, in the field of $\mathrm{Li}-\mathrm{O}_{2} /$ air batteries, where metallic lithium is an indispensable component, researchers have utilized three approaches to mitigate the various issues: (1) Stabilizing the SEI, either by designing the anode/electrolyte interface (artificial SEI) and/or by optimizing the salt-solvent coordination. The latter can be accomplished by using super concentrated electrolyte solutions with fewer free solvent molecules, and an ionic liquid-like bulk nature; (2) developing selective membranes to restrict the crossover of $\mathrm{O}_{2}, \mathrm{CO}_{2}$, redox mediators, and other contaminants; (3) engineering the metallic $\mathrm{Li}$ anode structure to overcome morphology and volume changes.

The first approach relies predominantly on controlling the composition of the SEI which can, in turn, stabilize the lithium 

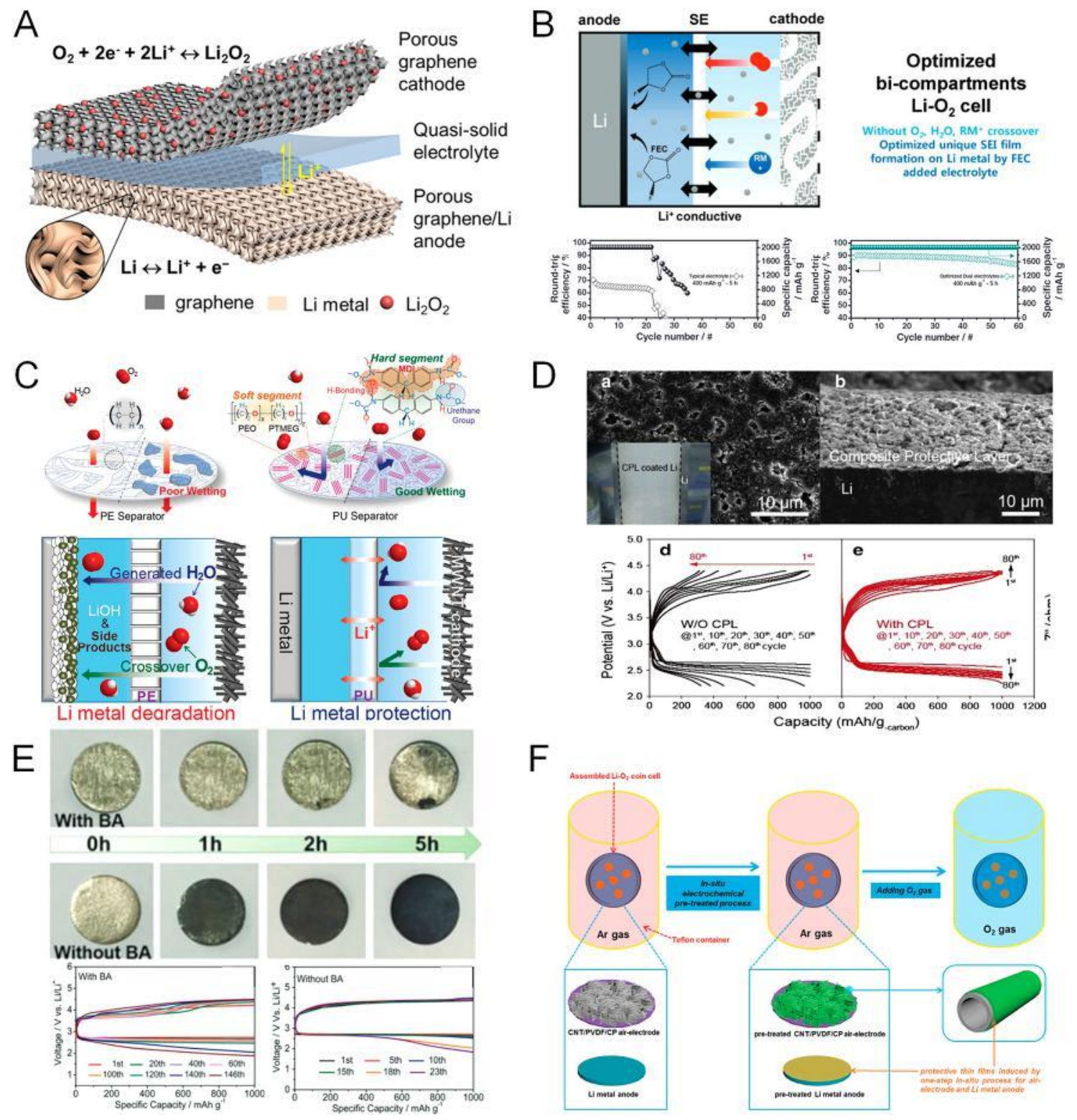

$\mathrm{F}$

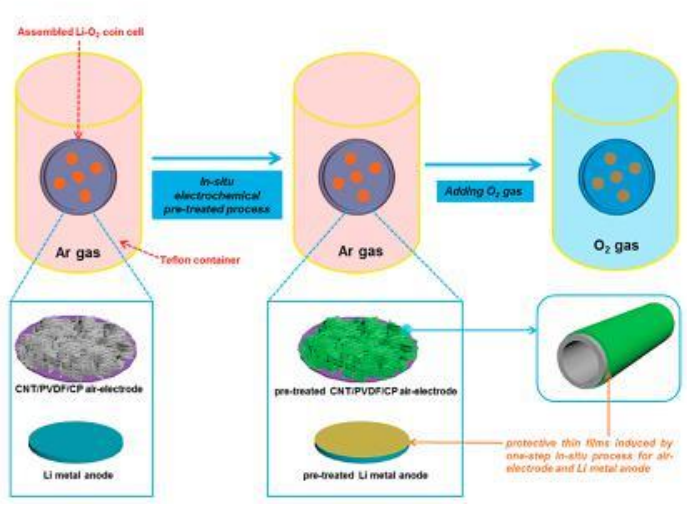

Figure 28. Representative methods for protecting $\mathrm{Li}$ metal in $\mathrm{Li}-\mathrm{O}_{2}$ batteries. (A) Gel or solid electrolyte. Reproduced with permission from ref 256. Copyright 2018 Springer. (B) Separation of electrolytes by lithium conductive membrane. Reproduced with permission from ref 252 . Copyright 2017 John Wiley \& Sons. (C) Separator. Reproduced with permission from ref 253. Copyright 2016 John Wiley \& Sons. (D) Coating composite materials on Li metal. Reproduced with permission from ref 257. Copyright 2014 Elsevier. (E) Pre-electrochemical treat. Reproduced with permission from ref 258. Copyright 2018 John Wiley \& Sons. (F) Additive for protection of Li. Reproduced with permission from ref 244. Copyright 2018 John Wiley \& Sons.

metal by suppressing the parasitic side reactions and by controlling the metal ion flux. 236-241 Many kinds-of approaches have been studied for direct coating of $\mathrm{Li}$ metal anodes by artificial protective layers to avoid contact of $\mathrm{Li}$ metal with reactive electrolyte solutions. Among these, liquid or gas treatments have been reported. ${ }^{242-244}$ In addition, the use of electrolyte solution additives or cosolvents like FEC were adapted for elaborating a stable artificial SEI on $\mathrm{Li}$ metal electrodes. ${ }^{245}$

It is now well-known that a smartly designed interface can ensure uniform metal deposition and high Coulombic efficiency by reducing rupture/repair of reinforced interfaces. Recently, Kozen et al. ${ }^{246}$ experimentally demonstrated the success of this approach by designing a hybrid organic/inorganic artificial SEI on a lithium surface, which exhibited stable cycling over 110 cycles at a current density as high as $2 \mathrm{~mA} \mathrm{~cm}{ }^{-2}$. Additionally, by optimizing the electrolyte composition, the solubility and diffusion of ions, gases, and other contaminants can be controlled. This is accomplished by exploiting the different solubility of reaction intermediates/discharge products in the different solvents or salts depending on their Guttman number and ionic strength. This can be clearly inferred from the stabilizing ability of super concentrated electrolyte solutions based on LiTFSI-DMSO (1:3 molar ratio), ${ }^{192} 3 \mathrm{M}$ LiTFSI- DME, ${ }^{146}$ and $4 \mathrm{M} \mathrm{LiNO}_{3}-\mathrm{DMSO}^{247}$ With the above compositions, it has been demonstrated that $\mathrm{Li}-\mathrm{O}_{2}$ batteries with super concentrated solutions exhibit significantly enhanced cycle life with a $\mathrm{CE}>90$. Enhanced reversibility of $\mathrm{Li}-\mathrm{O}_{2}$ batteries containing an advanced $\mathrm{Li}$ salt, LiTNFSI, for formation of a stable SEI layer, was also reported by Tong et al. ${ }^{248}$ The use 
A
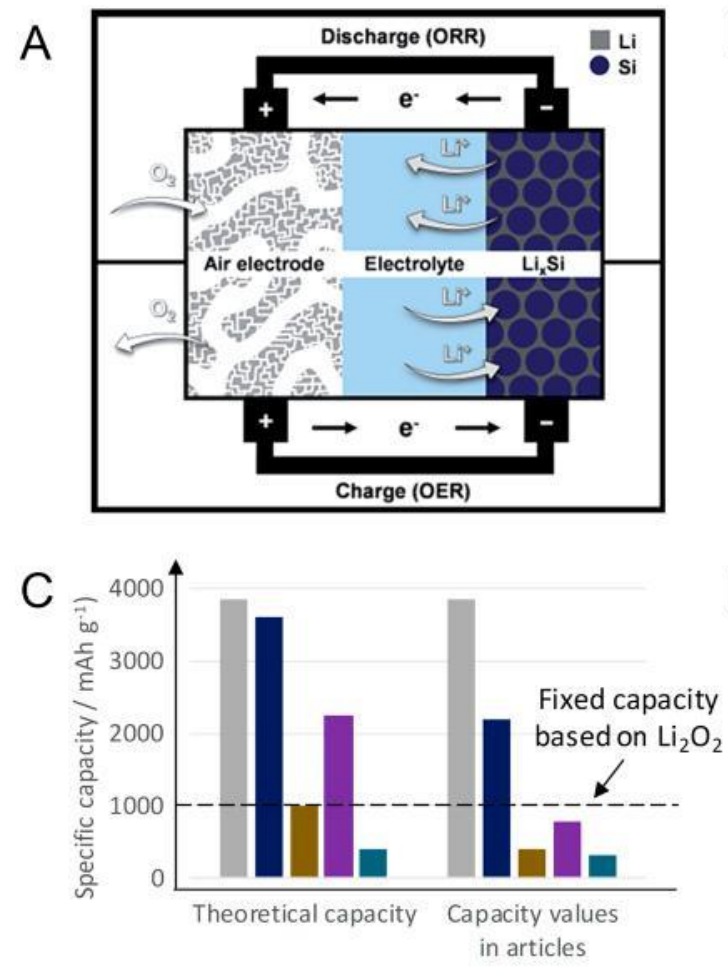

Li $\mathbf{S i}=\mathrm{Sn}=\mathrm{Al}=\mathrm{Hard}$ carbon
B
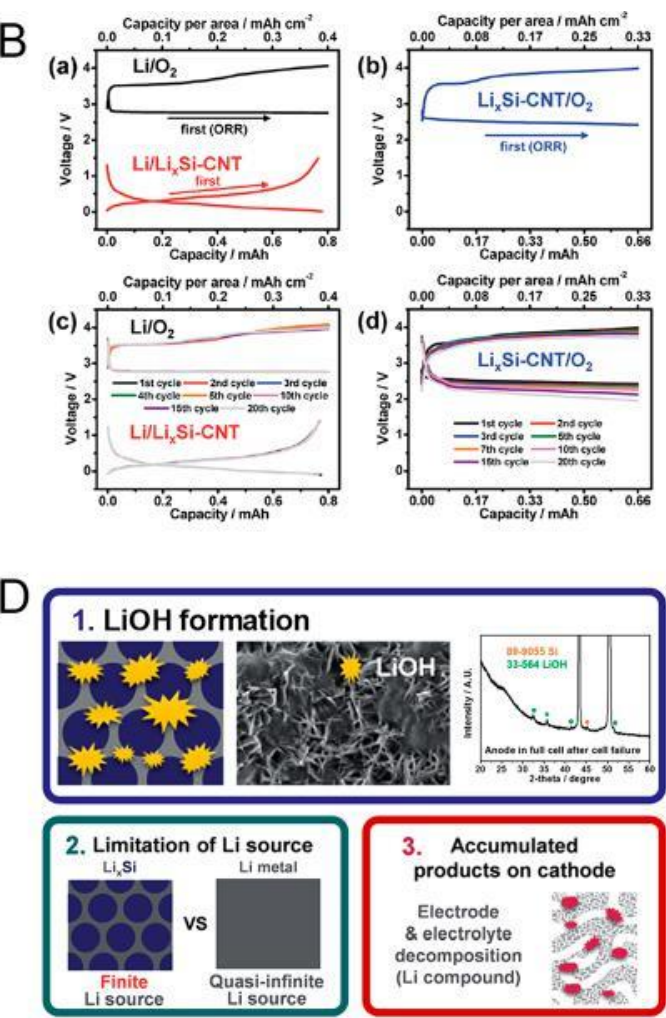

Figure 29. Alternative electrodes for $\mathrm{Li}$ metal in $\mathrm{Li}-\mathrm{O}_{2}$ batteries: (A) Schematic images for the discussion of the $\mathrm{Li}-\mathrm{O}_{2}$ full-cell with lithiated silicon as the negative electrode. (B) Galvanostatic cycling test results of half-cells and full-cells. (C) Theoretical and practical capacities of Li and alternative electrodes. Capacity for formation and decomposition $\mathrm{Li}_{22} 2$ is fixed as $1168 \mathrm{mAh} \mathrm{g}{ }^{-1}$ based on the reaction $\left(2 \mathrm{Li}^{+}+\mathrm{O}_{2}+2 \mathrm{e}^{-} \leftrightarrow \mathrm{Li}_{2} \mathrm{O}_{2}\right)$. The values in the chart come from refs 254,260-263. (D) Major issues for the $\mathrm{Li}-\mathrm{O}_{2}$ full-cell related to Li loss. (A,C,D) Reproduced with permission from ref 259. Copyright 2016 Royal Society of Chemistry.

of gel or solid electrolytes instead of standard liquid solutions are also known to help in eliminating side reactions and suppressing dendrites formation (Figure 28). However, solid electrolytes are associated with low migration kinetics of the Li ions.

Another way to prolong the cycle life of the negative electrode is to utilize membranes with selective permeability or functionalized separators. ${ }^{59,249-251}$ These can create barriers to the crossover of contaminants that accelerate the deterioration responsible for lithium instability. By restricting the gases and radical species reaching the lithium surface, such membranes can attenuate the multiple degradation pathways and accumulation of side products on the metal interface. This approach is particularly important for the Li-air system, where the cathode's active mass forms highly reactive moieties on reduction. In these systems, it is important to protect the $\mathrm{Li}$ anode from all other active atmospheric contaminants like $\mathrm{N}_{2}, \mathrm{CO}_{2}$, and moisture that can instantly corrode the negative electrode and shorten the battery life. The use of bicompartment cells in which the $\mathrm{Li}$ anodes and the carbon cathodes can operate in the most appropriate liquid electrolyte solutions (relevant for them) separated by a membrane (ceramic or polymeric), which can transport only $\mathrm{Li}$ ions from side to side were proposed in order to limit the cross-talk. The bicompartment configuration (Figure 28B) fully prevents detrimental crossover of reactive products between the reactive electrodes. While such a configuration may not be practical due to the relatively low specific energy of these cells, nevertheless, it is excellent for systematic studies of the behavior of components in $\mathrm{Li}-\mathrm{O}_{2}$ cells without interference of side reactions. For instance, with such cells it was possible to study separately the effectiveness of redox mediators at the cathode side and effective ways to stabilize the $\mathrm{Li}$ metal anode. ${ }^{252}$ Alternatively, functional polymer membranes that fully block detrimental crossover between the electrodes can be used in similar bicompartment $\mathrm{Li}-\mathrm{O}_{2}$ cells. Kim et al. reported on the use of a polyurethane-based modified separator for stable and reversible $\mathrm{Li}-\mathrm{O}_{2}$ batteries. ${ }^{253}$ From the viewpoint of the cell's energy density, using modified separators in $\mathrm{Li}-\mathrm{O}_{2}$ cells is more advantageous than using bicompartment cells separated by ceramic membranes.

In addition to the above-described problems and solutions (related to the reactivity of Li metal anodes), there is a great need to accommodate the massive volume expansion observed on stripping/plating of lithium. In the past few years, material scientists have explored the problem of volume expansion and dendritic growth via 3D architecture hosts (such as reduced graphene oxide and silicon nanostructures) to accommodate $\mathrm{Li}$ deposition. ${ }^{240,251,254,255}$ Because of the availability of free spaces and voids, such structures can control volume expansion and suppress dendritic growth, with an additional advantage of restricted contact between $\mathrm{Li}$ and the electrolyte, leading to fewer side reactions and high cycling efficiency. However, these 3D architectures help in accomplishing safe operation of LOB's at the expense of decreasing energy density.

The growing attention and the increasing number of papers focusing on the lithium electrode gives a good measure of the importance of the metallic negative electrode in LOBs. Despite some progress, the achieved cyclability and CE is still far away from the set milestones. A better understanding of the surface phenomena on Li metal anodes (surface reactions, the structure of the surface films) seems to be critical for enabling high 
A

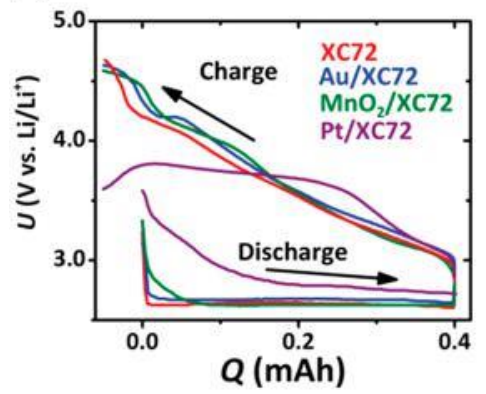

B

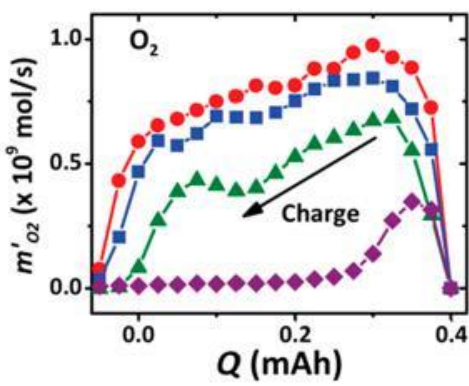

C

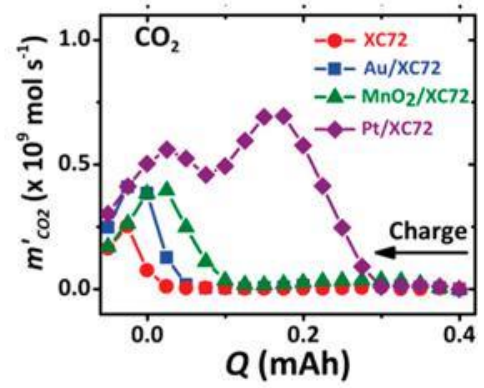

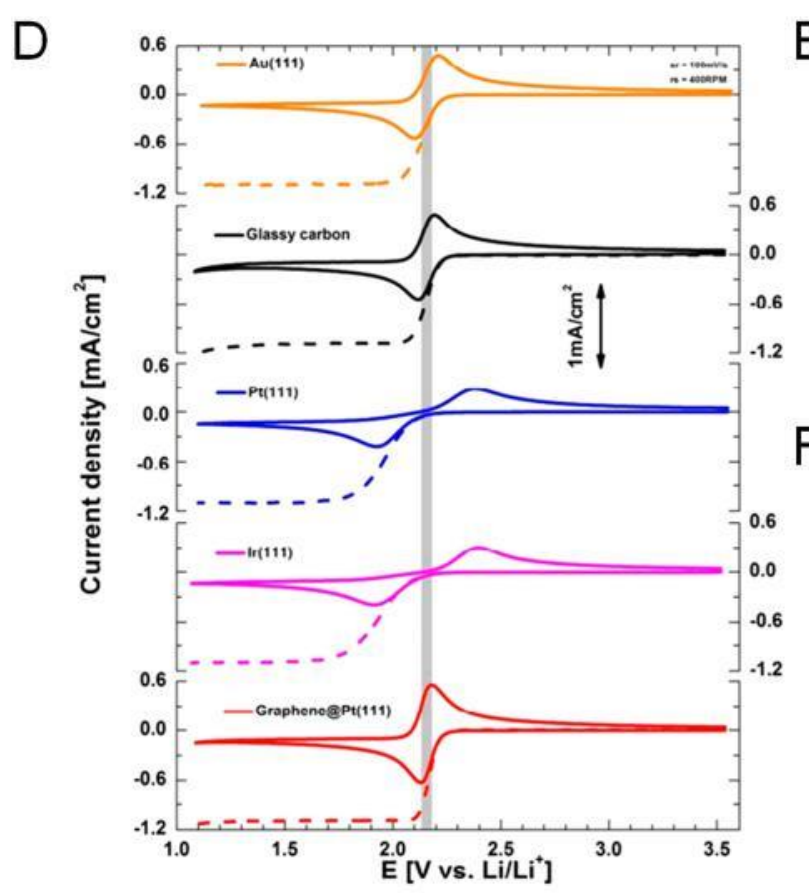

E Irreversible Reversible
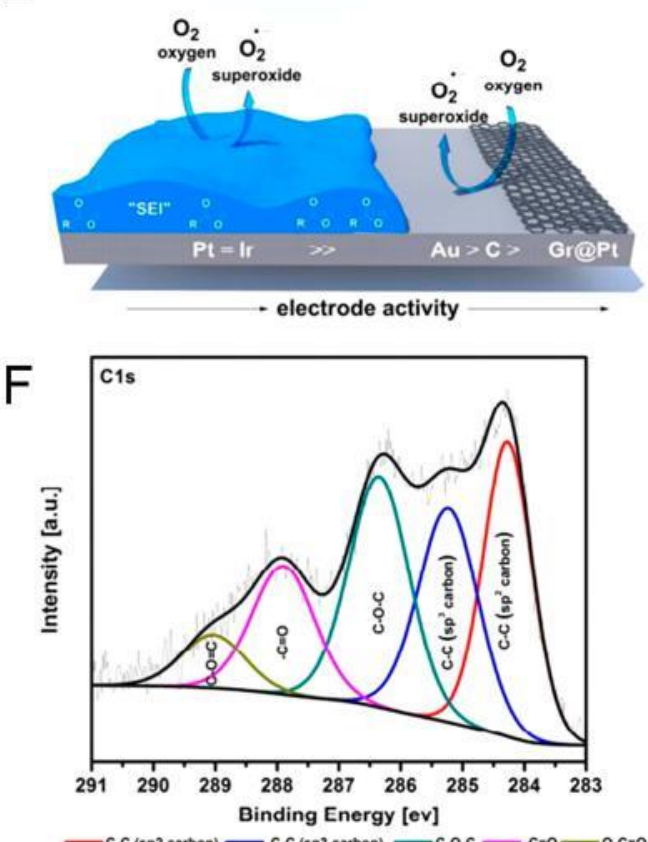

Figure 30. (A) Cycling profile of $\mathrm{Li}-\mathrm{O}_{2}$ cells containing DME and various cathode catalysts and the corresponding (B) $\mathrm{O}_{2}$ and $(\mathrm{C}) \mathrm{CO}_{2}$ evolution during charging. Reproduced with permission from ref 85. Copyright 2011 American Chemical Society. (D) Cyclic voltammetry (sweep rate; 100 $\mathrm{mV} \mathrm{s}^{-1}$ ) and polarization curves by rotating disk electrode voltammetry (rotation rate; $400 \mathrm{rpm}$ ) of $\mathrm{O}_{2}$ electrochemistry in dry $0.15 \mathrm{M}$ TBAPF6/DME saturated with $10 \% \mathrm{O}_{2}$ in Ar at various single crystal metal electrodes and carbons. (E) Schematics of solid electrolyte interface (SEI) formation with corresponding electrode activity increase. (F) X-ray photoelectron C 1s spectra of the SEI formed during $\mathrm{O}_{2}$ electrochemistry in DME on Pt(111). Reproduced with permission from ref 143. Copyright 2016 American Chemical Society.

efficiency deposition of metallic $\mathrm{Li}$ in the corrosive environment developed in $\mathrm{Li}-\mathrm{O}_{2}$ cells.

While Li anodes are the first choice, nevertheless, several studies have focused on alternative anodes including lithiated $\mathrm{Si}, \mathrm{Sn}, \mathrm{Al}$, and carbons. Lithiated $\mathrm{Si}$ anodes were predominantly used to satisfy the required anode capacity. These alternative anodes are electrochemically or chemically lithiated before they are used in the $\mathrm{Li}-\mathrm{O}_{2}$ cells (Figure 29A). It was generally realized that $\mathrm{Li}-\mathrm{O}_{2}$ cells using alternative anodes behave less reversibly than typical $\mathrm{Li}-\mathrm{O}_{2}$ cells containing $\mathrm{Li}$ metal anodes (Figure 29B). This is because these lithiated alternative anodes contain a much lower amount of $\mathrm{Li}$ (Figure 29C), which quickly deteriorates and becomes inactive due to side reactions not only at the anode side but also at the cathode side (Figure 29D) ${ }^{259}$ Hence, the use of alternative lithiated anodes (like $\mathrm{Li}-\mathrm{Si}$ ) may also require their surface protection.

From an experimental/didactic perspective, alternative anodes can be useful in experiments, concentrating on the evaluation of the reversibility of cathodes. ${ }^{264}$ However, for practical purposes, the use of protected Li-metal as the anode is inevitable. To replace Li-metal anodes by safer, alternative materials such as $\mathrm{Li}-\mathrm{Si}$ alloys (which specific content of active $\mathrm{Li}$ is lower), several requirements should be addressed. Such electrodes should be protected from side reactions and fully reversible cathodes should be used in order to maintain the limited $\mathrm{Li}$ source in full capacity during prolonged cycling. Also, it is important to develop effective prelithiation processes.

\subsection{Catalysis}

3.5.1. Heterogeneous Catalysis for the ORR and OER. Heterogeneous catalysis (or electrocatalysis) is a contentious topic in the lithium-air battery field. First, there is a reasonable argument that any solid catalyst should be of a limited use because it should be quickly passivated by insulating lithium peroxide or only catalyze oxidation of lithium peroxide in direct contact. The use of redox mediators designed to avoid contact between the cathode surface and the bulk of the lithium peroxide only exacerbates this problem. Second, there is a strong evidence that the introduction of a heterogeneous catalyst induces 


\section{A}

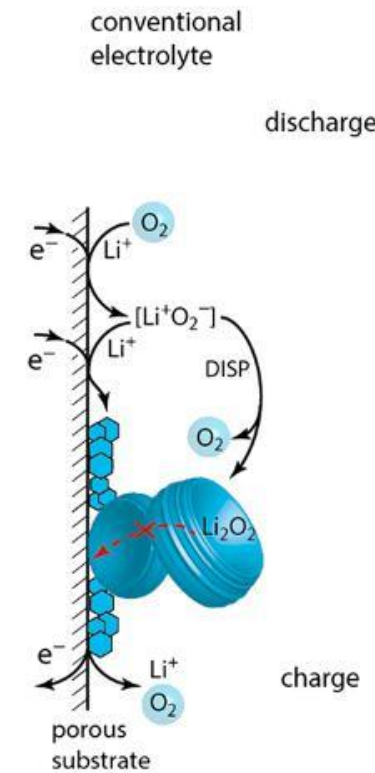

B

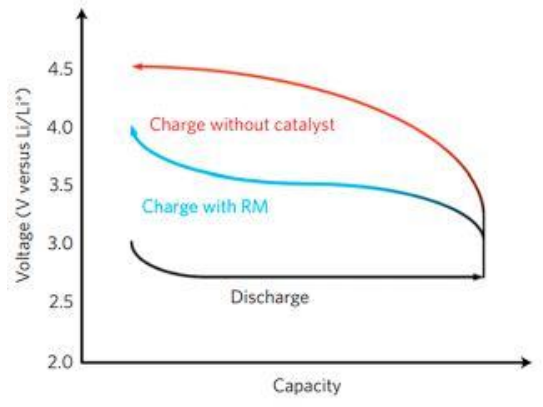

mediated electron / hole conduction
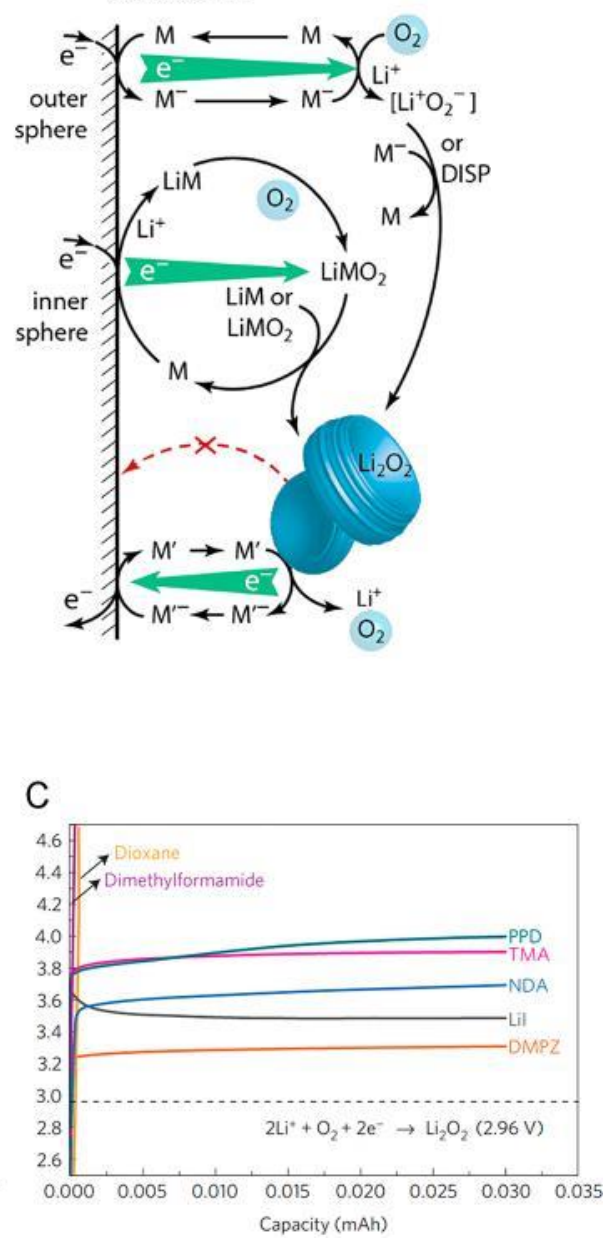

Figure 31. Redox mediators as soluble electron transfer agents. (A) Schematic of the reactions in a conventional $\mathrm{Li}-\mathrm{O}_{2}$ cathode. The insoluble and insulating discharge product Li2O2 passivates the surface of the conducting porous substrate. Charging is hampered by poor electron transport (left). Mediated electron/hole transport by mediators $\mathrm{M}$ and $\mathrm{M}^{\prime}$. The reduction mediator $\mathrm{M}$ may transfer electrons to $\mathrm{O}_{2}$ either in an outer sphere process or via an $\mathrm{O}_{2}$-binding transition state in an inner sphere process (right). (B) Schematic discharge (black line) and charge profiles of $\mathrm{Li}^{-} \mathrm{O}_{2}$ batteries with (blue line) and without RM (red line). (C) Charge curves with some examples of RMs. Molecular orbital energies of redox mediators and TEGDME. Highest occupied molecular orbital (HOMO) and lowest unoccupied molecular orbital (LUMO) energies of original RMs (black bar) and first oxidized RMs (red bar) in TEGDME electrolyte based on DFT calculations. (A) Reproduced with permission from ref 135 . Copyright 2016 Royal Society of Chemistry. (B,C) Reproduced with permission from ref 278. Copyright 2016 Springer.

decomposition. For example, during the early development of the $\mathrm{Li}-\mathrm{O}_{2}$ battery, $\mathrm{MnO}_{2}$ catalysts were thought to offer improved performance ${ }^{227}$ but have since been shown to induce significant decomposition of the electrolyte. ${ }^{85}$ It should be noted that these earlier studies generally used carbonate-based electrolytes, which are now known to be unstable. McCloskey et al. studied the impact of a series of heterogeneous catalysts including $\mathrm{Pt}, \mathrm{MnO}_{2}$, and $\mathrm{Au}$ and showed, through analysis of gas evolution, that both $\mathrm{Pt}$ and $\mathrm{MnO}_{2}$ induced considerable decomposition and an increase in $\mathrm{CO}_{2}$ evolution (Figure 30A-C). ${ }^{85}$ Neither $\mathrm{Au}$ nor $\mathrm{MnO}_{2}$ appeared to demonstrate any catalytic activity, although we highlight that the primary purpose of Au cathodes is stability. Studies by Ma et al. have similarly demonstrated that both $\mathrm{Pd}$ - and $\mathrm{Ru}$-based catalysts increase the degree of irreversibility in $\mathrm{Li}-\mathrm{O}_{2}$ cells. ${ }^{265}$ Genorio et al. studied oxygen reduction in dimethoxyethane at well-defined single crystal electrodes (Figure 30$).{ }^{143}$ A decrease in the electrochemical reversibility of the redox couple is observed in the order $\mathrm{Au}>\mathrm{Pt}>\mathrm{Ir}$, and chemical analysis of the electrode surface showed formation of a solid electrolyte interphase in the case of
Pt and Ir. This is shown schematically in Figure 30E. These data suggest that the only transition metal suitable for use in lithiumair cathodes is $\mathrm{Au}$ and makes any use of a metal catalyst questionable.

3.5.2. Homogenous Catalysis with Redox Mediators. Because of the problems associated with the use of heterogeneous catalysts, mobile homogeneous catalysts, dubbed "Redox Mediators" (RM), were developed for rechargeable aprotic $\mathrm{Li}-\mathrm{O}_{2}$ batteries. RMs act as mobile charge carriers in the electrolyte solution, which facilitate electron transfer between the electrode surface and $\mathrm{O}_{2}$ on discharge and ${ }_{\mathrm{Li} 2 \mathrm{O} 2}$ on charge (Figure 31A) . During charging, the $\mathrm{RM}$ is oxidized to $\mathrm{RM}^{+}$at the electrode surface and is then able to diffuse in the electrolyte, where it oxidizes the solid $\mathrm{Li}_{2} \mathrm{O}_{2}$, resulting in oxygen evolution and regeneration of the $\mathrm{RM}$. This greatly lowers the charging potential during the cycling (Figure 31B,C). The decreased charging potential not only increases the energy efficiency but also promotes cell durability. ${ }^{208}$

The first generation of mediators were reported by Giordani et al. ${ }^{266}$ and Chen et al., who demonstrated the concept with LiI 
and tetrathiafulvalene (TTF), respectively. ${ }^{267} \mathrm{Li}-\mathrm{O}_{2}$ cells using TTF in the electrolyte solution exhibited suppressed charge potential, improved rate capability, and cycling stability. Since these earlier studies, several other charge mediators have been proposed. ${ }^{268,269}$ Bergner et al. demonstrated the use of 2,2,6,6tetramethylpiperidinyloxyl (TEMPO) ${ }^{270}$ and achieved enhanced cycle life compared to LiI or TTF. This work was extended to include other structurally similar mediators based on the nitroxyl group. $^{271}$ 10-Methylphenothiazine (MPT), ${ }^{272}$ tris [4(diethylamino)phenyl] amine (TDPA), ${ }^{273}$ 2-phenyl-4,4,5,5tetramethylimidazoline-1-oxyl-3-oxide (PTIO), ${ }^{274}$ transition metal complexes (metal porphyrins and metal phthalocyanines), ${ }^{275-277}$ and various other organic materials have also been proposed as potential redox mediators for oxidation of $\mathrm{Li}_{2} \mathrm{O}_{2}$. While LiI has largely been abandoned as a mediator for $\mathrm{Li}_{2} \mathrm{O}_{2}$ oxidation, it has found use in lithium-oxygen cells where $\mathrm{LiOH}$ is the discharge product. ${ }^{100}$

OER RMs were mostly evaluated for their charging potential and partly for the electron-to- $\mathrm{O}_{2}$ ratio. The kinetics of mediated $\mathrm{Li}_{2} \mathrm{O}_{2}$ oxidation has only recently received attention.279-281 Chen et al. studied a variety of organic $\mathrm{RMs}$ for the kinetics of $\mathrm{Li}_{2} \mathrm{O}_{2}$ decomposition using scanning electrochemical microscopy (SECM) and demonstrated that the rate is highly dependent on the RM used (Figure 32). ${ }^{279}$ Among the studied RMs, nitroxides including TEMPO were found to be the fastest. Notably, no clear ratio between heterogeneous rate constant of the $\mathrm{RM}$ at $\mathrm{Au}$ and $\mathrm{C}$ electrodes and the apparent rate constant
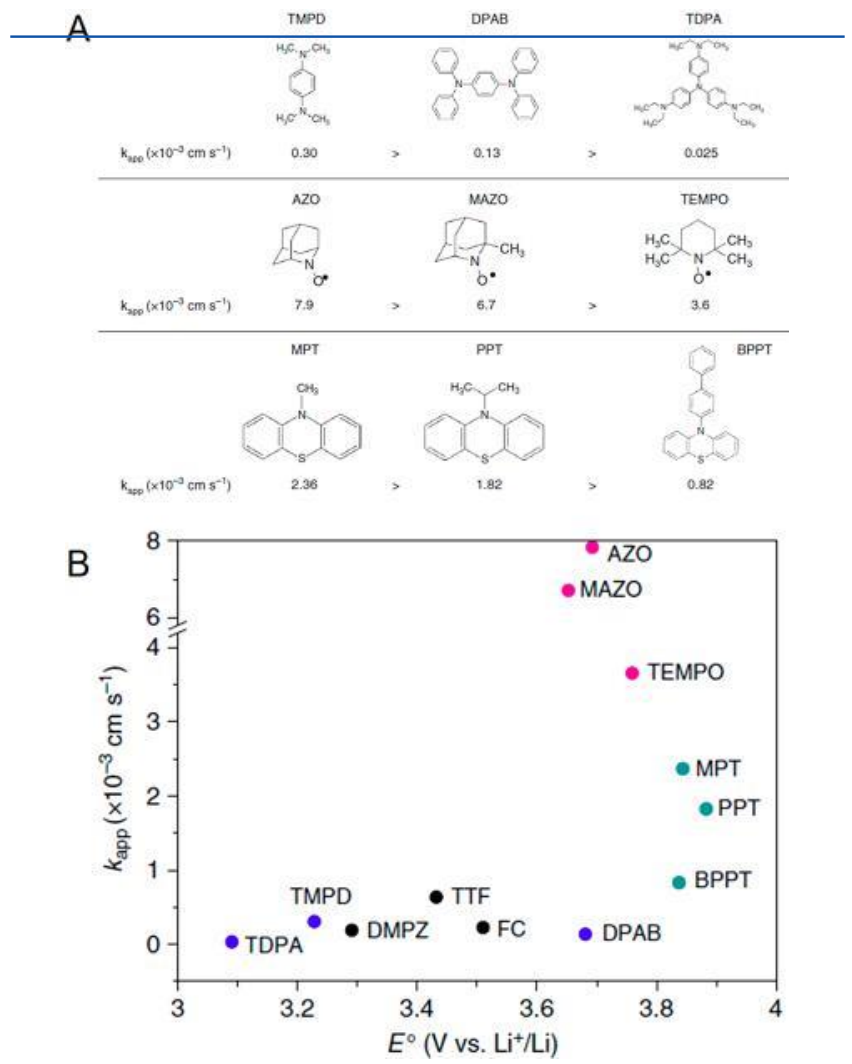

Figure 32. Li2O2 oxidation kinetics of redox mediators. (A) Structures of a selection of oxidation mediators and their kinetics of $\mathrm{Li}_{2} \mathrm{O}_{2}$ oxidation. (B) Comparison of the apparent rate constants (kapp) for the reaction between the redox mediators and $\mathrm{Li}_{\mathrm{2} 2}$ grouped by structure. Reproduced with permission from ref 279. Copyright 2018 Springer. (kapp) for Li2O2 oxidation was found. Equally, no simple proportionality between RM potential and kapp was found. Both were attributed to dominating steric effects on kapp. An important conclusion was that even the slowest mediators allow for charging rates in porous electrodes that by far exceed practically required values. Importantly, however, the detailed mechanism of mediated oxidation and particularly pathways therein that cause electron-to- $\mathrm{O}_{2}$ ratios to differ from the ideal of two are unknown.

Just as RMs for OER help the decomposition of $\mathrm{Li}_{2 \mathrm{O} 2}$ during charging, there are compounds that can serve as mediators for ORR, assisting in the formation of $\mathrm{Li}_{2} \mathrm{O} 2$ deposits during discharging. ${ }^{282-287}$ The first generation of discharge mediators was reported by Lacey et al. ${ }^{269}$ They used ethyl viologen ditriflate as a redox shuttle to transfer electrons from the electrode surface to oxygen, which then forms $\mathrm{O}_{2}$ - followed by disproportionation to $\mathrm{Li}_{2} \mathrm{O}_{2}$. While these results were promising, due to the simple shuttle mechanism, this mediator operates at the same potential as the ORR reaction, did not eliminate parallel $\mathrm{O}_{2}$ reduction at the cathode, and hence the intrinsic problem of electrode passivation on discharge persisted.

In contrast, the mediator 2,5-ditert-butyl-1,4-benzoquinone (DBBQ) as reported by Gao et al. ${ }^{286}$ raises the voltage of mediated process above direct $\mathrm{O}_{2}$ reduction at the cathode. Unlike previous ORR mediators, DBBQ operates as a catalyst, altering the discharge route, Figure 33A. Following reduction, DBBQ formed $\mathrm{Li}^{+}-\mathrm{DBBQ}-\mathrm{O}_{2}$ in solution instead of the reactive intermediate $\mathrm{LiO}_{2}$. This process occurs at voltages positive of those needed for direct ORR, and thus the problematic oxygen redox chemistry that limits lithium-air capacity is removed. As a result, the cell capacity increased 80- 100 -fold with a higher discharge voltage in comparison to the case without DBBQ (Figure 33A). Vitamin K2, ${ }^{283}$ a biological quinone, has been reported to work in a fashion similar to DBBQ. As discussed previously, protic additives such as $\mathrm{H}_{2} \mathrm{O}$ can improve the discharge performance. Inspired by this, Gao et al. demonstrated that phenol is able to improve ORR in $\mathrm{Li}_{-}-\mathrm{O}_{2}$ batteries by solvating $\mathrm{Li}_{2} \mathrm{O} 2$ and promoting growth of large $\mathrm{Li}_{2} \mathrm{O}_{2}$ particles while avoiding surface passivation. ${ }^{287}$ The result is a greatly enhanced capacity (35-fold increase) as shown in Figure 33B.

To facilitate $\mathrm{Li2O2}$ formation and decomposition during both discharge and recharge processes in $\mathrm{Li}-\mathrm{O}_{2}$ cells, several bifunctional redox mediators were suggested and tested.273,274,288,289

The combined use of ORR mediator and OER mediator at the same time has shown synergistic effects. ${ }^{208,290,291}$ Gao et al. demonstrated a cell containing DBBQand TEMPO as discharge and charge mediators respectively, as shown in Figure 34. ${ }^{208}$ This dual redox mediator cell operates without any direct oxygen redox chemistry at the electrode surface and thus was able to significantly suppress parasitic chemistry and enhance cycling stability.

Building on this concept, Liang et al. exploited the mobile nature of the discharge redox mediator to promote growth of lithium peroxide away from the cathode, thus avoiding degradation and cell failure (Figure 35). ${ }^{291}$ This is achieved by inserting an electrolyte soaked inert storage layer between the electrochemically active carbon cathode and the electrolyte $-\mathrm{O}_{2}$ interface. The electrolyte contains both ORR and OER RMs, DBBQ, and TEMPO in the present example. At the stationary state, on discharge, a retarded $\mathrm{O}_{2}$ supply through the storage layer causes $\mathrm{O}_{2}$ to be fully reduced within the storage layer by the 

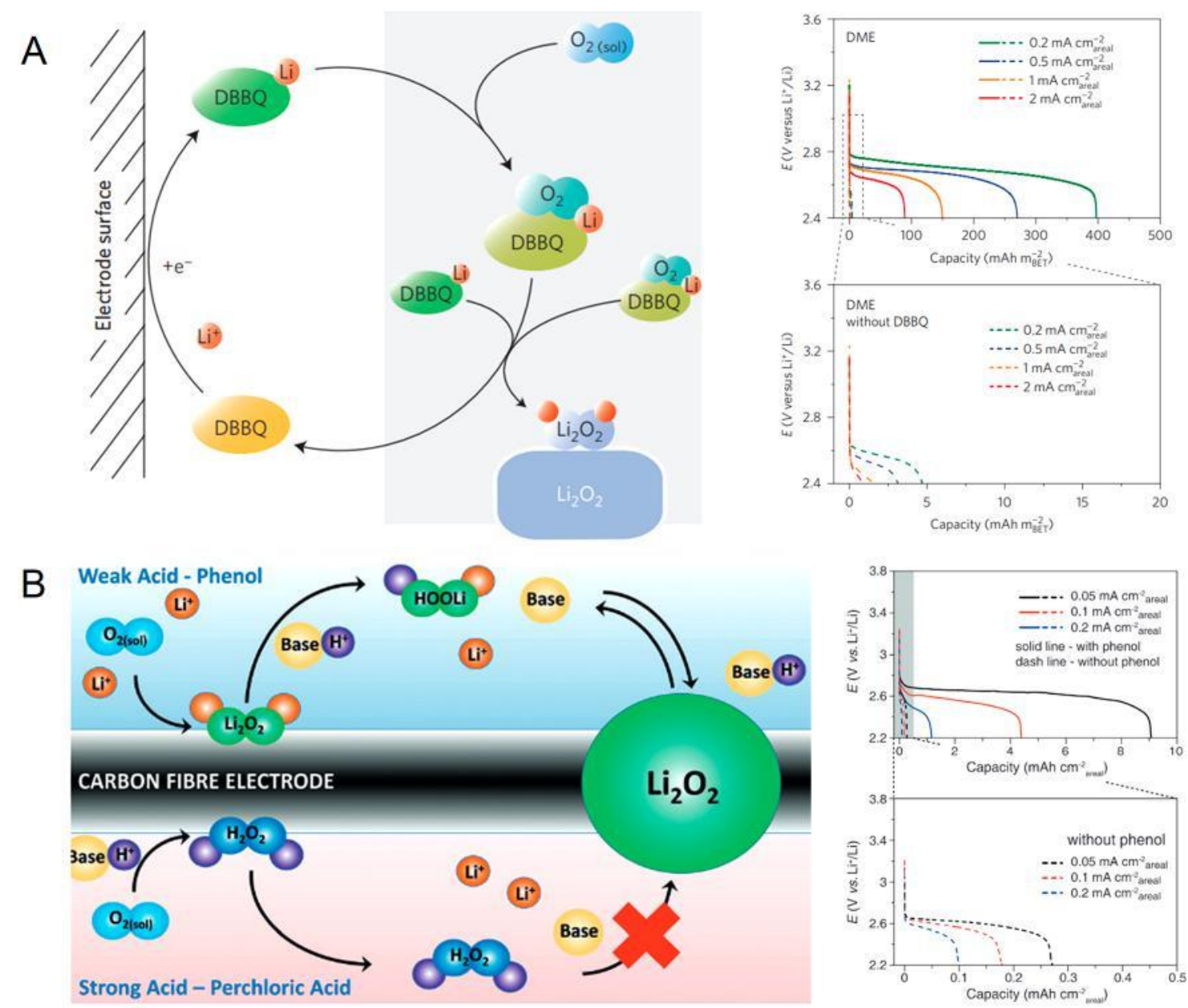

Figure 33. $\mathrm{Li2} 2$ formation mediators in $\mathrm{Li}-\mathrm{O}_{2}$ batteries. (A) DBBQ. Reproduced with permission from ref 286. Copyright 2016 Springer. (B) Phenol. Reproduced with permission from ref 287. Copyright 2017 John Wiley \& Sons.

outward-diffusing reduced form of the ORR RM. This way the carbon cathode only serves to reduce (oxidize) the ORR (OER) $\mathrm{RM}$ but does not perform $\mathrm{O}_{2}$ electrochemistry.

3.5.3. Instability Issues with Mediators. Despite their advantages, RMs introduce further complexity to the cell and not least potential instability. First, they may themselves not be stable with $\mathrm{Li}$ metal or may introduce a redox shuttle that curbs Coulombic efficiency. Second, as the RMs are in many cases organic molecules, they may be subject to similar decomposition as the electrolyte or carbon.

Redox mediators can cross over to the reactive lithium metal anode due to their mobile nature. Such a phenomenon is referred to as a "redox shuttle"272,292,293 and could be detrimental to lithium metal, the redox mediator itself, and cycling stability. Similarly, oxidized redox mediators formed during the $\mathrm{Li}-\mathrm{O}_{2}$ cell charging step can diffuse to the anode side and be reduced by reaction with the lithium metal, which constitutes selfdischarge (Figure 36). Ha et al. ${ }^{294}$ also investigated the failure mechanism of the $\mathrm{Li}-\mathrm{O}_{2}$ cell containing o-methylphenothiazine (MPT). They showed that the redox mediator decomposes the lithium oxide layer within the Li metal SEI through the same catalytic reaction mechanism. This exposed Li metal then directly reacts with the redox mediator resulting in irreversible decomposition and loss of Li metal. Because of these problems, it is accepted that the lithium metal surface will need to be protected with an artificial SEI or solid electrolyte.
Lim et al. investigated representative organic RMs to find key factors that determine the catalytic activity and electrochemical stability with solvents. ${ }^{278}$ They demonstrated that the ionization energy (IE) is a suitable proxy to predict the energy level (redox potential) of a candidate RM, helping to indicate to what extent it can interact with oxygen species in $\mathrm{Li}-\mathrm{O}_{2}$ cells without promoting electrolyte solution degradation. They have shown that RMs with their singly occupied orbitals (SOMO) of the oxidized form close to the HOMO of the solvent are prone to extract electrons from the solvent and decompose it (Figure 37). This is seen in irreversible electrochemistry of these RMs. On the basis of experimental data and DFT calculations, they suggested dimethylphenazine (DMPZ) as a low-voltage RM which is not attacking the solvent.

In addition to the problem of the RM being degraded by reaction with Li metal, and considering the potential instability of RMs at the cathode, Kwak et al. ${ }^{297}$ have shown that several commonly used RMs already decompose in an $\mathrm{O}_{2}$-free environment upon prolonged cycling. Figure 38A shows, for example, that TTF readily decomposes when cycled over both of its oxidation steps, while it proved more stable when only the first step was accessed. Such instabilities could arise from the oxidized mediator oxidizing the electrolyte as shown by Kang et al. ${ }^{278}$ as discussed above. Because most mediators are organic molecules, they are susceptible to the same decomposition as organic electrolytes or carbon by reactive $\mathrm{O}_{2}$ species. This was tentatively ascribed to instability with superoxide or peroxide. ${ }^{270}$ 
A
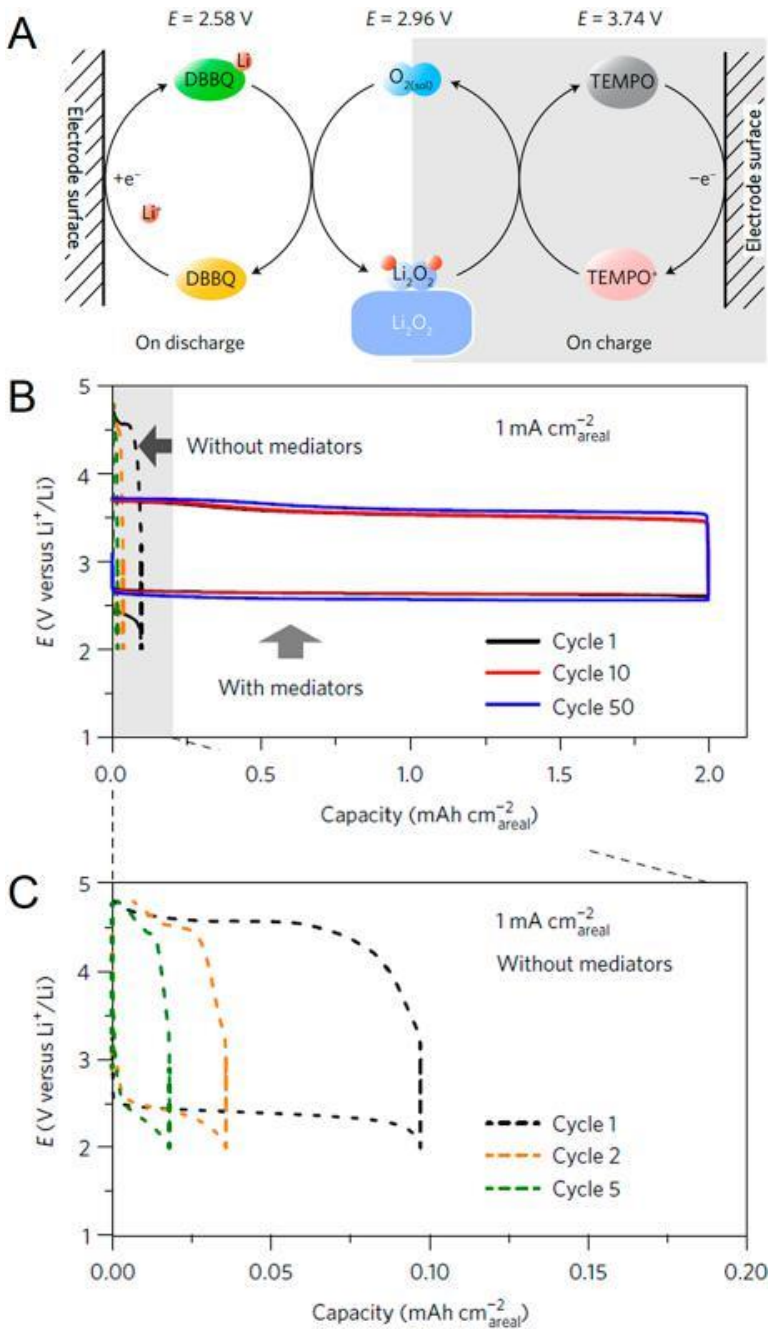

Figure 34. Dual mediators for ORR and OER in $\mathrm{Li}-\mathrm{O}_{2}$ batteries. (A) Schematics of positive electrode reactions on discharge and charge in the presence of DBBQ and TEMPO. (B) Discharge-charge curves of $\mathrm{Li}-\mathrm{O}_{2}$ batteries with (solid lines) and without mediators (dashed lines). (C) Enlarged section of the discharge-charge curves recorded without DBBQ-TEMPO in (B). Reproduced with permission from ref 208. Copyright 2017 Springer.

Recently, Kwak et al. 156 investigated the reactivity of TTF and DMPZ toward various $\mathrm{O}_{2}$ species to clarify possible degeneration routes in typical ethereal electrolyte solutions (Figure 38B). Analogous to the predominant decomposition of solvents by ${ }^{1} \mathrm{O}_{2}$ (see above), it was confirmed that singlet oxygen $\left({ }^{1} \mathrm{O}_{2}\right)$ predominantly causes RM decomposition. The electro-philic nature of ${ }^{1} \mathrm{O}_{2}$ addition reactions render reduced RMs particularly susceptible to attack. While the negative, detrimental effect of ${ }^{1} \mathrm{O}_{2}$ formation in $\mathrm{Li}-\mathrm{O}_{2}$ cells on the stability of electrolyte solutions and RMs is evident, understanding the exact mechanisms requires further work.

\subsection{The Important Analogous Systems}

3.6.1. Sodium-Oxygen Batteries. As the higher analogue of $\mathrm{Li}-\mathrm{O}_{2}$, nonaqueous sodium-air batteries (also known as $\mathrm{Na}-\mathrm{O}_{2}$ cells) open up interesting possibilities. Hartman et al. first demonstrated that sodium superoxide $\left(\mathrm{NaO}_{2}\right)$ can be produced as the main discharge product by using a diglyme-based electrolyte. ${ }^{119}$ Although $\mathrm{Na}-\mathrm{O}_{2}$ cells offer a lower formal specific energy (1105 Wh kg-1 based on $\mathrm{NaO}_{2}$ ) than $\mathrm{Li}-\mathrm{O}_{2}$ cells, they feature a much more abundant, sustainable element, sodium, a lower charge overpotential (typically below $0.2 \mathrm{~V}$ ), and higher reversibility (Figures 39A,B). These merits suggest that $\mathrm{Na}-\mathrm{O}_{2}$ batteries may have practical advantages, and they have attracted great research interest.

Superoxide versus peroxide stability is a function of the alkali cations. On the basis of the Hard-Soft Acid-Base (HSAB) theory, the $\mathrm{Na}$ ion with a larger radius possesses lower charge density as compared to $\mathrm{Li}$ and is therefore more effective in stabilizing $\mathrm{O}_{2}-71$ It suppresses the spontaneous disproportiona-tion of $\mathrm{NaO}_{2}$ to sodium peroxide $\left(\mathrm{Na}_{2} \mathrm{O}_{2}\right)$. On the basis of rotating ring-disk electrode (RRDE) and in situ X-ray diffraction (XRD) studies, it was found that solution-mediated superoxide transfers accounts for the growth and oxidation of cube-shaped $\mathrm{NaO}_{2}$ products. ${ }^{95,298}$ As shown in Figure 39C, superoxide species are exclusively formed at the cathode surface upon discharge and then transferred to the electrolyte. Once supersaturation is achieved, $\mathrm{NaO}_{2}$ precipitates and forms cube-shaped crystals. During charge, superoxide species are resolubilized in electrolyte and diffuse to the cathode for oxidation. This reversible solution-mediated pathway with a lower energy barrier leads to a large discharge capacity and a low charge overpotential. It is reported that the Gutmann DNs of organic solvents and the addition of phase transfer catalysts significantly influence this solution process, albeit through different mechanisms. On the basis of surface enhanced Raman spectroscopy (SERS) results, Aldous et al. suggested that dimethyl sulfoxide (DMSO) with a large DN facilitates the solution-mediated growth of $\mathrm{NaO}_{2}$ by forming soluble DMSO-solvated $\left[\mathrm{Na}^{-}-\mathrm{O}_{2}^{-}\right]$ion pairs. ${ }^{288} \mathrm{Xia}$ et al. demonstrated that trace amount of weak acids (e.g., $\mathrm{H}_{2} \mathrm{O}$, benzoic acid) function as proton-based phase transfer catalysts, enabling the solubilizing of superoxide via the formation of an hydroperoxyl $\left(\mathrm{HO}_{2}\right)$ intermediate. ${ }^{95,299}$ They further provided direct evidence of $\mathrm{HO}_{2}$ species existing in a diglyme-based electrolyte by using in situ electron spin resonance (ESR). ${ }^{300}$ Clearly, such reversible solution processes play a critical role in $\mathrm{Na}-\mathrm{O}_{2}$ chemistry with a lower overpotential and higher rechargeability. By contrast, the spontaneous disproportionation of $\mathrm{LiO}_{2}$ leads to irreversible discharge/charge pathways and the poor rechargeability and high overpotential of $\mathrm{Li}-\mathrm{O}_{2}$ cells.

In addition to $\mathrm{NaO}_{2}$, sodium peroxide $\left(\mathrm{Na}_{2} \mathrm{O}_{2}\right)$ and its dihydrate form $\left(\mathrm{Na}_{2} \mathrm{O}_{2} \cdot \mathrm{H}_{2} \mathrm{O}\right)$ were also reported as discharge products of $\mathrm{Na}-\mathrm{O}_{2}$ cells, although which of these is preferred is not fully understood. ${ }^{301}$ Thermodynamically, the formation of $\mathrm{Na}_{2} \mathrm{O}_{2}$ is more favorable than $\mathrm{NaO}_{2}\left(-449.7 \mathrm{~kJ}\right.$ mol $\left(\mathrm{Na}_{2} \mathrm{O}_{2}\right)-1$ vs -437.5 $\mathrm{kJ}$ mol $\left.\left(2 \mathrm{NaO}_{2}\right)^{-1}\right){ }^{128}$ On the other hand, $\mathrm{NaO}_{2}$ may be the kinetically preferred product due to the requirement of only a $1 \mathrm{e}^{-}$ transfer (compared to two electrons for $\mathrm{Na}_{2} \mathrm{O}_{2}$ ). Thus, generally disproportionation in the presence of $\mathrm{Na}^{\prime}$ or $\mathrm{H}^{\prime}$ will trigger the conversion of superoxide into peroxide (see Figure. 10A). Solvent dependent $\mathrm{NaO}_{2}$ disproportionation has been shown by Sheng et al. to be accelerated with high DN solvents. ${ }^{160}$

Although $\mathrm{Na}-\mathrm{O}_{2}$ cells based on $\mathrm{NaO}_{2}$ products exhibit the desired electrochemical behavior, their long-term stabilities are still a topic of concern due to the associated parasitic chemistry. A number of studies have shown instability of $\mathrm{NaO}_{2}$ upon prolonged rest. ${ }^{118,130,132,162,180}$ Although details vary, they generally report gradual conversion of $\mathrm{NaO}_{2}$ into $\mathrm{Na}_{2} \mathrm{O}_{2} \cdot \mathrm{H}_{2} \mathrm{O}$ accompanied by electrolyte degradation to form $\mathrm{NaOH}, \mathrm{Na}_{2} \mathrm{CO}_{3}$, and organic compounds including $\mathrm{Na}$ formate and acetate. Explanations included nucleophilic attack, $\mathrm{H}$ and $\mathrm{H}$ atom abstraction by superoxide. Black et al. reported that $10 \mathrm{~mol}$ 
A

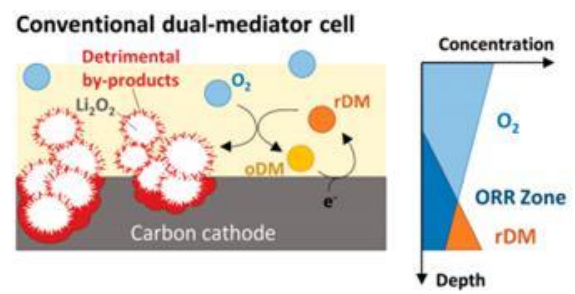

B

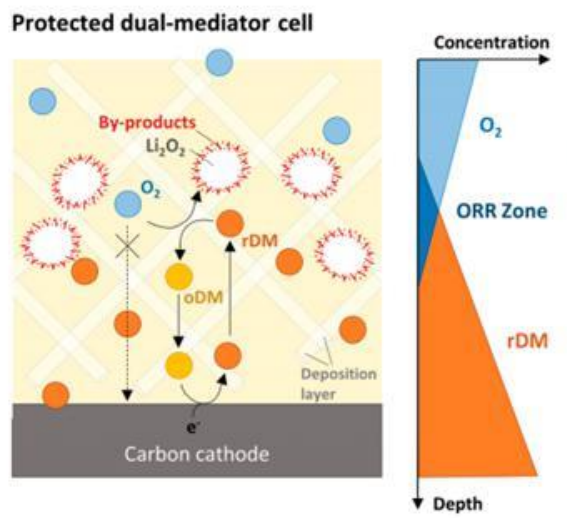

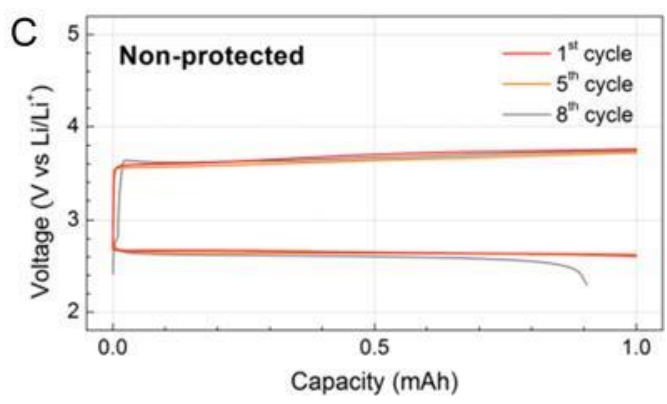

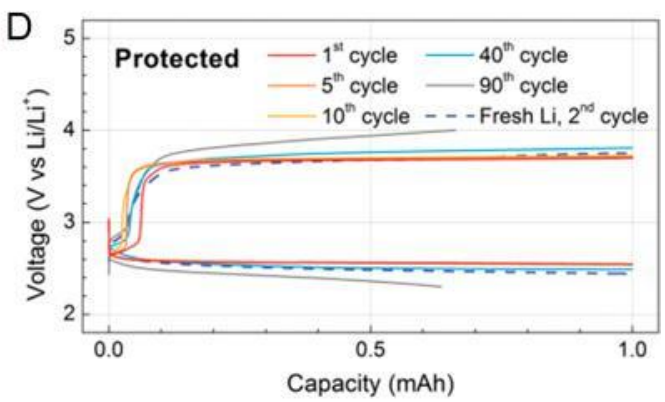

Figure 35. Strategy to protect the carbon electrode from ${ }_{\mathrm{Li} 2 \mathrm{O} 2}$ using dual mediators in $\mathrm{Li}-\mathrm{O}_{2}$ batteries. During discharge in (A) a conventional dualmediator cell, the carbon cathode is corroded by reactive oxygen species and passivated by the byproducts. By contrast, the cathode in (B) a protected dual-mediator cell is isolated from both the $\mathrm{Li}^{-} \mathrm{O}_{2}$ reaction intermediates and products by a dynamic $\mathrm{O}_{2}$ shield consisting of reduced dual mediator (rDM) . Comparison of cycling stability of the (C) nonprotected cell and (D) protected cell. Reproduced with permission from ref 291. Copyright 2018 Royal Society of Chemistry.

\% of discharge products are such side products as quantified by $\mathrm{H}$ NMR and acid-titration measurements. ${ }^{130}$ By using an isotopically labeled ${ }^{13} \mathrm{C}$ model cathode, they also demonstrated that the carbon cathode is oxidized by $\mathrm{NaO}_{2}$, irreversibly forming carbonate.

Singlet oxygen $\left({ }^{1} \mathrm{O}_{2}\right)$ is now recognized an essential trigger for parasitic reactions as is formed at all stages of cycling. ${ }^{107}$ Recently, poor $\mathrm{Na} 2 \mathrm{O} 2$ yield and pronounced degradation upon $\mathrm{NaO}_{2}$ disproportionation has been explained within a unified ${ }^{1} \mathrm{O}_{2}$ formation mechanism that shows growing ${ }^{1} \mathrm{O}_{2}$ yields as superoxide disproportionates in the presence of increasingly weakly Lewis acidic cations (Lewis acidity, $\mathrm{H}^{+}>\mathrm{Li}^{+}>\mathrm{Na}^{+} ;{ }^{1} \mathrm{O}_{2}$ yield, $\left.\mathrm{H}^{+}<\mathrm{Li}^{+}<\mathrm{Na}^{+}\right){ }^{134} \mathrm{~A}$ major conclusion from this mechanism in conjunction with all papers showing instability of $\mathrm{NaO}_{2}$-based $\mathrm{Na}-\mathrm{O}_{2}$ cells is that $\mathrm{NaO}_{2}$ as a thermodynamically metastable discharge product must be avoided as it lacks the required tolerance to slow discharge and rest periods; it will gradually convert to $\mathrm{Na}_{2} \mathrm{O} 2$ and side products. Cycling the $\mathrm{Na}-\mathrm{O}_{2}$ cell highly reversible requires therefore controlled formation/decomposition of $\mathrm{Na} 2 \mathrm{O} 2$ without superoxide disproportionation steps.

In addition, similar to a Li metal anode, sodium deposits easily grow into a dendritic pattern, resulting in safety concerns. ${ }^{302}$ Oxygen species (including oxygen and superoxide) diffuse through electrolyte solution and contaminate the surface of $\mathrm{Na}$ anode. Thus, a variety of protective membranes (e.g., polymer, ceramic, etc.) have been used to restrict growth of sodium dendrites and prevent the diffusion of oxygen species.303,304 Alternatively, Bender et al. replaced sodium metal with a sodiated carbon anode to improve the reversibility of the anode and avoid dendritic growth. ${ }^{305}$ However, the long-term reliability of these approaches needs to be further examined.

3.6.2. The Potassium-Oxygen Battery. In seeking alternative metal-oxygen chemistry to overcome the challenges in $\mathrm{Li}-\mathrm{O}_{2}$ batteries, the potassium-oxygen battery based on potassium superoxide ( $\mathrm{KO}_{2}$ ) as the product was first established by Ren et al. ${ }^{306}$ The net battery reaction is $\mathrm{K}+\mathrm{O}_{2} \leftrightarrow \mathrm{KO}_{2}\left(\Delta \mathrm{G}^{0}=\right.$ $-239.4 \mathrm{~kJ}$ mol-1, $\left.\mathrm{E}^{0}=2.48 \mathrm{~V}\right)$, which gives a formal specific energy of $935 \mathrm{Wh} \mathrm{kg}^{-1}$ (based on $\mathrm{KO}_{2}$ ). Differing from $\mathrm{LiO}_{2}$ and $\mathrm{NaO}_{2}, \mathrm{KO}_{2}$ is a thermodynamically favorable product (see Figure $10 \mathrm{~A})$. This allows $\mathrm{K}-\mathrm{O}_{2}$ cells to operate exclusively via the $\mathrm{O}_{2} / \mathrm{O}_{2}$ -redox couple, presenting a high superoxide yield above $98 \%$ (vs $95 \%$ for $\mathrm{Na}-\mathrm{O}_{2}$ cells) and a low overpotential of $50 \mathrm{mV}$ (vs 200 $\mathrm{mV}$ for $\mathrm{Na}-\mathrm{O}_{2}$ cells). ${ }^{126}$ After aging in a glyme-based electrolyte for 30 days, electrochemically formed $\mathrm{KO}_{2}$ remains stable in the cell and demonstrates $94 \%$ Coulombic efficiency. By contrast, $\mathrm{NaO}_{2}$ quickly undergoes irreversible decomposition upon aging in the electrolyte. Thus, the higher stability and reversibility of $\mathrm{KO}_{2}$, as compared with $\mathrm{LiO}_{2}$ and $\mathrm{NaO}_{2}$, offers $\mathrm{K}-\mathrm{O}_{2}$ chemistry significant advantages.

Although ether-based electrolytes are considered to be relatively stable against $\mathrm{O}_{2}$ - attack, their decomposition in the $\mathrm{K}-\mathrm{O}_{2}$ cell is still problematic. By using ion chromatography, Xiao et al. reported that $0.3 \%$ of the $\mathrm{KO}_{2}$ product is consumed with the decomposition of dimethoxyethane (DME) solvent after the first discharge. ${ }^{126}$ More seriously, potassium metal presents much higher reactivity with ether-based electrolytes than lithium and sodium. ${ }^{307}$ This is owed to the formation of highly reactive solvated electrons and/or potasside (negatively charged potassium ions) by dissolution of $\mathrm{K}$ metal in ether solvents. These dissolved species cleave the $\mathrm{C}-\mathrm{O}$ bonds in ether molecules, leading to a very thick passivating layer $(\sim 500 \mu \mathrm{m})$ precipitated on the potassium surface. Moreover, the crossover $\mathrm{O}_{2}$ is continuously reduced to superoxide species by potassium, which also accelerates the decomposition of electrolyte. Thus, forming a stable solid electrolyte interface (SEI) is highly desired for achieving reversible potassium stripping/plating. By using appropriate electrolyte salts, applying an artificial SEI, and employing a Nafion $-\mathrm{K}^{+}$membrane, the cyclability of $\mathrm{K}-\mathrm{O}_{2}$ cells has been significantly improved from a few cycles to 

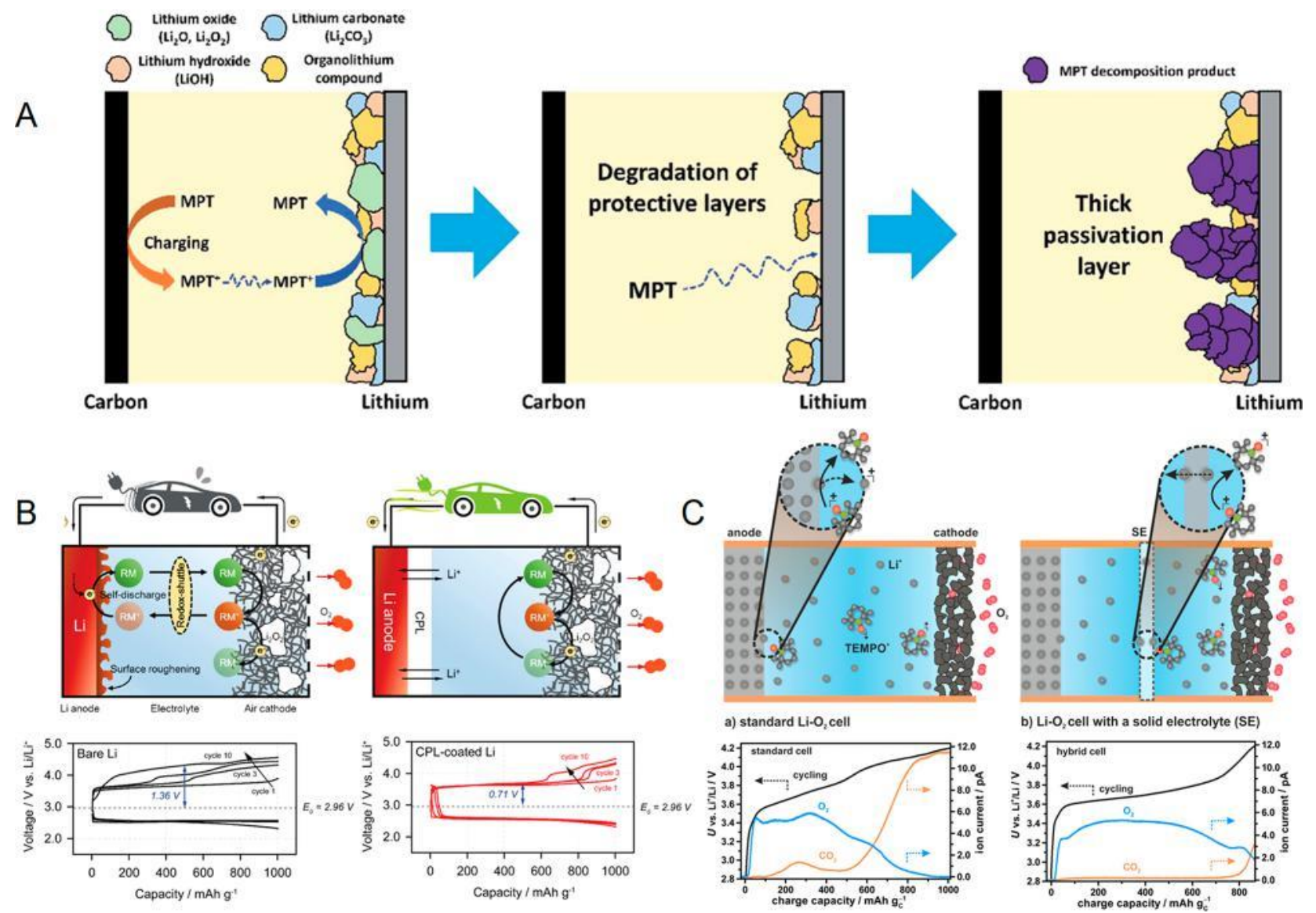

Figure 36. Issue and solution for side reaction of RM with $\mathrm{Li}$ metal. (A) Schematic of the failure mechanism of the $\mathrm{Li}-\mathrm{O}_{2}$ cell with redox mediator. Reproduced with permission from ref 294. Copyright 2017 Royal Society of Chemistry. (B) Coating protective layer on Li metal to prohibit parasitic reaction between $\mathrm{RM}$ and Li metal. Reproduced with permission from ref 295. Copyright 2016 John Wiley \& Sons. (C) Solid electrolyte as Li ${ }^{+}$ conductive membrane to prohibit crossover of RM to Li metal. Reproduced with permission from ref 296. Copyright 2016 American Chemical Society.

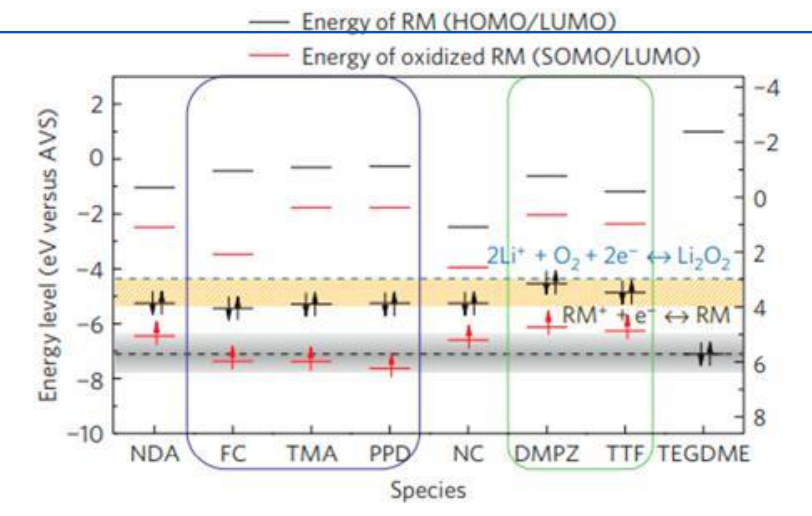

Figure 37. Molecular orbital energies of redox mediators and TEGDME. HOMO and LUMO energies of original RMs (black bar), singly occupied orbital (SOMO) energies of oxidized RMs (red bars with arrows), and HOMO energies of TEGDME electrolyte based on DFT calculations. Adapted with permission from ref 278. Copyright 2016 Springer Nature.

hundreds of cycles. ${ }^{307-309}$ In addition, potassium-based alloys (e.g., $\mathrm{K}-\mathrm{Sb}$ alloy and liquid $\mathrm{Na}-\mathrm{K}$ alloy) as anew class of anode materials demonstrate advantages over $\mathrm{K}$ metal in terms of SEI stabilization and elimination of dendrites. ${ }^{310,311}$ Very recently, Lu et al. reported on an organic-oxygen cell using a potassium biphenyl complex (BpK)/DME anode and a DMSO-mediated potassium superoxide cathode (Figure 40A). On the basis of cyclic voltammetry studies, Lu et al. found that Bp

- /Bp redox is stable and reversible. The cell exhibits an unprecedented cycle life (3000 cycles) with a superior average Coulombic efficiency of more than $99.84 \%$ at a high current density of $4.0 \mathrm{~mA} \mathrm{~cm}^{-2}$ (Figures 40B,C). ${ }^{120}$ Clearly, developing alternative anode materials with higher stability and reversibility is a promising approach to increase the cycle life of $\mathrm{K}-\mathrm{O}_{2}$ cells; more importantly, it is likely applicable to other metal-oxygen battery systems.

3.6.3. The Magnesium-Oxygen Battery. Metallic magnesium is an attractive negative-electrode material for battery applications due to its high abundance in the earth's crust, low cost, and better safety in comparison to alkali metals ( $\mathrm{Li}$ and $\mathrm{Na}){ }^{312} \mathrm{~A}$ magnesium-oxygen battery based on magnesium oxide $(\mathrm{MgO})$ products theoretically delivers a volumetric and a gravimetric energy density of $14 \mathrm{~kW} \mathrm{~h} \mathrm{~L}^{-1}$ and $3.9 \mathrm{~kW} \mathrm{~h} \mathrm{~kg}^{-1}$, respectively. These values are even higher than those of $\mathrm{Li}^{-} \mathrm{O}_{2}$ cells $\left(8.0 \mathrm{~kW} \mathrm{~h} \mathrm{~L}-1\right.$ and $\left.3.4 \mathrm{~kW} \mathrm{~h} \mathrm{~kg}^{-1}\right)$. This makes $\mathrm{Mg}-\mathrm{O}_{2}$ batteries compelling candidates for large scale and sustainable energy storage devices required for grid integration.

In the past decade, aqueous $\mathrm{Mg}-\mathrm{O}_{2}$ cells were mainly studied as primary batteries owing to the nonrechargeability of the magnesium hydroxide $\left(\mathrm{Mg}(\mathrm{OH})_{2}\right)$ product. ${ }^{313}$ Shiga et al. first reported a secondary $\mathrm{Mg}-\mathrm{O}_{2}$ cell using a DMSO-based 

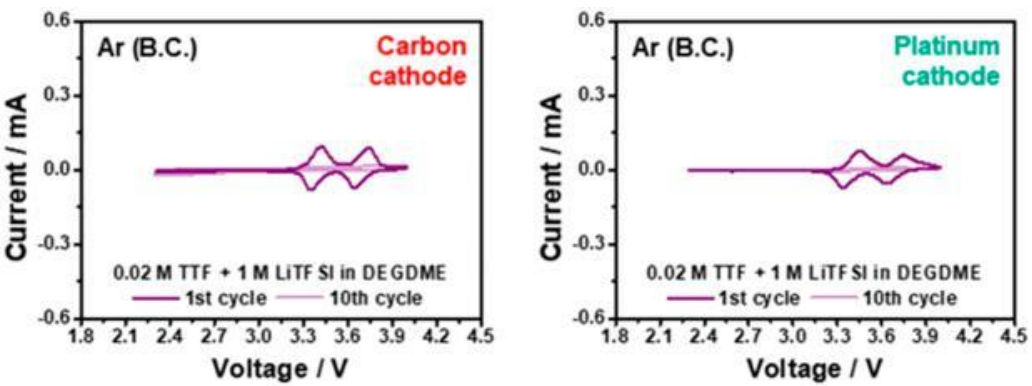

\section{$50^{\text {th }}$ CV cycles \\ $0.05 \mathrm{mV} \mathrm{s}^{-1}$ \\ 3.1-3.55 V vs. Li Narrow voltage range}
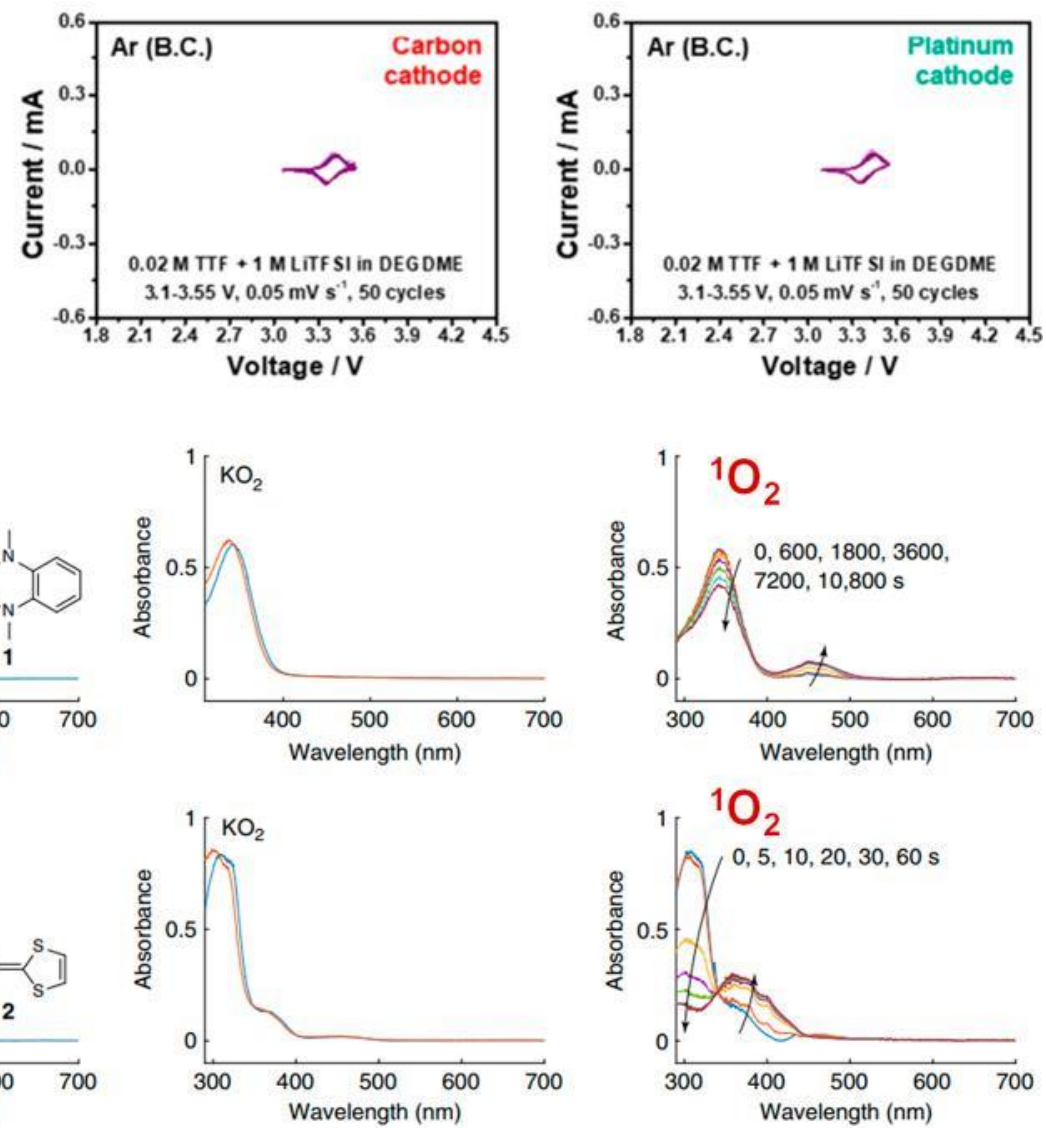

Figure 38. RM instability at the cathode. (A) Instability of doubly oxidized RMs while the singly oxidized form may cycle reversibly. Data were collected under Ar at C cathodes. Reproduced with permission from ref 297. Copyright 2018 The Electrochemical Society. (B) Decomposition by singlet oxygen. Reproduced with permission from ref 156. Copyright 2019 Springer.

electrolyte that operates at elevated temperature $\left(60^{\circ} \mathrm{C}\right){ }^{314}$ The discharge product was assumed to be $\mathrm{MgO}$ that is rechargeable in the presence of redox mediators, e.g., iodine $\left(\mathrm{I}_{2}\right)$ and 2,2,6,6tetramethyl-1-piperidinyloxy (TEMPO).314,315 On the basis of XRD and Raman analysis, Vardar et al. identified that the discharge products were composed of a mixture of crystalline $\mathrm{MgO}$ and amorphous magnesium peroxide $\left(\mathrm{MgO}_{2}\right)$ when a Grignard reagentbased electrolyte was used in a $\mathrm{Mg}-\mathrm{O}_{2}$ cell. ${ }^{316}$ They speculated that $\mathrm{O}_{2}$ is formed first upon discharge followed by its disproportionation to $\mathrm{MgO}_{2}$ and $\mathrm{MgO}$. After charge, $\mathrm{MgO}_{2}$ is fully oxidized, whereas some $\mathrm{MgO}$ remains. The incomplete oxidation of $\mathrm{MgO}$ causes low Columbic efficiency and rapid capacity fading. Thus, exploring more effective OER catalysts and redox mediators to oxidize $\mathrm{MgO}$ is necessary. Meanwhile, more studies are required to examine the reversibility of $\mathrm{Mg}-\mathrm{O}_{2}$ cells and reveal the underlying chemistry.

\subsection{Novel Electrolytes and Electrodes}

3.7.1. The Possibilities and Development of Active Metal (Li, Na) Protection. As discussed above, various approaches and results have been reported for $\mathrm{Li}$ metal stabilization in $\mathrm{Li}-\mathrm{O}_{2}$ batteries. Metal stabilization is required in order to control overall battery performance including stability, lifetime, and efficiency of the battery. In contrast to $\mathrm{Li}-$ metal and $\mathrm{Li}-\mathrm{S}$ batteries, the $\mathrm{Li}-\mathrm{O}_{2}$ battery involves reactive oxygen, and more attention needs to be paid to the details. In this chapter, we will discuss the important aspects of $\mathrm{Li}$-metal protection in $\mathrm{Li}-\mathrm{O}_{2}$ batteries and directions for the future.

Li-metal deterioration, rather than dendrite formation, is a primary issue in $\mathrm{Li}-\mathrm{O}_{2}$ cells. It results from side reactions with oxygen species, moisture, reaction byproducts, and soluble additives which can crossover from the cathode side. However, most studies have been focused on the advantage of protective layers to protect the $\mathrm{Li}$ metal without consideration of their stability to reactive oxygen species. To verify the importance of 

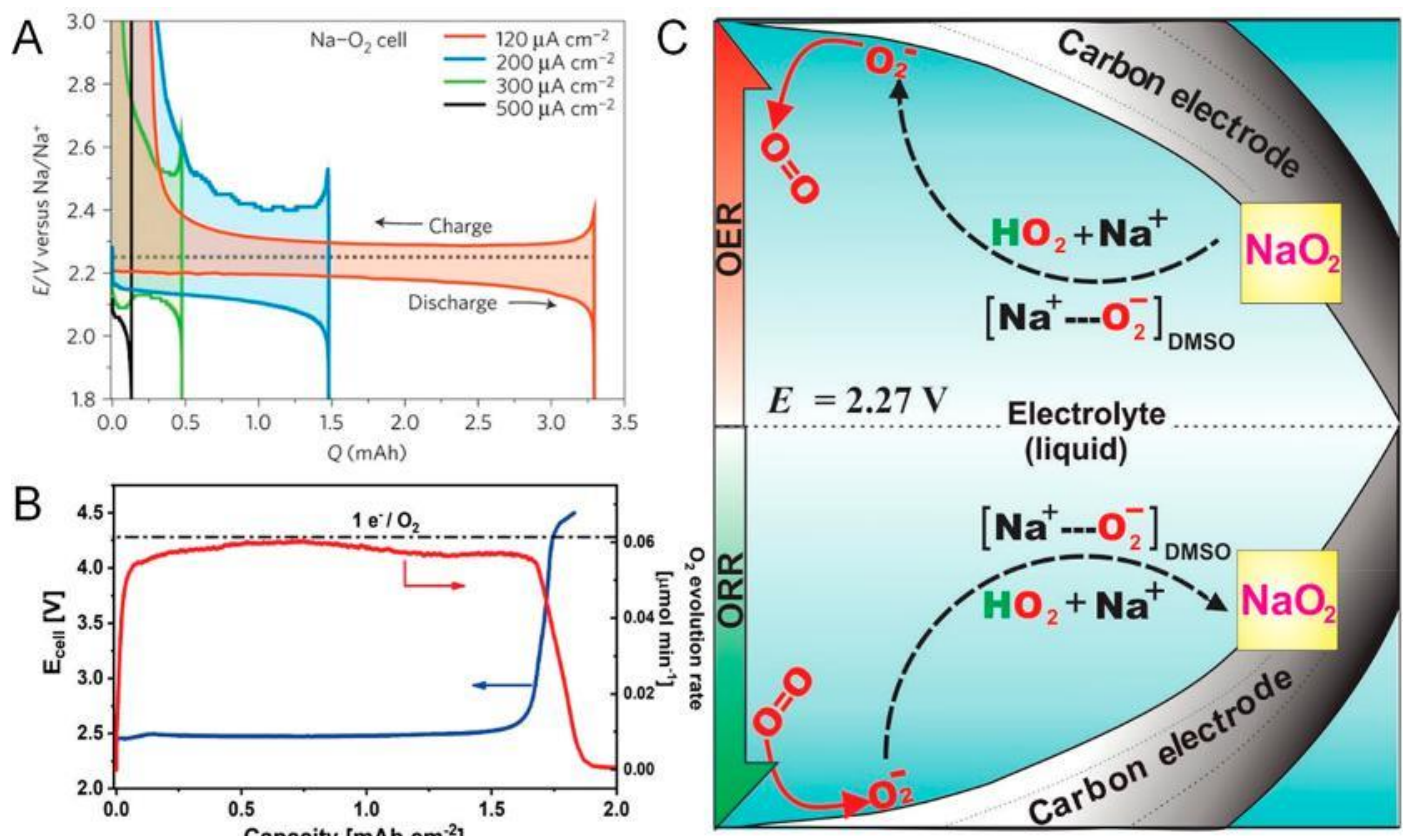

Figure 39. A rechargeable $\mathrm{Na}-\mathrm{O}_{2}$ battery based on $\mathrm{NaO}_{2}$. (A) Discharge-charge cycles of $\mathrm{Na}-\mathrm{O}_{2}$ cells at various current densities. Cut-off potentials were set to $1.8 \mathrm{~V}$ for discharge and 3.6 V for charge. Dotted line: $\mathrm{E}^{0}\left(\mathrm{NaO}_{2}\right)=2: 27 \mathrm{~V}$. Reproduced with permission from ref 119 . Copyright 2012 Springer Nature. (B) Online mass spectrometry analysis of oxygen evolution rate (red curve) upon charge (blue curve is the charge profile). The dashed line indicates an oxygen evolution rate corresponding to a $1 \mathrm{e}^{-} / \mathrm{O}_{2}$ process. (C) Schematic illustration of the solution-mediated superoxide transfer mechanism during discharge (bottom) and charge (upper). Superoxide anion is solvated as ion pairs in $\mathrm{DMSO}^{-}\left[\mathrm{Na}^{-} \mathrm{O}_{2}\right]$ or by generating $\mathrm{HO} 2$ intermediate upon reaction with proton-based phase transfer catalysts. Once supersaturation is achieved, $\mathrm{NaO}_{2}$ precipitates forming cubic-shaped crystals. The charge process follows the reverse pathway of discharge process. (B,C) Reproduced with permission from ref 95 . Copyright 2015 Springer Nature.
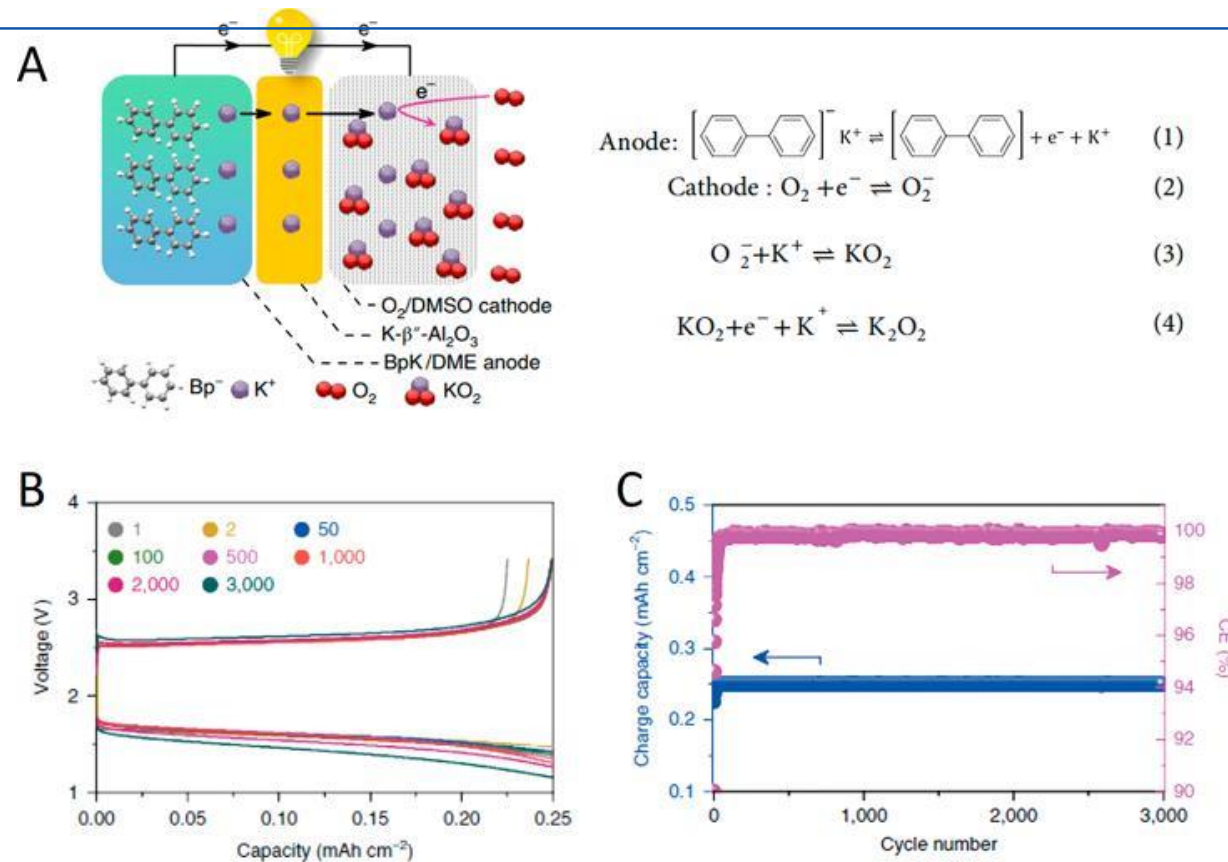

Figure 40. A long-life potassium biphenyl complex-oxygen $\left(\mathrm{BpK}^{-} \mathrm{O}_{2}\right)$ cell. (A) Cell configuration and working principle of $\mathrm{BpK}^{-} \mathrm{O} 2$ chemistry. (B) Galvanostatic voltage profiles of the $\mathrm{BpK}-\mathrm{O}_{2}$ cell at a current density of $4.0 \mathrm{~mA} \mathrm{~cm}{ }^{-2}$ during cycling. (C) The corresponding charge capacities (dark blue) and CEs (purple) of the $\mathrm{BpK}^{-} \mathrm{O}_{2}$ cell in $\mathrm{B}$. Reproduced with permission from ref 120. Copyright 2019 Springer Nature.

the stability of protective layers against parasitic reactions of reactive oxygen species (ROS), Kwak et al. evaluated the chemical stability of different layers and oxygen concentration during recharge in $\mathrm{Li}-\mathrm{O}_{2}$ batteries. It was previously reported that a protective layer containing PVDF or PEO exhibited chemical change and continuous decrease of oxygen. Nevertheless, a composite layer (NCL) based on Nafion, which is known to be stable against oxygen attack, gave effective metal 

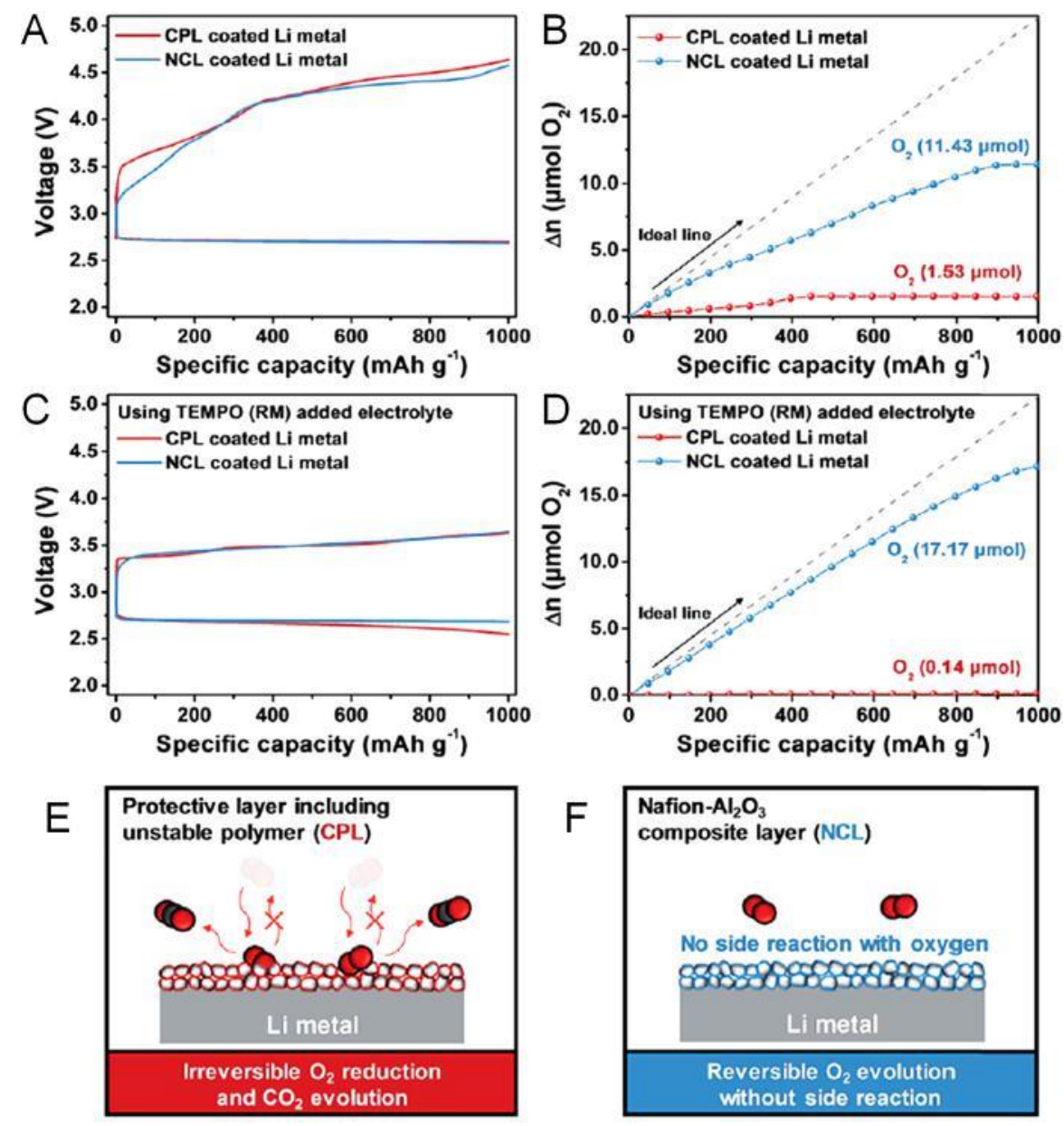

Figure 41. Chemical stability of protective layer on $\mathrm{Li}$ metal in $\mathrm{Li}-\mathrm{O}_{2}$ batteries: (A) Galvanostatic voltage profiles and (B) integration of $\mathrm{O}_{2}$ gas amount for the corresponding charge process. (C) Galvanostatic voltage profiles with redox mediator in the same electrolyte solution and at the same current rate and (D) integration of the amount of $\mathrm{O}_{2}$ gas for the corresponding charge process. The red and blue graphs indicate PVdF-based CPL and Nafion-based NCL, respectively. The dashed line in (B,D) indicates the ideal total amount of $\mathrm{O}_{2}$ gas. (E,F) schematic illustrations of side reactions on the CPL and the negligible parasitic reaction on the inert NCL, respectively. Reproduced with permission from ref 317 . Copyright 2019 Royal Society of Chemistry.

protection without any parasitic reactions by reactive oxygen $\left(\mathrm{O}_{2}{ }^{-},{ }^{1} \mathrm{O}_{2}\right)$ as shown in Figure 41A. Future studies need to confirm these important results.

Another problem sometimes overlooked in the protection of lithium metal in $\mathrm{Li}-\mathrm{O}_{2}$ batteries is the formation of dendrites. Currently, this problem is not so serious because the actual capacity value $(\mathrm{mAh})$ and current $(\mathrm{mA})$ are relatively low compared to practical Li-ion batteries, although the specific capacity based on the mass of cathode is high.

In a scale up study ${ }^{317-319}$ using large area electrodes and pouch cells (Figure 42A), it was found that the dendritic growth of $\mathrm{Li}$ metal was much more pronounced than that of a small sized system based on either coin cells or Swagelok cells (Figure 42BE). As the area of the electrode increases, uniform distribution of current is difficult and dendrite problems become aggravated due to uneven local reactions. This problem leads to an imbalance in Li2O2 formation, which greatly reduces the reversibility of the system (Figure 42F).

As a result, not only must the side reactions of the Li metal surface be considered but also dendrite growth and volume changes. To make the battery more practical, along with the chemical and physical stability of the protective film, a study of the effect of local current is also required. Future research directions must include scale up through controlling the local current density ${ }^{320}$ or using pouch type cells.317-319

3.7.2. Solid-State Li-Air and Na-Air Batteries. Studies on solid-state $\mathrm{Li}-\mathrm{O}_{2}$ batteries using solid electrolytes (SE) have been conducted in order to overcome many problems (see below) in $\mathrm{Li}-\mathrm{O}_{2}$ batteries which contain electrolytes in organic solvents. In $\mathrm{SEs}, \mathrm{Li}-\mathrm{O}_{2}$ cells, comprised of ceramic and/or polymeric materials which conduct $\mathrm{Li}$ ions, convey $\mathrm{Li}$ ions between the carbonaceous oxygen cathode and the lithium metal anode. Dozens of papers have been published in this area over the past decade, and several characteristic examples are mentioned below. The use of SEs in these systems have the aim of solving chemical and electrochemical problems of instability, flammability, toxicity, and volatility of organic electrolyte solutions. The SE can protect the $\mathrm{Li}$ or $\mathrm{Na}$ metal anodes and prevent crossover of reactive oxygen reduction products from the cathode to the anode. Using polymeric electrolytes also enables fabrication of flexible batteries 321,322

The first demonstration of solid-state $\mathrm{Li}-\mathrm{O}_{2}$ cells was presented by Kumar et al. ${ }^{323}$ Their design was comprised of a ceramic-glass electrolyte (LAGP) placed between polymeric membranes based on poly(ethylene oxide) (PEO) blended with lithium salt. The cells demonstrated stable performance for 40 cycles and excellent thermal stability up to $105^{\circ} \mathrm{C}$. 

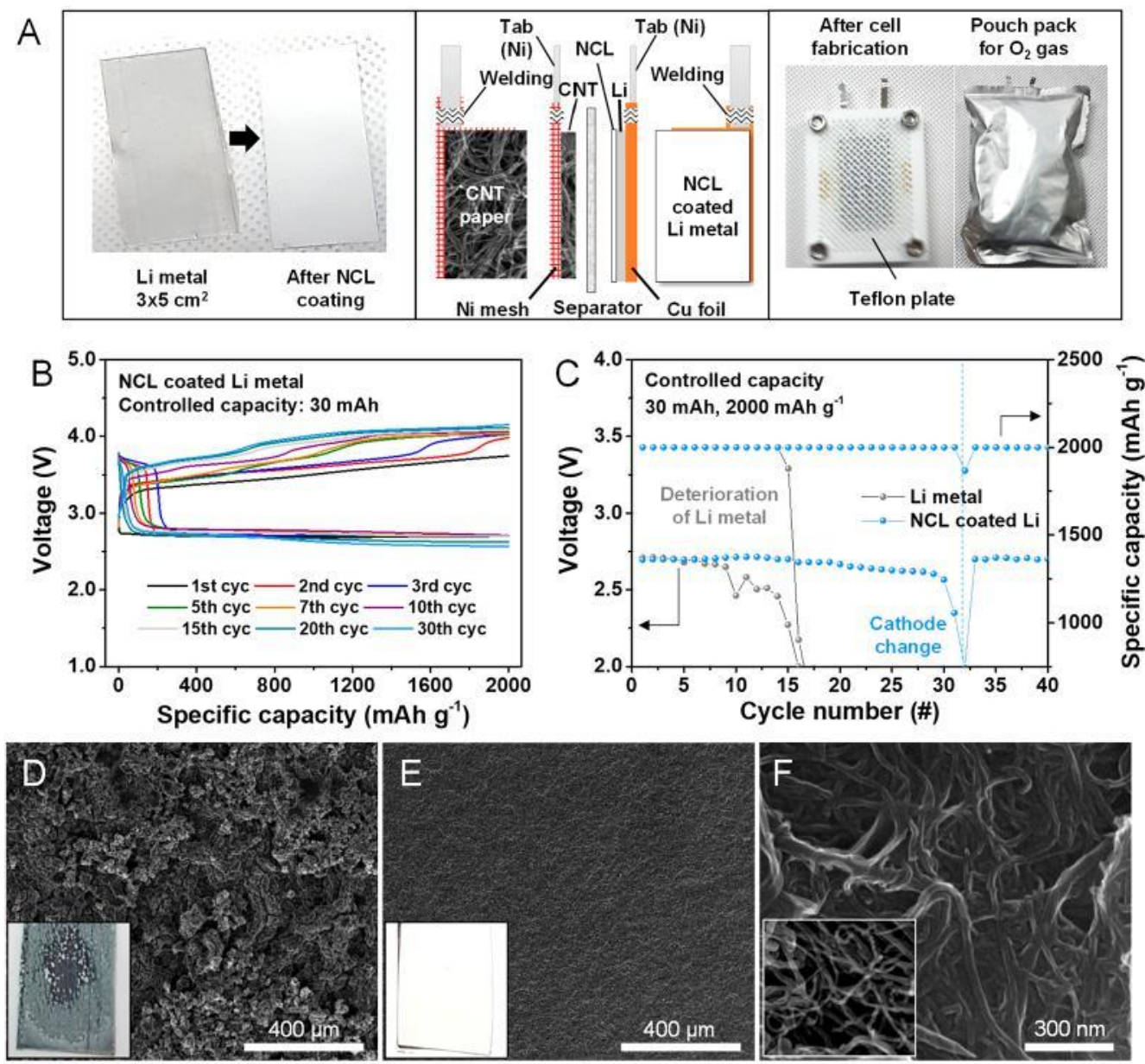

Figure 42. Protective layer for $\mathrm{Li}$ metal in large sized $\mathrm{Li}-\mathrm{O}_{2}$ cell. (A) Photograph of a $\mathrm{Li}$ electrode before and after NCL coating for pouch-type cell fabrication (left), schematic image of the cell configuration of the $\mathrm{Li}-\mathrm{O}_{2}$ pouch cell (middle), and a photograph of a $\mathrm{Li}-\mathrm{O}_{2}$ pouch cell before and after pouch packing with $\mathrm{O}_{2}$ gas (right). (B) Voltage profiles during the galvanostatic cycling test of a $\mathrm{Li}-\mathrm{O}_{2}$ pouch cell using NCL-coated $\mathrm{Li}$ metal. (C) Cycling performance (i.e., end voltage of discharge and specific capacity) of $\mathrm{Li}-\mathrm{O}_{2}$ pouch cells using $\mathrm{Li}$ metal and NCL-coated $\mathrm{Li}$ metal as a function of the cycle number. (D-F) SEM images and photographs of (D) Li metal and (E) NCL-coated $\mathrm{Li}^{-}$metal after the cycling test of $\mathrm{Li}^{-} \mathrm{O}_{2}$ pouch cells. (F) SEM image of a CNT paper electrode in a $\mathrm{Li}^{-} \mathrm{O}_{2}$ pouch cell using NCL-coated Li metal after the cycling test until cell failure. Reproduced with permission from ref 317. Copyright 2019 Royal Society of Chemistry.

Research on solid-state $\mathrm{Li}-\mathrm{O}_{2}$ batteries can be divided into two categories: one direction promotes the use of pure solid-state electrolytes and does not contain any liquid component; in the other, quasi-solid-state systems are developed, including mixtures comprised of polymeric matrices (sometimes including ceramic particles) and liquid electrolyte solutions based on organic solvents or ionic liquids. An example of the first category is the work of Wang et al., in which pure solid electrolyte $\mathrm{Li}-\mathrm{O}_{2}$ cells utilizing the $\mathrm{Li}^{+}$conducting materials $\mathrm{Li}$ $1+x+y(\mathrm{~T}$ i, $\mathrm{G} \mathrm{e}) 2-x \mathrm{Si}_{\text {y }} \mathrm{P}_{3}-$ y $\mathrm{O} 12(\mathrm{Li} \mathrm{S} \mathrm{I} \mathrm{C} \mathrm{O} \mathrm{N}),{ }^{324}$ Li1.3Al0.3Ti1.7(PO4)3 (LATP), and Li1.5Al0.5Ge1.5(PO4)3 (LAGP) were used. This cell also emphasized the problem of the generally low ionic conductivity of the solid electrolytes, which results in low rate capability. In addition, there are severe interfacial contact failure problems between the electrodes and the solid electrolytes during the cycling of these cells. ${ }^{325} \mathrm{~A}$ possible solution to problems of contact between solid electrolytes and cathodes could be their integration into a single solid mixture, as suggested by Zhu et al. ${ }^{326}$

An important use of solid electrolytes in $\mathrm{Li}-\mathrm{O}_{2}$ cells is in developing protected $\mathrm{Li}$ anodes. Once the Li metal anodes are protected by artificial predesigned solid electrolyte interphases, the reactivity problems related to the negative electrodes can be fully alleviated. 327,328

Another approach in design and elaboration of solid-state $\mathrm{Li}^{-}$ $\mathrm{O}_{2}$ or $\mathrm{Na}-\mathrm{O}_{2}$ cells is the use of polymeric electrolyte membranes that separate the anode and cathode in the cells. ${ }^{329,330}$ These systems may be fully polymeric or quasi-

solid, gel-type, comprising polymeric matrices and electrolyte solution included therein.330-332

It is worth mentioning the pioneering work of Peled et al., which was a first step in developing solid $\mathrm{Na}^{-} \mathrm{O}_{2}$ battery systems, namely polymeric matrices containing $\mathrm{NaClO}_{4}$ and a carbonaceous oxygen cathode. ${ }^{333}$ Peled's preliminary $\mathrm{Na}^{-} \mathrm{O}_{2}$ cells were operated at $105^{\circ} \mathrm{C}$, which is above the sodium melting point of $97.8^{\circ} \mathrm{C}$. The liquid sodium metal cells demonstrated 100 cycles with limited normalized capacity. That work was a first attempt in the direction of using sodium anodes in a solid-state configuration.

Using quasi-solid polymeric matrices as the electrolytes in $\mathrm{Li}^{-}$ $\mathrm{O}_{2}$ or $\mathrm{Na}-\mathrm{O}_{2}$ cells reflects a compromise. These matrices are less reactive with the electrodes and the oxygen reduction products than the liquid electrolytes. Using such cells at elevated temperatures enable achievement of reasonable rate capabilities. Hence, one may be able to obtain longer life cycle compared to 

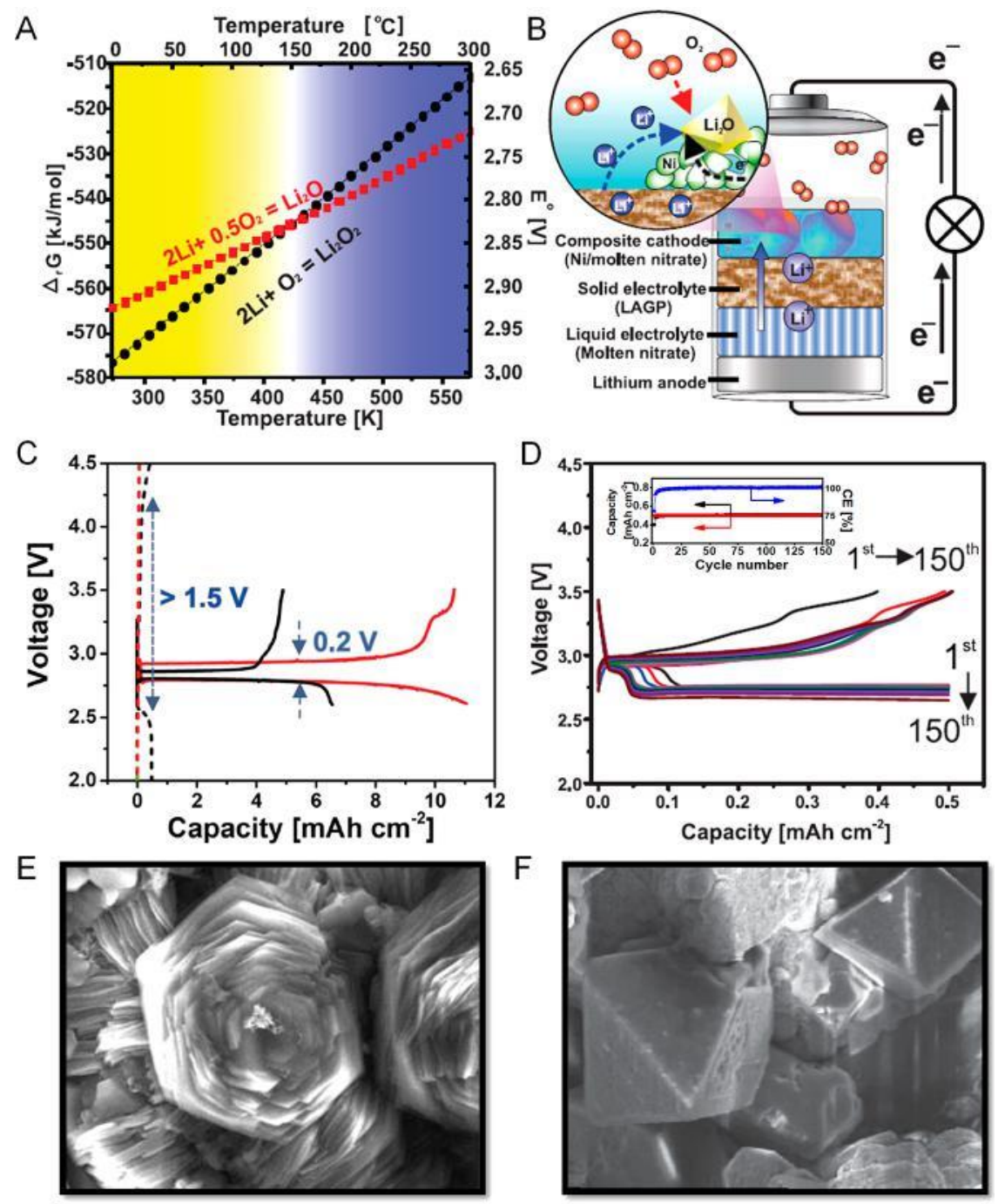

Figure 43. $\mathrm{Li}_{2} \mathrm{O}$-based $\mathrm{Li}-\mathrm{O}_{2}$ cell using molten salt-based electrolytes. (A) Thermodynamics and configuration of the $\mathrm{Li}-\mathrm{O}_{2}$ cell. (A) Gibbs reaction energy for formation of $\mathrm{Li}_{2} \mathrm{O}$ and $\mathrm{Li}_{2} \mathrm{O} 2$ as a function of temperature. (B) Configuration of the inorganic electrolyte $\mathrm{Li}^{-} \mathrm{O}_{2}$ cell and schematic illustration of $\mathrm{Li} 2 \mathrm{O}$ formation during discharge. (C) Voltage profiles of $\mathrm{Li}-\mathrm{O}_{2}$ cells with a carbon cathode (black) and a Ni-based cathode (red) using aprotic electrolyte, $0.5 \mathrm{M}$ LiTFSI in TEGDME, were examined at $25^{\circ} \mathrm{C}$ (dashed lines), whereas the cells using the molten nitrate electrolyte were measured at $150{ }^{\circ} \mathrm{C}$ (solid lines). (D) Cycling performance of a molten nitrate $\mathrm{Li}-\mathrm{O}_{2}$ cell with a lithiated-nickel oxide catalyst at $150{ }^{\circ} \mathrm{C}$. SEM images of the discharged cathodes using molten nitrate electrolyte and carbon cathode (E), and molten nitrate electrolyte and lithiated-nickel oxide catalyst (F), respectively. Reproduced with permission from ref 342. Copyright 2018 The American Association for the Advancement of Science.

$\mathrm{Li}-\mathrm{O}_{2}$ cells with liquid electrolytes solutions. However, their use does not fully mitigate side reactions and there are obviously contact problems that impede fully uniform current distribution in these cells.

An interesting use of polymeric membranes as in $\mathrm{Li}-\mathrm{O}_{2}$ cells was demonstrated by $\mathrm{Wu}$ et al., who fabricated and tested $\mathrm{Li}-\mathrm{O}_{2}$ cells containing a superhydrophobic quasi-solid electrolyte incorporating poly isobutylene, silicon dioxide treated with dimethyl-dichlorosilane, and ionic liquids. ${ }^{334}$ The main advantages of these cells included a flexible configuration, good protection of the Li metal anodes, and blockage of detrimental flux of oxygen reduction products from the cathode to the anode. An important advantage in the use of such combinations is the possibility of solving the contact problems, from which most types of $\mathrm{SE}$-based $\mathrm{Li}(\mathrm{Na})-\mathrm{O}_{2}$ cells suffer. At first glance, while solving some instability problems, the complexity of solid-state $\mathrm{Li} / \mathrm{Na}-\mathrm{O}_{2}$ batteries may set aside many possible advantages of such systems regarding energy density and rate. A great advantage of this system may be the ability to use ambient air as the feed gas instead of pure oxygen. Because a solid electrolyte at elevated temperatures is used in this case, the presence of water and $\mathrm{CO}_{2}$ contaminations in air may be much less detrimental for basic $\mathrm{Li}-\mathrm{O}_{2}$ cell operation as compared to $\mathrm{Li}-\mathrm{O}_{2}$ cells based on liquid electrolyte solutions. Work in this direction continues.

3.7.3. On the Use of Ionic Liquids and Molten Salts. Ionic liquids (ILs), also known as room temperature molten salts, possess negligible volatility, a wider electrochemical window, and lower flammability than conventional organic solvents. ${ }^{335}$ Kuboki et al. first used imidazolium-based electrolytes for primary Li-air cells. ${ }^{336}$ The hydrophobic ILs with zero vapor pressure avoid the evaporation of electrolyte and the hydrolysis of lithium anode in moist air. These make ILs excellent solvents for the lithium-air batteries operated under ambient conditions. Subsequently, a variety of IL-based electrolytes (e.g., pyrrolidium and ammonium-based electrolytes) were developed for secondary $\mathrm{Li}-\mathrm{O}_{2}$ cells. ${ }^{337}$ Nevertheless, the chemical stability of ILs is still under debate. On the 

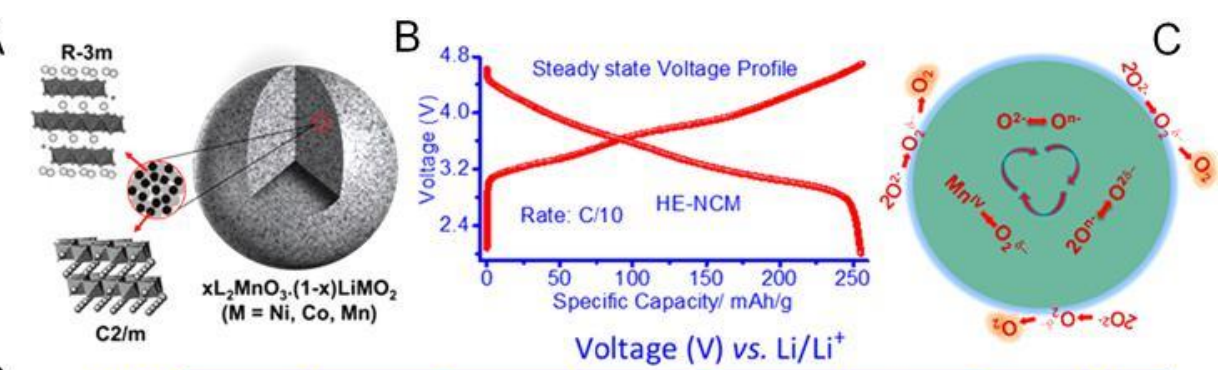

D

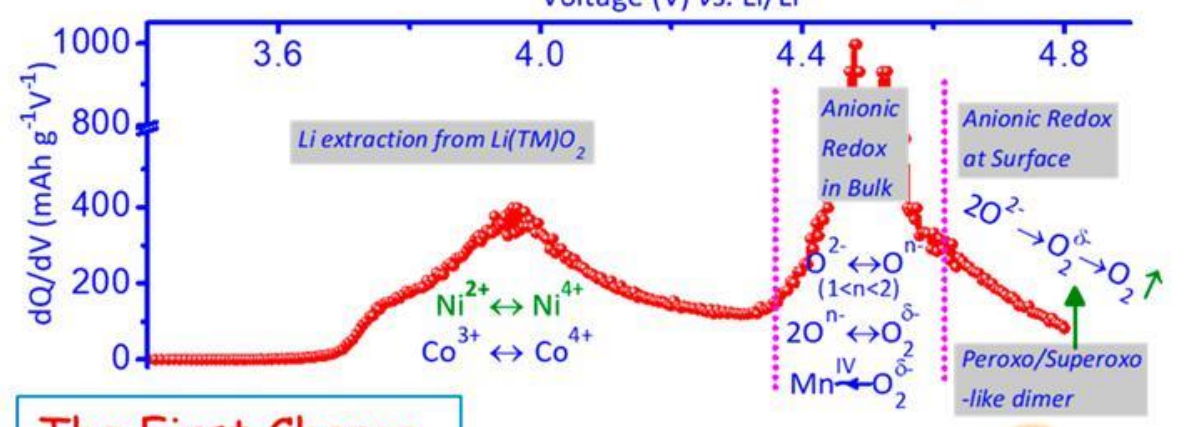

\section{The First Charge}

E

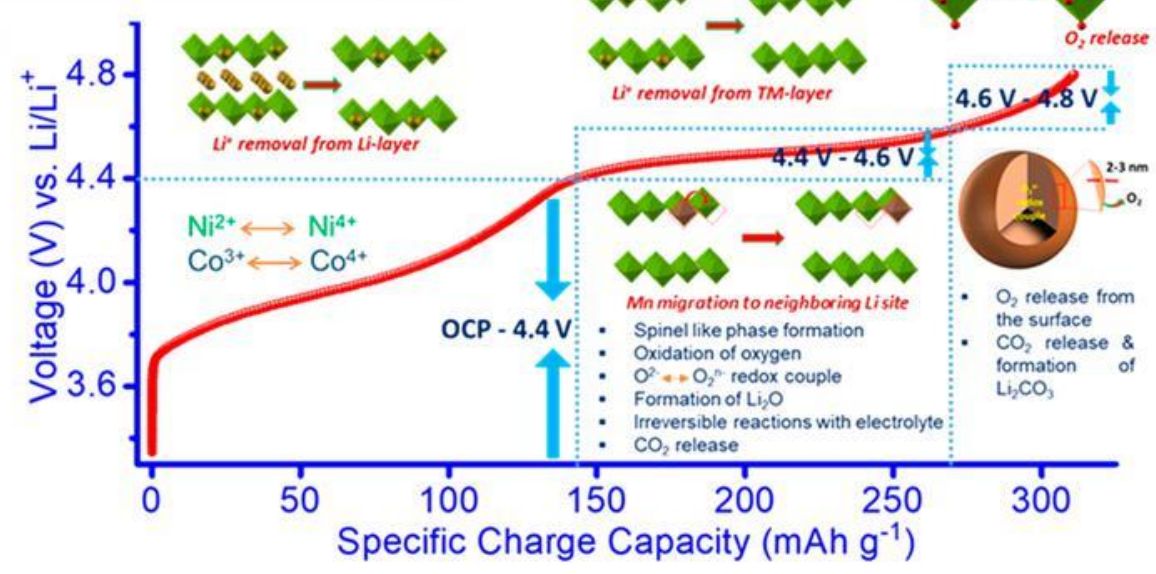

Figure 44. Li and Mn-rich cathode materials: schematically describing (A) structure, (B) steady-state voltage profiles, (C) anionic oxygen redox activity in the bulk and on the surface, and (D,E) the first charge $\mathrm{dQ} / \mathrm{dV}$ vs $\mathrm{V}$ and voltage profile demonstrating Li extraction, cationic, and anionic redox activity. $346-364$

basis of rotating ring-disk electrode (RRDE) studies, Herranz et al. found that the pseudo-first-order reaction constant of 1-butyl1-methylpyrrolidinium bis (trifluoromethylsulfonyl)imide ( $\mathrm{Pyr}_{14}$ TFSI) with $\mathrm{O}_{2}$ - is at least 3 orders of magnitude lower than that of propylene carbonate (PC). ${ }^{338}$ By contrast, Piana et al., through DEMS and NMR studies, concluded that Pyr14TFSI does not have sufficient long-term stability against superoxide attack. $^{339}$ Katayama et al. also reported the instability of imidazolium-based IL electrolytes based on cyclic voltammetry measurements. ${ }^{340}$ In addition, the viscosities of ILs are usually one magnitude higher than those of conventional organic solvents. They lower the ionic conductivity of electrolyte and decrease the diffusion coefficient of oxygen/superoxide, which results in a low discharge capacity and poor rate capability. ${ }^{341}$ Therefore, more efforts are needed to explore novel ILs with higher stability and lower viscosity.

Inorganic molten salts (e.g., molten nitrate eutectic) typically melt above $100{ }^{\circ} \mathrm{C}$ and thereby allow $\mathrm{Li}-\mathrm{O}_{2}$ cells to operate at higher temperatures. The first molten salt $\mathrm{Li}-\mathrm{O}_{2}$ cell was reported by Giordani et al. using the $\mathrm{LiNO}_{3}-\mathrm{KNO}_{3}$ eutectic. ${ }^{343}$ The cell shows a very low overpotential of $50 \mathrm{mV}$ and an improved rate capacity at $150{ }^{\circ} \mathrm{C}$ due to the reversible transfer of the tizez product in the molten nitrate electrolyte. On the basis of in situ pressure and gas analyses, they found that $\mathrm{Li}-\mathrm{O}_{2}$ chemistry is reversible in this medium, which reflects on the high stability of the inorganic electrolyte. Recently, Xia et al. reported on a $\mathrm{Li}-\mathrm{O}_{2}$ cell using a molten nitrate electrolyte and solid ceramic membrane that reversibly forms and oxidizes $\mathrm{Li}_{2} \mathrm{O}$ in a stepwise four-electron redox process (Figure 43A-C). ${ }^{342}$ As shown in Figure 43D, the cell exhibits stable cycling performance for 150 cycles with a very low polarization of $0.2 \mathrm{~V}$ and a high Coulombic efficiency close to $100 \%$. By tuning the operating temperature and using a bifunctional lithiated nickel oxide catalyst, this $\mathrm{Li}-\mathrm{O}_{2}$ battery overcomes the barriers of thermodynamics and kinetics, leading to the electrochemically reversible formation of octahedral lithium oxide $\left(\mathrm{Li}_{2} \mathrm{O}\right)$ crystals instead of hexagonally shaped $\mathrm{Li}_{2} \mathrm{O} 2$ crystals that are formed on carbon cathodes (Figure 43E,F). The use of chemically stable inorganic electrolytes and a noncarbonaceous cathode circumvents the degradation of organic electrolyte and carbon corrosion, which are the main failure mechanisms for nonaqueous $\mathrm{Li}-\mathrm{O}_{2}$ cells. It demonstrates that $\mathrm{Li}-\mathrm{O}_{2}$ electrochemistry is not intrinsically limited once problems of electrolyte, superoxide, and cathode host are overcome. 

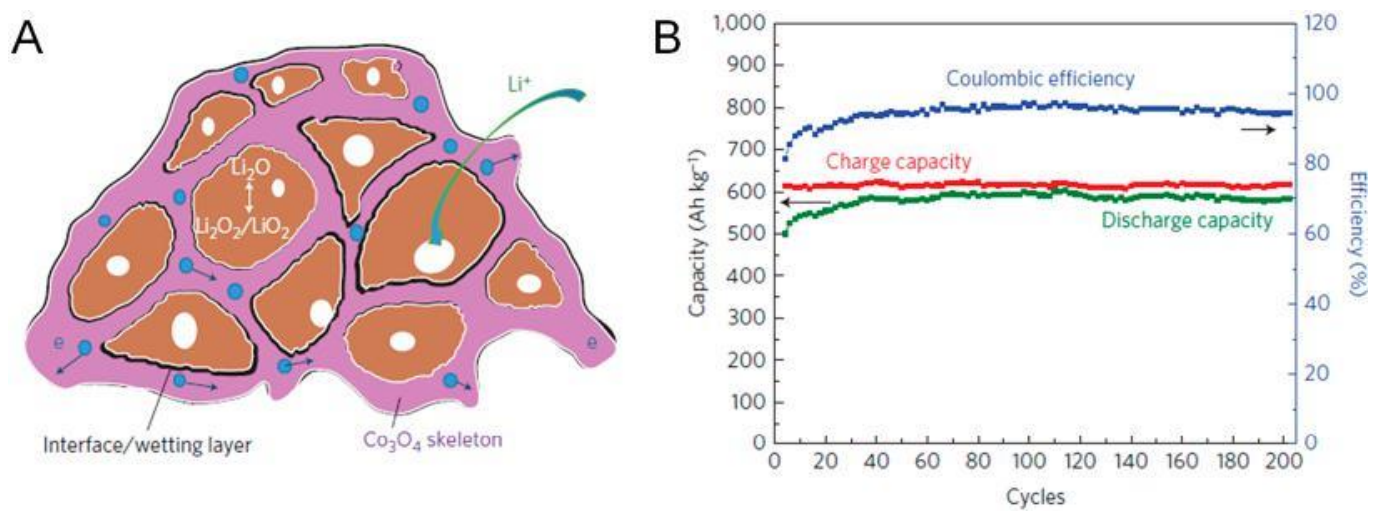

Figure 45. (A) Schematic of $\mathrm{C}_{3} 34$ skeleton wetted by amorphous $\mathrm{Li}_{2} \mathrm{O} / \mathrm{Li}_{2} \mathrm{O}_{2} / \mathrm{LiO}_{2}$, the arrows indicate the diffusion paths of electrons and $\mathrm{Li}$ ions. (B) Cycling performance and Coulombic efficiency of nanolithia cathode vs Li metal anode. Reproduced with permission from ref 369 . Copyright 2016 Springer Nature.

Bevelopment of $\mathrm{Li}_{-}-\mathrm{O}_{2}$ batteries using molten salts may have advantages in terms of fast kinetics. However, this means work at elevated temperatures, selection of suitable electrodes, materials and cell components that can withstand successfully elevated temperatures and harder experimental work. It should be noted that the research in this direction is at a very early stage and the number of publications is very small. Much further work is required in order to find out if such a direction is useful to the field.

3.7.4. On the Possible Use of Solid Li-Oxide Cathodes and the Connection to Lithiated Transition Metals. Intensive studies have been carried out on high capacity cathodes for $\mathrm{Li}$ ion batteries with the formulas $\mathrm{Li} 1+x \mathrm{MnyCozNi} 1-x-y-z \mathrm{O}_{2}(\mathrm{x}>$ $0, \mathrm{y}>0.5)$, known as $\mathrm{Li}$ and $\mathrm{Mn}$ rich NMC cathodes. These studies revealed that their redox mechanisms, leading to a very high specific capacity (approaching $300 \mathrm{mAh} \mathrm{g}^{-1}$ ), involve electrochemical activity of oxygen species. The synthesis of these materials that includes high temperature calcination stages naturally forms a mixture of integrated phases: an electrochemically inactive monoclinic phase, $\mathrm{Li}_{2} \mathrm{MnO}_{3}$, and an active rhombohedral phase with the general stoichiometry

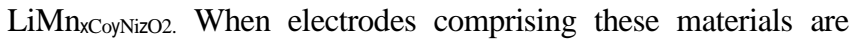
polarized to high enough potentials (e.g., $4.8 \mathrm{~V}$ vs $\mathrm{Li}$ ), a complex activation process takes place which affects the structure of the monoclinic phase, delithiates the entire cathode material, and makes it fully electrochemically reversible (Figure 44). Traditional thinking attributed the activation process and the subsequent further behavior of these systems to changes in the oxidation state of the transition metal cations and related structural rearrangements. However, recent studies, starting with the pioneering work of Sathiya et al., ${ }^{344}$ discovered that the activation process of these materials involves oxidation of the oxide anions to oxygen moieties with a higher oxidation state at a potential $>4.6 \mathrm{~V}$ vs $\mathrm{Li}$. Upon repeated cycling, the process is reversible and the oxidized oxygen moieties are reduced back to oxides at around 3 $\mathrm{V}$. This involvement of oxygen electrochemistry, in fact, enables the high specific capacity of these cathode materials that may reach the highest limit relevant for $\mathrm{Li}$ insertion cathodes with the general formula Li1+xM1-xO2 $\left(300 \mathrm{mAh} \mathrm{g}^{-1}\right)$. Thackeray et al. reported on a similar study in an approach exploiting $\mathrm{Li}-\mathrm{O}_{2}$ electrochemistry using particularly iron oxides $(\mathrm{Li}-\mathrm{F}-\mathrm{O})$ which can react with lithium and oxygen to produce compounds that contain a $\mathrm{Li}_{2} \mathrm{O}$ component for hybrid $\mathrm{Li}$-ion $/ \mathrm{O}_{2}$ batteries. ${ }^{345}$
However, the process of activation and reversible operation, capacity fading mechanisms, and average voltage fading mechanisms are not fully clear yet. It appears that oxidation of the oxide moieties may lead to irreversible evolution of molecular singlet oxygen which is detrimental. Also, because of their partial oxidation, upon charging, the resulting nucleophilic oxygen moieties are highly reactive with the electrophilic alkyl carbonate solvents. Thereby, effective surface protection of these materials by coatings (to avoid oxygen release and detrimental contact with solution species) is mandatory for their stable reversible cycling. Figure 44 summarizes several important experimental aspects related to these cathodes. Intensive work is being currently carried out on these materials (refs 355-364 are typical examples out of hundreds of publications that have appeared in recent years).

\subsection{Studies with Consideration of Practical Metal-Air Batteries}

3.8.1. Li Batteries with Lithium Oxygen Compound Cathodes (and Closed Systems). One of the ways to overcome the challenge of operating in air (which requires reduction in $\mathrm{CO}_{2}$ and $\mathrm{H}_{2} \mathrm{O}$ levels from the incoming gas stream) is to have a closed $\mathrm{Li}-\mathrm{O}_{2}$ system, where the oxygen is already stored in the battery. One approach is to store $\mathrm{O}_{2}$ in a tank, while this adds weight and volume, it is offset, to a greater or lesser extent, by obviating the need for gas scrubbers. An alternative approach is to incorporate the oxygen in the solid state, e.g., to make the cell in the discharged state incorporating $\mathrm{Li}_{2} \mathrm{O} 2$ powder in a conductive carbon matrix to form a composite cathode. Early studies used this cathode preparation method to investigate the OER mechanism in a more controlled manner. The first composite cathode was described by Ogasawara et al., where ball-milling was used to mix commercial Li2O2 with high surface carbon and PTFE binder. ${ }^{83}$ It was demonstrated that the $\mathrm{Li}_{2} \mathrm{O}_{2}$ can be completely oxidized at high enough potentials. In a later study, Meini et al. reported that commercial $\mathrm{Li2O} 2$ contains $5 \%$ of impurities such as $\mathrm{LiOH}$ and $\mathrm{Li}_{2} \mathrm{CO}_{3} .{ }^{365}$ They explained that these impurities can influence the OER process and can introduce undesirable side products. As mentioned above, several studies have described the chemical and electrochemical differences between crystalline and amorphous $\mathrm{Li}_{2} \mathrm{O}_{2}$ phases. ${ }^{102,103}$ We note that these studies did not investigate the cyclability of these types of preloaded $\mathrm{Li}_{2} \mathrm{O} 2$ cathodes.

Bhargav et al. attempted to cycle a closed $\mathrm{Li}-\mathrm{O}_{2}$ battery comprised of a composite cathode prepared from commercial $\mathrm{Li}_{2} \mathrm{O}_{2}$ and nanographite to form a composite cathode. ${ }^{366}$ The 
first discharge process showed a high specific capacity of more than $1000 \mathrm{mAh} \mathrm{g}^{-1}$. However, after four cycles, the discharge capacity dropped by more than $50 \%$. The capacity fading was attributed to the purity and size of the $\mathrm{Li}_{2} \mathrm{O} 2$ particles and their dispersion in the carbon matrix. The same group observed improvement in the battery cycle life when the cathode was made from highly pure synthesized nanocrystalline $\mathrm{Li}_{2} \mathrm{O}_{2}$ particles that were embedded in carbon nanofibers. ${ }^{367}$ The influence of the $\mathrm{Li}_{2} \mathrm{O} 2$ loading in the carbon cathode can also be a limiting factor in maximizing the energy density of the cathode. Luo et al. showed that the impedance of the preloaded cathodes increased with more insulating $\mathrm{Li}_{2} \mathrm{O}_{2}$. They concluded that $20 \mathrm{wt}$ $\% \mathrm{Li}_{2} \mathrm{O}_{2}$ in the carbon black matrix delivered the highest energy efficiency. The crossover of oxygen evolved from $\mathrm{Li}_{2} \mathrm{O}_{2}$ particles to the lithium anode can result in different decomposition reactions which can degrade the $\mathrm{Li}-\mathrm{O}_{2}$ performance. 64,368

In a recent study, Zhu et al. proposed a new alternative closed $\mathrm{Li}-\mathrm{O}_{2}$ system where a cathode made of $\mathrm{Co}_{0} \mathrm{O} 4$ nanoporous matrix is filled with nanolithia $\left(\mathrm{Li}_{2} \mathrm{O}\right){ }^{369}$ In this type of cell, the cathode cycles between the discharged $\mathrm{Li}_{2} \mathrm{O}$ and the $\mathrm{Li}_{2} \mathrm{O}_{2} / \mathrm{LiO}_{2}$ formed during the charge process. The authors proposed that the large OER overpotential observed in standard $\mathrm{Li}-\mathrm{O}_{2}$ cells is due to the phase transition between the solid products $\left(\mathrm{Li}_{2} \mathrm{O}_{2}\right)$ and the evolving $\mathrm{O}_{2}$ gas, which leads to a severe kinetic bottleneck. Unlike a standard $\mathrm{Li}-\mathrm{O}_{2}$ cell, the proposed lithia-based system is based on redox chemistry in the condensed state. As can be seen from the cyclic voltammogram in Figure 45, the difference in voltage between the reduction and oxidation peaks is only $0.24 \mathrm{~V}$. As seen from Figure 45 , a cell comprised of a lithia cathode and lithium metal anode exhibited 200 cycles at around $600 \mathrm{Ah} \mathrm{kg}^{-1}$ capacity with low capacity loss.

3.8.2. Challenges of Capacity and Kinetics. The use of redox mediators has overcome many of the challenges introduced by the intrinsic oxygen electrochemistry, especially the otherwise limited rate and capacity of $\mathrm{Li}-\mathrm{O}_{2}$ cells when operated in low DN solvents such as ethers, as described above in section 3.5. However, oxygen redox limitations are only one aspect of the problem. Lithium peroxide preferentially forms at the air interface of the cathode and blocks the electrode pores (Figure 46A). ${ }^{208}$ The bulk of the cathode volume remains relatively free of discharge product which is detrimental to capacity. Simulated discharge curves by Liu shows that oxygen depletion and pore clogging is mainly responsible for limited capacity and cell death. ${ }^{370}$ Figure 46 presents this schematically, showing the $\mathrm{O}_{2}$ concentration through the cathode at high and low rates. It indicates that the $\mathrm{O}_{2}$ availability is limited to the air interface and much of the cathode is starved and inactive. Gittleson et al. explored the effect of $\mathrm{O}_{2}$ and $\mathrm{Li}^{+}$transport in different solvents and concluded that low oxygen solubility and pore blocking at the air interface were now the major factors limiting capacity and inducing cell death. ${ }^{371}$

These results highlight the need for methods to enhance $\mathrm{O}_{2}$ mass transport in the lithium-air battery. It is unlikely that strategies can be directly translated from the aqueous fuel cell as the solvents share little common chemistry. In addition, operation of the two systems differ considerably. The product of the aqueous fuel cell is the solvent, while the Li-air battery forms a new solid phase (lithium peroxide). New engineering and chemical methods for oxygen delivery are required for the lithium-air battery. One such example of a chemical solution to this problem is the use of the perfluorocarbons (PFC), which increase oxygen solubility and mass transport. PFC additives can
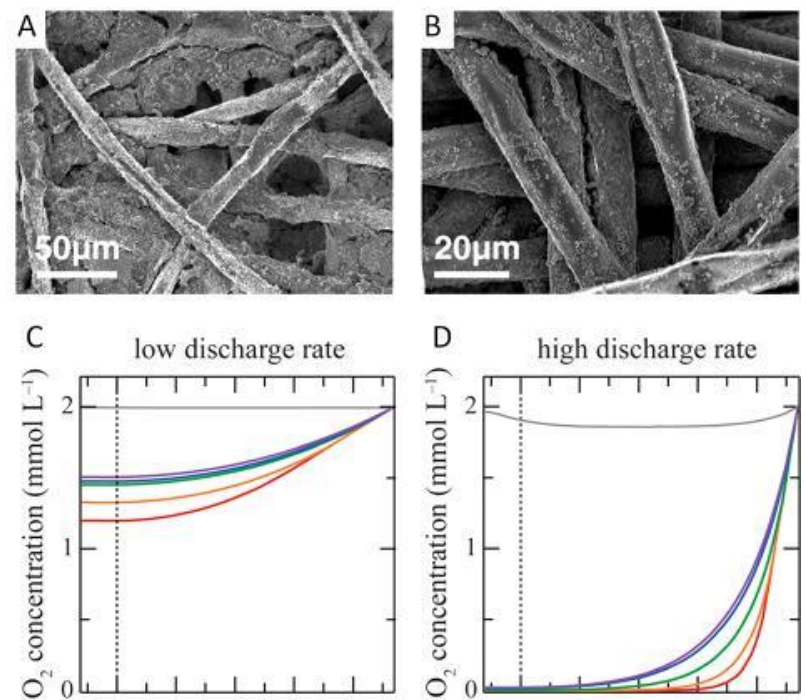

Figure 46. SEM images of a dual mediator cathode at (A) the $\mathrm{O}_{2}$ interface and (B) the separator interface. Reproduced with permission from ref 208. Copyright 2017 Springer Nature. (C,D) Plots of $\mathrm{O}_{2}$ concentration distribution in the electrolyte of the cathode at six depths of discharge. Reproduced with permission from ref 370. Copyright 2016 Royal Society of Chemistry.

be classified as miscible ${ }^{372-374}$ and immiscible. ${ }^{375,376}$ Nishikami et al. showed that $\mathrm{BrC}_{\mathrm{C}} \mathrm{F} 13$ forms a miscible solution with TEGDME up to $60 \mathrm{wt} \%$, improving the discharge capacity by $50 \%,{ }^{374}$ although at the expense of electrolyte conductivity. Contentiously, Wijaya et al. suggested that the enhancement observed with miscible PFCs is due to parasitic currents from PFC attack by superoxide. ${ }^{377}$ Immiscible PFCs have been proposed to avoid this problem and introduce three phase regions into the cathode where the PFC acts as oxygen channels. ${ }^{377}$ This method doubled the discharge capacity at low current densities but had a negative impact on capacity at higher rates. The authors proposed that this was due to greater pore blocking. Enhancement is also seen when immiscible PFCs are introduced to a dual mediator cell. ${ }^{376}$

3.8.3. On the Validity of Energy Density Calculation of Li (Na)-Oxygen Batteries. The exceptional theoretical specific energy of the Li-air cell led many people to rush to the conclusion that this would translate into practical specific energies and energy densities many times that of Li-ion. Such confusion is often compounded by reports that use only the carbon mass to normalize the capacity. By analyzing current reported protocols for $\mathrm{Li}-\mathrm{O}_{2}$ cells evaluation in the literature, Noked et al. demonstrated that many of the reports fall short in specifying the exact cell composition and cycling conditions. ${ }^{61}$ When trying to clarify the practical potential of the Li-air battery system, we need to keep two major aspects in mind: (1) careful examination of reported values in the literature and (2) what we can expect as performance from a Li-air battery, even if we solve all the stability and kinetic limitation issues of these systems. Of course, Li-ion batteries are not immune from this problem, for example, the often quoted

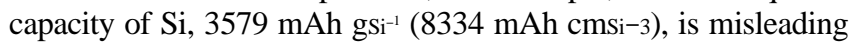
as it ignores the $\mathrm{Li}$ in $\mathrm{Li} 3.75 \mathrm{Si}$, and the need for volume expansion is also often ignored. The true figures are $1857 \mathrm{mAh} \mathrm{g}^{-1}$ and 2290

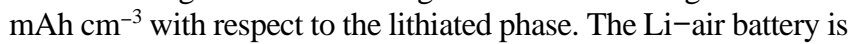
very different from Li-ion, most notably the former requires a balance of plant associated with gas handling and the need to reduce the $\mathrm{CO}_{2}$ and 
$\mathrm{H}_{2} \mathrm{O}$ content in the gas stream. These uncertainties led some researchers to question whether even if the problems of $\mathrm{Li}$-air can be solved, it would outperform Li-ion and $\mathrm{Li}-\mathrm{S}$. The first rigorous attempt to truly compare $\mathrm{Li}-\mathrm{ion}, \mathrm{Li}-\mathrm{S}$, and $\mathrm{Li}-$ air batteries (as opposed to cells), was made by Gallagher et al. in 2014. ${ }^{53}$ They modified the Argonne Batpac modeling software to permit prediction of the specific energy and energy density of a practical Li-air battery, including the air handling/balance of plant. They concluded that while $\mathrm{Li}$-air was shown to have a higher specific energy compared with $\mathrm{Li}$-ion and $\mathrm{Li}-\mathrm{S}$, this would not be the case volumetrically compared with a cell containing a $\mathrm{Li}$ metal anode and a $\mathrm{Li}$ rich NMC cathode. However, as detailed in this review, our understanding of the $\mathrm{Li}$-air battery has been transformed over the last six years and the introduction of redox mediators and recognition that significant quantities of $\mathrm{H}_{2} \mathrm{O}$ can be tolerated, alleviating the need to complex, heavy, and bulky air handling, changes the assumptions required to model performance. Taking account of recent advances including the use of redox mediators, reduced balance of plant overhead, and a protected $\mathrm{Li}$ anode, which reduces the need for a large excess of $\mathrm{Li}$, we predict the specific energy and the energy density of a full $\mathrm{Li}$-air battery, including the balance of plant, to be $610 \mathrm{Wh} \mathrm{kg}^{-1}$ and $680 \mathrm{Wh} \mathrm{L}^{-1}$, respectively, compared with 450 for each in the case of $\mathrm{Li}-\mathrm{S}$ and $300 \mathrm{Wh} \mathrm{kg}^{-1}$ and $500 \mathrm{Wh} \mathrm{L}^{-1}$ for a Li anode and Li-rich NMC. Larger energy batteries increase this difference as the mass fraction associated with the balance of plant diminishes relative to the pack, and conversely, $\mathrm{Li}$-air is not competitive for small batteries such as consumer electronics. The major advantage of $\mathrm{Li}$-air is in specific energy. As a result, it might prove particularly useful for challenges such as aviation, where mass and specific energies beyond what Li-ion can deliver are essential.

In summary, the gap between the very high theoretical energy density of $\mathrm{Li}$-air batteries, and practical expectations is very wide, reducing the advantage of $\mathrm{Li}$-air over other $\mathrm{Li}$ batteries; however, $\mathrm{Li}$-air is still predicted to offer performance beyond the other battery technologies, especially in terms of mass, and this is based on full cell analysis and operation in air. As a result, while $\mathrm{Li}$-air is still some way from a technology, the advances indicate that work on these systems should be further promoted as discussed in the Conclusion.

3.8.4. From Oxygen to Air. The lithium-air battery must operate in air if it is to reach its maximum performance. Most lab scale cells operate using pure oxygen, but a scaled practical battery pack using pure $\mathrm{O}_{2}$ would offer significantly lower specific energy compared to an open battery. ${ }^{53}$ Moving to an atmospheric gas introduces a number of challenges but surprisingly also brings some benefits. Lowering the $\mathrm{O}_{2}$ partial pressure has been shown to impact capacity. ${ }^{378}$ As discussed above, as yet unimagined strategies are needed for oxygen delivery which may help to eliminate this problem. Atmospheric nitrogen will not be compatible with the lithium metal anode, but it is generally accepted that lithium will have to be protected with an artificial SEI or ceramic interphase in any case.

Contrary to established thinking, a series of papers from Meini, Schwenke, and Aetukuri showed that $\mathrm{H}_{2} \mathrm{O}$ can be an advantageous additive in lithium-air electrolytes by increasing capacity and lowering the charge overpotential. ${ }^{94,96,97}$ Later, this was convincingly shown in work by Qiao et al. (Figure 47), where increasing the $\mathrm{H}_{2} \mathrm{O}$ content from 0 to $30 \%$ results in increasing discharge capacity and lowers the charge potential to below $3.5 \mathrm{~V} .{ }^{379} \mathrm{SEM}$ analyses shows that the lithium peroxide particle size increases with increasing $\mathrm{H}_{2} \mathrm{O}$ content and X-ray
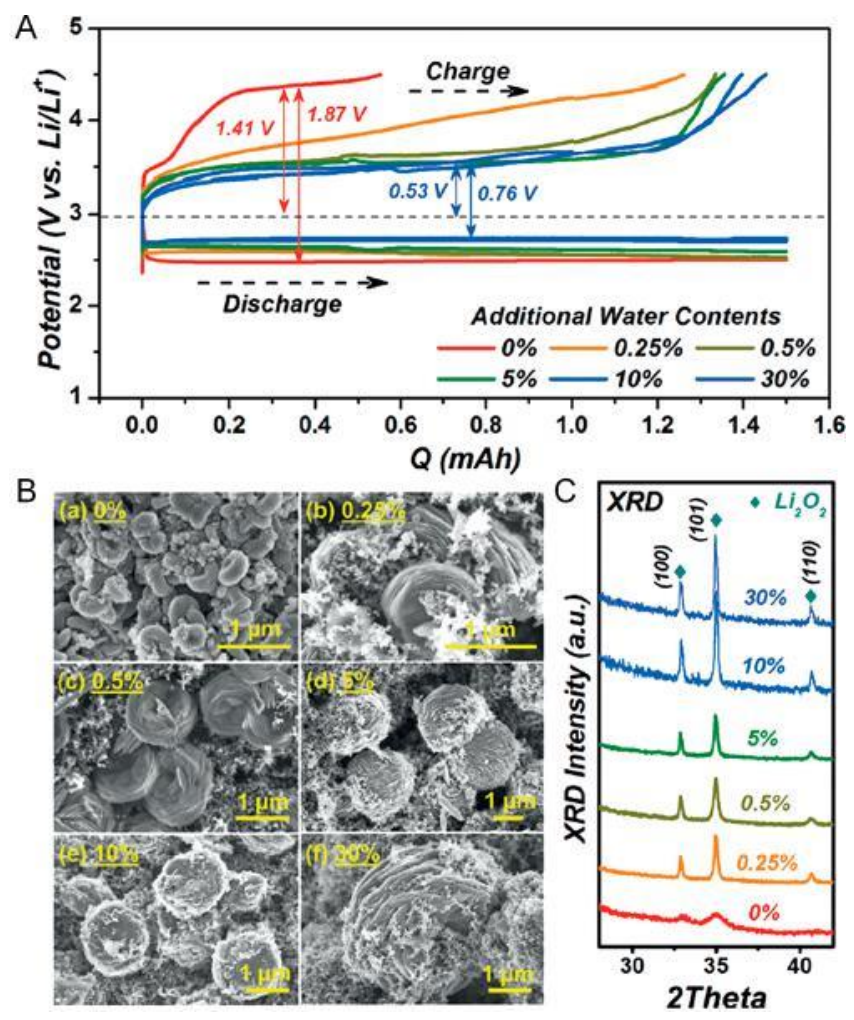

Figure 47. Discharge profiles of lithium- $-\mathrm{O}_{2}$ cells with varying $\mathrm{H}_{2} \mathrm{O}$ content and SEM images and XRD patterns of the discharge cathodes. Reproduced with permission from ref 379. Copyright 2017 Wiley$\mathrm{VCH}$.

diffraction confirms formation of lithium peroxide. We note, however, that $\mathrm{LiOH}$ has been observed at higher $\mathrm{H}_{2} \mathrm{O}$ concentrations. ${ }^{96}$ The large particles and enhanced capacity confirm discharge by a solution route, and two theories have been proposed to explain this. Aetukuri et al. suggest that the acceptor number of the $\mathrm{H}_{2} \mathrm{O}$ additive results in enhanced solvation of superoxide. ${ }^{94}$ Schwenke et al. proposed that protonation of lithium peroxide by water results in soluble peroxide. ${ }^{96}$ Both mechanisms effectively enable formation of a soluble product, able to nucleate large particles and avoid electrode surface passivation. $\mathrm{H}_{2} \mathrm{O}$ is also beneficial for performance when using quinone-based discharge mediators and more than doubles the discharge capacity. ${ }^{380}$ It is proposed that this is due to stabilization of the reduced quinone and quinone $-\mathrm{O}_{2}$ complex by $\mathrm{H}_{2} \mathrm{O}$, which effectively increases diffusion lengths and supports peroxide filling of the cathode structure. Finally, in the presence of an LiI catalyst, $\mathrm{H}_{2} \mathrm{O}$ can promote formation of $\mathrm{LiOH}$ in a $4 \mathrm{e}^{-}$reduction step.100,381 Decomposition due to $\mathrm{H}_{2} \mathrm{O}$ is an area that needs further consideration.

In contrast to $\mathrm{H}_{2} \mathrm{O}, \mathrm{CO}_{2}$ may be detrimental to the performance of the lithium-air battery. Thermodynamically, the reaction between lithium peroxide and carbon dioxide to form lithium carbonate is favorable. ${ }^{63}$ Early work in this area by Takechi et al. showed that introduction of $\mathrm{CO}_{2}$ into the lithium-air battery results in the formation of lithium carbonate and proposed that this occurred via formation of a peroxydicarbonate ion $\left(\mathrm{C}_{2} \mathrm{O}^{2-}{ }^{2-}{ }^{382}\right.$

Unfortunately, these studies used carbonate-based electrolytes which are now known to be unstable and decompose to $\mathrm{Li}_{2} \mathrm{CO}_{3}$ and $\mathrm{CO}_{2}{ }^{63}$ Gowda et al. performed similar studies but 
using a more stable DME-based electrolyte, which also clearly demonstrated the formation of $\mathrm{Li}_{2} \mathrm{CO}_{3}{ }^{384}$ Yin et al. proposed a holistic reactions mechanism for $\mathrm{Li}-\mathrm{O}_{2} / \mathrm{CO}_{2}$ in these $\mathrm{Li}$-active gas batteries, Figure $48{ }^{383}$ Three possible pathways are

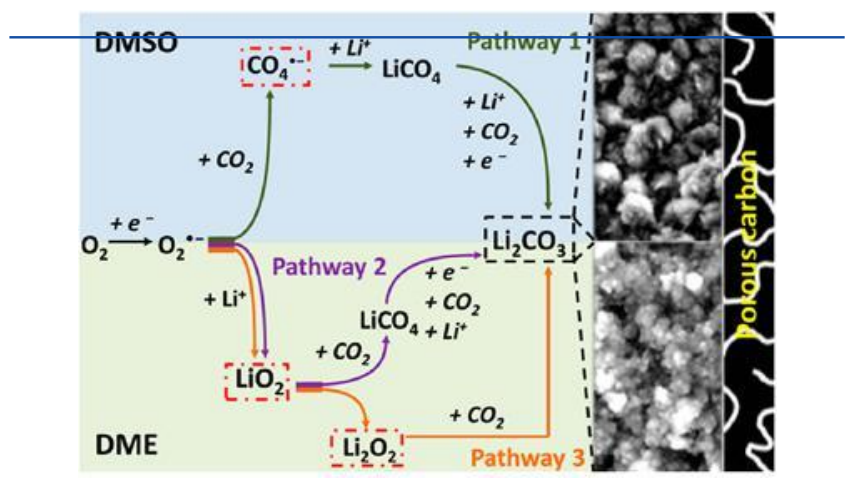

Figure 48. Reaction routes for the most likely paths in $\mathrm{Li}-\mathrm{O}_{2} / \mathrm{CO}_{2}$ battery. Reproduced with permission from ref 383. Copyright 2016 American Chemical Society.

described that can be summarized as reaction of $\mathrm{CO}_{2}$ with either $\mathrm{O}_{2}^{-}, \mathrm{LiO}_{2}$, or $\mathrm{Li}_{2} \mathrm{O}_{2}$. Theoretical and experimental studies by $\mathrm{Lim}$ et al. imply that the solvent can influence the reaction of superoxide with $\mathrm{CO}_{2}$. The reaction of $\mathrm{CO}_{2}$ with $\mathrm{Li}_{22}$ suggests that the formation of $\mathrm{Li}_{2} \mathrm{CO}_{3}$ in lithium-air batteries is inevitable and that $\mathrm{CO}_{2}$ must be removed from the oxygen feed gas. However, Liu et al. has demonstrated the use of redox mediators to remove accumulated $\mathrm{Li}_{2} \mathrm{CO}_{3}$ in the lithium-air battery. ${ }^{385}$ Recently there has also been interest in harnessing the $\mathrm{Li}-\mathrm{O}_{2} / \mathrm{CO}_{2}$ reaction, either as a higher performance battery or as a means of $\mathrm{CO}_{2}$ capture.386-388,382

These studies have enabled the expansion of this research field to the study of new batteries using pure $\mathrm{CO}_{2}$ gas as the cathode' $\mathrm{s}$ active material, having $\mathrm{Li}_{2} \mathrm{CO}_{3}$ as the main discharge product. This new system can be denoted as a $\mathrm{Li}-\mathrm{CO}_{2}$ battery (Figure 49). However, several research groups have cast doubts on their technological viability because batteries which use pure $\mathrm{CO}_{2}$ gas exhibit low discharge capacity as compared to batteries that use a mixture of $\mathrm{O}_{2} / \mathrm{CO}_{2}$ as the cathode active mass. Therefore, there is a serious debate about possible mechanisms that can enable effective electrochemical reduction of $\mathrm{CO}_{2}$ in $\mathrm{Li}-\mathrm{CO}_{2}$ batteries without the presence/involvement of $\mathrm{O}_{2}{ }^{173}$

It is important to note that the study of $\mathrm{Li}-\mathrm{O}_{2} / \mathrm{CO}_{2}$ batteries and $\mathrm{Li}-\mathrm{CO}_{2}$ batteries is rather new. As a result, there are no established mechanisms that explain how these systems can work reversibly. There are controversial opinions whether the reduction of pure $\mathrm{CO}_{2}$ is possible during discharge and which mechanism is reliable for this system. It seems that possible reaction mechanisms for such systems can be determined only by the use of in situ spectro-electrochemical techniques.

3.8.5. Configuration of Li-Air Cells and the Balance of Plant. The lithium-air battery field has rightly focused on advancing the basic science and understanding of battery chemistry. Impractical coin and Swagelok cells account for the bulk of the studies. Thus, an established cell, pack, and system design has yet to emerge. Because of the pace of advancement in the field over the past five years, this is perhaps not unfortunate as designs would quickly become obsolete. For example, a lithium-air system designed today would benefit from the development of redox mediators and an increased tolerance to $\mathrm{H}_{2} \mathrm{O}$. The excellent system model by Gallagher et al. provides the most robust design of a full lithium-air battery, which considers the complete system including the pack design and the balance of plant. ${ }^{53}$ Figure 50 shows the proposed layer structure for a practical lithium-air cell. ${ }^{53}$ The layer consists of a lithium anode on copper foil protected from the cathode by a ceramic electrolyte. Excess lithium must be minimized to achieve the highest performance. The cathode consists of a porous carbon and would house $60 \mathrm{vol}$ $\%$ of lithium peroxide. Use of a thick cathode is essential for minimizing excessive current collector mass. An aluminum foil flow field is used for oxygen delivery.

An alternative cell design (Figure 51) has been proposed by Samsung, which employed a folded cell architecture that minimizes inactive component volume and mass. ${ }^{319}$ Here, the carbon cathode fulfils the additional roles of oxygen flow field and current collector. Performance of $1214 \mathrm{Wh} \mathrm{kg-1}$ cell and 896 Wh $\mathrm{L}_{-1 \text { cell }}$ at the cell level is demonstrated, which exceeds that of Gallagher's cell model (Figure 51), although like-for-like comparisons between cell designs are not trivial. ${ }^{53}$

Repeated bilayers would form a module, typically based on a bipolar plate design similar to those used in a fuel cell, ${ }^{390}$ The system model by Gallagher proposes a doubling of the mass and volume from cell to pack (Figure 52). This includes consideration of thermal management and oxygen delivery. If the battery is to operate in air, then a balance of plant (BoP) will be needed to deliver a suitable oxygen and manage solvent volatility. The system proposed by Gallagher consists of a compressor, pressure swing adsorption unit, and a solvent addition and capture unit. ${ }^{53}$ The BoP adds an additional $70 \mathrm{~kg}$ to the overall system mass and has a significant impact on overall performance. On the basis of this overall design, and included recent advances, a favorable lithium-air system level perform-

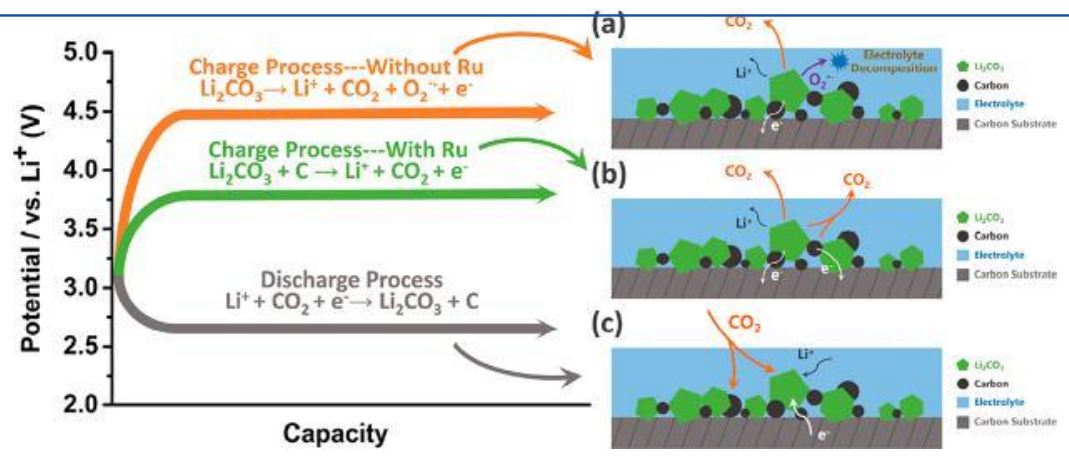

Figure 49. Proposed reaction routes for $\mathrm{Li}-\mathrm{CO}_{2}$ batteries without $\mathrm{O}_{2}$. Reproduced with permission from ref 389 . Copyright 2017 Royal Society of Chemistry. 

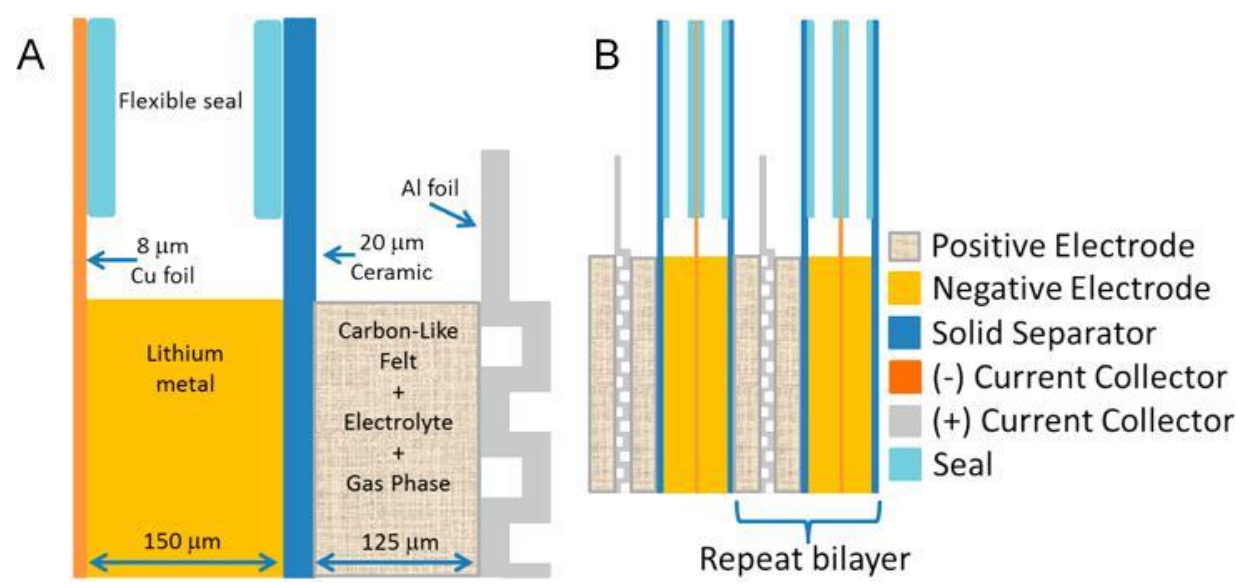

Figure 50. Schematic of a (A) single layer and (B) multiple layers of a lithium-air cell. Reproduced with permission from ref 53. Copyright 2014 Royal Society of Chemistry.

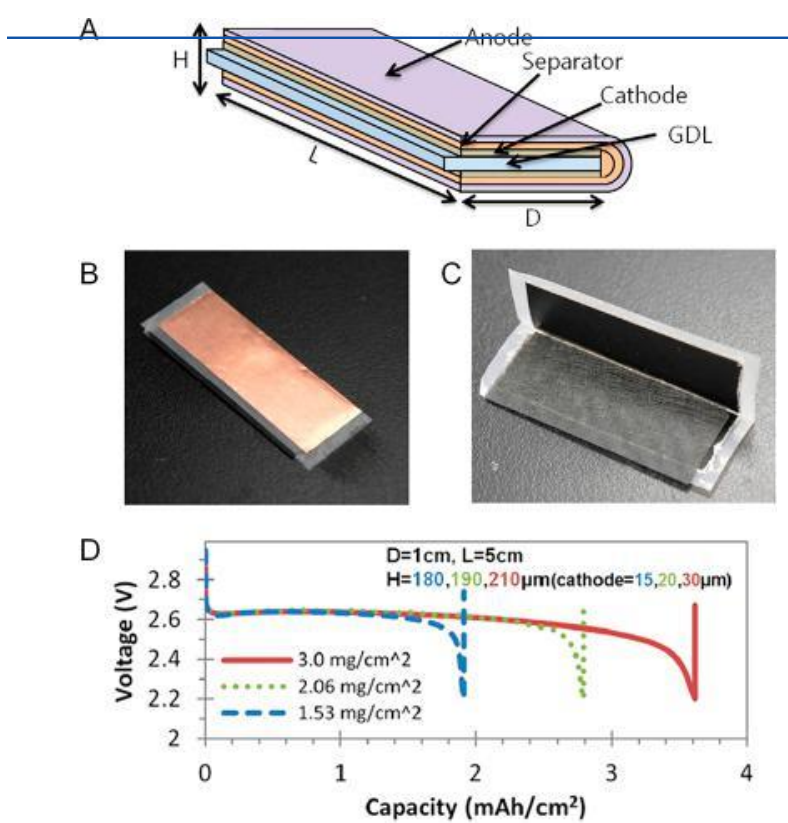

Figure 51. (A) Schematic, (B,C) images, and (D) discharge curves of a single folded cell. Reproduced with permission from ref 319. Copyright 2019 Elsevier.

ance of 610 Wh $\mathrm{kg}-1$ system is predieted versus 300 Wh $\mathrm{kg}^{-1}$ system for a lithium metal/Li-rich NMC system. For example, the model assumes electrochemical performance based on a lithium-air cell without mediators. ${ }^{391}$ The balance of plant is designed to achieve ppm levels of $\mathrm{H}_{2} \mathrm{O}$ in the gas stream, but it is likely that this is not necessary and $\mathrm{H}_{2} \mathrm{O}$ may improve performance. Of course, the presence of $\mathrm{H}_{2} \mathrm{O}$ in $\mathrm{Li}-\mathrm{O}_{2}$ cells is detrimental to the stability of the $\mathrm{Li}$ anodes. Parasitic reactions that form $\mathrm{LiOH}$ on both anode and cathode sides when the cells are contaminated by trace water, shorten the cycle life $\mathrm{Li}-\mathrm{O}_{2}$ batteries. Therefore, the presence of trace water in these cells should be avoided as much as possible.

Further improvements may be achieved in the pressure swing adoption units by development of efficient selective gas scrubbers that are able to remove only $\mathrm{CO}_{2}$ or fractional amounts of $\mathrm{H}_{2} \mathrm{O}$, e.g., metal-organic frameworks and amine-based compounds. ${ }^{392-394}$ In addition, selective membranes have been proposed as methods of eliminating atmospheric impurities. ${ }^{395}$ Lower vapor pressure solvents such as TEGDME will help minimize the mass penalty imposed by solvent capture units, which is based on DMSO in current models.396,397 Perhaps most importantly, current models are designed for automotive applications, but varying the energy versus power needs can significantly lower the relative contribution of the parasitic BoP overhead and increase performance. System models must be continuously developed and updated to help direct research, identify challenges and opportunities, track progress, and evaluate advancement.

\section{FUTURE PERSPECTIVE}

A number of the significant advances made in the last five years in understanding the science of the rechargeable aprotic lithium-air battery have been reviewed here. It is important to understand that $\mathrm{O}_{2}$ reduction to $\mathrm{Li}_{2} \mathrm{O} 2$ on discharge, and the reverse on charge, does not have to occur on the electrode surface as previously thought, leading to low rates and capacities. Rather, it can occur in solution: avoiding electrode passivation and yielding significantly higher rates and capacities. This realization can begin to change the prospect for the lithium-air battery. Redox mediators can enable solution mediated $\mathrm{O}_{2} / \mathrm{Li}_{2} \mathrm{O}_{2}$ to occur in more stable, low polarity solvents such as ethers. The rates and capacities in these solvents are several $\mathrm{mA} \mathrm{cm}-2$ and $\mathrm{mAh} \mathrm{cm}{ }^{-2}$, while also significantly reducing the overpotential on discharge and charge will further advance the prospects of a lithium-air technology.

Although cells maybe cycled 100 times with minimal capacity loss, this does not mean that all the challenges of lithium-air have been met. Stability of the electrolyte solution is one of the main problems that must be addressed, as discussed above. However, the recent recognition that singlet oxygen $\left({ }^{1} \mathrm{O}_{2}\right)$ is formed during oxidation of $\mathrm{Li}_{2} \mathrm{O} 2$ during charge as well as during its formation on discharge and that this reactive species appears to be the main culprit in electrolyte degradation provides the new understanding necessary to mitigate instability. Oxidation mediators offer the opportunity to change mechanisms that form ${ }^{1} \mathrm{O}_{2}$, which would suppress electrolyte degradation.

In addition, it has been shown that mediators enhance the stability of carbon electrodes making them viable despite critical instability with $\mathrm{O}_{2}$ electrochemistry directly taking place on their surface. Focus on oxidation mediators is therefore a key challenge for future research. The use of redox mediators to facilitate the O2/Li2O2 reaction has largely addressed the limitations of the intrinsic electrochemistry at the cathode. The 

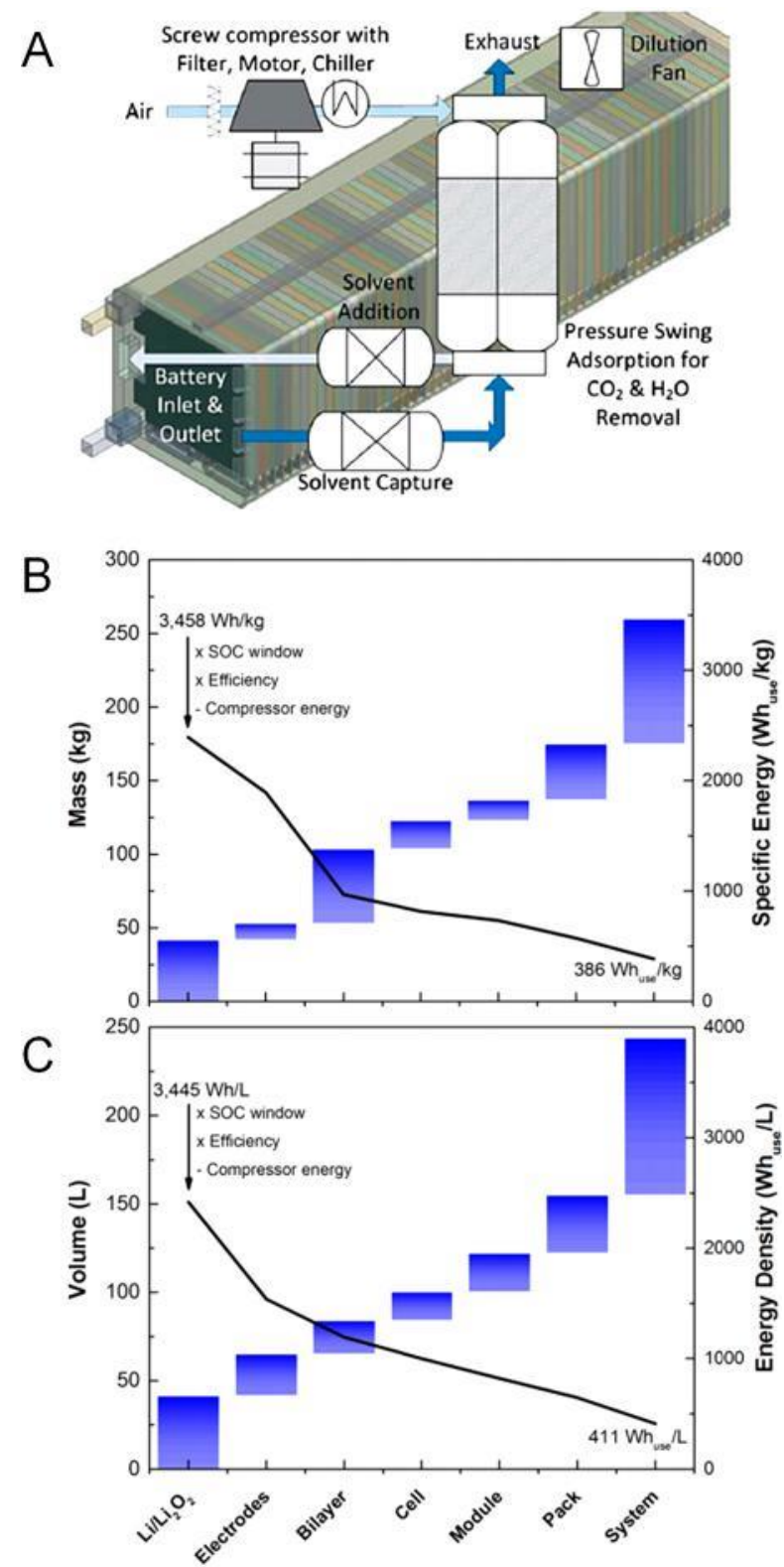

Functionality building to the system level

Figure 52. A proposed lithium-air system showing: (A) the components required to the balance of plant needed to operate under atmospheric gas and plots showing the (B) mass and (C) volume breakdown of the open lithium-air system (100 kWh and $80 \mathrm{~kW})$ together with the specific and volumetric energies. Reproduced with permission from ref 53. Copyright 2014 Royal Society of Chemistry.

rate and capacity are now limited by the mass transport of $\mathrm{O}_{2}$ and the pore space. In the flooded porous electrode, this relies on the dissolution of $\mathrm{O}_{2}$ at the gas interface and then its diffusion throughout the electrode. As for fuel cells, a true gas diffusion electrode is required. This is because $\mathrm{O}_{2}$ transport occurs in the gas phase by entering the electrolyte solution such that it only has to defuse short distances to the reduction mediator in order to be converted to $\mathrm{Li}_{2} \mathrm{O}_{2}$. We cannot utilize the approach of aqueous fuel cells, which relies on hydrophobic gas channels and hydrophilic pores for the electrolyte.

New approaches and designs of electrode architecture are needed that will facilitate mass transport in aprotic $\mathrm{Li}-$ air cells. The design of porous gas diffusion cathodes would enable a further step change toward the realization of our $\mathrm{Li}-\mathrm{O}_{2}$ cell; however, alone these do not address the problem of operating in air. As discussed in the review, it is now understood that significant quantities of $\mathrm{H}_{2} \mathrm{O}$ can be tolerated in ether-based solvents, while preserving the two-electron reduction of $\mathrm{O}_{2}$ to $\mathrm{Li}_{2} \mathrm{O}_{2}$; indeed, some water can be advantageous. The ability to operate with a gas stream which does not have to be rigorously dried, potentially operating up to $2 \mathrm{gH} 2 \mathrm{O} / \mathrm{m}, 3$ makes operation in air much more viable than was thought previously. The extensive work on $\mathrm{CO}_{2}$ removal by, for example, porous metal organic framework solids (MOFs), driven by interest in other fields, provides potential routes to the removal of sufficient $\mathrm{CO}_{2}$ from the gas stream.

It is important to develop further approaches to the balance of plant especially related to air handling. Much of the focus has been on the challenges associated with the reaction at the cathode. To realize the full potential of the Li-air battery, it is necessary to develop a protected lithium metal anode, which avoids reactivity with $\mathrm{O}_{2}$ and with redox mediators. While specific attention will be critical to understand the solid electrolyte/liquid electrolyte interface of a protected anode in the lithium-air battery, the anode itself is being pursued intensively because of its potential application in other lithium battery technologies. Therefore, this challenge is not specific to $\mathrm{Li}$-air.

There is a well-established path to disruptive technologies. It starts with recognition that the technology would, if realized, provide a step change in performance or cost reduction or both. This drives a "gold rush" to commercialization that almost inevitably fails as the underpinning science is unknown. The attempts to commercialize do uncover the barriers facing the technology. Concentrated effort follows on the basic science, which provides the knowledge that is essential to either overcome the barriers or demonstrate that the barriers are insurmountable. Lithium-air is on this journey.

\section{CONCLUSION}

Research and development of Li-air batteries is one of the most exciting and interesting fields of modern electrochemistry, with its emphasis on power sources, energy, and materials science. These systems possess the highest theoretical energy density, promising cost effectiveness and the chance to rival internal combustion engines by clean and elegant electrochemical power sources. Over the past decade, intensive work has been invested into these systems by many of the most prominent research groups worldwide. Despite these impressive efforts, more work is required even to reach various go/no-go decisions. This is due to the highly complex nature of $\mathrm{Li}-\mathrm{O}_{2}$ cells (even before dealing with ambient air as the cathode feed).

While the intensive R\&D efforts related to these systems have yet to reach practical goals, the electrochemistry, energy, and materials science communities have gained a lot from the prolific research work carried out during recent years. The benefits and spinoffs from these studies include highly innovative contributions to electrocatalysis, active metals electrochemistry, oxygen chemistry, nonaqueous electrochemistry, and solution chemistry, as we describe in this review article. The scope of this paper has included several important related analogous systems: various active metal anodes (sodium, potassium), assorted active gas cathode materials like $\mathrm{CO}_{2}$, and recently discovered reversible oxygen redox activity in high capacity lithium transition metal oxide cathodes. 
In this review, we described in detail important aspects of this field: heterogeneous electrocatalysis, homogeneous electrocatalysis by redox mediators, and possible side reactions of the relevant electrolyte solutions with the highly reactive oxygen moieties which are formed in $\mathrm{Li}-\mathrm{O}_{2}$ cells. Special attention was paid to the recently discovered role of the reactive singlet oxygen which forms during disproportionation of $\mathrm{Li}$ superoxide to $\mathrm{Li}$ peroxide.

The article covers all aspects of major components: anodes (including search for alternative, less reactive ones), cathodes, and electrolyte systems, including organic or ionic liquid-based solutions and solid-state electrolytes (ceramic and polymeric). We described also innovative efforts to develop new solvents that can be more stable toward the reactive oxygen moieties in these cells. In addition, we have covered a detailed description of basic science aspects. The article analyzes all facets of the gap between the state-of-the-art $\mathrm{Li}-\mathrm{O}_{2}$ cells and practical $\mathrm{Li}-$ air battery technology.

We have covered past, present, and future perspectives of this challenging field. After great initial enthusiasm that also included some unsupported promises, the large research community working on active metals and air battery technologies has reached an appropriate maturity and realistic approaches to the R\&D efforts of these systems. Work is in progress, and further work and investments of innovative efforts and means is required. It should also be noted that the field can further expand to include $\mathrm{Li}-\mathrm{Li}_{2} \mathrm{O}$ closed systems, high temperature solid-state $\mathrm{Li}$ and $\mathrm{Na}$ air batteries, and $\mathrm{Li}(\mathrm{Na})-\mathrm{CO}_{2}$ batteries

The risk of failure is obvious, but the benefits of success are enormous. Developing practical rechargeable active metal-air batteries will revolutionize the field of electrochemical power sources and will further promote the electromobility revolution.

\section{AUTHOR INFORMATION}

\section{Corresponding Authors}

Doron Aurbach - Department of Chemistry, Bar-Ilan University, Ramat Gan 5290002, Israel; Bar-Ilan Institute of

Nanotechnology and Advanced Materials, Ramat Gan 5290002, Israel; orcid.org/0000-0001-8047-9020; Email: Doron.Aurbach@biu.ac.il

Peter G. Bruce - Departments of Materials and Chemistry, University of Oxford, Oxford OX1 3PH, U.K.; orcid.org/ 0000-0001-6748-3084; Email: peter.bruce@ materials.ox.ac.uk

Linda F. Nazar - Department of Chemistry and the Waterloo Institute for Nanotechnology, University of Waterloo, Waterloo, Ontario N2L 3G1, Canada; orcid.org/0000-0002-3314-8197; Email:1fnazar@uwaterloo.ca

Yang-Kook Sun - Department of Energy Engineering, Hanyang University, Seoul 04763, Republic of Korea; orcid.org/00000002-0117-0170; Email: yksun@hanyang.ac.kr

\section{Authors}

Won-Jin Kwak - Department of Energy Engineering, Hanyang University, Seoul 04763, Republic of Korea; Energy \& Environment Directorate, Pacific Northwest National Laboratory, Richland, Washington 99354, United States; Department of Chemistry, Ajou University, Suwon 16499, Republic of Korea; orcid.org/0000-0002-9807-1434

Rosy - Department of Chemistry, Bar-Ilan University, Ramat Gan 5290002, Israel; Bar-Ilan Institute of Nanotechnology and Advanced Materials, Ramat Gan 5290002, Israel; orcid.org/ 0000-0001-5985-8587
Daniel Sharon - Pritzker School of Molecular Engineering, University of Chicago, Chicago, Illinois 60637, United States; Materials Science Division, Argonne National Laboratory, Lemont, Illinois 60439, United States; orcid.org/0000-0002-3385-1536

Chun Xia - Department of Chemistry and the Waterloo Institute for Nanotechnology, University of Waterloo, Waterloo, Ontario N2L 3G1, Canada

Hun Kim - Department of Energy Engineering, Hanyang University, Seoul 04763, Republic of Korea

Lee R. Johnson - School of Chemistry and GSK Carbon Neutral Laboratory for Sustainable Chemistry, University ofNottingham, Nottingham NG7 2TU, U.K.

Aryeh A. Frimer - Department of Chemistry, Bar-Ilan University, Ramat Gan 5290002, Israel

Malachi Noked - Department of Chemistry, Bar-Ilan University, Ramat Gan 5290002, Israel; Bar-Ilan Institute of Nanotechnology and Advanced Materials, Ramat Gan 5290002, Israel; orcid.org/0000-0001-8995-0632

Stefan A. Freunberger - Institute for Chemistry and Technology ofMaterials, Graz University of Technology, 8010 Graz, Austria; Institute ofScience and Technology Austria, 3400 Klosterneuburg, Austria; orcid.org/0000-0003-2902-5319

\section{Author Contributions}

${ }^{\circ}$ Won-Jin Kwak and Rosy have contributed equally. Notes

The authors declare no competing financial interest.

\section{Biographies}

Won-Jin Kwak obtained his Ph.D. in Energy Engineering from Hanyang University and was a post-doctoral researcher with Prof. Yang-Kook Sun, working on material and system design of lithium-oxygen batteries. He has been a Postdoctorate Research Associate in the Energy and Environment Directorate at Pacific Northwest National Laboratory, and since 2020, Assistant Professor in the Department of Chemistry at Ajou University. His research interests are focused on the verification of reaction mechanism, the development of functional materials, and the design of novel cell configuration for stable and efficient next generation batteries. His key contributions to metal- oxygen chemistry concern stabilization of metal electrode and elucidation of stability issue of redox mediators including parasitic chemistry with singlet oxygen.

Rosy is a Post-Doctoral researcher in the Noked group under the PBC fellowship program for outstanding postdoctoral researchers from India and China. She received her Ph.D. in Electrochemistry in 2017 from the Indian Institute of Technology, Roorkee, India. Her research includes alkali metal batteries, electrode protection, and online electrochemical mass spectrometry studies.

Daniel Sharon is currently a postdoctoral fellow in the Institute for Molecular Engineering at the University of Chicago. He earned his Ph.D. in Physical Chemistry from the Bar-Ilan University in Israel under the supervision of Professor Doron Aurbach. Daniel has been working on the development of new electrolyte solutions, including polymer electrolytes, for next-generation nonaqueous lithium ion batteries. His research focuses on understanding the electrochemical processes occurring at the electrodes-electrolyte interfaces.

Chun Xia obtained his Bachelor of Science degree from Yanghzou University (China) in 2006 and Ph.D. degree from Tianjin University 
(China) in 2011. He was a postdoctoral researcher at Justus Liebig University Giessen (Germany) between 2012 and 2014. Since April 2014, he has worked as a postdoctor in the group of Prof. Linda Nazar at the University of Waterloo (Canada). His research focus on the fundamental chemistry and electrocatalysis in lithium-oxygen and sodium-oxygen batteries.

Hun Kim is a Ph.D. candidate under the supervision of Prof. Yang-Kook Sun at Hanyang University. He received a Bachelor of Science degree in the department of Energy Engineering at Hanyang University. He has been interested in lithium metal protections and redox mediators in lithium-oxygen batteries. His researches are focused on material chemistry and materials development of next generation metal-oxygen batteries.

Lee R. Johnson received his Ph.D. from the University of Nottingham in 2011 and was a postdoctoral fellow at the University of Oxford working under the supervision of Prof P. G. Bruce. He is an Associate Professor at the University of Nottingham and the recipient of a Nottingham Research Fellowship and an EPSRC-UKRI Innovation Fellowship. He is the author of 24 original research articles. His research interests include organic electrochemistry and the study of electrochemical phenomena of electrolytes and interfaces in batteries. He established theory that underpins aprotic oxygen reduction with alkali ions within the lithium-air battery and identified leading redox mediators for catalysis of the discharge reaction.

Peter G. Bruce is Wolfson Professor of Materials at the University of Oxford. His research interests embrace materials chemistry and electrochemistry, with a particular emphasis on energy storage, especially lithium and sodium batteries. Recent efforts have focused on the synthesis and understanding of new materials for lithium and sodiumion batteries, on understanding anomalous oxygen redox processes in transition metal oxides used as high capacity Li-ion cathodes, the challenges of the lithium-air battery, and the influence of order on the ionic conductivity of polymer electrolytes. His pioneering work has provided many advances. Peter received the Tilden Prize of the Royal Society of Chemistry in 2008, the Carl Wagner Award of the Electrochemical Society in 2011, the Liversidge Award of the Royal Society of Chemistry in 2016, and the Hughes Medal of the Royal Society in 2017. He has also been selected as a Highly Cited Researcher by Thomson Reuters/Clarivate Analytics in 2015, 2016, 2017, and 2018. As well as directing the UK Energy Storage Hub (SuperStore), a consortium on solid-state batteries, and a consortium on lithium batteries, Peter is a founder and Chief Scientist of the Faraday Institution, the UK Centre for Research on Electrochemical Energy Storage. Peter also took up the position of Physical Secretary and Vice President of the Royal Society (UK's national academy) in November 2018.

Linda F. Nazar, FRS(C), received her Ph.D. in Chemistry from the University of Toronto in 1986 with Prof. Geoff Ozin in inorganic materials chemistry and was an Exxon postdoctoral fellow at the Exxon Research Laboratories in Annandale, NJ, with Dr. Allan Jacobson, where she started to work on electrochemistry. She then joined the faculty at the University of Waterloo, Ontario, Canada, where she is now a Senior Canada Research Chair in Solid State Energy Materials and Distinguished Research (full) Professor. Nazar is known for her research on electrochemical energy storage with topics that span $\mathrm{Li}$-ion batteries and "beyond $\mathrm{Li}$-ion" (including $\mathrm{Li}^{-} \mathrm{O}_{2}$ and $\mathrm{Li}-\mathrm{S}$ ), solid-state ionics, and the role that nanotechnology plays in energy materials. She has coauthored over 235 publications garnering over 35000 citations on the WoS. She is on the Web of Science's 2014, 2016, 2017, and 2018 Highly Cited Research Lists, and an Officer of the Order of Canada.
Yang-Kook Sun received his Ph.D. degree from the Seoul National University, Korea. He has worked at the Hanyang University in Korea as a professor since 2000. His research focuses on electrode materials for Li-ion secondary battery for electric vehicle, lithium sulfur and lithium air batteries, electrode materials for $\mathrm{Na}, \mathrm{K}$-ion battery, and lithium-metal batteries. He published more than 580 papers, and his papers were cited more than 46000 times, and he filed more than 450 patents and patent applications. As recognized for research, he was selected as the Highly Cited Researcher at the field of material science from Clarivate Analytics and received Research Award, Technology Awards from The Electrochemical Society. He continues his active research works to contribute to the popularization of science and to the world society.

Aryeh A. Frimer received his Ph.D. at Harvard University with Prof. Paul D. Bartlett in 1974, elucidating the mechanism of singlet oxygen with vinyl ethers. He then crossed the ocean to become a Senior Weizmann Fellow with Prof. Dov Elad. In 1975, Dr. Frimer joined the faculty of Bar Ilan University, where he is now the Ethel and David Resnick Professor Emeritus of Active Oxygen Chemistry. In addition to active oxygen species, his group has been exploring chemistry within biomembranes, the preparation and neutralization of green energetic materials, and most recently the formation and chemistry of active species in $\mathrm{Li}-\mathrm{O}_{2}$ batteries.

Malachi Noked is currently senior lecturer (Assistant Professor) Alon Fellow in the Department of Chemistry at Bar Ilan University in Israel. He earned his Ph.D. in chemistry in 2013 and was a Fulbright IlanRamon postdoctoral fellow and research associate at the University of Maryland from 2013 to 2016. His research interest focuses on electrochemistry, energy storage, and functional thin films.

Stefan Freunberger obtained his Ph.D. in Chemistry from ETH Zürich and was a post doc with Peter Bruce at the University of St. Andrews, working on many aspects of $\mathrm{Li}-\mathrm{O}_{2}$ chemistry. He has been primary investigator at Graz University of Technology, Austria, and since 2020, Assistant Professor at the Institute of Science and Technology Austria (IST Austria) with research interests embracing energy-storage materials, including alkaline-ion and metal- $\mathrm{O}_{2}$ batteries, electrolytes, and in situ techniques. Key contributions to metal- $\mathrm{O}_{2}$ chemistry concern elucidation of reaction mechanisms, parasitic chemistry, and most recently the involvement of singlet oxygen. His research has been recognized by the Srinivasan Young Investigator Award of The Electrochemical Society, the invited visiting professorship La Chaire Total de la Fondation Balard, elected membership of the Austrian Academy of Sciences, the Tajima Prize of the International Society of Electrochemistry, and an ERC Starting Grant.

Doron Aurbach is a full professor, Department of Chemistry, chemical engineer, leading the electrochemistry group (40 people) at Bar-Ilan University (BIU), Israel, He leads INREP: Israel National Research Center for Electrochemical Propulsion (since 2012, 25 research groups, 7 Israeli institutions), which develops power sources for electric vehicles. His teams study the electrochemistry of active metals, nonaqueous electrochemical systems, develop spectroscopic methods (in situ and ex situ) for sensitive electrochemical systems, study electrochemical intercalation processes, electrochemical water desalination, electronically conducting red-ox polymers, and develop rechargeable high energy density batteries and supercapacitors. He serves as a senior editor in the Journal of the Electrochemical Society (JES), ECS, ISE, MRS fellow, recipient of the Alan Bard Award of the Electrochemical Society (ECS, 2017), the Alexander Frumkin Medal of the International Society of Electrochemistry (ISE, 2018), and the Eric and Sheila Samson Prime Minister Prize for innovation in alternative fuels for transportation (2018). 


\section{ACKNOWLEDGMENTS}

This work was supported by a grant from the Human Resources Development program (no. 20184010201720) of the Korea Institute of Energy Technology Evaluation and Planning (KETEP), funded by the Ministry of Trade, Industry, and Energy of the Korean Government. D.A. thanks the Israeli Prime Minister office and the Israel Committee for high education for their support, in the framework of the INREP project. S.A.F. is indebted to the European Research Council (ERC) under the European Union's Horizon 2020 research and innovation programme (grant agreement no. 636069). M.N. thanks the United States-Israel Binational Science Foundation (BSF) for the start-up grant (grant no. 2018327).

\section{ABBREVIATIONS USED}

\author{
${ }^{1} \mathrm{O}_{2}=$ singlet oxygen \\ $\mathrm{AN}=$ acceptor number \\ $\mathrm{AFM}=$ atomic force microscopy \\ $\mathrm{CE}=$ Coulombic efficiency \\ $\mathrm{CPL}=$ composite protective layer \\ $\mathrm{CT}=$ charge transfer \\ $\mathrm{DABCO}=$ 1,4-diazabicyclo[2.2.2] octane \\ DABCOnium = onium salt form of 1,4-diazabicyclo[2.2.2]- \\ octane \\ DBBQ = 2,5-ditert-butyl-1,4-benzoquinone \\ $\mathrm{DFT}=$ density functional theory \\ DMA $=9,10$-dimethylanthracene \\ DMDMB = 2,3-dimethyl-2,3-dimethyoxybutane \\ DMDMP = 2,4-dimethoxy-2,4-dimethylpentan-3-one \\ $\mathrm{DME}=1,2$-dimethoxyethane \\ DMF $=$ dimethylformamide \\ DMPZ $=$ dimethylphenazine \\ DMSO = dimethyl sulfoxide \\ $\mathrm{DN}=$ donor number \\ DOL $=1,3$-dioxolane \\ $E_{\text {act }}=$ activation energy \\ $E_{0}=$ equilibrium potential \\ EDDI = energy dispersive diffraction \\ $\mathrm{EPR}=$ electron paramagnetic resonance \\ $\mathrm{ESR}=$ electron spin resonance \\ $\mathrm{EVs}=$ electric vehicles \\ HGVs = heavy goods vehicles \\ HMD = 2,2,4,4,5,5-hexamethyl-1,3-dioxolane \\ $\mathrm{HOMO}=$ highest occupied molecular orbital \\ HPLC = high-performance liquid chromatography \\ $\mathrm{IE}=$ ionization energy \\ $\mathrm{IL}=$ ionic liquid \\ $k_{\text {app }}=$ apparent rate constant \\ LIB = lithium-ion battery \\ LiTf = lithium trifluoromethanesulfonate \\ LiTFSI = lithium bis(trifluoromethanesulfonyl)imide \\ LOB $=$ lithium - oxygen battery \\ LUMO = lowest unoccupied molecular orbital \\ Me-Im = methyl-imidazole \\ MPT $=10$-methylphenothiazine \\ MWCNT $=$ multiwalled carbon nanotubes \\ $\mathrm{NCL}=$ Nafion-based composite protective layer \\ $\mathrm{NIR}=$ near-infrared \\ $\mathrm{NMC}=$ nickel - manganese - cobalt \\ $\mathrm{NMP}=N$-methyl-2-pyrrolidone \\ $\mathrm{NMR}=$ nuclear magnetic resonance \\ $\mathrm{OCV}=$ open circuit voltage
}

OEMS $=$ online electrochemical mass spectroscopy

OER $=$ oxygen evolution reaction

ORR = oxygen reduction reaction

$\mathrm{PAN}=$ polyacrylonitrile

$\mathrm{PC}=$ propylene carbonate

$\mathrm{PEO}=\operatorname{poly}($ ethylene oxide $)$

$\mathrm{PFC}=$ perfluorocarbons

PMMA = poly (methyl methacrylate $)$

PTIO = 2-phenyl-4,4,5,5-tetramethylimidazoline-1-oxyl-3-

oxide

PVC = polyvinyl chloride

$\mathrm{PVdF}=$ polyvinylidene fluoride

PVdF-HFP = poly(vinylidene fluoride-co-hexafluoropropy-

lene)

PTFE = polytetrafluoroethylene

$\mathrm{PVP}=$ polyvinylpyrrolidone

$\mathrm{RM}=$ redox mediator

ROS $=$ reactive oxygen species

$\mathrm{RRDE}=$ rotating ring-disc electrode

RROS $=$ reduced reactive oxygen species

$\mathrm{SE}=$ solid electrolyte

SECM = scanning electrochemical microscopy

SEI $=$ solid electrolyte interphase

SERS = surface enhanced Raman spectroscopy

$\mathrm{SFG}=$ sum frequency generation

SOMO = singly occupied orbitals

TBA = tetrabutylammonium

TDPA $=$ tris[4-(diethylamino)phenyl $]$ amine

TEGDME = tetraethylene glycol dimethyl ether

TEMPO = 2,2,6,6-tetramethylpiperidinyloxyl

TTE = 1,1,2,2-tetrafluoroethyl 2,2,3,3-tetrafluoropropyl ether

$\mathrm{TTF}=$ tetrathiafulvalene

$\mathrm{TMO}=$ transition metal oxide

$\mathrm{UV}=$ ultraviolet

XANES = X-ray absorption near edge structure

$\mathrm{XPS}=\mathrm{X}$-ray photoelectron spectroscopy

$\mathrm{XRD}=\mathrm{X}$-ray diffraction

\section{REFERENCES}

(1)Zubi, G.; Dufo-López, R.; Carvalho, M.; Pasaoglu, G. The Lithium-Ion Battery: State of the Art and Future Perspectives. Renewable Sustainable Energy Rev. 2018, 89, 292-308.

(2)Thackeray, M. M.; Wolverton, C.; Isaacs, E. D. Electrical

Energy Storage for Transportation-approaching the Limits Of, and Going Beyond, Lithium-Ion Batteries. Energy Environ. Sci. 2012, 5, 7854- 7863.

(3)Li, M.; Lu, J.; Chen, Z.; Amine, K. 30 Years of Lithium-Ion Batteries. Adv. Mater. 2018, 30, 1800561.

(4)Choi, S.; Wang, G. Advanced Lithium-Ion Batteries for Practical Applications: Technology, Development, and Future Perspectives. $A d v$. Mater. Technol. 2018, 3, 1700376.

(5)Sun, Y.-K.; Kim, D.-H.; Yoon, C. S.; Myung, S.-T.; Prakash, J.; Amine, K. A Novel Cathode Material with a Concentration-Gradient for High-Energy and Safe Lithium-Ion Batteries. Adv. Funct. Mater. 2010, 20, 485-491.

(6)Kim, U.; Ryu, H.; Kim, J.; Mücke, R.; Kaghazchi, P.; Yoon, C. S.; Sun, Y. Microstructure-Controlled Ni-Rich Cathode Material by Microscale Compositional Partition for Next-Generation Electric Vehicles. Adv. Energy Mater. 2019, 9, 1803902.

(7)Manthiram, A.; Knight, J. C.; Myung, S.-T.; Oh, S.-M.; Sun, Y.-K. Nickel-Rich and Lithium-Rich Layered Oxide Cathodes: Progress and Perspectives. Adv. Energy Mater. 2016, 6, 1501010.

(8)Markevich, E.; Salitra, G.; Hartmann, P.; Kulisch, J.; Aurbach, D.; Park, K. J.; Yoon, C. S.; Sun, Y. K. New Insights Related to Rechargeable Lithium Batteries: Li Metal Anodes, Ni Rich LiNixCoyMnzO2 
Cathodes and beyond Them. J. Electrochem. Soc. 2019, 166, A5265- A5274.

(9) Rosy; Sclar, H.; Evenstein, E.; Haber, S.; Maiti, S.; Sharabani, T.; Leskes, M.; Noked, M. Mitigating Structural Instability of High-Energy Lithium- and Manganese-Rich LiNixMny $\mathrm{COz}_{z} \mathrm{Oxide}$ by Interfacial Atomic Surface Reduction. Chem. Mater. 2019, 31, 3840-3847.

(10)Weigel, T.; Schipper, F.; Erickson, E. M.; Susai, F. A.; Markovsky, B.; Aurbach, D. Structural and Electrochemical Aspects of LiNi0.8Co0.1Mn0.1 $\mathrm{O}_{2}$ Cathode Materials Doped by Various Cations. ACS Energy Lett. 2019, 4, 508-516.

(11)Kim, J.; Lee, H.; Cha, H.; Yoon, M.; Park, M.; Cho, J. Prospect and Reality of Ni-Rich Cathode for Commercialization. Adv. Energy Mater. 2018, 8, 1702028.

(12)Schipper, F.; Erickson, E. M.; Erk, C.; Shin, J.-Y.; Chesneau, F. F.; Aurbach, D. Review-Recent Advances and Remaining Challenges for Lithium Ion Battery Cathodes. J. Electrochem. Soc. 2017, 164, A6220A6228.

(13)Liu, W.; Oh, P.; Liu, X.; Lee, M. J.; Cho, W.; Chae, S.; Kim, Y.; Cho, J. Nickel-Rich Layered Lithium Transition-Metal Oxide for HighEnergy Lithium-Ion Batteries. Angew. Chem., Int. Ed. 2015, 54, 44404457.

(14)Ryu, H. H.; Park, K. J.; Yoon, C. S.; Sun, Y. K. Capacity Fading of Ni-Rich li[NixCo YMnl-X-Y]O2 $(0.6 \leq X \leq 0.95)$ Cathodes for High-EnergyDensity Lithium-Ion Batteries: Bulk or Surface Degradation? Chem. Mater. 2018, 30, 1155-1163.

(15)Han, B.; Key, B.; Lapidus, S. H.; Garcia, J. C.; Iddir, H.; Vaughey, J. T.; Dogan, F. From Coating to Dopant: How the Transition Metal Composition Affects Alumina Coatings on Ni-Rich Cathodes. ACS Appl. Mater. Interfaces 2017, 9, 41291-41302.

(16)Dixit, M.; Markovsky, B.; Schipper, F.; Aurbach, D.; Major, D. T. Origin of Structural Degradation During Cycling and Low Thermal Stability of Ni-Rich Layered Transition Metal-Based Electrode Materials. J. Phys. Chem. C 2017, 121, 22628-22636.

(17)Kim, U.-H.; Jun, D.-W.; Park, K.-J.; Zhang, Q.; Kaghazchi, P.; Aurbach, D.; Major, D. T.; Goobes, G.; Dixit, M.; Leifer, N.; et al. Pushing the Limit of Layered Transition Metal Oxide Cathodes for High-Energy Density Rechargeable Li Ion Batteries. Energy Environ. Sci. 2018, 11, 1271-1279.

(18)Markevich, E.; Salitra, G.; Chesneau, F.; Schmidt, M.; Aurbach, D. Very Stable Lithium Metal Stripping-Plating at a High Rate and High Areal Capacity in Fluoroethylene Carbonate-Based Organic Electrolyte Solution. ACS Energy Lett. 2017, 2, 1321-1326.

(19)Liu, D.; Zhu, W.; Kim, C.; Cho, M.; Guerfi, A.; Delp, S. A.; Allen, J. L.; Jow, T. R.; Zaghib, K. High-Energy Lithium-Ion Battery Using Substituted LiCoPO4: From Coin Type to 1 Ah Cell. J. Power Sources 2018, 388, 52-56.

(20)Li, W.; Song, B.; Manthiram, A. High-Voltage Positive Electrode Materials for Lithium-Ion Batteries. Chem. Soc. Rev. 2017, 46, 30063059.

(21)Zhang, M.; Garcia-Araez, N.; Hector, A. L. Understanding and Development of Olivine $\mathrm{LiCoPO}_{4}$ Cathode Materials for Lithium-Ion Batteries. J. Mater. Chem. A 2018, 6, 14483-14517.

(22)Choi, J. W.; Aurbach, D. Promise and Reality of Post-LithiumIon Batteries with High Energy Densities. Nat. Rev. Mater. 2016, 1, 16013.

(23)Zuo, X.; Zhu, J.; Müller-Buschbaum, P.; Cheng, Y.-J. Silicon Based Lithium-Ion Battery Anodes: A Chronicle Perspective Review. Nano Energy 2017, 31, 113-143.

(24)Feng, K.; Li, M.; Liu, W.; Kashkooli, A. G.; Xiao, X.; Cai, M.; Chen, Z. Silicon-Based Anodes for Lithium-Ion Batteries: From Fundamentals to Practical Applications. Small 2018, 14, 1702737.

(25)Wu, H.; Cui, Y. Designing Nanostructured Si Anodes for High Energy Lithium Ion Batteries. Nano Today 2012, 7, 414-429.

(26)Hwang, J.-Y.; Park, S.-J.; Yoon, C. S.; Sun, Y. K. Customizing A Li-Metal Battery That Survives Practical Operating Conditions for Electric Vehicle Applications. Energy Environ. Sci. 2019, 12, 21742184.

(27)Wang, X.; Zhai, H.; Qie, B.; Cheng, Q.; Li, A.; Borovilas, J.; Xu, B.; Shi, C.; Jin, T.; Liao, X.; Li, Y.; He, X.; Du, S.; Fu, Y.; Dontigny, M.;
Zaghib, K.; Yang, Y. Rechargeable Solid-State Lithium Metal Batteries With Vertically Aligned Ceramic Nanoparticle/Polymer Composite Electrolyte. Nano Energy 2019, 60, 205-212.

(0) Xia, S.; Wu, X.; Zhang, Z.; Cui, Y.; Liu, W. Practical Challenges and Future Perspectives of All-Solid-State Lithium-Metal Batteries. Chem. 2019, 5, 753-785.

(1) Croguennec, L.; Palacin, M. R. Recent Achievements on Inorganic Electrode Materials for Lithium-Ion Batteries. J. Am. Chem. Soc. 2015, 137, 3140-3156.

(2) Wang, K.-X.; Li, X.-H.; Chen, J.-S. Surface and Interface Engineering of Electrode Materials for Lithium-Ion Batteries. Adv. Mater. 2015, 27, 527-545.

(3) Markevich, E.; Salitra, G.; Aurbach, D. Fluoroethylene Carbonate as an Important Component for the Formation of an Effective Solid Electrolyte Interphase on Anodes and Cathodes for Advanced Li-Ion Batteries. ACS Energy Lett. 2017, 2, 1337-1345.

(4) Erickson, E. M.; Markevich, E.; Salitra, G.; Sharon, D.; Hirshberg, D.; de la Llave, E.; Shterenberg, I.; Rosenman, A.; Frimer, A.; Aurbach, D. Review-Development of Advanced Rechargeable Batteries: A Continuous Challenge in the Choice of Suitable Electrolyte Solutions. J. Electrochem. Soc. 2015, 162, A2424-A2438.

(5) Delmas, C. Sodium and Sodium-Ion Batteries: 50 Years of Research. Adv. Energy Mater. 2018, 8, 1703137.

(6) Vaalma, C.; Buchholz, D.; Weil, M.; Passerini, S. A Cost and Resource Analysis of Sodium-Ion Batteries. Nat. Rev. Mater. 2018, 3,18013 .

(7) Luntz, A. Beyond Lithium Ion Batteries. J. Phys. Chem. Lett. 2015, 6, 300-301.

(8) Neburchilov, V.; Zhang, J. Metal-Air and Metal-Sulfur Batteries: Fundamentals and Applications, 1st ed.; Taylor \& Francis, CRC Press: Boca Raton, 2016.

(9) Aurbach, D.; McCloskey, B. D.; Nazar, L. F.; Bruce, P. G. Advances in Understanding Mechanisms Underpinning Lithium-air Batteries. Nat. Energy 2016, $1,16128$.

(10) Bruce, P. G.; Freunberger, S. A.; Hardwick, L. J.; Tarascon, J.-M. $\mathrm{Li}_{-} \mathrm{O}_{2}$ and Li-S Batteries with High Energy Storage. Nat. Mater. 2012, 11, 19-29.

(11) Seh, Z. W.; Sun, Y.; Zhang, Q.; Cui, Y. Designing High-Energy Lithium-sulfur Batteries. Chem. Soc. Rev. 2016, 45, 5605-5634.

(12) Manthiram, A.; Chung, S.-H.; Zu, C. Lithium-Sulfur Batteries: Progress and Prospects. Adv. Mater. 2015, 27, 1980-2006.

(13) Zhang, X.; Wang, X.-G.; Xie, Z; Zhou, Z. Recent Progress in Rechargeable Alkali Metal-air Batteries. Green Energy Environ 2016, 1, 4-17.

(14) Li, Y.; Lu, J. Metal-Air Batteries: Will They Be the Future Electrochemical Energy Storage Device of Choice? ACS Energy Lett. 2017, 2, 1370-1377.

(15) Blurton, K. F.; Sammells, A. F. Metal/air Batteries: Their Status and Potential - a Review. J. Power Sources 1979, 4, 263-279.

(16) Heise, G. W. Air-Depolarized Primary Battery. US US49404A, 1933.

(17) Liu, Y.; Sun, Q.; Li, W.; Adair, K. R.; Li, J.; Sun, X. A Comprehensive Review on Recent Progress in Aluminum-air Batteries. Green Energy Environ 2017, 2, 246-277.

(18) Zaromb, S. The Use and Behavior of Aluminum Anodes in Alkaline Primary Batteries. J. Electrochem. Soc. 1962, 109, 1125-1130.

(19) Hoey, G. R.; Cohen, M. Corrosion of Anodically and Cathodically Polarized Magnesium in Aqueous Media. J. Electrochem. Soc. 1958, 105, 245.

(20) Sharon, D.; Hirshberg, D.; Afri, M.; Frimer, A. A.; Noked, M.; Aurbach, D. Aprotic Metal-Oxygen Batteries: Recent Findings and Insights; Springer Berlin Heidelberg, 2017; Vol. 21, pp 1861-1878.

(21) Abraham, K. M. A. Polymer Electrolyte-Based Rechargeable Lithium/Oxygen Battery. J. Electrochem. Soc. 1996, 143, 1-5.

(22) Visco, S. J.; Nimon, V. Y.; Petrov, A.; Pridatko, K.; Goncharenko, N.; Nimon, E.; De Jonghe, L.; Volfkovich, Y. M.; Bograchev, D. A. Aqueous and Nonaqueous Lithium-Air Batteries Enabled by WaterStable Lithium Metal Electrodes. J. Solid State Electrochem. 2014, 18, 1443-1456. 
(51) Luntz, A. C.; McCloskey, B. D. Nonaqueous Li-Air Batteries: A Status Report. Chem. Rev. 2014, 114, 11721-11750.

(52) Imanishi, N.; Yamamoto, O. Rechargeable Lithium-air Batteries: Characteristics and Prospects. Mater. Today 2014, 17, 2430.

(53) Gallagher, K. G.; Goebel, S.; Greszler, T.; Mathias, M.; Oelerich, W.; Eroglu, D.; Srinivasan, V. Quantifying the Promise of Lithium-air Batteries for Electric Vehicles. Energy Environ. Sci. 2014, 7, 1555.

(54) Ko, Y.; Park, H.; Kim, B.; Kim, J. S.; Kang, K. Redox Mediators: A Solution for Advanced Lithium-Oxygen Batteries. Trends Chem. 2019, 1, 349-360.

(55) Jung, K.-N.; Kim, J.; Yamauchi, Y.; Park, M.-S.; Lee, J.-W.; Kim, J. H. Rechargeable Lithium-air Batteries: A Perspective on the Development of Oxygen Electrodes. J. Mater. Chem. A 2016, 4, 14050-14068.

(56) Tan, P.; Jiang, H. R.; Zhu, X. B.; An, L.; Jung, C. Y.; Wu, M. C.; Shi, L.; Shyy, W.; Zhao, T. S. Advances and Challenges in Lithium-Air Batteries. Appl. Energy 2017, 204, 780-806.

(57) Wang, L.; Zhou, Z.; Yan, X.; Hou, F.; Wen, L.; Luo, W.; Liang, J.; Dou, S. X. Engineering of Lithium-Metal Anodes towards a Safe and Stable Battery. Energy Storage Mater. 2018, 14, 22-48.

(58) Guo, Y.; Li, H.; Zhai, T. Reviving Lithium-Metal Anodes for Next-Generation High-Energy Batteries. Adv. Mater. 2017, 29, 1700007.

(59) Lin, D.; Liu, Y.; Cui, Y. Reviving the Lithium Metal Anode for High-Energy Batteries. Nat. Nanotechnol. 2017, 12, 194-206.

(60) Hong, Y.; Zhao, C.; Xiao, Y.; Xu, R.; Xu, J.; Huang, J.; Zhang, Q.; Yu, X.; Li, H. Safe Lithium-Metal Anodes for Li-O2 Batteries: From Fundamental Chemistry to Advanced Characterization and Effective Protection. Batter. Supercaps 2019, 2, 638-658.

(61) Noked, M.; Schroeder, M. A.; Pearse, A. J.; Rubloff, G. W.; Lee, S. B. Protocols for Evaluating and Reporting $\mathrm{Li}_{-} \mathrm{O}_{2}$ Cell Performance. J. Phys. Chem. Lett. 2016, 7, 211-215.

(62) Augustin, M.; Vullum, P. E.; Vullum-Bruer, F.; Svensson, A. M. Inside the Electrode: Looking at Cycling Products in $\mathrm{Li} / \mathrm{O}_{2}$ Batteries. J. Power Sources 2019, 414, 130-140.

(63) Lim, H.-K.; Lim, H.-D.; Park, K.-Y.; Seo, D.-H.; Gwon, H.; Hong, J.; Goddard, W. A.; Kim, H.; Kang, K. Toward a Lithium-"Air" Battery: The Effect of $\mathrm{CO}_{2}$ on the Chemistry of a Lithium-Oxygen Cell. J. Am. Chem. Soc. 2013, 135, 9733-9742.

(64) Assary, R. S.; Lu, J.; Du, P.; Luo, X.; Zhang, X.; Ren, Y.; Curtiss, L. A.; Amine, K. The Effect of Oxygen Crossover on the Anode of a Li-O2 Battery Using an Ether-Based Solvent: Insights from Experimental and Computational Studies. ChemSusChem 2013, 6, 51-55.

(65) Zhang, X.; Mu, X.; Yang, S.; Wang, P.; Guo, S.; Han, M.; He, P.; Zhou, H. Research Progress for the Development of Li-Air Batteries: Addressing Parasitic Reactions Arising from Air Composition. Energy Environ. Mater. 2018, 1, 61-74.

(66) Lai, J.; Xing, Y.; Chen, N.; Li, L.; Wu, F.; Chen, R. A Comprehensive Insight into the Electrolytes for Rechargeable LithiumAir Batteries. Angew. Chem., Int. Ed. Engl. 2019, 59, 2974-2997.

(67) Saito, M.; Fujinami, T.; Yamada, S.; Ishikawa, T.; Otsuka, H.; Ito,

K.; Kubo, Y. Effects of Li Salt Anions and $\mathrm{O}_{2}$ Gas on Li Dissolution/ deposition Behavior at Li Metal Negative Electrode for Non-Aqueous Li-Air Batteries. J. Electrochem. Soc. 2017, 164, A2872-A2880.

(68) Grande, L.; Paillard, E.; Hassoun, J.; Park, J.-B.; Lee, Y.-J.; Sun, Y.K.; Passerini, S.; Scrosati, B. The Lithium/Air Battery: Still an Emerging System or a Practical Reality? Adv. Mater. 2015, 27, 784-800.

(69) Vegge, T.; Garcia-Lastra, J. M.; Siegel, D. J. Lithium-oxygen Batteries: At a Crossroads? Curr. Opin. Electrochem. 2017, 6, 100-107.

(70) Abraham, K. M. A Brief History of Non-Aqueous Metal-Air Batteries. ECS Trans. 2006, 3, 67-71.

(71) Laoire, C. O.; Mukerjee, S.; Abraham, K. M.; Plichta, E. J.; Hendrickson, M. A. Elucidating the Mechanism of Oxygen Reduction for Lithium-Air Battery Applications. J. Phys. Chem. C 2009, 113, 20127-20134.

(72) Laoire, C. O.; Mukerjee, S.; Abraham, K. M.; Plichta, E. J.; Hendrickson, M. A. Influence of Nonaqueous Solvents on the
Electrochemistry of Oxygen in the Rechargeable Lithium-Air Battery. J. Phys. Chem. C 2010, 114, 9178-9186.

(73) McCloskey, B. D.; Scheffler, R.; Speidel, A.; Girishkumar, G.; Luntz, A. C. On the Mechanism of Nonaqueous Li-O2 Electrochemistry on $\mathrm{C}$ and Its Kinetic Overpotentials: Some Implications for Li-Air Batteries. J. Phys. Chem. C 2012, 116, 23897-23905.

(74) Visco, S. J., Katz, B. D., Nimon, Y. S., De Jonghe, L. C. Protected Active Metal Electrode and Battery Cell Structures with Non-Aqueous Interlayer Architecture. US US7282295B2. 2007.

(75) Visco, S. J., Nimon, Ye. S., Katz, B. D. Ionically Conductive Composites for Protection of Active Metal Anodes. US 0040142244, A1, 2004.

(76) Visco, S. J.; Nimon, Ye. S.; Katz, B. D.; De Jonghe, L. C. Active Metal Fuel Cells. US 0090286114A1, 2009.

(77) Zhang, T.; Imanishi, N.; Takeda, Y.; Yamamoto, O. Aqueous Lithium/Air Rechargeable Batteries. Chem. Lett. 2011, 40, 668-673.

(78) Sunahiro, S.; Matsui, M.; Takeda, Y.; Yamamoto, O.; Imanishi, N. Rechargeable Aqueous Lithium-air Batteries with an Auxiliary Electrode for the Oxygen Evolution. J. Power Sources 2014, 262, 338- 343.

(79) Hasegawa, S.; Imanishi, N.; Zhang, T.; Xie, J.; Hirano, A.; Takeda, Y.; Yamamoto, O. Study on Lithium/air Secondary batteriesStability of NASICON-Type Lithium Ion Conducting Glass - ceramics with Water. J. Power Sources 2009, 189, 371-377.

(80) Read, J. Ether-Based Electrolytes for the Lithium/Oxygen Organic Electrolyte Battery. J. Electrochem. Soc. 2006, 153, A96-A100.

(81) Read, J.; Mutolo, K.; Ervin, M.; Behl, W.; Wolfenstine, J.; Driedger, A.; Foster, D. Oxygen Transport Properties of Organic Electrolytes and Performance of Lithium/Oxygen Battery. J. Electro-chem. Soc. 2003, 150, A1351-1356.

(82) Read, J. Characterization of the Lithium/Oxygen Organic Electrolyte Battery. J. Electrochem. Soc. 2002, 149, A1190-A1195.

(83) Ogasawara, T.; Debart, A.; Holzapfel, M.; Novak, P.; Bruce, P. G. Rechargeable Li202 Electrode for Lithium Batteries. J. Am. Chem. Soc. 2006, 128, 1390-1393.

(84) Freunberger,S. A.; Chen, Y.; Peng, Z.; Griffin, J. M.; Hardwick, L. J.; Barde, F.; Novak, P.; Bruce, P. G. Reactions in the Rechargeable Lithium- $\mathrm{O}_{2}$ Battery with Alkyl Carbonate Electrolytes. J. Am. Chem. Soc. 2011, 133, 8040-8047.

(85) McCloskey, B. D.; Scheffler, R.; Speidel, A.; Bethune, D. S.; Shelby, R. M.; Luntz, A. C. On the Efficacy of Electrocatalysis in Nonaqueous Li-O2 Batteries. J. Am. Chem. Soc. 2011, 133, 1803818041.

(86) Goolsby, A. D.; Sawyer, D. T. The Electrochemical Reduction of Superoxide ION and Oxidation Of Hydroxide Ion in Dimethyl Sulfoxide. Anal. Chem. 1968, 40, 83-86.

(87) Merritt, M. V.; Sawyer, D. T. Electrochemical Studies of the Reactivity of Superoxide Ion with Several Alkyl Halides in Dimethyl Sulfoxide. L. Org. Chem. 1970, 35, 2157-2159.

(88) Sharon, D.; Hirshberg, D.; Afri, M.; Garsuch, A.; Frimer, A. A.; Aurbach, D. Lithium-Oxygen Electrochemistry in NonAqueous Solutions. Isr. J. Chem. 2015, 55, 508-520.

(89) Hirshberg, D.; Sharon, D.; Afri, M.; Lavi, R.; Frimer, A. A.; Metoki, N.; Eliaz, N.; Kwak, W.; Sun, Y.-K.; Aurbach, D. Shedding Light on the Oxygen Reduction Reaction Mechanism in Ether-Based Electrolyte Solutions: A Study Using Operando UV-Vis Spectroscopy. ACS Appl. Mater. Interfaces 2018, 10, 10860-10869.

(90) Johnson, L.; Li, C.; Liu, Z.; Chen, Y.; Freunberger, S. A.; Tarascon, J.-M.; Ashok, P. C.; Praveen, B. B.; Dholakia, K.; Bruce, P. G. The Role of $\mathrm{LiO}_{2}$ Solubility in $\mathrm{O}_{2}$ Reduction in Aprotic Solvents and Its Consequences for $\mathrm{Li}_{2} \mathrm{O}_{2}$ Batteries. Nat. Chem. 2014, 6, 1091-1099.

(91) Liu, B.; Xu, W.; Zheng, J.; Yan, P.; Walter, E. D.; Isern, N.; Bowden, M. E.; Engelhard, M. H.; Kim, S. T.; Read, J.; Adams, B. D.; Li, X.; Cho, J.; Wang, C.; Zhang, J.-G. Temperature Dependence of the Oxygen Reduction Mechanism in Nonaqueous Li-O2 Batteries. ACS Energy Lett. 2017, 2, 2525-2530.

(92) Sharon, D.; Hirsberg, D.; Afri, M.; Chesneau, F.; Lavi, R.; Frimer, A. a.; Sun, Y.-K.; Aurbach, D. Catalytic Behavior of Lithium Nitrate in LiO $\mathrm{O}_{2}$ Cells. ACS Appl. Mater. Interfaces 2015, 7, 16590-16600. 
(93) Sharon, D.; Hirsberg, D.; Salama, M.; Afri, M.; Frimer, A. A.; Noked, M.; Kwak, W.-J.; Sun, Y.-K.; Aurbach, D. Mechanistic Role of $\mathrm{Li}^{+}$ Dissociation Level in Aprotic Li-O2 Battery. ACS Appl. Mater. Interfaces 2016, 8, 5300-5307.

(94) Aetukuri, N. B.; McCloskey, B. D.; Garcia, J. M.; Krupp, L. E.; Viswanathan, V.; Luntz, A. C. Solvating Additives Drive SolutionMediated Electrochemistry and Enhance Toroid Growth in NonAqueous Li- $\mathrm{O}_{2}$ Batteries. Nat. Chem. 2015, 7, 50-56.

(95) Xia, C.; Black, R.; Fernandes, R.; Adams, B.; Nazar, L. F. The Critical Role of Phase-Transfer Catalysis in Aprotic Sodium Oxygen Batteries. Nat. Chem. 2015, 7, 496-501.

(96) Schwenke, K. U.; Metzger, M.; Restle, T.; Piana, M.; Gasteiger, H. A. The Influence of Water and Protons on Li202 Crystal Growth in Aprotic Li$\mathrm{O}_{2}$ Cells. J. Electrochem. Soc. 2015, 162, A573-A584.

(97) Meini, S.; Solchenbach, S.; Piana, M.; Gasteiger, H. A. The Role of Electrolyte Solvent Stability and Electrolyte Impurities in the Electrooxidation of $\mathrm{Li}_{2} \mathrm{O} 2$ in $\mathrm{Li}^{-\mathrm{O}_{2}}$ Batteries. J. Electrochem. Soc. 2014, 161, A1306-A1314.

(98) Li, F.; Wu, S.; Li, D.; Zhang, T.; He, P.; Yamada, A.; Zhou, H. The Water Catalysis at Oxygen Cathodes of Lithium-oxygen Cells. Nat. Commun. 2015, 6, 7843.

(99) Kwak, W.-J.; Hirshberg, D.; Sharon, D.; Shin, H.-J.; Afri, M.; Park, J.-B.; Garsuch, A.; Chesneau, F. F.; Frimer, A. A.; Aurbach, D.; et al. Understanding the Behavior of Li-oxygen Cells Containing LiI. J. Mater. Chem. A 2015, 3, 8855-8864.

(100) Liu, T.; Leskes, M.; Yu, W.; Moore, A. J.; Zhou, L.; Bayley, P. M.; Kim, G.; Grey, C. P. Cycling $\mathrm{Li}_{2} \mathrm{O}_{2}$ Batteries via LiOH Formation and Decomposition. Science 2015, 350, 530-533.

(101) Burke, C. M.; Black, R.; Kochetkov, I. R.; Giordani, V.; Addison, D.; Nazar, L. F.; McCloskey, B. D. Implications of 4 E- Oxygen Reduction via Iodide Redox Mediation in $\mathrm{Li}^{-\mathrm{O}_{2}}$ Batteries. ACS Energy Lett. 2016, 1, 747-756.

(102) Ganapathy, S.; Adams, B. D.; Stenou, G.; Anastasaki, M. S.; Goubitz, K.; Miao, X. F.; Nazar, L. F.; Wagemaker, M. Nature of $\mathrm{Li}_{2} \mathrm{O}_{2}$ Oxidation in a Li-O 2 Battery Revealed by Operando X-Ray Diffraction. J. Am. Chem. Soc. 2014, 136, 16335-16344.

(103) Zhang, Y.; Cui, Q.; Zhang, X.; McKee, W. C.; Xu, Y.; Ling, S.; Li, H.; Zhong, G.; Yang, Y.; Peng, Z. Amorphous $\mathrm{Li}_{2} \mathrm{O}_{2}$ : Chemical Synthesis and Electrochemical Properties. Angew. Chem., Int. Ed. 2016, 55, 10717-10721.

(104) Dunst, A.; Epp, V.; Hanzu, I.; Freunberger, S. A.; Wilkening, M. Short-Range Li Diffusion vs. Long-Range Ionic Conduction in Nanocrystalline Lithium Peroxide $\mathrm{Li2O}_{2}$-the Discharge Product in Lithium-Air Batteries. Energy Environ. Sci. 2014, 7, 2739-2752.

(105) McCloskey, B. D.; Speidel, A.; Scheffler, R.; Miller, D. C.; Viswanathan, V.; Hummelshøj, J. S.; Nørskov, J. K.; Luntz, A. C. Twin Problems of Interfacial Carbonate Formation in Nonaqueous Li-O2 Batteries. J. Phys. Chem. Lett. 2012, 3, 997-1001.

(106) Wandt, J.; Jakes, P.; Granwehr, J.; Gasteiger, H. A.; Eichel, R. A. Singlet Oxygen Formation during the Charging Process of an Aprotic Lithium-Oxygen Battery. Angew. Chem., Int. Ed. 2016, 55, 6892-6895. (107) Schafzahl, L.; Mahne, N.; Schafzahl, B.; Wilkening, M.; Slugovc, C.; Borisov, S. M.; Freunberger, S. A. Singlet Oxygen during Cycling of the Aprotic Sodium-O 2 Battery. Angew. Chem., Int. Ed. 2017, 56, 15728-15732.

(108) Mahne, N.; Schafzahl, B.; Leypold, C.; Leypold, M.; Grumm, S.; Leitgeb, A.; Strohmeier, G. A.; Wilkening, M.; Fontaine, O.; Kramer,

D.; Slugovc, C.; Borisov, S. M.; Freunberger, S. A. Singlet Oxygen Generation as a Major Cause for Parasitic Reactions during Cycling of Aprotic Lithium-Oxygen Batteries. Nat. Energy 2017, 2, 17036.

(109) Mourad, E.; Petit, Y. K.; Spezia, R.; Samojlov, A.; Summa, F. F.; Prehal, C.; Leypold, C.; Mahne, N.; Slugovc, C.; Fontaine, O.; et al. Singlet Oxygen from Cation Driven Superoxide Disproportionation and Consequences for Aprotic metal-O2 Batteries. Energy Environ. Sci. 2019, 12, 2559-2568.

(110) Peng, Q.; Chen, J.; Ji, H.; Morita, A.; Ye, S. Origin of the Overpotential for the Oxygen Evolution Reaction on a Well-Defined Graphene Electrode Probed by in Situ Sum Frequency Generation Vibrational Spectroscopy. J. Am. Chem. Soc. 2018, 140, 15568-15571.
(111) Hong, M.; Yang, C.; Wong, R. A.; Nakao, A.; Choi, H. C.; Byon, H. R. Determining the Facile Routes for Oxygen Evolution Reaction by in

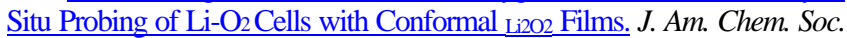
2018, 140, 6190-6193.

(112) Liu, C.; Ye, S. In Situ Atomic Force Microscopy (AFM) Study of Oxygen Reduction Reaction on a Gold Electrode Surface in a Dimethyl Sulfoxide (DMSO)-Based Electrolyte Solution. J. Phys. Chem. C 2016, 120, 25246-25255.

(113) Wang, Y.; Lai, N.-C.; Lu, Y.-R.; Zhou, Y.; Dong, C.-L.; Lu, Y.-C. A Solvent-Controlled Oxidation Mechanism of Li2O2 in Lithium-Oxygen Batteries. Joule 2018, 2, 2364-2380.

(114) Kang, S.; Mo, Y.; Ong, S. P.; Ceder, G. A Facile Mechanism for ${\text { Recharging } \mathrm{Li}_{2} \mathrm{O} 2 \text { in Li-O }}_{2}$ Batteries. Chem. Mater. 2013, 25, 3328- 3336.

(115) Lu, Y.; Shao-Horn, Y. Probing the Reaction Kinetics of the Charge Reactions of Nonaqueous Li-O 2 Batteries. J. Phys. Chem. Lett. 2013, 4, 93-99.

(116) Zhai, D.; Wang, H.-H.; Yang, J.; Lau, K. C.; Li, K.; Amine, K.; Curtiss, L. A. Disproportionation in $\mathrm{Li}_{2} \mathrm{O}_{2}$ Batteries Based on a Large Surface Area Carbon Cathode. J. Am. Chem. Soc. 2013, 135, 1536415372.

(117) Lu, Y.-C.; Gallant, B. M.; Kwabi, D. G.; Harding, J. R.; Mitchell, R. R.; Whittingham, M. S.; Shao-Horn, Y. Lithium-oxygen Batteries: Bridging Mechanistic Understanding and Battery Performance. Energy Environ. Sci. 2013, 6, 750-768.

(118) Liu, T.; Kim, G.; Casford, M. T. L.; Grey, C. P. Mechanistic Insights into the Challenges of Cycling a Nonaqueous $\mathrm{Na}-\mathrm{O}_{2}$ Battery. $J$. Phys. Chem. Lett. 2016, 7, 4841-4846.

(119) Hartmann, P.; Bender, C. L.; Vračar, M.; Dür, A. K.; Garsuch, A.; Janek, J.; Adelhelm, P. A Rechargeable Room-Temperature Sodium Superoxide $\left(\mathrm{NaO}_{2}\right)$ Battery. Nat. Mater. 2013, 12, 228-232.

(120) Cong, G.; Wang, W.; Lai, N.-C.; Liang, Z.; Lu, Y.-C. A High-Rate and Long-Life Organic-oxygen Battery. Nat. Mater. 2019, 18, 390-396.

(121) Freunberger, S. A.; Chen, Y.; Drewett, N. E.; Hardwick, L. J.; Barde, F.; Bruce, P. G. The Lithium-Oxygen Battery with Ether-Based Electrolytes. Angew. Chem., Int. Ed. 2011, 50, 8609-8613.

(122) McCloskey, B. D.; Bethune, D. S.; Shelby, R. M.; Gịishkumar, G.; Luntz, A. C. Solvents' Critical Role in Nonaqueous Lithium A Oxygen Battery. J. Phys. Chem. Lett. 2011, 2, 1161-1166.

(123) McCloskey, B. D.; Valery, A.; Luntz, A. C.; Gowda, S. R.; Wallraff, G. M.; Garcia, J. M.; Mori, T.; Krupp, L. E. Combining Accurate $\mathrm{O}_{2}$ and $\mathrm{Li}_{2} \mathrm{O} 2$ Assays to Separate Discharge and Charge Stability Limitations in Nonaqueous $\mathrm{Li}_{2} \mathrm{O}_{2}$ Batteries. J. Phys. Chem. Lett. 2013, 4, 2989-2993.

(124) Bender, C. L.; Schröder, D.; Pinedo, R.; Adelhelm, P.; Janek, J. One- or Two-Electron Transfer? The Ambiguous Nature of the Discharge Products in Sodium-Oxygen Batteries. Angew. Chem., Int. Ed. 2016, 55, 4640-4649.

(125) Wang, W.; Lai, N.-C.; Liang, Z.; Wang, Y.; Lu, Y.-C. Superoxide Stabilization and a Universal $\mathrm{KO}_{2}$ Growth Mechanism in Potassium-Oxygen Batteries. Angew. Chem., Int. Ed. 2018, 57, 5042-5046.

(126) Xiao, N.; Rooney, R. T.; Gewirth, A. A.; Wu, Y. The Long-Term Stability of $\mathrm{KO}_{2}$ in $\mathrm{K}^{-\mathrm{O}_{2}}$ Batteries. Angew. Chem., Int. Ed. 2018, 57, 1227-1231.

(127) McCloskey, B. D.; Garcia, J. M.; Luntz, A. C. Chemical and Electrochemical Differences in Nonaqueous $\mathrm{Li}^{-\mathrm{O}_{2}}$ and $\mathrm{Na}-\mathrm{O}_{2}$ Batteries. J. Phys. Chem. Lett. 2014, 5, 1230-1235.

(128) Bender, C. L.; Hartmann, P.; Vracar, M.; Adelhelm, P.; Janek, J. On the Thermodynamics, the Role of the Carbon Cathode, and the Cycle Life of the Sodium Superoxide $\left(\mathrm{NaO}_{2}\right)$ Battery. Adv. Energy Mater. 2014, 4, 1301863.

(129) Lutz, L.; Yin, W.; Grimaud, A.; Alves Dalla Corte, D.; Tang, M.; Johnson, L.; Azaceta, E.; Sarou-Kanian, V.; Naylor, A. J.; Hamad, S.; et al. High Capacity Na-O2 Batteries: Key Parameters for Solution-Mediated Discharge. J. Phys. Chem. C 2016, 120, 20068-20076.

(130) Black, R.; Shyamsunder, A.; Adeli, P.; Kundu, D.; Murphy, G. K.; Nazar, L. F. The Nature and Impact of Side Reactions in GlymeBased Sodium-Oxygen Batteries. ChemSusChem 2016, 9, 1795-1803. 
(131) McCloskey, B. D.; Bethune, D. S.; Shelby, R. M.; Mori, T.; Scheffler, R.; Speidel, A.; Sherwood, M.; Luntz, A. C. Limitations in Rechargeability of $\mathrm{Li}^{-\mathrm{O}_{2}}$ Batteries and Possible Origins. J. Phys. Chem. Lett. 2012, 3, 3043-3047.

(132) Sayed, S. Y.; Yao, K. P. C.; Kwabi, D. G.; Batcho, T. P.; Amanchukwu, C. V.; Feng, S.; Thompson, C. V.; Shao-Horn, Y. Revealing Instability and Irreversibility in Nonaqueous sodium- $\mathrm{O}_{2}$ Battery Chemistry. Chem. Commun. 2016, 52, 9691-9694.

(133) Adams, B. D.; Black, R.; Williams, Z.; Fernandes, R.; Cuisinier, M.; Berg, E. J.; Novak, P.; Murphy, G. K.; Nazar, L. F. Towards a Stable Organic Electrolyte for the Lithium Oxygen Battery. Adv. Energy Mater. 2015, 5, 1400867.

(134) McCloskey, B. D.; Burke, C. M.; Nichols, J. E.; Renfrew, S. E. Mechanistic Insights for the Development of $\mathrm{Li}^{-\mathrm{O}_{2}}$ Battery Materials: Addressing Li202 Conductivity Limitations and Electrolyte and Cathode Instabilities. Chem. Commun. 2015, 51, 12701-12715.

(135) Mahne, N.; Fontaine, O.; Thotiyl, M. O.; Wilkening, M.; Freunberger, S. A. Mechanism and Performance of Lithium-oxygen Batteries - a Perspective. Chem. Sci. 2017, 8, 6716-6729.

(136) Sawyer, D. T.; Valentine, J. S. How Super Is Superoxide? Acc. Chem. Res. 1981, 14, 393-400.

(0) Aurbach, D.; Daroux, M.; Faguy, P.; Yeager, E. The Electrochemistry of Noble Metal Electrodes in Aprotic Organic Solvents Containing Lithium Salts. J. Electroanal. Chem. Interfacial Electrochem. 1991, 297, 225-244.

(137) Bryantsev, V. S.; Blanco, M. Computational Study of the Mechanisms of Superoxide-Induced Decomposition of Organic Carbonate-Based Electrolytes. J. Phys. Chem. Lett. 2011, 2, 379-383.

(138) Bryantsev, V. S. Predicting the Stability of Aprotic Solvents in Li-Air Batteries: pKa Calculations of Aliphatic $\mathrm{C}-\mathrm{H}$ Acids in Dimethyl Sulfoxide. Chem. Phys. Lett. 2013, 558, 42-47.

(139) Bryantsev, V. S.; Faglioni, F. Predicting Autoxidation Stability of Ether- and Amide-Based Electrolyte Solvents for Li-Air Batteries. J. Phys. Chem. A 2012, 116, 7128-7138.

(140) Bryantsev, V. S.; Giordani, V.; Walker, W.; Blanco, M.; Zecevic, S.; Sasaki, K.; Uddin, J.; Addison, D.; Chase, G. V.Predicting Solvent Stability in Aprotic Electrolyte Li-Air Batteries: Nucleophilic Substitution by the Superoxide Anion Radical $\left(\mathrm{O}_{2--}\right)$. J. Phys. Chem. A 2011, 115, 12399-12409.

(141) Bryantsev, V. S.; Uddin, J.; Giordani, V.; Walker, W.; Addison, D.; Chase, G. V. The Identification of Stable Solvents for Nonaqueous Rechargeable Li-Air Batteries. J. Electrochem. Soc. 2013, 160, A160A171.

(142) Genorio, B.; Staszak-Jirkovsky, J.; Assary, R. S.; Connell, J. G.; Strmcnik, D.; Diesendruck, C. E.; Lopes, P. P.; Stamenkovic, V. R.; Moore, J. S.; Curtiss, L. A.; et al. Superoxide (Electro)Chemistry on WellDefined Surfaces in Organic Environments. J. Phys. Chem. C 2016, 120, 15909-15914.

(143) Zhang, Z.; Lu, J.; Assary, R. S.; Du, P.; Wang, H.-H.; Sun, Y.K.; Qin, Y.; Lau, K. C.; Greeley, J.; Redfern, P. C.; et al.Increased Stability Toward Oxygen Reduction Products for Lithium-Air Batteries with Oligoether-Functionalized Silane Electrolytes. J. Phys. Chem. C 2011, 115, 25535-25542.

(1) Carboni, M.; Marrani, A. G.; Spezia, R.; Brutti, S. 1,2Dimethoxyethane Degradation Thermodynamics in Li-O 2 Redox Environments. Chem. - Eur. J. 2016, 22, 17188-17203.

(144) Liu, B.; Xu, W.; Yan, P.; Sun, X.; Bowden, M. E.; Read, J.; Qian, J.; Mei, D.; Wang, C. M.; Zhang, J. G. Enhanced Cycling Stability of Rechargeable Li- $\mathrm{O}_{2}$ Batteries Using High-Concentration Electrolytes. $A d v$. Funct. Mater. 2016, 26, 605-613.

(145) Khetan, A.; Pitsch, H.; Viswanathan, V. Solvent Degradation in Nonaqueous $\mathrm{Li}_{2}$-O Batteries: Oxidative Stability versus $\mathrm{H}$ Abstraction. J. Phys. Chem. Lett. 2014, 5, 2419-2424.

(146) Assary, R. S.; Lau, K. C.; Amine, K.; Sun, Y.-K.; Curtiss, L. A. Interactions of Dimethoxy Ethane with Li2O2 Clusters and Likely Decomposition Mechanisms for $\mathrm{Li}_{2} \mathrm{O}_{2}$ Batteries. J. Phys. Chem. C 2013, 117, 8041-8049.

(147) Li, Q.; Chen, F.; Zhao, W.; Xu, M.; Fang, B.; Zhang, Y.; Duo, L.; Jin, Y.; Sang, F. A Spectroscopic Study on Singlet Oxygen Production from Different Reaction Paths Using Solid Inorganic Peroxides as Starting Materials. Bull. Korean Chem. Soc. 2007, 28, 1656-1660.

(2) Hassoun, J.; Croce, F.; Armand, M.; Scrosati, B. Investigation of $\underline{\text { the } \mathrm{O}_{2}}$ Electrochemistry in a Polymer Electrolyte Solid-State Cell. Angew. Chem., Int. Ed. 2011, 50, 2999-3002.

(3) Aubry, J. M.; Rigaudy, J.; Ferradini, C.; Pucheault, J. Search for Singlet Oxygen in the Disproportionation of Superoxide Anion. J. Am. Chem. Soc. 1981, 103, 4965-4966.

(4) Nanni, E. J.; Birge, R. R.; Hubbard, L. M.; Morrison, M. M.; Sawyer, D. T. Oxidation and Dismutation of Superoxide Ion Solutions to Molecular Oxygen. Singlet vs. Triplet State. Inorg. Chem. 1981, 20, 737-741.

(5) Black, R.; Lee, J.-H.; Adams, B.; Mims, C. A.; Nazar, L. F. The Role of Catalysts and Peroxide Oxidation in Lithium-Oxygen Batteries. Angew. Chem., Int. Ed. 2013, 52, 392-396.

(6) Ottakam Thotiyl, M. M.; Freunberger, S. A.; Peng, Z.; Bruce, P. G. The Carbon Electrode in Nonaqueous Li-O2 Cells. J. Am. Chem. Soc. 2013, 135, 494-500.

(7) Luntz, A. C.; McCloskey, B. D. Li-air Batteries: Importance of Singlet Oxygen. Nat. Energy 2017, 2, 17056.

(8) Kwak, W.-J.; Kim, H.; Petit, Y. K.; Leypold, C.; Nguyen, T. T.; Mahne, N.; Redfern, P.; Curtiss, L. A.; Jung, H.-G.; Borisov, S. M.; Freunberger, S. A.; Sun, Y.-K. Deactivation of Redox Mediators in Lithium-Oxygen Batteries by Singlet Oxygen. Nat. Commun. 2019, 10, 1380.

(9) Kwak, W.-J.; Freunberger, S. A.; Kim, H.; Park, J.; Nguyen, T. T.; Jung, H.-G.; Byon, H. R.; Sun, Y.-K. Mutual Conservation of Redox Mediator and Singlet Oxygen Quencher in Lithium-Oxygen Batteries. ACS Catal. 2019, 9, 9914-9922.

(10) Zhang, Y.; Zhang, X.; Wang, J.; McKee, W. C.; Xu, Y.; Peng, Z. Potential-Dependent Generation of $\mathrm{O}_{2}-$ and $\mathrm{LiO}_{2}$ and Their Critical Roles in $\mathrm{O}_{2}$ Reduction to Li2O2 in Aprotic Li-O⿰冫⿰亅⿱丿丶丶 2 Batteries. J. Phys. Chem. C 2016, 120, 3690-3698.

(11) Allen, C. J.; Hwang, J.; Kautz, R.; Mukerjee, S.; Plichta, E. J.; Hendrickson, M. A.; Abraham, K. M. Oxygen Reduction Reactions in Ionic Liquids and the Formulation of a General ORR Mechanism for LiAir Batteries. J. Phys. Chem. C 2012, 116, 20755-20764.

(12) Sheng, C.; Yu, F.; Wu, Y.; Peng, Z.; Chen, Y. Disproportionation of Sodium Superoxide in Metal-Air Batteries. Angew. Chem., Int. Ed. 2018, 57, 9906-9910.

(13) Das, U.; Lau, K. C.; Redfern, P. C.; Curtiss, L. A. Structure and Stability of Lithium Superoxide Clusters and Relevance to $\mathrm{Li}-\mathrm{O}_{2}$ Batteries. J. Phys. Chem. Lett. 2014, 5, 813-819.

(14) Landa-Medrano, I.; Pinedo, R.; Bi, X.; Ruiz de Larramendi, I.; Lezama, L.; Janek, J.; Amine, K.; Lu, J.; Rojo, T. New Insights into the Instability of Discharge Products in $\mathrm{Na}_{2} \mathrm{O}_{2}$ Batteries. ACS Appl. Mater. Interfaces 2016, 8, 20120-20127.

(15) Chen, Y.; Jovanov, Z. P.; Gao, X.; Liu, J.; Holc, C.; Johnson, L. R.; Bruce, P. G. High Capacity Surface Route Discharge at the PotassiumO2 Electrode. J. Electroanal. Chem. 2018, 819, 542-546.

(16) Amanchukwu, C. V.; Chang, H.-H.; Gauthier, M.; Feng, S.; Batcho, T. P.; Hammond, P. T. One-Electron Mechanism in a GelPolymer Electrolyte Li-O2 Battery. Chem. Mater. 2016, 28, 7167-7177.

(17) Kwabi, D. G.; Bryantsev, V. S.; Batcho, T. P.; Itkis, D. M.; Thompson, C. V.; Shao-Horn, Y. Experimental and Computational Analysis of the Solvent-Dependent $\mathrm{O}_{2} / \mathrm{Li}^{+}-\mathrm{O}_{2}-$ Redox Couple: Standard Potentials, Coupling Strength, and Implications for LithiumOxygen Batteries. Angew. Chem., Int. Ed. 2016, 55, 3129-3134.

(18) Peng, Z.; Freunberger, S. A.; Hardwick, L. J.; Chen, Y.; Giordani, V.; Barde, F.; Novak, P.; Graham, D.; Tarascon, J.-M.; Bruce, P. G. Oxygen Reactions in a Non-Aqueous $\mathrm{Li}^{+}$Electrolyte. Angew. Chem., Int. Ed. 2011, 50, 6351-6355.

(19) Mo, Y.; Ong, S. P.; Ceder, G. First-Principles Study of the Oxygen Evolution Reaction of Lithium Peroxide in the Lithium-Air Battery. Phys. Rev. B: Condens. Matter Mater. Phys. 2011, 84, 205446.

(20) Huang, J.; Tong, B.; Li, Z.; Zhou, T.; Zhang, J.; Peng, Z.Probing the Reaction Interface in Li-Oxygen Batteries Using Dynamic Electrochemical Impedance Spectroscopy: Discharge-Charge Asym- 
metry in Reaction Sites and Electronic Conductivity. J. Phys. Chem. Lett. 2018, 9, 3403-3408.

(169) Wang, J.; Zhang, Y.; Guo, L.; Wang, E.; Peng, Z. Identifying Reactive Sites and Transport Limitations of Oxygen Reactions in Aprotic Lithium- $\mathrm{O}_{2}$ Batteries at the Stage of Sudden Death. Angew. Chem., Int. Ed. 2016, 55, 5201-5205.

(170) Yin, W.; Grimaud, A.; Lepoivre, F.; Yang, C.; Tarascon, J. M. Chemical vs Electrochemical Formation of $\mathrm{Li}_{2} \mathrm{CO}_{3}$ as a Discharge Product in $\mathrm{Li}-\mathrm{O}_{2} / \mathrm{CO}_{2}$ Batteries by Controlling the Superoxide Intermediate. J. Phys. Chem. Lett. 2017, 8, 214-222.

(171) Gowda, S. R.; Brunet, A.; Wallraff, G. M.; McCloskey, B. D. Implications of $\mathrm{CO}_{2}$ Contamination in Rechargeable Nonaqueous Li-O 2 Batteries. J. Phys. Chem. Lett. 2013, 4, 276-279.

(172) Renfrew, S. E.; McCloskey, B. D. Residual Lithium Carbonate Predominantly Accounts for First Cycle $\mathrm{CO}_{2}$ and $\mathrm{CO}$ Outgassing of Li-Stoichiometric and Li-Rich Layered Transition-Metal Oxides. J. Am. Chem. Soc. 2017, 139, 17853-17860.

(173) Zhao, Z.; Huang, J.; Peng, Z. Achilles' Heel of LithiumAir Batteries: Lithium Carbonate. Angew. Chem., Int. Ed. 2018, 57, 3874- 3886.

(174) Mahne, N.; Renfrew, S. E.; McCloskey, B. D.; Freunberger, S. A. Electrochemical Oxidation of Lithium Carbonate Generates Singlet Oxygen. Angew. Chem., Int. Ed. 2018, 57, 5529-5533.

(175) Schweitzer, C.; Schmidt, R. Physical Mechanisms of Generation and Deactivation of Singlet Oxygen. Chem. Rev. 2003, 103, 1685-1758.

(176) Petit, Y. K.; Leypold, C.; Mahne, N.; Mourad, E.; Schafzahl, L.; Slugove, C.; Borisov, S. M.; Freunberger, S. A. DABCOnium: An Efficient and High-Voltage Stable Singlet Oxygen Quencher for Metal$\mathrm{O}_{2}$ Cells. Angew. Chem., Int. Ed. 2019, 58, 6535-6539.

(177) Das, S.; Højberg, J.; Knudsen, K. B.; Younesi, R.; Johansson, P.; Norby, P.; Vegge, T. Instability of Ionic Liquid-Based Electrolytes in Li-O2 Batteries. J. Phys. Chem. C 2015, 119, 18084-18090.

(178) Piana, M.; Wandt, J.; Meini, S.; Buchberger, I.; Tsiouvaras, N.; Gasteiger, H. A. Stability of a Pyrrolidinium-Based Ionic Liquid in $\mathrm{Li}_{2} \mathrm{O}_{2}$ Cells. J. Electrochem. Soc. 2014, 161, A1992-A2001.

(179) Zhang, S.; Nava, M. J.; Chow, G. K.; Lopez, N.; Wu, G.; Britt, D. R.; Nocera, D. G.; Cummins, C. C. On the Incompatibility of lithium$\mathrm{O}_{2}$ Battery Technology with $\mathrm{CO}_{2}$. Chem. Sci. 2017, 8, 6117-6122.

(180) Kim, J.; Park, H.; Lee, B.; Seong, W. M.; Lim, H.-D.; Bae, Y.; Kim, H.; Kim, W. K.; Ryu, K. H.; Kang, K. Dissolution and Ionization of Sodium Superoxide in Sodium-oxygen Batteries. Nat. Commun. 2016, 7 , 10670.

(181) Freunberger, S. A. True Performance Metrics in beyondIntercalation Batteries. Nat. Energy 2017, 2, 17091.

(182) Mizuno, F.; Nakanishi, S.; Kotani, Y.; Yokoishi, S.; Iba, H. Rechargeable Li-Air Batteries with Carbonate-Based Liquid Electrolytes. Electrochemistry 2010, 78, 403-405.

(183) McCloskey, B. D.; Bethune, D. S.; Shelby, R. M.; Girishkumar, G.; Luntz, A. C. Solvents' Critical Role in Nonaqueous Lithium-Oxygen Battery Electrochemistry. J. Phys. Chem. Lett. 2011, 2, 1161-1166.

(184) Sharon, D.; Etacheri, V.; Garsuch, A.; Afri, M.; Frimer, A. A.; Aurbach, D. On the Challenge of Electrolyte Solutions for Li-Air Batteries: Monitoring Oxygen Reduction and Related Reactions in Polyether Solutions by Spectroscopy and EQCM. J. Phys. Chem. Lett. 2013, 4, 127-131.

(185) Sharon, D.; Hirshberg, D.; Afri, M.; Frimer, A. A.; Aurbach, D. The Importance of Solvent Selection in $\mathrm{Li}_{2} \mathrm{O}_{2}$ Cells. Chem. Commun. 2017, 53, 3269-3272.

(186) Carbone, L.; Moro, P. T.; Gobet, M.; Munoz, S.; Devany, M.; Greenbaum, S. G.; Hassoun, J. Enhanced Lithium Oxygen Battery Using a Glyme Electrolyte and Carbon Nanotubes. ACS Appl. Mater. Interfaces 2018, 10, 16367-16375.

(187) Viswanathan, V.; Thygesen, K. S.; Hummelshøj, J. S.; Nørskov, J. K.; Girishkumar, G.; McCloskey, B. D.; Luntz, A. C. Electrical Conductivity in $\mathrm{Li}_{2} \mathrm{O} 2$ and Its Role in Determining Capacity Limitations in Non-Aqueous $\mathrm{Li}^{-\mathrm{O}_{2}}$ Batteries. J. Chem. Phys. 2011, 135, 214704.

(188) Peng, Z.; Freunberger, S. A.; Chen, Y.; Bruce, P. G. A Reversible and Higher-Rate Li-O2 Battery. Science 2012, 337, 563-566.
(131) Xu, D.; Wang, Z.; Xu, J.; Zhang, L.; Zhang, X. Novel DMSO-

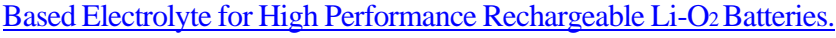
Chem. Commun. 2012, 48, 6948.

(132) Trahan, M. J.; Mukerjee, S.; Plichta, E. J.; Hendrickson, M. A.; Abraham, K. M. Studies of Li-Air Cells Utilizing Dimethyl SulfoxideBased Electrolyte. J. Electrochem. Soc. 2013, 160, A259-A267.

(133) Sharon, D.; Afri, M.; Noked, M.; Garsuch, A.; Frimer, A. A.; Aurbach, D. Oxidation of Dimethyl Sulfoxide Solutions by Electrochemical Reduction of Oxygen. J. Phys. Chem. Lett. 2013, 4, 3115- 3119.

(134) Liu, B.; Xu, W.; Yan, P.; Kim, S. T.; Engelhard, M. H.; Sun, X.; Mei, D.; Cho, J.; Wang, C.-M.; Zhang, J.-G. Stabilization of Li Metal Anode in DMSO-Based Electrolytes via Optimization of Salt-Solvent Coordination for Li-O2 2 Batteries. Adv. Eneryy Mater. 2017, 7, 1602605.

(135) Uddin, J.; Bryantsev, V. S.; Giordani, V.; Walker, W.; Chase, G. V.; Addison, D. Lithium Nitrate as Regenerable SEI Stabilizing Agent for Rechargeable Li/O ${ }_{2}$ Batteries. J. Phys. Chem. Lett. 2013, 4, 37603765.

(136) Walker, W.; Giordani, V.; Uddin, J.; Bryantsev, V. S.; Chase, G. V.; Addison, D. A Rechargeable Li-O $\mathrm{O}_{2}$ Battery Using a Lithium Nitrate/ N, N -Dimethylacetamide Electrolyte. J. Am. Chem. Soc. 2013, 135, 2076-2079.

(137) Chen, Y.; Freunberger, S. A.; Peng, Z.; Barde, F.; Bruce, P. G. Li$\mathrm{O}_{2}$ Battery with a Dimethylformamide Electrolyte. J. Am. Chem. Soc. 2012, 134, 7952-7957.

(138) Sharon, D.; Hirsberg, D.; Afri, M.; Garsuch, A.; Frimer, A. A.; Aurbach, D. Reactivity of Amide Based Solutions in Lithium-Oxygen Cells. J. Phys. Chem. C 2014, 118, 15207-15213.

(139) Lim, H. D.; Lee, B.; Bae, Y.; Park, H.; Ko, Y.; Kim, H.; Kim, J.; Kang, K. Reaction Chemistry in Rechargeable Li-O2 Batteries. Chem. Soc. Rev. 2017, 46, 2873-2888.

(140) Walker, W.; Giordani, V.; Uddin, J.; Bryantsev, V. S.; Chase, G. V.; Addison, D. A Rechargeable Li-O2 Battery Using a Lithium Nitrate/ N,N-Dimethylacetamide Electrolyte. J. Am. Chem. Soc. 2013, 135, 2076-2079.

(141) Sharon, D.; Hirsberg, D.; Afri, M.; Chesneau, F.; Lavi, R.; Frimer, A. a.; Sun, Y.-K.; Aurbach, D. The Catalytic Behavior of Lithium Nitrate in Li-O2 Cells. ACS Appl. Mater. Interfaces 2015, 7, $16590-16600$.

(142) Rosy; Akabayov, S.; Leskes, M.; Noked, M. Bifunctional Role of $\mathrm{LiNO}_{3}$ in $\mathrm{Li}_{-} \mathrm{O}_{2}$ Batteries: Deconvoluting Surface and Catalytic Effects. ACS Appl. Mater. Interfaces 2018, 10, 29622-29629.

(143) Nasybulin, E.; Xu, W.; Engelhard, M. H.; Nie, Z.; Burton, S. D.; Cosimbescu, L.; Gross, M. E.; Zhang, J. G. Effects of Electrolyte Salts on the Performance of $\mathrm{Li}_{2} \mathrm{O}_{2}$ Batteries. J. Phys. Chem. C 2013, 117, 26352645.

(144) Nakanishi, A.; Thomas, M. L.; Kwon, H. M.; Kobayashi, Y.; Tatara, R.; Ueno, K.; Dokko, K.; Watanabe, M. Electrolyte Composition in $\mathrm{Li} / \mathrm{O}_{2}$ Batteries with LiI Redox Mediators: Solvation Effects on Redox Potentials and Implications for Redox Shuttling. J. Phys. Chem. C 2018, 122, 1522-1534.

(145) Kwak, W.-J.; Hirshberg, D.; Sharon, D.; Afri, M.; Frimer, A. A.; Jung, H.-G.; Aurbach, D.; Sun, Y.-K. Li-O2 Cells with $\mathrm{LiBr}$ as an Electrolyte and a Redox Mediator. Energy Environ. Sci. 2016, 9, 23342345.

(146) Sharon, D.; Sharon, P.; Hirshberg, D.; Salama, M.; Afri, M.; Shimon, L. J. W.; Kwak, W. J.; Sun, Y. K.; Frimer, A. A.; Aurbach, D. 2,4 Dimethoxy-2,4-Dimethylpentan-3-One: An Aprotic Solvent Designed for Stability in Li-O2 Cells. J. Am. Chem. Soc. 2017, 139, 11690-11693.

(147) Huang, Z.; Zeng, H.; Xie, M.; Lin, X.; Huang, Z.; Shen, Y.; Huang, Y. A Stable Lithium-Oxygen Battery Electrolyte Based on Fully Methylated Cyclic Ether. Angew. Chem., Int. Ed. 2019, 58, 2345-2349.

(148) Dong, Q.; Yao, X.; Zhao, Y.; Qi, M.; Zhang, X.; Sun, H.; He, Y.; Wang, D. Cathodically Stable Li-O2 Battery Operations Using Water-inSalt Electrolyte. Chem. 2018, 4, 1345-1358.

(149) Zhao, Q.; Zhang, Y.; Sun, G.; Cong, L.; Sun, L.; Xie, H.; Liu, J. Binary Mixtures of Highly Concentrated Tetraglyme and Hydrofluoroether as a Stable and Nonflammable Electrolyte for $\mathrm{Li}-\mathrm{O}_{2}$ Batteries. ACS Appl. Mater. Interfaces 2018, 10, 26312-26319. 
(208) Gao, X.; Chen, Y.; Johnson, L. R.; Jovanov, Z. P.; Bruce, P. G. A Rechargeable Lithium-oxygen Battery with Dual Mediators Stabilizing the Carbon Cathode. Nat. Energy 2017, 2, 17118.

(209) Lu, Y.-C.; Gasteiger, H. A.; Parent, M. C.; Chiloyan, V.; ShaoHorn, Y. The Influence of Catalysts on Discharge and Charge Voltages of Rechargeable Li-Oxygen Batteries. Electrochem. Solid-State Lett. 2010, 13, A69-A72.

(210) Woo, H.; Kang, J.; Kim, J.; Kim, C.; Nam, S.; Park, B. Development of Carbon-Based Cathodes for Li-Air Batteries: Present and Future. Electron. Mater. Lett. 2016, 12, 551-567.

(211) Ding, N.; Chien, S. W.; Hor, T. S. A.; Lum, R.; Zong, Y.; Liu, Z. Influence of Carbon Pore Size on the Discharge Capacity of $\underline{\mathrm{Li}}_{2} \mathrm{O}_{2}$ Batteries. J. Mater. Chem. A 2014, 2, 12433-12441.

(212) Nie, H.; Zhang, Y.; Li, J.; Zhou, W.; Lai, Q.; Liu, T.; Zhang, H. Synthesis of a Meso-macro Hierarchical Porous Carbon Material for Improvement of $\mathrm{O}_{2}$ Diffusivity in $\mathrm{Li}^{-\mathrm{O}_{2}}$ Batteries. RSC Adv. 2014, 4, 17141.

(213) Xiao, J.; Mei, D.; Li, X.; Xu, W.; Wang, D.; Graff, G. L.; Bennett, W. D.; Nie, Z.; Saraf, L. V.; Aksay, I. A.; et al. Hierarchically Porous Graphene as a Lithium-Air Battery Electrode. Nano Lett. 2011, 11, 5071-5078.

(214) Zhang, W.; Zhu, J.; Ang, H.; Zeng, Y.; Xiao, N.; Gao, Y.; Liu, W.; Hng, H. H.; Yan, Q. Binder-Free Graphene Foams for $\mathrm{O}_{2}$ Electrodes of LiO 2 Batteries. Nanoscale 2013, 5, 9651-9658.

(215) Mitchell, R. R.; Gallant, B. M.; Thompson, C. V.; Shao-Horn, Y. All-Carbon-Nanofiber Electrodes for High-Energy Rechargeable Li-O Batteries. Energy Environ. Sci. 2011, 4, 2952-2958.

(216) Zhao, C.; Yu, C.; Liu, S.; Yang, J.; Fan, X.; Huang, H.; Qiu, J. 3D Porous N-Doped Graphene Frameworks Made of Interconnected Nanocages for Ultrahigh-Rate and Long-Life Li-O 2 Batteries. $A d v$. Funct. Mater. 2015, 25, 6913-6920.

(217) Gao, X.; Chen, Y.; Johnson, L.; Bruce, P. G. Promoting Solution Phase Discharge in $\mathrm{Li}_{2} \mathrm{O}_{2}$ Batteries Containing Weakly Solvating Electrolyte Solutions. Nat. Mater. 2016, 15, 882-888.

(218) Gallant, B. M.; Mitchell, R. R.; Kwabi, D. G.; Zhou, J.; Zuin, L.; Thompson, C. V.; Shao-Horn, Y. Chemical and Morphological Changes of Li-O2 Battery Electrodes upon Cycling. J. Phys. Chem. C 2012, 116, 20800-20805.

(219) Carboni, M.; Brutti, S.; Marrani, A. G. Surface Reactivity of a Carbonaceous Cathode in a Lithium Triflate/Ether Electrolyte-Based Li$\mathrm{O}_{2}$ Cell. ACS Appl. Mater. Interfaces 2015, 7, 21751-21762.

(220) Itkis, D. M.; Semenenko, D. A.; Kataev, E. Y.; Belova, A. I.; Neudachina, V. S.; Sirotina, A. P.; Hävecker, M.; Teschner, D.; KnopGericke, A.; Dudin, P.; et al. Reactivity of Carbon in Lithium-Oxygen Battery Positive Electrodes. Nano Lett. 2013, 13, 4697-4701.

(221) Liang, Z.; Lu, Y. C. Critical Role of Redox Mediator in Suppressing Charging Instabilities of Lithium-Oxygen Batteries. $J$. Am. Chem. Soc. 2016, 138, 7574-7583.

(222) Ottakam Thotiyl, M. M.; Freunberger, S. A.; Peng, Z.; Chen, Y.; Liu, Z.; Bruce, P. G. A Stable Cathode for the Aprotic Li-O2 Battery. Nat. Mater. 2013, 12, 1050-1056.

(223) Wang, Z.; Sun, J.; Cheng, Y.; Niu, C. Adsorption and Deposition of Li2O2 on TiC $\{111\}$ Surface. J. Phys. Chem. Lett. 2014, 5, 3919-3923.

(224) Adams, B.; Black, R.; Radtke, C.; Williams, Z.; Mehdi, B. L.; Browning, N. D.; Nazar, L. The Importance of Nanometric Passivating Films on Cathodes for Li Air Batteries. ACS Nano 2014, 8, 1248312493.

(225) Kundu, D.; Black, R.; Adams, B.; Harrison, K.; Zavadil, K.; Nazar, L. F. Nanostructured Metal Carbides for Aprotic $\mathrm{Li}_{-} \mathrm{O}_{2}$ Batteries: New Insights into Interfacial Reactions and Cathode Stability. J. Phys. Chem. Lett. 2015, 6, 2252-2258.

(226) Kundu, D.; Black, R.; Berg, E. J.; Nazar, L. F. A Highly Active Nanostructured Metallic Oxide Cathode for Aprotic $\mathrm{Li}^{-\mathrm{O}_{2}}$ batteries. Energy Environ. Sci. 2015, 8, 1292-1298.

(227) Debart, A.; Paterson, A. J.; Bao, J.; Bruce, P. G. $\alpha-\mathrm{MnO}_{2}$ Nanowires: A Catalyst for the $\mathrm{O}_{2}$ Electrode in Rechargeable Lithium Batteries. Angew. Chem., Int. Ed. 2008, 47, 4521-4524.
(150) Black, R.; Lee, J.-H.; Adams, B.; Mims, C. A.; Nazar, L. F. The Role of Catalysts and Peroxide Oxidation in Lithium-Oxygen Batteries. Angew. Chem., Int. Ed. 2013, 52, 392-396.

(151) Wang, Y.; Zhou, H. A Lithium-Air Battery with a Potential to Continuously Reduce $\mathrm{O}_{2}$ from Air for Delivering Energy. $J$. Power Sources 2010, 195, 358-361.

(152) Lu, J.; Lei, Y.; Lau, K. C.; Luo, X.; Du, P.; Wen, J.; Assary, R. S.; Das, U.; Miller, D. J.; Elam, J. W.; et al. A Nanostructured Cathode Architecture for Low Charge Overpotential in Lithium-Oxygen Batteries. Nat. Commun. 2013, 4, 2383.

(153) Amanchukwu, C. V.; Harding, J. R.; Shao-Horn, Y.; Hammond, P. T. Understanding the Chemical Stability of Polymers for Lithium-Air Batteries. Chem. Mater. 2015, 27, 550-561.

(154) Black, R.; Oh, S. H.; Lee, J.-H.; Yim, T.; Adams, B.; Nazar, L. F. Screening for Superoxide Reactivity in $\mathrm{Li}_{2} \mathrm{O}_{2}$ Batteries: Effect on $\mathrm{Li}_{2} \mathrm{O}_{2}$ /LiOH Crystallization. J. Am. Chem. Soc. 2012, 134, 2902-2905.

(155) Papp, J. K.; Forster, J. D.; Burke, C. M.; Kim, H. W.; Luntz, A. C.; Shelby, R. M.; Urban, J. J.; McCloskey, B. D. Poly(vinylidene Fluoride) (PVDF) Binder Degradation in Li-O $\mathrm{O}_{2}$ Batteries: $\mathrm{A}$ Consideration for the Characterization of Lithium Superoxide. J. Phys. Chem. Lett. 2017, 8, 1169-1174.

(156) Shui, J.-L.; Okasinski, J. S.; Kenesei, P.; Dobbs, H. A.; Zhao, D.; Almer, J. D.; Liu, D.-J. Reversibility of Anodic Lithium in Rechargeable Lithium-oxygen Batteries. Nat. Commun. 2013, 4, 2255.

(157) Sun, F.; Gao, R.; Zhou, D.; Osenberg, M.; Dong, K.; Kardjilov, N.; Hilger, A.; Markötter, H.; Bieker, P. M.; Liu, X.; et al. Revealing Hidden Facts of Li Anode in Cycled Lithium-Oxygen Batteries through X-Ray and Neutron Tomography. ACS Energy Lett. 2019, 4, 306-316.

(158) Tikekar, M. D.; Choudhury, S.; Tu, Z.; Archer, L. A. Design Principles for Electrolytes and Interfaces for Stable Lithium-Metal Batteries. Nat. Energy 2016, 1, 16114.

(159) Kozen, A. C.; Lin, C. F.; Pearse, A. J.; Schroeder, M. A.; Han, X.; Hu, L.; Lee, S. B.; Rubloff, G. W.; Noked, M. Next-Generation Lithium Metal Anode Engineering via Atomic Layer Deposition. ACS Nano 2015, 9, 5884-5892.

(160) Fan, L.; Zhuang, H. L.; Gao, L.; Lu, Y.; Archer, L. A. Regulating Li Deposition at Artificial Solid Electrolyte Interphases. J. Mater. Chem. A 2017, 5, 3483-3492.

(161) Ma, L.; Kim, M. S.; Archer, L. A. Stable Artificial Solid Electrolyte Interphases for Lithium Batteries. Chem. Mater. 2017, 29, 4181-4189.

(162) Liu, W.; Lin, D.; Pei, A.; Cui, Y. Stabilizing Lithium Metal Anodes by Uniform Li-Ion Flux Distribution in Nanochannel Confinement. J. Am. Chem. Soc. 2016, 138, 15443-15450.

(163) Rosy; Noked, M. Multifunctional Interphase. Nat. Energy 2018, 3, 253-254.

(164) Ma, G.; Wen, Z.; Wu, M.; Shen, C.; Wang, Q.; Jin, J.; Wu, X. A Lithium Anode Protection Guided Highly-Stable LithiumSulfur Battery. Chem. Commun. 2014, 50, 14209-14212.

(165) Wu, M.; Wen, Z.; Liu, Y.; Wang, X.; Huang, L. Electrochemical Behaviors of a Li3N Modified Li Metal Electrode in Secondary Lithium Batteries. J. Power Sources 2011, 196, 8091-8097.

(166) Huang, Z.; Ren, J.; Zhang, W.; Xie, M.; Li, Y.; Sun, D.; Shen, Y.; Huang, Y. Protecting the Li-Metal Anode in a Li-O2 Battery by Using Boric Acid as an SEI-Forming Additive. Adv. Mater. 2018, 30, 1803270.

(167) Liu, Q.-C.; Xu, J.-J.; Yuan, S.; Chang, Z.-W.; Xu, D.; Yin, Y.-B.; Li, L.; Zhong, H.-X.; Jiang, Y.-S.; Yan, J.-M.; et al. Artificial Protection Film on Lithium Metal Anode toward Long-Cycle-Life Lithium-Oxygen Batteries. Adv. Mater. 2015, 27, 5241-5247.

(168) Kozen, A. C.; Lin, C. F.; Zhao, O.; Lee, S. B.; Rubloff, G. W.; Noked, M. Stabilization of Lithium Metal Anodes by Hybrid Artificial Solid Electrolyte Interphase. Chem. Mater. 2017, 29, 6298-6307.

(169) Togasaki, N.; Momma, T.; Osaka, T. Enhanced Cycling Performance of a Li Metal Anode in a Dimethylsulfoxide-Based Electrolyte Using Highly Concentrated Lithium Salt for a Lithiumoxygen Battery. J. Power Sources 2016, 307, 98-104.

(170) Tong, B.; Huang, J.; Zhou, Z.; Peng, Z. The Salt Matters: Enhanced Reversibility of $\mathrm{Li}_{-} \mathrm{O}_{2}$ Batteries with a $\mathrm{Li}\left[\left(\mathrm{CF}_{3} \mathrm{SO}_{2}\right)(\mathrm{N}-\right.$ $\left.\left.\mathrm{C}_{4} \mathrm{~F}_{9} \mathrm{SO}_{2}\right) \mathrm{N}\right]-$ Based Electrolyte. Adv. Mater. 2018, 30, 1704841. 
(249) Tu, Z.; Zachman, M. J.; Choudhury, S.; Wei, S.; Ma, L.; Yang, Y.; Kourkoutis, L. F.; Archer, L. A. Nanoporous Hybrid Electrolytes for HighEnergy Batteries Based on Reactive Metal Anodes. Adv. Energy Mater. 2017, 7, 1602367.

(250) Liu, Y.; Liu, Q.; Xin, L.; Liu, Y.; Yang, F.; Stach, E. A.; Xie, J. Making Li-Metal Electrodes Rechargeable by Controlling the Dendrite Growth Direction. Nat. Energy 2017, 2, 17083.

(251) Liu, B.; Zhang, J.-G.; Xu, W. Advancing Lithium Metal Batteries. Joule 2018, 2, 833-845.

(252) Kwak, W.-J.; Jung, H.-G.; Aurbach, D.; Sun, Y.-K. Optimized Bicompartment Two Solution Cells for Effective and Stable Operation of Li-O 2 Batteries. Adv. Energy Mater. 2017, 7, 1701232.

(253) Kim, B. G.; Kim, J.-S.; Min, J.; Lee, Y.-H.; Choi, J. H.; Jang, M. C.; Freunberger, S. A.; Choi, J. W. A Moisture- and OxygenImpermeable Separator for Aprotic Li-O 2 Batteries. Adv. Funct. Mater. 2016, 26, 1747-1756.

(254) Lin, D.; Liu, Y.; Liang, Z.; Lee, H.-W.; Sun, J.; Wang, H.; Yan, K.; Xie, J.; Cui, Y. Layered Reduced Graphene Oxide with Nanoscale Interlayer Gaps as a Stable Host for Lithium Metal Anodes. Nat. Nanotechnol. 2016, 11, 626-632.

(255) Yang, C.-P.; Yin, Y.-X.; Zhang, S.-F.; Li, N.-W.; Guo, Y.-G. Accommodating Lithium into 3D Current Collectors with a Submicron Skeleton towards Long-Life Lithium Metal Anodes. Nat. Commun. 2015, 6, 8058.

(256) Huang, G.; Han, J.; Yang, C.; Wang, Z.; Fujita, T.; Hirata, A.; Chen, M. Graphene-Based Quasi-Solid-State Lithium-oxygen Batteries with High Energy Efficiency and a Long Cycling Lifetime. NPG Asia Mater. 2018, 10, 1037-1045.

(257) Lee, D. J.; Lee, H.; Song, J.; Ryou, M.-H.; Lee, Y. M.; Kim, H.T.; Park, J.-K. Composite Protective Layer for Li Metal Anode in HighPerformance Lithium-oxygen Batteries. Electrochem. Commun. 2014, $40,45-48$.

(258) Liu, B.; Xu, W.; Tao, J.; Yan, P.; Zheng, J.; Engelhard, M. H.; Lu, D.; Wang, C.; Zhang, J. G. Enhanced Cyclability of Lithium-Oxygen Batteries with Electrodes Protected by Surface Films Induced via In Situ Electrochemical Process. Adv. Energy Mater. 2018, 8, 1702340.

(259) Kwak, W. J.; Shin, H. J.; Reiter, J.; Tsiouvaras, N.; Hassoun, J.; Passerini, S.; Scrosati, B.; Sun, Y. K. Understanding Problems of Lithiated Anodes in Lithium Oxygen Full-Cells. J. Mater. Chem. A 2016, 4, 10467-10471.

(260) Hirshberg, D.; Sharon, D.; De La Llave, E.; Afri, M.; Frimer, A. A.; Kwak, W. J.; Sun, Y. K.; Aurbach, D. Feasibility of Full (Li-Ion)-O 2 Cells Comprised of Hard Carbon Anodes. ACS Appl. Mater. Interfaces 2017, 9, 4352-4361.

(261) Wu, S.; Zhu, K.; Tang, J.; Liao, K.; Bai, S.; Yi, J.; Yamauchi, Y.; Ishida, M.; Zhou, H. A Long-Life Lithium Ion Oxygen Battery Based on Commercial Silicon Particles as the Anode. Energy Environ. Sci. 2016, 9 , 3262-3271.

(262) Qin, L.; Zhai, D.; Lv, W.; Yang, W.; Huang, J.; Yao, S.; Cui, J.; Chong, W.-G.; Huang, J.-Q.; Kang, F.; et al. A High-Performance Lithium Ion Oxygen Battery Consisting of Li202 Cathode and Lithiated Aluminum Anode with Nafion Membrane for Reduced $\mathrm{O}_{2}$ Crossover. Nano Energy 2017, 40, 258-263.

(263) Elia, G. A.; Bernhard, R.; Hassoun, J. A Lithium-Ion Oxygen Battery Using a Polyethylene Glyme Electrolyte Mixed with an Ionic Liquid. RSC Adv. 2015, 5, 21360-21365.

(264) Zhang, W.; Shen, Y.; Sun, D.; Huang, Z.; Zhou, J.; Yan, H.; Huang, Y. Promoting Li2O2 Oxidation via Solvent-Assisted Redox Shuttle Process for Low Overpotential Li-O 2 Battery. Nano Energy 2016, 30, 43-51.

(265) Ma, S.; Wu, Y.; Wang, J.; Zhang, Y.; Zhang, Y.; Yan, X.; Wei, Y.; Liu, P.; Wang, J.; Jiang, K.; et al. Reversibility of Noble Metal-Catalyzed Aprotic Li-O2 Batteries. Nano Lett. 2015, 15, 8084-8090.

(266) Chase, G. V.; Zecevic, S.; Walker Wesley, T.; Uddin, J.; Sasaki, K. A.; Giordani Vincent, P.; Bryantsev, V.; Blanco, M.; Addison, D. D. Soluble Oxygen Evolving Catalysts for Rechargeable Metal-Air Batteries. US US20120028137A1, 2011.
(267) Chen, Y.; Freunberger, S. A.; Peng, Z.; Fontaine, O.; Bruce, P. G. Charging a Li-O2 Battery Using a Redox Mediator. Nat. Chem. 2013, 5 , 489-494.

(268) Park, J.-B.; Lee, S. H.; Jung, H.-G.; Aurbach, D.; Sun, Y.K. Redox Mediators for $\mathrm{Li}_{2} \mathrm{O}_{2}$ Batteries: Status and Perspectives. Adv. Mater. 2018, 30, 1704162.

(269) Landa-Medrano, I.; Lozano, I.; Ortiz-Vitoriano, N.; Ruiz de Larramendi, I.; Rojo, T. Redox Mediators: A Shuttle to Efficacy in metal-O2 Batteries. J. Mater. Chem. A 2019, 7, 8746-8764.

(270) Bergner, B. J.; Schürmann, A.; Peppler, K.; Garsuch, A.; Janek, J. TEMPO: A Mobile Catalyst for Rechargeable Li-O2 Batteries. J. Am. Chem. Soc. 2014, 136, 15054-15064.

(271) Bergner, B. J.; Hofmann, C.; Schürmann, A.; Schröder, D.; Peppler, K.; Schreiner, P. R.; Janek, J. Understanding the Fundamentals of Redox Mediators in Li-O2 2 Batteries: A Case Study on Nitroxides. Phys. Chem. Chem. Phys. 2015, 17, 31769-31779.

(272) Feng, N.; He, P.; Zhou, H. Enabling Catalytic Oxidation of $\mathrm{Li}_{2} \mathrm{O}_{2}$ at the Liquid-Solid Interface: The Evolution of an Aprotic Li-O2 Battery. ChemSusChem 2015, 8, 600-602.

(273) Kundu, D.; Black, R.; Adams, B.; Nazar, L. F. A Highly Active Low Voltage Redox Mediator for Enhanced Rechargeability of LithiumOxygen Batteries. ACS Cent. Sci. 2015, 1, 510-515.

(274) Xu, C.; Xu, G.; Zhang, Y.; Fang, S.; Nie, P.; Wu, L.; Zhang, X. Bifunctional Redox Mediator Supported by an Anionic Surfactant for Long-Cycle Li-O2 Batteries. ACS Energy Lett. 2017, 2, 2659-2666.

(275) Matsuda, S.; Mori, S.; Kubo, Y.; Uosaki, K.; Hashimoto, K.; Nakanishi, S. Cobalt Phthalocyanine Analogs as Soluble Catalysts That Improve the Charging Performance of $\mathrm{Li}_{-} \mathrm{O}_{2}$ Batteries. Chem. Phys. Lett. 2015, 620, 78-81.

(276) Sun, D.; Shen, Y.; Zhang, W.; Yu, L.; Yi, Z.; Yin, W.; Wang, D.; Huang, Y.; Wang, J.; Wang, D.; et al. A Solution-Phase Bifunctional Catalyst for Lithium-Oxygen Batteries. J. Am. Chem. Soc. 2014, 136, 8941-8946.

(277) Ryu, W.-H.; Gittleson, F. S.; Thomsen, J. M.; Li, J.; Schwab, M. J.; Brudvig, G. W.; Taylor, A. D. Heme Biomolecule as Redox Mediator and Oxygen Shuttle for Efficient Charging of Lithium-Oxygen Batteries. Nat. Commun. 2016, 7, 12925.

(278) Lim, H.-D.; Lee, B.; Zheng, Y.; Hong, J.; Kim, J.; Gwon, H.; Ko, Y.; Lee, M.; Cho, K.; Kang, K. Rational Design of Redox Mediators for Advanced Li-O 2 Batteries. Nat. Energy 2016, 1, 16066.

(279) Chen, Y.; Gao, X.; Johnson, L. R.; Bruce, P. G. Kinetics of Lithium Peroxide Oxidation by Redox Mediators and Consequences for the Lithium-oxygen Cell. Nat. Commun. 2018, 9, 767.

(280) Ko, Y.; Park, H.; Lee, B.; Bae, Y.; Park, S. K.; Kang, K. A Comparative Kinetic Study of Redox Mediators for High-Power Lithium-oxygen Batteries. J. Mater. Chem. A 2019, 7, 6491-6498.

(281) Bawol, P. P.; Reinsberg, P.; Bondue, C. J.; Abd-El-Latif, A. A.; Königshoven, P.; Baltruschat, H. A New Thin Layer Cell for Battery Related DEMS-Experiments: The Activity of Redox Mediators in the Li$\mathrm{O}_{2}$ Cell. Phys. Chem. Chem. Phys. 2018, 20, 21447-21456.

(282) Zhang, Y.; Wang, L.; Zhang, X.; Guo, L.; Wang, Y.; Peng, Z. High-Capacity and High-Rate Discharging of a Coenzyme Q10Catalyzed Li-O2 Battery. Adv. Mater. 2018, 30, 1705571.

(283) Ko, Y.; Park, H.; Kim, J.; Lim, H. D.; Lee, B.; Kwon, G.; Lee, S.; Bae, Y.; Park, S. K.; Kang, K. Biological Redox Mediation in Electron Transport Chain of Bacteria for Oxygen Reduction Reaction Catalysts in Lithium-Oxygen Batteries. Adv. Funct. Mater. 2019, 29, 1805623.

(284) Yang, L.; Frith, J. T.; Garcia-Araez, N.; Owen, J. R. A New Method to Prevent Degradation of Lithium-Oxygen Batteries: Reduction of Superoxide by Viologen. Chem. Commun. 2015, 51, 1705-1708.

(285) Tesio, A. Y.; Blasi, D.; Olivares-Marín, M.; Ratera, I.; Tonti, D.; Veciana, J. Organic Radicals for the Enhancement of Oxygen Reduction Reaction in $\mathrm{Li}_{2} \mathrm{O}_{2}$ Batteries. Chem. Commun. 2015, 51, 17623-17626.

(286) Gao, X.; Chen, Y.; Johnson, L.; Bruce, P. G. Promoting Solution Phase Discharge in $\mathrm{Li}^{-\mathrm{O}_{2}}$ Batteries Containing Weakly Solvating Electrolyte Solutions. Nat. Mater. 2016, 15, 882-888. 
(287) Gao, X.; Jovanov, Z. P.; Chen, Y.; Johnson, L. R.; Bruce, P. G. Phenol-Catalyzed Discharge in the Aprotic Lithium-Oxygen Battery. Angew. Chem., Int. Ed. 2017, 56, 6539-6543.

(288) Lee, S. H.; Kwak, W. J.; Sun, Y. K. A New Perspective of the Ruthenium Ion: A Bifunctional Soluble Catalyst for High Efficiency Li$\mathrm{O}_{2}$ Batteries. J. Mater. Chem. A 2017, 5, 15512-15516.

(289) Liu, H.; Liu, M.; Yang, L.; Song, Y.; Wang, X.; Yang, K.; Pan, F. A Bi-Functional Redox Mediator Promoting the ORR and OER in Non-Aqueous $\mathrm{Li}_{2} \mathrm{O}_{2}$ Batteries. Chem. Commun. 2019, 55, 6567-6570.

(290) Kwak, W.-J.; Ha, S. H.; Kim, D. H.; Shin, K. H.; Sun, Y.-K.; Lee, Y. J. Synergistic Integration of Soluble Catalysts with Carbon-Free Electrodes for Li-O 2 Batteries. ACS Catal. 2017, 7, 8192-8199.

(291) Liang, Z.; Zhou, Y.; Lu, Y. C. Dynamic Oxygen Shield Eliminates Cathode Degradation in Lithium-Oxygen Batteries. Energy Environ. Sci. 2018, 11, 3500-3510.

(292) Shen, X.; Zhang, S.; Wu, Y.; Chen, Y. Promoting Li-O2 Batteries With Redox Mediators. ChemSusChem 2019, 12, 104-114.

(293) Wang, Y.; Xia, Y. Li-O2 Batteries: An Agent for Change. Nat. Chem. 2013, 5, 445-447.

(294) Ha, S.; Kim, Y.; Koo, D.; Ha, K. H.; Park, Y.; Kim, D. M.; Son, S.; Yim, T.; Lee, K. T. Investigation into the Stability of Li Metal Anodes in $\mathrm{Li}_{-} \mathrm{O}_{2}$ batteries with a Redox Mediator. J. Mater. Chem. A 2017, 5 , 10609-10621.

(295) Lee, D. J.; Lee, H.; Kim, Y.-J.; Park, J.-K.; Kim, H.-T. Sustainable Redox Mediation for Lithium-Oxygen Batteries by a Composite Protective Layer on the Lithium-Metal Anode. Adv. Mater. 2016, 28, 857-863.

(296) Bergner, B. J.; Busche, M. R.; Pinedo, R.; Berkes, B. B.; Schroder, D.; Janek, J. How To Improve Capacity and Cycling Stability for Next Generation $\mathrm{Li}_{2} \mathrm{O}_{2}$ Batteries: Approach with a Solid Electrolyte and Elevated Redox Mediator Concentrations. ACS Appl. Mater. Interfaces 2016, 8, 7756-7765.

(297) Kwak, W.-J.; Kim, H.; Jung, H.-G.; Aurbach, D.; Sun, Y.K. Review-A Comparative Evaluation of Redox Mediators for Li$\mathrm{O}_{2}$ Batteries: A Critical Review. J. Electrochem. Soc. 2018, 165, A2274- A2293.

(298) Pinedo, R.; Weber, D. A.; Bergner, B.; Schröer, D.; Adelhelm, P.; Janek, J. Insights into the Chemical Nature and Formation Mechanisms of Discharge Products in Na-O2 Batteries by Means of Operando X-Ray Diffraction. J. Phys. Chem. C 2016, 120, 8472-8481.

(299) Aldous, I. M.; Hardwick, L. J. Solvent-Mediated Control of the Electrochemical Discharge Products of Non-Aqueous Sodium-Oxygen Electrochemistry. Angew. Chem., Int. Ed. 2016, 55, 8254-8257.

(300) Xia, C.; Fernandes, R.; Cho, F. H.; Sudhakar, N.; Buonacorsi, B.; Walker, S.; Xu, M.; Baugh, J.; Nazar, L. F. Direct Evidence of SolutionMediated Superoxide Transport and Organic Radical Formation in Sodium-Oxygen Batteries. J. Am. Chem. Soc. 2016, 138, 11219-11226.

(301) Yadegari, H.; Li, Y.; Banis, M. N.; Li, X.; Wang, B.; Sun, Q.; Li, R.; Sham, T.-K.; Cui, X.; Sun, X. On Rechargeability and Reaction Kinetics of Sodium-air Batteries. Energy Environ. Sci. 2014, 7, 37473757.

(302) Medenbach, L.; Bender, C. L.; Haas, R.; Mogwitz, B.; Pompe, C.; Adelhelm, P.; Schröder, D.; Janek, J. Origins of Dendrite Formation in Sodium-Oxygen Batteries and Possible Countermeasures. Energy Technol. 2017, 5, 2265-2274.

(303) Bi, X.; Ren, X.; Huang, Z.; Yu, M.; Kreidler, E.; Wu, Y. Investigating Dendrites and Side Reactions in Sodium-oxygen Batteries for Improved Cycle Lives. Chem. Commun. 2015, 51, 7665-7668.

(304) Hartmann, P.; Bender, C. L.; Sann, J.; Dür, A. K.; Jansen, M.; Janek, J.; Adelhelm, P. A Comprehensive Study on the Cell Chemistry of the Sodium Superoxide $\left(\mathrm{NaO}_{2}\right)$ Battery. Phys. Chem. Chem. Phys. 2013, 15, 11661-11672.

(305) Bender, C. L.; Jache, B.; Adelhelm, P.; Janek, J. Sodiated Carbon: A Reversible Anode for Sodium-oxygen Batteries and Route for the Chemical Synthesis of Sodium Superoxide $\left(\mathrm{NaO}_{2}\right) . J$. Mater. Chem. A 2015, 3, 20633-20641.

(306) Ren, X.; Wu, Y. A Low-Overpotential Potassium-Oxygen Battery Based on Potassium Superoxide. J. Am. Chem. Soc. 2013, 135, 2923-2926.
(287) Ren, X.; Lau, K. C.; Yu, M.; Bi, X.; Kreidler, E.; Curtiss, L. A.; $\mathrm{Wu}, \mathrm{Y}$. Understanding Side Reactions in $\mathrm{K}_{-} \mathrm{O}_{2}$ Batteries for Improved Cycle Life. ACS Appl. Mater. Interfaces 2014, 6, 19299-19307.

(288) Xiao, N.; McCulloch, W. D.; Wu, Y. Reversible Dendrite-Free Potassium Plating and Stripping Electrochemistry for Potassium Secondary Batteries. J. Am. Chem. Soc. 2017, 139, 9475-9478.

(289) Xiao, N.; Gourdin, G.; Wu, Y. Simultaneous Stabilization of Potassium Metal and Superoxide in $\mathrm{K}_{-} \mathrm{O}_{2}$ Batteries on the Basis of Electrolyte Reactivity. Angew. Chem., Int. Ed. 2018, 57, 10864-10867.

(290) Yu, W.; Lau, K. C.; Lei, Y.; Liu, R.; Qin, L.; Yang, W.; Li, B.; Curtiss, L. A.; Zhai, D.; Kang, F. Dendrite-Free Potassium-Oxygen Battery Based on a Liquid Alloy Anode. ACS Appl. Mater. Interfaces 2017, 9, 31871-31878

(291) McCulloch, W. D.; Ren, X.; Yu, M.; Huang, Z.; Wu, Y. Potassium-Ion Oxygen Battery Based on a High Capacity Antimony Anode. ACS Appl. Mater. Interfaces 2015, 7, 26158-26166.

(292) Sun, X.; Bonnick, P.; Nazar, L. F. Layered TiS 2 Positive Electrode for Mg Batteries. ACS Energy Lett. 2016, 1, 297-301.

(293) Li, C.-S.; Sun, Y.; Gebert, F.; Chou, S.-L. Current Progress on Rechargeable Magnesium-Air Battery. Adv. Energy Mater. 2017, 7, 1700869.

(294) Shiga, T.; Hase, Y.; Kato, Y.; Inoue, M.; Takechi, K. A Rechargeable Non-Aqueous $\mathrm{Mg}-\mathrm{O}_{2}$ Battery. Chem. Commun. 2013, 49, 9152.

(295) Shiga, T.; Hase, Y.; Yagi, Y.; Takahashi, N.; Takechi, K. Catalytic Cycle Employing a TEMPO-Anion Complex to Obtain a Secondary Mg-O2 Battery. J. Phys. Chem. Lett. 2014, 5, 1648-1652.

(296) Vardar, G.; Nelson, E. G.; Smith, J. G.; Naruse, J.; Hiramatsu, H.; Bartlett, B. M.; Sleightholme, A. E. S.; Siegel, D. J.; Monroe, C. W. Identifying the Discharge Product and Reaction Pathway for a Secondary Mg/O $\mathrm{O}_{2}$ Battery. Chem. Mater. 2015, 27, 7564-7568.

(297) Kwak, W. J.; Park, J.; Nguyen, T. T.; Kim, H.; Byon, H. R.; Jang, M.; Sun, Y. K. A Dendrite-and Oxygen-Proof Protective Layer for Lithium Metal in Lithium-Oxygen Batteries. J. Mater. Chem. A 2019, 7, 3857-3862.

(298) Shin, H.-J.; Kwak, W.-J.; Aurbach, D.; Sun, Y.-K. Large-Scale Li$\mathrm{O}_{2}$ Pouch Type Cells for Practical Evaluation and Applications. Adv. Funct. Mater. 2017, 27, 1605500.

(299) Lee, H. C.; Park, J. O.; Kim, M.; Kwon, H. J.; Kim, J. H.; Choi, K. H.; Kim, K.; Im, D. High-Energy-Density Li-O2 Battery at Cell Scale with Folded Cell Structure. Joule 2019, 3, 542-556.

(300) Ye, L.; Liao, M.; Sun, H.; Yang, Y.; Tang, C.; Zhao, Y.; Wang, L.; Xu, Y.; Zhang, L.; Wang, B.; et al. Stabilizing Lithium into Cross-Stacked Nanotube Sheets with an Ultra-High Specific Capacity for Lithium Oxygen Batteries. Angew. Chem., Int. Ed. 2019, 58, 2437-2442.

(301) Zhang, Y.; Wang, L.; Guo, Z.; Xu, Y.; Wang, Y.; Peng, H. HighPerformance Lithium-Air Battery with a Coaxial-Fiber Architecture. Angew. Chem., Int. Ed. 2016, 55, 4487-4491.

(302) Liu, Q.-C.; Liu, T.; Liu, D.-P.; Li, Z.-J.; Zhang, X.-B.; Zhang, Y.A Flexible and Wearable Lithium-Oxygen Battery with Record Energy Density Achieved by the Interlaced Architecture Inspired by Bamboo Slips. Adv. Mater. 2016, 28, 8413-8418.

(303) Kumar, B.; Kumar, J.; Leese, R.; Fellner, J. P.; Rodrigues, S. J.; Abraham, K. M. A Solid-State, Rechargeable, Long Cycle Life LithiumAir Battery. J. Electrochem. Soc. 2010, 157, A50-A54.

(304) Wang, Y.; Zhou, H. To Draw an Air Electrode of a Li-air Battery by Pencil. Energy Environ. Sci. 2011, 4, 1704-1707.

(305) Liu, Y.; He, P.; Zhou, H. Rechargeable Solid-State Li-Air and Li-S Batteries: Materials, Construction, and Challenges. Adv. Energy Mater. 2018, 8, 1701602.

(306) Zhu, X.; Zhao, T.; Tan, P.; Wei, Z.; Wu, M. A HighPerformance Solid-State Lithium-Oxygen Battery with a CeramicCarbon Nanostructured Electrode. Nano Energy 2016, 26, 565-576.

(307) Koerver, R.; Zhang, W.; de Biasi, L.; Schweidler, S.; Kondrakov, A. O.; Kolling, S.; Brezesinski, T.; Hartmann, P.; Zeier, W. G.; Janek, J. Chemo-Mechanical Expansion of Lithium Electrode Materials - on the Route to Mechanically Optimized All-Solid-State Batteries. Energy Environ. Sci. 2018, 11, 2142-2158. 
(328) Jin, Y.; Liu, K.; Lang, J.; Zhuo, D.; Huang, Z.; Wang, C.; Wu, H.; Cui, Y. An Intermediate Temperature Garnet-Type Solid ElectrolyteBased Molten Lithium Battery for Grid Energy Storage. Nat. Energy 2018, 3, 732-738.

(329) Balaish, M.; Peled, E.; Golodnitsky, D.; Ein-Eli, Y. Liquid-Free Lithium-Oxygen Batteries. Angew. Chem. 2015, 54, 436-440.

(330) Shu, C.; Long, J.; Dou, S.-X.; Wang, J. Component-Interaction Reinforced Quasi-Solid Electrolyte with Multifunctionality for Flexible $\mathrm{Li}_{2} \mathrm{O}_{2}$ Battery with Superior Safety under Extreme Conditions. Small 2019, 15, 1804701.

(331) Choi, Y.; Jung, K.; Kim, H. J.; Moon, J. W.; Lee, J. W. LithiumOxygen Batteries with Triplex Li+-Selective Solid Membranes. Chem. Commun. 2019, 55, 7643-7646.

(332) Liu, T.; Liu, Q. C.; Xu, J. J.; Zhang, X. B. Cable-Type WaterSurvivable Flexible Li-O 2 Battery. Small 2016, 12, 3101-3105.

(333) Peled, E.; Golodnitsky, D.; Mazor, H.; Goor, M.; Avshalomov, S. Parameter Analysis of a Practical Lithium- and Sodium-Air Electric Vehicle Battery. J. Power Sources 2011, 196, 6835-6840.

(334) Wu, S.; Yi, J.; Zhu, K.; Bai, S.; Liu, Y.; Qiao, Y.; Ishida, M.; Zhou, H. A Super-Hydrophobic Quasi-Solid Electrolyte for $\mathrm{Li}_{2} \mathrm{O}_{2}$ Battery with Improved Safety and Cycle Life in Humid Atmosphere. Adv. Energy Mater. 2017, 7, 1601759.

(335) Yang, Q.; Zhang, Z.; Sun, X.-G.; Hu, Y.-S.; Xing, H.; Dai, S. Ionic Liquids and Derived Materials for Lithium and Sodium Batteries. Chem. Soc. Rev. 2018, 47, 2020-2064.

(336) Kuboki, T.; Okuyama, T.; Ohsaki, T.; Takami, N. LithiumAir Batteries Using Hydrophobic Room Temperature Ionic Liquid Electrolyte. J. Power Sources 2005, 146, 766-769.

(337) Bresser, D.; Paillard, E.; Passerini, S. Ionic Liquid-Based Electrolytes for Li Metal/Air Batteries: A Review of Materials and the New 'LABOHR' Flow Cell Concept. J. Electrochem. Sci. Technol. 2014, 5,37-44.

(338) Herranz, J.; Garsuch, A.; Gasteiger, H. A. Using Rotating Ring Disc Electrode Voltammetry to Quantify the Superoxide Radical Stability of Aprotic Li-Air Battery Electrolytes. J. Phys. Chem. C 2012, 116, 19084-19094.

(339) Piana, M.; Wandt, J.; Meini, S.; Buchberger, I.; Tsiouvaras, N.; Gasteiger, H. A. Stability of a Pyrrolidinium-Based Ionic Liquid in $\mathrm{Li}^{-\mathrm{O}_{2}}$ Cells. J. Electrochem. Soc. 2014, 161, A1992-A2001.

(0) Katayama, Y.; Onodera, H.; Yamagata, M.; Miura, T. Electrochemical Reduction of Oxygen in Some Hydrophobic RoomTemperature Molten Salt Systems. J. Electrochem. Soc. 2004, 151, A59.

(340) Knipping, E.; Aucher, C.; Guirado, G.; Aubouy, L. Room Temperature Ionic Liquids: Versus Organic Solvents as LithiumOxygen Battery Electrolytes. New J. Chem. 2018, 42, 4693-4699.

(341) Xia, C.; Kwok, C. Y.; Nazar, L. F. A High-Energy-Density Lithium-Oxygen Battery Based on a Reversible Four-Electron Conversion to Lithium Oxide. Science 2018, 361, 777-781.

(342) Giordani, V.; Tozier, D.; Tan, H.; Burke, C. M.; Gallant, B. M.; Uddin, J.; Greer, J. R.; McCloskey, B. D.; Chase, G. V.; Addison, D. A Molten Salt Lithium-Oxygen Battery. J. Am. Chem. Soc. 2016, 138, 2656-2663.

(343) Sathiya, M.; Rousse, G.; Ramesha, K.; Laisa, C. P.; Vezin, H.; Sougrati, M. T.; Doublet, M. L.; Foix, D.; Gonbeau, D.; Walker, W.; et al. Reversible Anionic Redox Chemistry in High-Capacity LayeredOxide Electrodes. Nat. Mater. 2013, 12, 827-835.

(344) Thackeray, M. M.; Chan, M. K. Y.; Trahey, L.; Kirklin, S.; Wolverton, C. Vision for Designing High-Energy, Hybrid Li Ion/Li- $\mathrm{O}_{2}$ Cells. J. Phys. Chem. Lett. 2013, 4, 3607-3611.

(345) Muhammad, S.; Kim, H.; Kim, Y.; Kim, D.; Song, J. H.; Yoon, J.; Park, J.-H.; Ahn, S.-J.; Kang, S.-H.; Thackeray, M. M.; et al. Evidence of Reversible Oxygen Participation in Anomalously High Capacity Liand Mn-Rich Cathodes for Li-Ion Batteries. Nano Energy 2016, 21, 172184.

(346) Myeong, S.; Cho, W.; Jin, W.; Hwang, J.; Yoon, M.; Yoo, Y.; Nam, G.; Jang, H.; Han, J.-G.; Choi, N.-S.; Kim, M. G.; Cho, J. Understanding Voltage Decay in Lithium-Excess Layered Cathode Materials through Oxygen-Centred Structural Arrangement. Nat. Commun. 2018, 9, 3285.
(308) Lee, J.; Kitchaev, D. A.; Kwon, D.-H.; Lee, C.-W.; Papp, J. K.; Liu, Y.-S.; Lun, Z.; Clement, R. J.; Shi, T.; McCloskey, B. D.; Guo, J.; Balasubramanian, M.; Ceder, G. Reversible Mn2+/Mn4+ double redox in lithium-excess cathode materials. Nature 2018, 556, 185-190.

(309) Hu, E.; Yu, X.; Lin, R.; Bi, X.; Lu, J.; Bak, S.; Nam, K.-W.; Xin, H. L.; Jaye, C.; Fischer, D. A.; et al. Evolution of Redox Couples in Liand Mn-Rich Cathode Materials and Mitigation of Voltage Fade by Reducing Oxygen Release. Nat. Energy 2018, 3, 690-698.

(310) Hong, J.; Gent, W. E.; Xiao, P.; Lim, K.; Seo, D. H.; Wu, J.; Csernica, P. M.; Takacs, C. J.; Nordlund, D.; Sun, C. J.; et al. Metal-oxygen Decoordination Stabilizes Anion Redox in Li-Rich Oxides. Nat. Mater. 2019, 18, 256-265.

(311) Ben Yahia, M.; Vergnet, J.; Saubanere, M.; Doublet, M. L. Unified Picture of Anionic Redox in Li/Na-Ion Batteries. Nat. Mater. 2019, 18, 496-502.

(312) Assat, G.; Tarascon, J. M. Fundamental Understanding and Practical Challenges of Anionic Redox Activity in Li-Ion Batteries. Nat. Energy 2018, 3, 373-386.

(313) Li, Q.; Zhou, D.; Zhang, L.; Ning, D.; Chen, Z.; Xu, Z.; Gao, R.; Liu, X.; Xie, D.; Schumacher, G.; et al. Tuning Anionic Redox Activity and Reversibility for a High-Capacity Li-Rich Mn-Based Oxide Cathode via an Integrated Strategy. Adv. Funct. Mater. 2019, 29, 1806706.

(314) Jacquet, Q.; Iadecola, A.; Saubanere, M.; Lemarquis, L.; Berg, E. J.; Alves Dalla Corte, D.; Rousse, G.; Doublet, M. L.; Tarascon, J. M. Competition between Metal Dissolution and Gas Release in Li-Rich $\mathrm{Li}_{3} \mathrm{Ruy}_{\mathrm{Ir} 1-\mathrm{y}} \mathrm{O}_{4}$ Model Compounds Showing Anionic Redox. Chem. Mater. 2018, 30, 7682-7690.

(315) Yin, W.; Mariyappan, S.; Grimaud, A.; Tarascon, J. M. Rotating Ring Disk Electrode for Monitoring the Oxygen Release at High Potentials in Li-Rich Layered Oxides. J. Electrochem. Soc. 2018, 165, A3326-A3333.

(316) Assat, G.; Foix, D.; Delacourt, C.; Iadecola, A.; Dedryvere, R.; Tarascon, J.-M. M. J. M. Fundamental Interplay between Anionic/ cationic Redox Governing the Kinetics and Thermodynamics of Lithium-Rich Cathodes. Nat. Commun. 2017, 8, 2219.

(317) Lin, R.; Hu, E.; Liu, M.; Wang, Y.; Cheng, H.; Wu, J.; Zheng, J.C.; Wu, Q.; Bak, S.; Tong, X.; Zhang, R.; Yang, W.; Persson, K. A.; Yu, X.; Yang, X.-Q.; Xin, H. L. Anomalous Metal Segregation in Lithium-Rich Material Provides Design Rules for Stable Cathode in Lithium-Ion Battery. Nat. Commun. 2019, 10, 1650.

(318) Yang, W.; Devereaux, T. P. Anionic and Cationic Redox and Interfaces in Batteries: Advances from Soft X-Ray Absorption Spectroscopy to Resonant Inelastic Scattering. J. Power Sources 2018, 389, 188-197.

(319) Assat, G.; Iadecola, A.; Foix, D.; Dedryvere, R.; Tarascon, J. M. Direct Quantification of Anionic Redox over Long Cycling of Li-Rich Nmc via Hard X-Ray Photoemission Spectroscopy. ACS Energy Lett. 2018, 3, 2721-2728.

(320) Xu, J.; Sun, M.; Qiao, R.; Renfrew, S. E.; Ma, L.; Wu, T.; Hwang, S.; Nordlund, D.; Su, D.; Amine, K.; Lu, J.; McCloskey, B. D.; Yang, W.; Tong, W. Elucidating Anionic Oxygen Activity in Lithium-Rich Layered Oxides. Nat. Commun. 2018, 9, 947.

(321) Yan, P.; Zheng, J.; Tang, Z. K.; Devaraj, A.; Chen, G.; Amine, K.; Zhang, J. G.; Liu, L. M.; Wang, C. Injection of Oxygen Vacancies in the Bulk Lattice of Layered Cathodes. Nat. Nanotechnol. 2019, 14, 602608.

(322) Li, Q.; Yao, Z.; Lee, E.; Xu, Y.; Thackeray, M. M.; Wolverton, C.; Dravid, V. P.; Wu, J. Dynamic Imaging of Crystalline Defects in Lithium-Manganese Oxide Electrodes during Electrochemical Activation to High Voltage. Nat. Commun. 2019, 10, 1692.

(323) Chen, Z.; Li, J.; Zeng, X. C. Unraveling Oxygen Evolution in LiRich Oxides: A Unified Modeling of the Intermediate Peroxo/ Superoxolike Dimers. J. Am. Chem. Soc. 2019, 141, 10751-10759.

(324) Susai, F. A.; Sclar, H.; Shilina, Y.; Penki, T. R.; Raman, R.; Maddukuri, S.; Maiti, S.; Halalay, I. C.; Luski, S.; Markovsky, B.; et al. Horizons for Li-Ion Batteries Relevant to Electro-Mobility: HighSpecific-Energy Cathodes and Chemically Active Separators. Adv. Mater. 2018, 30, 1801348. 
(365) Meini, S.; Tsiouvaras, N.; Schwenke, K. U.; Piana, M.; Beyer, H.; Lange, L.; Gasteiger, H. a. Rechargeability of Li-Air Cathodes PreFilled with Discharge Products Using an Ether-Based Electrolyte Solution: Implications for Cycle-Life of Li-Air Cells. Phys. Chem. Chem. Phys. 2013, 15, 11478-11493.

(366) Bhargav, A.; Fu, Y. Lithium Peroxide-Carbon Composite Cathode for Closed System $\mathrm{Li}_{2} \mathrm{O}_{2}$ Batteries. J. Electrochem. Soc. 2015, 162, A1327-A1333.

(367) Bhargav, A.; Guo, W.; Fu, Y. Chemically Synthesized Lithium Peroxide Composite Cathodes for Closed System $\mathrm{Li}_{2}$ Batteries. Chem. Commun. 2016, 52, 5678-5681.

(368) Marinaro, M.; Balasubramanian, P.; Gucciardi, E.; Theil, S.; Jörissen, L.; Wohlfahrt-Mehrens, M. Importance of Reaction Kinetics and Oxygen Crossover in Aprotic Li- $\mathrm{O}_{2}$ Batteries Based on a Dimethyl Sulfoxide Electrolyte. ChemSusChem 2015, 8, 3139-3145.

(369) Zhu, Z.; Kushima, A.; Yin, Z.; Qi, L.; Amine, K.; Lu, J.; Li, J. Anion-Redox Nanolithia Cathodes for Li-Ion Batteries. Nat. Energy 2016, 1, 16111.

(370) Liu, J.; Khaleghi Rahimian, S.; Monroe, C. W. CapacityLimiting Mechanisms in Li/O ${ }_{2}$ Batteries. Phys. Chem. Chem. Phys. 2016, 18, 22840-22851.

(371) Gittleson, F. S.; Jones, R. E.; Ward, D. K.; Foster, M. E. Oxygen Solubility and Transport in Li-Air Battery Electrolytes: Establishing Criteria and Strategies for Electrolyte Design. Energy Environ. Sci. 2017, 10, 1167-1179.

(372) Wang, Y.; Zheng, D.; Yang, X. Q.; Qu, D. High Rate Oxygen Reduction in Non-Aqueous Electrolytes with the Addition of Perfluorinated Additives. Energy Environ. Sci. 2011, 4, 3697-3702.

(373) Zhang, S. S.; Read, J. Partially Fluorinated Solvent as a CoSolvent for the Non-Aqueous Electrolyte of Li/air Battery. J. Power Sources 2011, 196, 2867-2870.

(374) Nishikami, Y.; Konishi, T.; Omoda, R.; Aihara, Y.; Oyaizu, K.; Nishide, H. Oxygen-Enriched Electrolytes Based on Perfluorochemicals for High-Capacity Lithium-Oxygen Batteries. J. Mater. Chem. A 2015, 3, 10845-10850.

(375) Balaish, M.; Ein-Eli, Y. The Role of Air-Electrode Structure on the Incorporation of Immiscible PFCs in Nonaqueous $\mathrm{Li}-\mathrm{O}_{2}$ Battery. ACS Appl. Mater. Interfaces 2017, 9, 9726-9737.

(376) Balaish, M.; Gao, X.; Bruce, P. G.; Ein-Eli, Y. Enhanced Li$\mathrm{O}_{2}$ Battery Performance in a Binary "Liquid Teflon" and Dual Redox Mediators. Adv. Mater. Technol. 2019, 4, 1800645.

(377) Wijaya, O.; Rinaldi, A.; Younesi, R.; Yazami, R. The Origin of $\mathrm{Li}_{2} \mathrm{O}_{2}$ Battery Performance Enhancement Using Fluorocarbon Additive. J. Electrochem. Soc. 2016, 163, A2660-A2664.

(378) Kwon, H. J.; Lee, H. C. H. C.; Ko, J.; Jung, I. S.; Lee, H. C. H. C.; Lee, H. C. H. C.; Kim, M.; Lee, D. J.; Kim, H.; Kim, T. Y.; et al. Effects of Oxygen Partial Pressure on Li-Air Battery Performance. J. Power Sources 2017, 364, 280-287.

(379) Qiao, Y.; Wu, S.; Yi, J.; Sun, Y.; Guo, S.; Yang, S.; He, P.; Zhou, $\mathrm{H}$. From $\mathrm{O}_{2}-$ to $\mathrm{HO}_{2}^{-}$: Reducing By-Products and Overpotential in Li$\underline{\mathrm{O}}_{2}$ Batteries by Water Addition. Angew. Chem., Int. Ed. 2017, 56, 49604964.

(380) Liu, T.; Frith, J. T.; Kim, G.; Kerber, R. N.; Dubouis, N.; Shao, Y.; Liu, Z.; Magusin, P. C. M. M.; Casford, M. T. L.; Garcia-Araez, N.; et al. The Effect ofWater on Quinone Redox Mediators in Nonaqueous Li$\mathrm{O}_{2}$ Batteries. J. Am. Chem., Soc. 2018, 140, 1428-1437.

(381) Liu, T.; Kim, G.; Jonsson, E.; Castillo-Martinez, E.; Temprano, I.; Shao, Y.; Carretero-Gonzalez, J.; Kerber, R. N.; Grey, C. P. Understanding $\mathrm{LiOH}$ Formation in a $\mathrm{Li}_{2} \mathrm{O}_{2}$ Battery with LiI and H2O Additives. ACS Catal. 2019, 9, 66-77.

(382) Takechi, K.; Shiga, T.; Asaoka, T. A Li-O2/CO2 Battery. Chem. Commun. 2011, 47, 3463-3465.

(383) Yin, W.; Grimaud, A.; Lepoivre, F.; Yang, C.; Tarascon, J. M. Chemical vs Electrochemical Formation of $\mathrm{Li}_{2} \mathrm{CO}_{3}$ as a Discharge Product in $\mathrm{Li}-\mathrm{O}_{2} / \mathrm{CO}_{2}$ Batteries by Controlling the Superoxide Intermediate. J. Phys. Chem. Lett. 2017, 8, 214-222.

(384) Gowda, S. R.; Brunet, A.; Wallraff, G. M.; McCloskey, B. D. Implications of $\mathrm{CO}_{2}$ Contamination in Rechargeable Nonaqueous Li$\mathrm{O}_{2}$ Batteries. J. Phys. Chem. Lett. 2013, 4, 276-279.
(385) Liu, Z.; Zhang, Y.; Jia, C.; Wan, H.; Peng, Z. Z.; Bi, Y.; Liu, Y.; Peng, Z. Z.; Wang, Q.; Li, H.; et al. Decomposing Lithium Carbonate with a Mobile Catalyst. Nano Energy 2017, 36, 390-397.

(386) Xu, S.; Das, S. K.; Archer, L. A. The Li-CO2 Battery: A Novel Method for $\mathrm{CO}_{2}$ Capture and Utilization. RSC Adv. 2013, 3 , 6656- 6660 .

(387) Qiao, Y.; Yi, J.; Wu, S.; Liu, Y.; Yang, S.; He, P.; Zhou, H. Li-CO2 Electrochemistry: A New Strategy for $\mathrm{CO}_{2}$ Fixation and Energy Storage. Joule 2017, 1, 359-370.

(388) Zhao, Z.; Huang, J.; Peng, Z. Achilles' Heel of Lithium-Air Batteries: Lithium Carbonate. Angew. Chem., Int. Ed. 2018, 57, 38743886.

(389) Yang, S.; He, P.; Liu, Y.; Cheng, Z.; Zhou, H.; Qiao, Y.; Zhu, J.-J. A Reversible Lithium- $\mathrm{CO}_{2}$ Battery with $\mathrm{Ru}$ Nanoparticles as a Cathode Catalyst. Energy Environ. Sci. 2017, 10, 972-978.

(390) Adams, J.; Karulkar, M. Bipolar Plate Cell Design for a Lithium Air Battery. J. Power Sources 2012, 199, 247-255.

(391) Viswanathan, V.; Nørskov, J. K.; Speidel, A.; Scheffler, R.; Gowda, S.; Luntz, A. C. Li-O2 Kinetic Overpotentials: Tafel Plots from Experiment and First-Principles Theory. J. Phys. Chem. Lett. 2013, 4, 556-560.

(392) Kumar, A.; Madden, D. G.; Lusi, M.; Chen, K. J.; Daniels, E. A.; Curtin, T.; Perry, J. J.; Zaworotko, M. J. Direct Air Capture of $\mathrm{CO}_{2}$ by Physisorbent Materials. Angew. Chem., Int. Ed. 2015, 54, 14372-14377.

(393) Ben-Mansour, R.; Habib, M. A.; Bamidele, O. E.; Basha, M.; Qasem, N. A. A.; Peedikakkal, A.; Laoui, T.; Ali, M. Carbon Capture by Physical Adsorption: Materials, Experimental Investigations and Numerical Modeling and Simulations - A Review. Appl. Energy 2016, 161, 225-255.

(394) Ünveren, E. E.; Monkul, B. O.; Sarıoglan, S.; Karademir, N.; Alper, E. Solid Amine Sorbents for $\mathrm{CO}_{2}$ Capture by Chemical Adsorption: A Review. Petroleum 2017, 3, 37-50.

(395) Cao, L.; Lv, F.; Liu, Y.; Wang, W.; Huo, Y.; Fu, X.; Sun, R.; $\mathrm{Lu}, \mathrm{Z}$. A High Performance $\mathrm{O}_{2}$ Selective Membrane Based on CAU-1$\mathrm{NH}_{2} @$ polydopamine and PMMA Polymer for Li-Air Batteries. Chem. Commun. 2010, 51, 4364-4367.

(396) Qian, X.; Han, B.; Liu, Y.; Yan, H.; Liu, R. Vapor Pressure of Dimethyl Sulfoxide and Water Binary System. J. Solution Chem. 1995, 24, 1183-1189.

(397) Tang, S.; Zhao, H. Glymes as Versatile Solvents for Chemical Reactions and Processes: From the Laboratory to Industry. RSC Adv. 2014, 4, 11251-11287. 